\title{
Viral hepatitis B
}

Citation for published version (APA):

Koc, Ö. M. (2021). Viral hepatitis B: the past, the present and future directions. [Doctoral Thesis, Maastricht University]. Universiteit Hasselt en Maastricht University. https://doi.org/10.26481/dis.20210629ok

Document status and date:

Published: 01/01/2021

DOI:

10.26481/dis.20210629ok

Document Version:

Publisher's PDF, also known as Version of record

\section{Please check the document version of this publication:}

- A submitted manuscript is the version of the article upon submission and before peer-review. There can be important differences between the submitted version and the official published version of record.

People interested in the research are advised to contact the author for the final version of the publication, or visit the DOI to the publisher's website.

- The final author version and the galley proof are versions of the publication after peer review.

- The final published version features the final layout of the paper including the volume, issue and page numbers.

Link to publication

\footnotetext{
General rights rights.

- You may freely distribute the URL identifying the publication in the public portal. please follow below link for the End User Agreement:

www.umlib.nl/taverne-license

Take down policy

If you believe that this document breaches copyright please contact us at:

repository@maastrichtuniversity.nl

providing details and we will investigate your claim.
}

Copyright and moral rights for the publications made accessible in the public portal are retained by the authors and/or other copyright owners and it is a condition of accessing publications that users recognise and abide by the legal requirements associated with these

- Users may download and print one copy of any publication from the public portal for the purpose of private study or research.

- You may not further distribute the material or use it for any profit-making activity or commercial gain

If the publication is distributed under the terms of Article $25 \mathrm{fa}$ of the Dutch Copyright Act, indicated by the "Taverne" license above, 




\title{
Viral hepatitis B: \\ the past, the present and future directions
}

\author{
PROEFSCHRIFT \\ ter verkrijging van de graad van doctor aan de Universiteit Maastricht, \\ op gezag van de Rector Magnificus, Prof. Dr. Rianne M. Letschert, \\ en de graad van doctor in Geneeskunde en levenswetenschappen aan de Universiteit \\ Hasselt, \\ op gezag van de Rector, Prof. Dr. Bernard Vanheusden, \\ volgens het besluit van het College van Decanen, \\ in het openbaar te verdedigen \\ op donderdag 29 juni 2021 om 13.00 uur in Maastricht
}

door

Özgür Muhammet Koc 
Promotores:

Co-promotores:

Beoordelingscommissie:

\section{January 2021}

Özgür M Koc was supported by the School of Nutrition and Translational Research in Metabolism (NUTRIM) and the Limburg Clinical Research Center (LCRC) UHasselt-ZOL-Jessa, supported by the foundation Limburg Sterk Merk, province of Limburg, Flemish government, Hasselt University, Jessa Hospital and Ziekenhuis Oost-Limburg. His institution received grants from Gilead Sciences and CyTuVax B.V. 



\section{Aut viam inveniam, aut facium}

I shall either find a way or make one

Of ik vind een weg, of ik maak er één 




\section{TABLE OF CONTENTS}

General introduction 7

Chapter 1 Outcome in Caucasian patients with hepatitis B e antigen negative 23 chronic infection: a long-term observational cohort study

Submitted for publication

Chapter 2 Acute hepatitis B notification rates in Flanders, 2009 to 2017

Euro Surveill. 2019;24(30):1900064

Chapter 3 Prevalence and risk factors of hepatitis B virus infection in MiddleLimburg Belgium, year 2017: importance of migration

J Med Virol. 2019;91(8):1479-1488

Chapter 4 Hepatitis B virus prevalence and risk factors in hard-to-reach Turkish population living in Belgium: a protocol for screening

Medicine (Baltimore). 2019;98(18):e15412

Chapter $5 \quad$ Early detection of chronic hepatitis B and risk factor assessment in 103 Turkish migrants, Middle Limburg, Belgium

Submitted for publication

Chapter 6 Safety and immunogenicity of HBAI20 vaccine in healthy naïve and 133 nonresponding adults

J Viral Hepat. 2018;25(9):1048-1056

Chapter 7 Immunogenicity and safety of HBAI20 Hepatitis B vaccine in healthy non-responders: double-blinded, randomised, controlled phase 2 trial

Submitted for publication

General discussion

Summary | Samenvatting | Özet

Impact paragraph

References

Dankwoord 


\section{LIST OF ABBREVIATIONS}

AI20 $20 \mu \mathrm{g}$ recombinant human IL-2 adsorbed to $20 \mu \mathrm{g}$ aluminium hydroxide

ALT alanine aminotransferase

ANOVA analysis of variance

Anti-HBc hepatitis B core antibodies

Anti-HBe antibodies against hepatitis $B$ e antigen

Anti-HBs hepatitis B surface antibodies

Anti-HIV antibodies against HIV

$\mathrm{aOR}$ adjusted odds ratio

AS04 adjuvant system 04 consisting of aluminium hydroxide and the adjuvant 3-O-desacyl-4'-monophosphoryl lipid A

AST aspartate aminotransferase

AUC area under the ROC curve

BMI body mass index

$\mathrm{CAH}$ chronic active hepatitis

CI confidence interval

CpG cytidine-phosphate-guanosine oligodeoxynucleotide

CRP c-reactive protein

DALY disability-adjusted life years

EASL European Association for the Study of the Liver

FCS fully conditional specification

FGM first-generation migrant

FT4 free thyroxine

Gamma-GT gamma-glutamyltransferase

GEE generalized estimating equations

GMC geometric mean concentrations

GMT geometric mean titres

GP

HBAI20 general practitioner new vaccine consisting of the standard HBVaxProC- $10 \mu \mathrm{g}$ vaccine and the AI20 adjuvant. See also AI20

HBcAg hepatitis B core antigen

HBeAg hepatitis B e antigen

HBsAg hepatitis B surface antigen

HBV hepatitis $B$ virus 


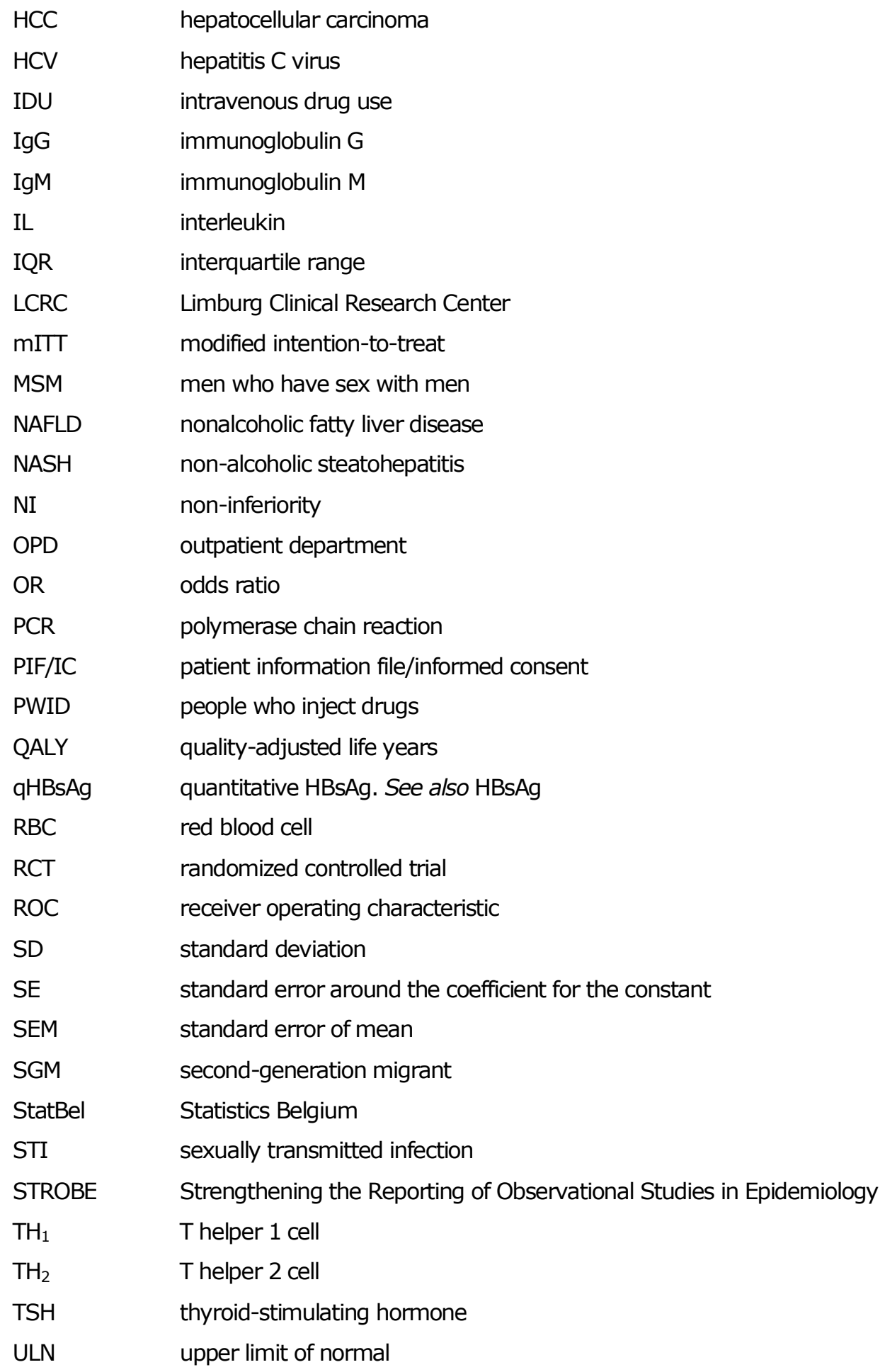


V

Vac

WBC

WHO

ZOL visit

vaccination

white blood cell

World Health Organization

Ziekenhuis Oost-Limburg 




\section{GENERAL INTRODUCTION}

"Get tested, get vaccinated; eliminate hepatitis B!"

The liver is the largest solid organ of the body, generally weighing between 1200 and 1800 gram in adults. ${ }^{1}$ As a metabolic centre, the liver's main function is to filter the blood coming from the entire digestive tract, before passing it to the rest of the body. ${ }^{1}$ The liver also operates as a manufacturer of plasma proteins and it has the capacity to detoxify many harmful substances. ${ }^{1}$ Another important function is the role in defense as it harbors innate immunological cells. In light of these important functions, it is not surprising that liver dysfunction is associated with extensive consequences for the entire body. ${ }^{2}$

The number of liver-related deaths in the World Health Organization (WHO) European region ( $n=53$ countries) are estimated to be 120,377 in the year 2015 , and those are mainly attributable to complications such as cirrhosis and hepatocellular carcinoma (HCC). ${ }^{3,4}$ The burden of liver disease in Europe is expected to continue growing. ${ }^{4}$ Besides an increased risk of mortality, economic impact is high and quality of life is low in patients with chronic liver disease. ${ }^{5,6}$

The burden of liver disease in Europe is a reflection of the three most common causes of chronic liver disease: alcohol-related liver disease, non-alcoholic fatty liver disease and viral hepatitis. $^{7-11}$ Many patients with chronic liver disease may remain undiagnosed, since there may be no signs or symptoms until the complications of cirrhosis and HCC has developed. ${ }^{11}$

In this thesis, we focus on hepatitis B virus (HBV) infection that accounts for a substantial proportion (29.9\%) of liver-related deaths in Europe. 3,12,13 Though there is a similar silent liver disease progression in HBV infection as in other chronic liver diseases, the availability of hepatitis B vaccines since 1982 and antiviral treatment since 1992 represents an important opportunity to eliminate hepatitis B by 2030 as advocated by the WHO. ${ }^{14,15}$ In general, elimination of infectious diseases is defined as a reduction to zero disease incidence. For hepatitis B in particular, elimination by 2030 is defined as a $90 \%$ reduction in the incidence of chronic HBV infection and a $65 \%$ reduction in mortality with the rates in year 2015 as baseline. ${ }^{14}$ This thesis will address the past, present and future directions of HBV infection and control. The general introduction describes our research in this context and illustrates the evidence in relation to scientific knowledge at the start of our studies. 


\section{HEPATITIS B VIRUS}

The observation of the Australia antigen in the serum of an Australian aboriginal was the most important exploration to the discovery of HBV in 1967.16,17 For a brief period, $20 \mathrm{~nm}$ spheres and filaments with the so-called Australia antigen on their surfaces were mistakenly considered to be the infectious virus. ${ }^{18,} 19$ Soon thereafter, however, electron microscopy evaluations revealed $42 \mathrm{~nm}$ particles which have a structure more consistent with that of a virus. ${ }^{18,} 20,21$ The $42 \mathrm{~nm}$ particles are now known as Dane particles and the infectious virion of HBV with an outer envelope comprised of three related envelope glycoproteins (or hepatitis B surface antigen ( $\mathrm{HBSAg}$ ) also known as Australia antigen). ${ }^{18,}{ }^{22}$ Within the envelope is the nucleocapsid or core, known as hepatitis $B$ core antigen ( $\mathrm{HBCAg})^{18,} 22$ Internal to this is the viral genome, a partially double-stranded, relaxed-circular DNA, and a polymerase that is responsible for the replication of viral DNA in infected cells (Figure 1). ${ }^{18,}$ 22

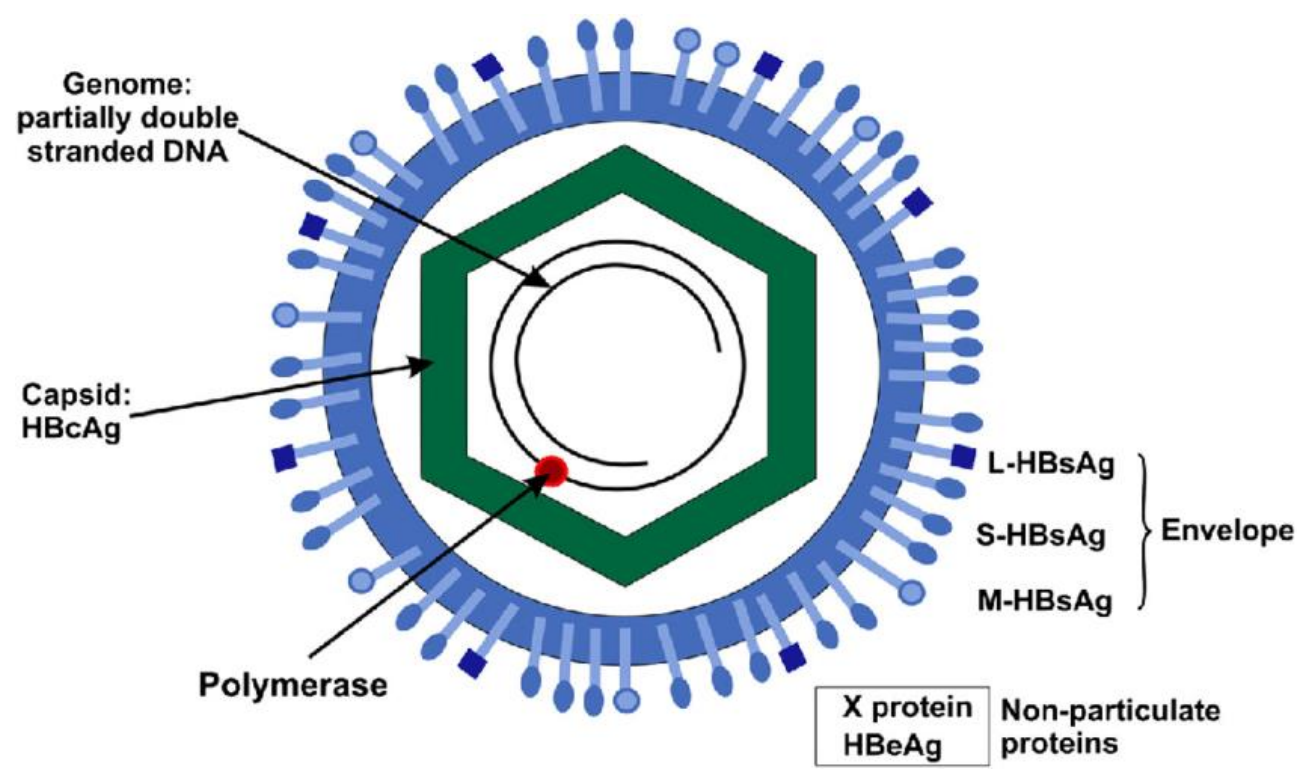

Figure 1: The structure of hepatitis B virus. Abbreviations: $\mathrm{HBCAg:} \mathrm{hepatitis} \mathrm{B} \mathrm{core} \mathrm{antigen;} \mathrm{HBs} A \mathrm{~g}$ : hepatitis B surface antigen; S: small, M: medium; L: large; HBeAg: hepatitis B e antigen. (Reprinted from: Kramvis A, Rev Med Virol, 201623; Copyright: open access article, non-commercial use permitted) 
Aside from $\mathrm{HBSAg}$ and $\mathrm{HBCAg}$, a third antigen, the hepatitis $\mathrm{B}$ e antigen (HBeAg), was described in $1972 .{ }^{24-26}$ The development of assays for HBsAg, HBeAg and HBV DNA analysis in the early 1980s further allowed a better understanding of the natural history of HBV infection. ${ }^{26-29}$

In 1985, McMahon et $\mathrm{al}^{30}$ described the relation between age and the likelihood of developing icteric hepatitis during acute HBV infection. An estimated $7-17 \%$ developed clinically apparent hepatitis after acute HBV infection at the age of one to four years as compared with $29-35 \%$ for adults. ${ }^{30}$ The rate of progression from acute to chronic HBV infection was also determined by the age at infection. The risk of developing chronic HBV infection was estimated at approximately $80-90 \%$ among infants infected perinatally in case of a HBeAg positive mother and less than $5 \%$ for an adult-acquired infection. ${ }^{30}$

For chronic HBV infection, the natural course was initially divided into a replicative HBeAgpositive phase and a non-replicative HBeAg-negative phase considering the close relation between HBeAg status and viral replication. ${ }^{31,} 32$ However, the absence of significant liver disease in a considerable amount of HBeAg-positive patients in Taiwan re-conceptualised chronic HBV infection in three phases: immune-tolerant phase (phase 1), immuneclearance phase (phase 2) and inactive carrier phase (phase 3). ${ }^{31} 33$ On the other hand, the delineation of patients with signs of liver damage and viral replication in the absence of serum HBeAg, advocated the introduction of a fourth phase, i.e. HBeAg-negative chronic hepatitis (phase 4). ${ }^{26,34}$ Figure 2 illustrates the natural history and new terminology for the four chronic HBV infection phases with their characteristic HBeAg status, HBV DNA levels and alanine aminotransferase (ALT) levels. ${ }^{7}$ The new nomenclature is based on the description of the two main characteristics of chronicity: infection versus hepatitis. 


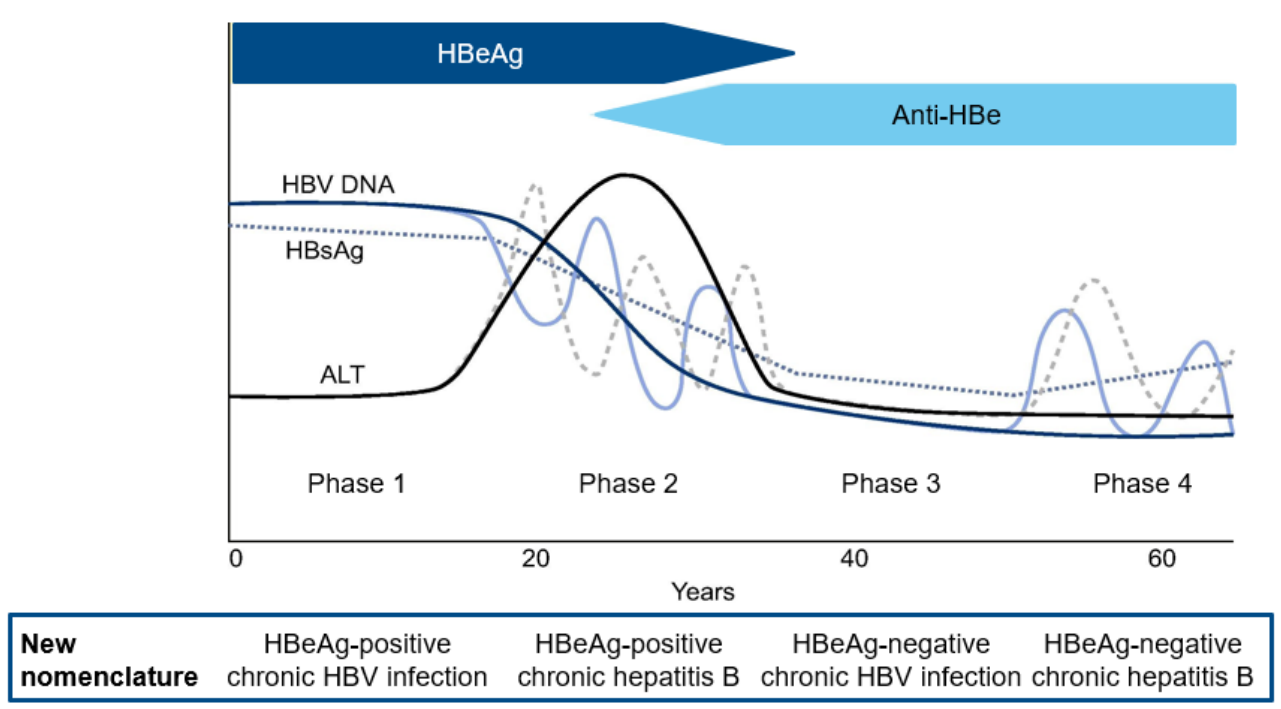

Figure 2: Natural history of chronic hepatitis B virus infection divided into four phases. Abbreviation: HBV: hepatitis B virus; HBsAg: hepatitis B surface antigen; ALT: alanine aminotransferase; HBeAg: hepatitis B e antigen; anti-HBe: antibodies against HBeAg. (Reprinted from: EASL, J Hepatol, 2017; Copyright: open access article, non-commercial use permitted)

An ongoing debate in the natural history of chronic HBV infection is the predetermined none or minimal liver disease progression in HBeAg-negative chronic infection state (previously termed inactive carrier). In the year 2000, the arbitrary cutoff HBV DNA level at 20,000 $\mathrm{IU} / \mathrm{mL}$ was chosen for the differentiation between HBeAg-negative chronic infection and the progressive HBeAg-negative chronic hepatitis phase because, at that time, hybridizationbased assays could not detect HBV DNA levels $<20,000 \mathrm{IU} / \mathrm{mL}^{35}$ However, Asian studies using high sensitive PCR-based HBV DNA assays in HBeAg-negative patients have contributed to our understanding that even low HBV DNA levels $(<20,000 \mathrm{IU} / \mathrm{mL}$ ) might still be associated with the risk of liver disease progression. ${ }^{36-39}$ Nevertheless, the risk of disease progression and its predictors in the Caucasian population living in Europe are unclear. The concept of a favourable long-term prognosis is critically reviewed in chapter 1. Based on historical data from 1987 onwards, we assessed the long-term outcome of HBeAg-negative Caucasian patients with serum HBV DNA level $<20,000 \mathrm{IU} / \mathrm{mL}$ and persistently normal ALT levels. 


\section{HEPATITIS B EPIDEMIOLOGY}

Besides an adequate understanding of the natural disease history among the Caucasian population living in Europe, it is imperative to elucidate the preceding epidemiological trends of HBV infection in furtherance of accurately estimating the current and future disease burden. Between 1990 and 2013, global HBV-related deaths increased from 0.5 to 0.7 million; there was also an increase in disability-adjusted life years (DALY) from 18.1 million to 20.6 million $^{13}$ (Figure 3). This increase might in part be explained by demographic changes (e.g. aging, global population increase) and the fact that the vast majority of people remain undiagnosed, and many who are diagnosed have advanced liver disease. ${ }^{40}$ The most recent data from WHO indicate that globally 257 million people are living with chronic HBV infection and hepatitis $B$ has resulted in 0.9 million deaths in 2015, mostly from serious sequelae cirrhosis and HCC. ${ }^{41}$ In the WHO European Region, hepatitis B causes 36,000 deaths per year and an estimated 13.3 million individuals live with chronic HBV infection. ${ }^{12}$ Although the epidemiological numbers of increasing global hepatitis B-related deaths over the years are sobering, they emphasize a crucial opportunity to improve public health given that hepatitis B is preventable by means of vaccination. ${ }^{7,14,41}$ Safe and effective hepatitis $B$ vaccines are available since 1982 and it is now more than 27 years since the WHO recommended all countries to implement universal infant vaccination by $1997.42-44$ As of 2019, 48 of the 53 WHO European countries conduct universal hepatitis B vaccination. ${ }^{45}, 46$ The most recent countries to follow the WHO recommendation were Ireland (in 2008), the Netherlands (in 2011) and the UK (in 2017). ${ }^{45}, 46$ Nonetheless, Denmark, Finland, Iceland, Norway and Sweden still implement a selective vaccination program targeting groups at risk of HBV infection only, instead of adding a universal vaccination program. ${ }^{45}$ 
A

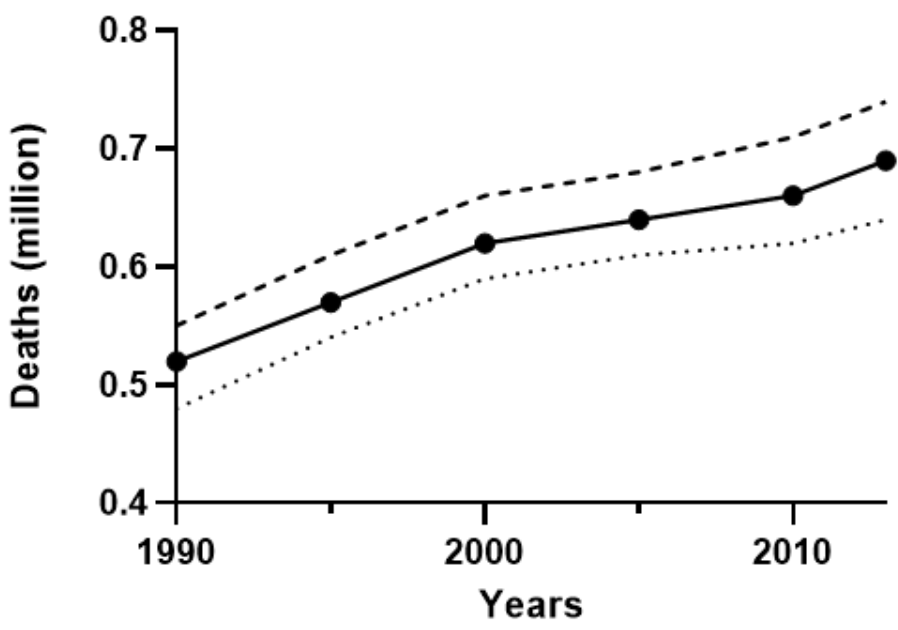

$\rightarrow$ Deaths

B

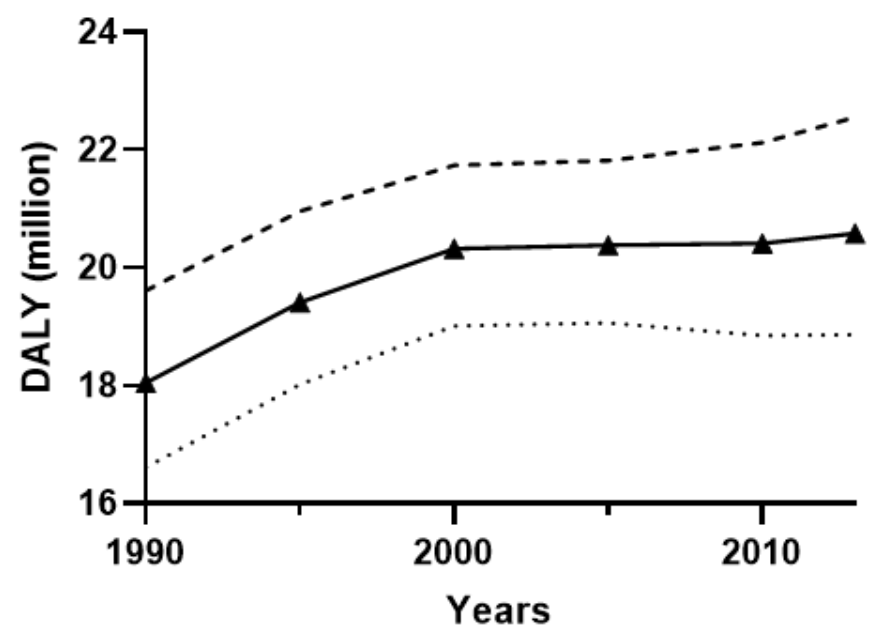

Figure 3: The absolute number global hepatitis B-related deaths ( $A$ ) and DALYs (B), by year, with $95 \%$ uncertainty intervals. Continuous lines represent the mean with dotted lines depicting $2.5^{\text {th }}$ percentile and dotted dash lines depicting $97.5^{\text {th }}$ percentile. Abbreviations: DALYs: disability-adjusted life years. (Adapted from: Stanaway JD et al, Lancet, 2016 ${ }^{13}$; Copyright: open access article, noncommercial use permitted) 
The impact of hepatitis B vaccination on acute HBV notification rates in Europe was demonstrated by Miglietta et al ${ }^{44}$ : a decrease from 1.6 per 100 thousand persons in 2006 to 0.7 in 2017, with the most significant decrease in countries with a universal HBV vaccination program before 1995 and a vaccine coverage of $\geq 95 \%$. Of the European countries, Belgium, Croatia and Italy were excluded from the study because a distinction between acute or chronic HBV cases was not possible. ${ }^{44}$ As Belgian data before the year 2009 could not distinguish between acute or chronic hepatitis, in chapter $\mathbf{2}$ we assessed the impact of HBV vaccination and other prevention strategies on surveillance data of the acute HBV notification rates in Flanders, Belgium, from 2009 to 2017.

\section{HEPATITIS B SCREENING}

Considering the fact that universal infant HBV vaccination in most European countries started after 1995, an appreciable number of the exposed population may at present already been infected with HBV and may remain undiagnosed due to the asymptomatic nature of chronic HBV infection until progression to cirrhosis and HCC. 44,47

Accordingly, the central idea of hepatitis B screening is early disease detection and antiviral treatment of undiagnosed eligible patients to prevent HBV-related deaths, prevent the onward transmission of HBV and reduce the economic burden of HBV-related complications in Europe. ${ }^{48-50}$ Although the central idea is simple, the path to its successful achievement on a national level may be far from simple. For this reason, Wilson and Jungner formulated several criteria for a suitable screening which have been revisited in $2008 . .^{51}$ The modified criteria are among others: 1 ) the disease should be an important health problem, 2) there should be a suitable test, 3) the availability of treatment, 4) the detection approach should be acceptable to the population and 5) the costs of diagnosis and treatment must be in an acceptable proportion to the costs of health care as a whole. ${ }^{51}$

With regard to the first criterium, hepatitis B is currently acknowledged as an important public health problem in the WHO European Region with approximately 13.3 million people living with chronic HBV infection and causing about 36,000 deaths per year. ${ }^{12}$ Considering the silent liver disease progression of HBV infection, only $15-60 \%$ of the patients with chronic HBV infection are diagnosed. ${ }^{52,} 53$ Increasing testing offer and uptake, particularly among those at risk, is essential to abide to WHO elimination goals for hepatitis $\mathrm{B}^{14}$ The 
WHO stimulates action towards diagnosing $90 \%$ of the patients with chronic HBV infection and treating $80 \%$ of the eligible patients. ${ }^{14}$

The prevalence of chronic HBV infection varies depending upon the geographic area from $<2 \%$ in low-prevalence areas (e.g. Western Europe) to $2-8 \%$ in intermediate-prevalence areas (e.g. Mediterranean region) to $\geq 8 \%$ in high-prevalence areas (e.g. Sub-Saharan Africa) ..$^{54-56}$ The burden of hepatitis $B$ also differs within Europe with a higher prevalence of chronic HBV infection in eastern and southern Europe than in countries in the northern and western parts. ${ }^{53}$ Figure 4 illustrates the geographic distribution of HBsAg prevalence worldwide.

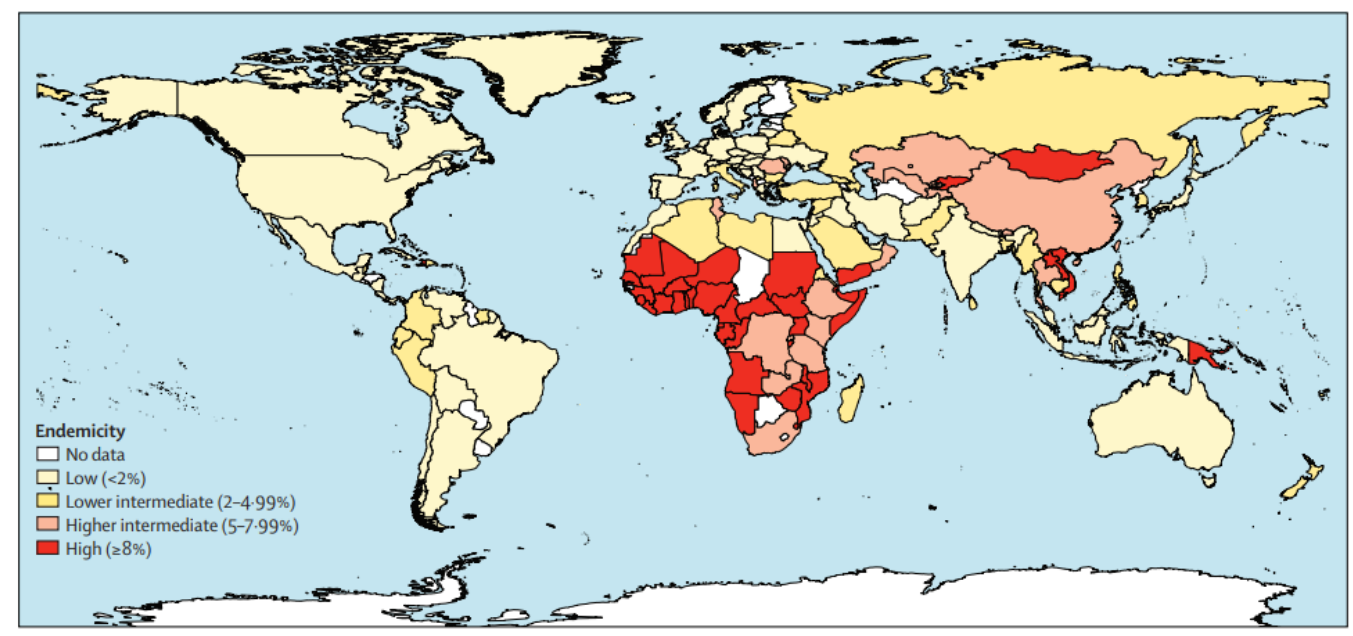

Figure 4: Geographic distribution of hepatitis B surface antigen prevalence worldwide. (Reprinted from: Schweitzer et al, Lancet, 201555; Copyright 2019, with permission from Elsevier)

Although most countries in Europe have a low prevalence of $\mathrm{HBsAg}(<2 \%)$ in the general population, several risk groups for HBV infection have been identified (Table 1). HBV can be found in the blood and to a lesser extent in body fluids (e.g. saliva, menstrual, vaginal, seminal fluids) of an infected person. ${ }^{57}$ In low-prevalence areas, HBV is most commonly spread in adulthood through sexual contact and injecting drug use. ${ }^{58}$ In areas with intermediate and high prevalence for hepatitis $B, \mathrm{HBV}$ infection occurs either from mother to child at birth (perinatal transmission), or from horizontal transmission through non-sexual close contact, especially from an infected child to an uninfected child during the first five years of life. ${ }^{57}$ Hepatitis $B$ is also spread by needlestick injury, tattooing and body piercing. ${ }^{57}$ 


\section{Table 1: Groups at risk for hepatitis B virus infection}

Individuals born in intermediate- or high-prevalence areas for HBV infection

People who have ever injected drugs

Men who have sex with men, sex workers and other individuals with multiple unsafe sexual contacts

Individuals with abnormal liver blood test results (ALT or AST) of unknown aetiology

Individuals who received blood, organ or surgery before 1992 or in the setting of suboptimal infection control standards

Predialysis and haemodialysis patients

Infants born to HBsAg-positive mothers

Persons with chronic liver disease

Persons with HIV

Household, needle-sharing, and sexual contacts of people diagnosed with HBV

Persons seeking evaluation or treatment for a sexually transmitted infection

Residents and staff of facilities for intellectual disabled people

People who were ever incarcerated

Abbreviations: HBV: hepatitis B virus; ALT: alanine aminotransferase; AST: aspartate aminotransferase; HBsAg: hepatitis B surface antigen. (Adapted from: Terrault NA et al, Hepatology, $2018^{59}$ and European Centre for Disease Prevention and Control. Public health guidance on HIV, hepatitis B and C testing in the EU/EEA - An integrated approach. Stockholm: ECDC; 2018 ${ }^{50}$ )

Serological markers used for screening of HBV infection include HBsAg, hepatitis B surface antibody (anti-HBs) and hepatitis B core antibody (anti-HBc). ${ }^{60-62}$ Serum HBsAg is the primary marker of infection. ${ }^{60-62}$ Chronic HBV infection is defined as the presence of $\mathrm{HBsAg}$ for at least six months. ${ }^{7,59,60}$ Table 2 summarizes the interpretation of hepatitis B serologic test results. 
Table 2: Interpretation of hepatitis B serologic test results

\begin{tabular}{llll}
\hline HBsAg & Anti-HBc & Anti-HBs & Interpretation \\
\hline Negative & Negative & Negative & Uninfected and not immune \\
Negative & Positive & Positive & Immune due to past HBV infection \\
Negative & Negative & Positive & Immune due to HBV vaccination \\
Positive & Positive & Negative & Acute or chronic HBV infection based on the presence \\
& & & of HBsAg for at least six months. \\
& & & Anti-HBc IgM is a marker of acute infection but may \\
& & also be raised in acute exacerbation of chronic HBV \\
& & infection. \\
& & Anti-HBc IgG is a marker of chronic infection \\
& & Four possibilities: \\
Negative & Positive & Negative & Past HBV infection (most common) \\
& & & False-positive anti-HBc \\
& & Resolving acute infection \\
& & Low grade chronic infection
\end{tabular}

Abbreviations: HBsAg: hepatitis B surface antigen; anti-HBc: hepatitis B core antibody; anti-HBs: hepatitis B surface antibody; HBV: hepatitis B virus; IgM: immunoglobulin M; IgG: immunoglobulin G. (Adapted from: Terrault NA et al, Hepatology, $2018^{59}$ and Mast EE, MMWR Recomm Rep, 2005 ${ }^{62}$ )

At present, we have serological assays that detect HBsAg at a relatively low cost and are therefore suitable for hepatitis B screening conform the second criterium by Wilson and Jungner. ${ }^{50,63}$ They are available in the form of laboratory-based immunoassay (e.g. enzyme immunoassays) or rapid diagnostic tests. ${ }^{50,63}$ Laboratory-based immunoassays have a superior sensitivity and specificity for HBsAg compared to rapid diagnostic tests but require laboratory infrastructure and can only be performed on specimen obtained by venipuncture. ${ }^{50}$ On the other hand rapid diagnostic tests do not need laboratory facilities, trained laboratory technician and can be performed with blood collected by fingerprick. ${ }^{50,63}$ Disadvantages include the lower sensitivity and specificity, and the current necessity of confirmation by laboratory-based immunoassays prior to diagnosis and initiation of treatment. 50, 63 
For a screening program aimed at secondary prevention, the availability of effective treatment is inevitable, i.e. the third criterium. At this time, there are two main options for the treatment of adults with chronic HBV infection: nucleos(t)ide analogues and pegylated interferon-alpha. The nucleos(t)ide analogues include those with high barrier against HBV resistance (entecavir, tenofovir disoproxil fumarate and tenofovir alafenamide) and those with low barrier to HBV resistance (lamivudine, adefovir dipivoxil and telbivudine). ${ }^{7,64,65}$ The long-term administration of a potent nucleos(t)ide analogue with high barrier to resistance is the treatment of choice for naïve patients with chronic HBV infection. ${ }^{7}$ After 5 years of treatment with antivirals with high barrier against HBV resistance, undetectable HBV DNA is achieved in $97-99 \%$ of HBeAg-positive persons and $92-100 \%$ of HBeAg-negative persons with a favourable safety profile. ${ }^{7,64,65}$ Long-term viral suppression is associated with a significant lower incidence of cirrhotic complications, HCC and liver-related deaths. ${ }^{66,67}$ In a lower proportion, namely $3.2-11.8 \%$ of HBeAg-positive patients and in $0.1-1.0 \%$ of HBeAg-negative patients, HBsAg loss, i.e. functional cure, occurs after long-term antiviral treatment with potent nucleos(t)ide analogues, thereby preventing $\mathrm{HBV}$ transmission. ${ }^{7,68-70}$ In addition to antiviral treatment, newly diagnosed patients with chronic HBV infection are advised to inform all first degree relatives and sexual partners to be tested for HBV infection and to be vaccinated if they are uninfected and not immune. ${ }^{7,59,65}$ This strategy facilitates the prevention of onward transmission.

With regards to the fourth criterium of Wilson and Jungner 'the detection approach should be acceptable to the population', several testing strategies have been postulated: testing in health care settings (e.g. primary health care settings, hospital settings, other practices), community settings and other settings, i.e. self-sampling and self-testing. ${ }^{50}$ Routine testing for HBV infection in health care settings can reduce stigmatisation and can improve testing rates in groups at risk for HBV infection. ${ }^{50}$ Moreover, as patients are generally undergoing venipuncture in the health care setting, the additional costs for HBV testing are reduced. ${ }^{50}$ However, testing rates are generally low and linkage to care may be inadequate due to lack of knowledge and limited time of health care professionals. ${ }^{50,71-74}$ In contrast, communitybased hepatitis $B$ testing are offered outside health care facilities and available data suggest that community-based testing services may result in high testing rates, high HBsAg positive rates in undiagnosed patients and may be effective at reaching groups at risk of HBV infection such as migrants from intermediate or high endemic countries. ${ }^{50}$ 
Regarding the fifth criterium and specifically for migrants originating from intermediate and high prevalence areas, it is shown that the costs of diagnosis and treatment of hepatitis $B$ are in an acceptable proportion to the costs of health care as a whole. ${ }^{49,75}$ However, before defining specific target groups for hepatitis B screening, it is advisable to assess HBV risk factors on recent national and local epidemiological data. Although recent data are available for the neighbouring countries (i.e. the Netherlands, France and Germany), the last epidemiological assessment for HBV infection in the general Belgian population dates from $2002-2003 .{ }^{76-78}$ Since there is also no information on the predominant risk factors for HBV infection in Belgium, in chapter $\mathbf{3}$ we assessed the current prevalence and risk factors of HBV infection in a multi-ethnic region situated in Middle Limburg Belgium in 2017.

Furthermore, in view of the lack of a current national screening program for HBV infection in migrants from intermediate or high endemic countries living in Europe, in chapter $\mathbf{4}$ we propose a protocol for community-based hepatitis B testing in the Turkish migrant population. After all, Turkey is an intermediate prevalence area with HBsAg prevalence ranging from $2-8 \%$ and with an estimated 97,255 chronic HBV cases among Turkish migrants in Europe, they form the third largest migrant population with the highest number of chronic HBV cases in Europe. ${ }^{79}, 80$ Moreover, limited data are available as to the Turkish migrant population in Europe since prior studies on hepatitis $B$ testing in the migrant population generally involve Asians in the USA, Canada and Australia. ${ }^{81-90}$ The results of the outreach hepatitis B testing in Turkish migrants are subsequently presented in chapter $\mathbf{5}$. In addition to the early detection of patients with chronic HBV infection, the current screening program could identify persons who are susceptible to infection and would benefit from vaccination. ${ }^{48}$

\section{UNRESOLVED PROBLEM IN HEPATITIS B VACCINATION}

Hepatitis $B$ vaccination is recommended within universal vaccination of infants as well as for all unvaccinated adults at risk for HBV infection and all adults requesting protection from HBV infection. ${ }^{91}$ Currently licensed hepatitis $B$ vaccines in Europe are safe. ${ }^{92}$ Primary vaccination generally consists of three vaccinations at 0,1 and 6 months and elicits seroprotection (anti-HBs levels $\geq 10 \mathrm{mIU} / \mathrm{mL}$ ) in $88-95 \%$ of the general adult population..$^{93-95}$ However, the remaining $5-12 \%$ of the population with an inadequate immune response (anti-HBs level $<10 \mathrm{mIU} / \mathrm{mL}$ ) are called hepatitis B vaccine nonresponders, remain susceptible for $\mathrm{HBV}$ infection and are an unresolved problem in hepatitis 
$B$ vaccination to reach elimination of hepatitis $B$. The standard of care for hepatitis $B$ vaccine non-responders usually consists of revaccination with licensed hepatitis $B$ vaccines in a 0 , 1,2 months schedule or a schedule of two co-administered doses followed by another two doses after 2 months, which is associated with a seroprotection rate of approximately 50 $69 \% .{ }^{96-100}$ Risk factors for non-response include age above 40 years, smoking, obesity, male sex, chronic medical condition, genetic factors and immune suppression. ${ }^{91,101,102}$

In view of these matters, there is a medical need for new more immunogenic hepatitis $B$ vaccines that will induce adequate antibody response in this hepatitis $B$ vaccine nonresponder population. Recently, various strategies have been developed to elicit protective anti-HBs levels in these hepatitis $B$ vaccine non-responders: increased antigen dose and altemative adjuvants, among others (Figure 5). ${ }^{103,}{ }^{104}$ In a double-blind, randomized controlled trial among healthy Chinese adult non-responders, increasing the antigen dose to $60 \mu \mathrm{g} \mathrm{HBsAg}$ is associated with a higher seroprotection rate of $92.1 \%$ compared to $83.0 \%$ after three revaccination doses of $10 \mu \mathrm{g} \mathrm{HBsAg} .{ }^{104}$ Compared to standard hepatitis B vaccines, higher immunogenic responses are attained in healthy non-responders with adjuvanted hepatitis $B$ vaccines Fendrix $\AA$ and Heplisav-B $(.97,98$ However, in Europe, Fendrix $\AA$ is currently only licensed (authorised in 2005) for patients with renal dysfunction and not for the healthy non-responder population. ${ }^{105}$ One should also acknowledge that the higher immunogenic response with Fendrix $®$ is not only linked to the adjuvant 3-O-desacyl4'-monophosphoryl lipid A but also to the higher antigen content. ${ }^{98}$ The second adjuvanted vaccine Heplisav- $B \circledast$ is for the moment not licensed in Europe. ${ }^{106}$

As the currently licensed hepatitis B vaccines in Europe all have an aluminium-based adjuvant, we tried to enhance the immune response by adding a cytokine-based adjuvant. The new HBAI20 vaccine consists of the standard HBVaxProC)-10 $\mu \mathrm{g}$ vaccine and the AI20 adjuvant, containing $20 \mu \mathrm{g}$ recombinant human IL-2 adsorbed to $20 \mu \mathrm{g}$ aluminium hydroxide. In chapter $\mathbf{6}$, we determined the safety and immunogenicity of this new HBAI20 hepatitis $B$ vaccine in a phase 1 study in healthy naïve and non-responder population. As reported under chapter $\mathbf{7}$, we further evaluated the immunogenicity and safety of the new HBAI20 hepatitis B vaccine among healthy non-responders in a well-designed double-blind, randomized controlled phase 2 trial. 


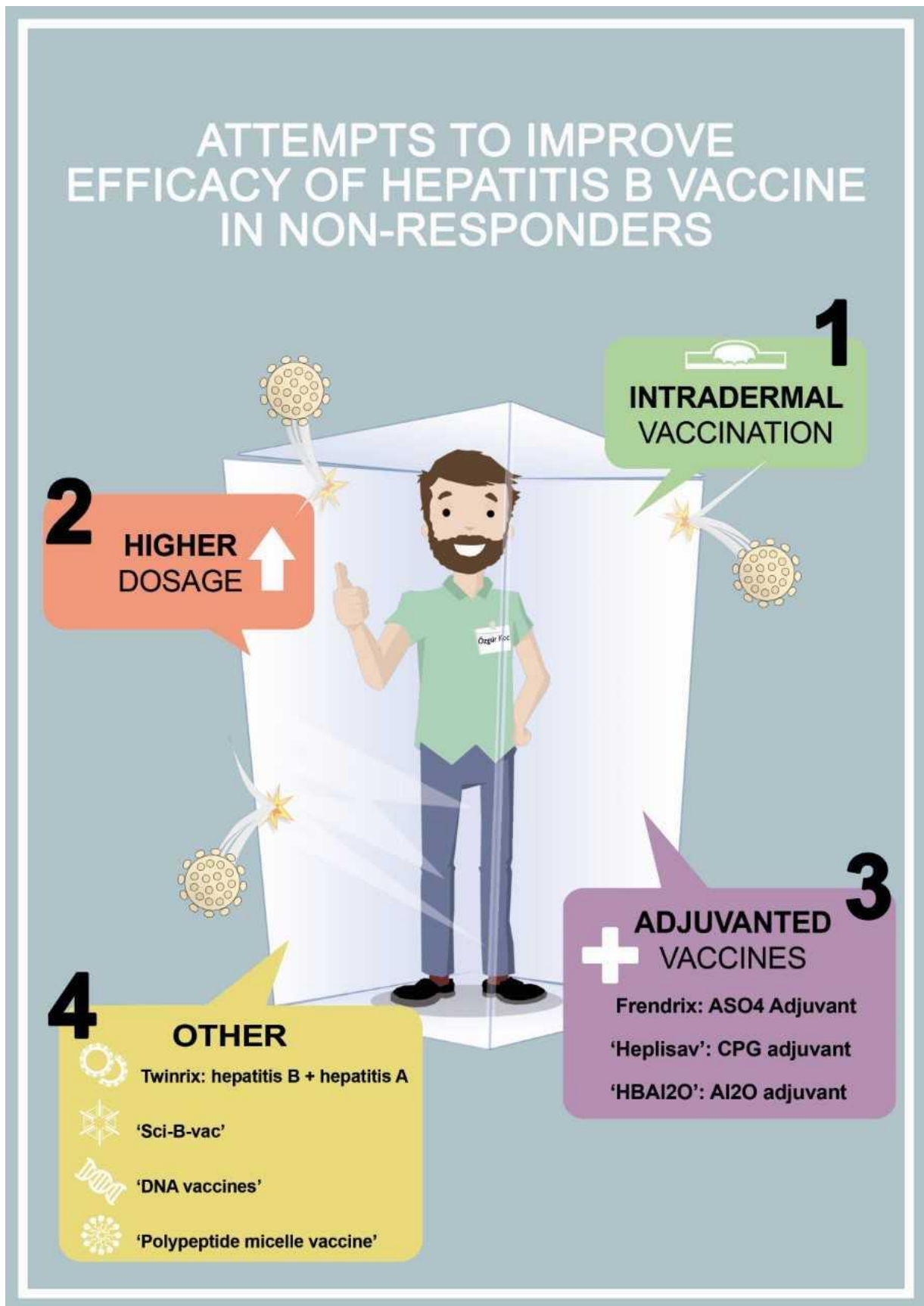

Figure 5: Attempts to improve efficacy of hepatitis B vaccine in non-responders. Abbreviations: AS04: adjuvant system 04 consisting of aluminium hydroxide and the adjuvant 3-O-desacyl-4'monophosphoryl lipid A; CpG: cytidine-phosphate-guanosine oligodeoxynucleotide; AI20: $20 \mu \mathrm{g}$ recombinant human IL-2 adsorbed to $20 \mu \mathrm{g}$ aluminium hydroxide. 


\section{RESEARCH OBJECTIVES}

This $\mathrm{PhD}$ thesis focuses on the past, the present and future directions in viral hepatitis B in Europe.

In chapter 1, we critically reviewed the expected long-term prognosis in patients with HBeAg-negative chronic infection. In a large historical cohort of Caucasian patients living in Europe, we specifically assessed whether there is a cut-off value of HBV DNA level that can predict those patients who would benefit from a strict follow-up program and those who do not require a stringent monitoring.

To estimate the current HBV disease burden, we further evaluated the effect of prevention and control strategies on acute hepatitis B notification rates in Flanders, Belgium, using prior data from 2009 - 2017 in chapter 2.

In chapter 3, we assessed the current prevalence and risk factors of HBV infection in a multi-ethnic region situated in Middle-Limburg, Belgium.

Chapter $\mathbf{4}$ describes the design of a study to assess the present HBV prevalence in the Turkish population living in Belgium.

In chapter 5, we subsequently report the results of the community-based hepatitis B testing in the Turkish population. We also determined the risk factors of HBV infection, uptake of HBV screening, vaccination and antiviral treatment in this Turkish migrant population.

Considering the medical need for a more immunogenic vaccine in non-responders, in chapter 6 \& 7 we determined the safety and immunogenicity of a new HBAI20 hepatitis B vaccine in non-responders in respectively a phase 1 and phase 2 study. 



\section{CHAPTER 1}

\section{Outcome in Caucasian patients with hepatitis B}

e antigen negative chronic infection: a longterm observational cohort study

Koc ÖM, Robaeys G, Topal H, Bielen R, Busschots D, Fevery J, Koek $\mathrm{GH}$, Nevens F

Submitted 


\section{ABSTRACT}

Background: Sensitive PCR assays to measure HBV DNA became only available the last decade. Hence, the long-term outcome of Caucasian patients in Western Europe with hepatitis B e antigen (HBeAg)-negative chronic infection, especially with a baseline HBV DNA level $\geq 2,000 \mathrm{IU} / \mathrm{mL}$, is still unclear.

Methods: Out of a cohort of 1,936 chronic HBV patients, 413 Caucasian patients were identified with HBeAg-negative chronic infection, defined as persistently normal alanine aminotransferase (ALT) levels and HBV DNA levels $<20,000 \mathrm{IU} / \mathrm{mL}$.

Results: During a mean follow-up of 12 years, 366 (88.6\%) maintained a HBeAg-negative chronic infection status, whereas 25 (6.1\%) developed chronic active hepatitis (CAH). Nine of these $25 \mathrm{CAH}$ cases were related to immunosuppression. Twenty-two (5.3\%) individuals had ALT $>2 \times$ ULN due to non-HBV related causes. The cumulative probability of spontaneous developing $\mathrm{CAH}$ after 10 years was almost exclusively seen in patients with baseline HBV DNA level $\geq 2,000 \mathrm{IU} / \mathrm{mL}(11.7 \%$ vs $1.2 \%, \mathrm{p}<0.001)$. Advanced liver disease developed significantly more in patients with baseline HBV DNA level $\geq 2,000 \mathrm{IU} / \mathrm{mL}(5.2 \%$ vs $1.5 \%, p=0.018)$ and occurred especially in patients with obesity $(16.7 \%$ vs $4.2 \% p=$ 0.049). The incidence of hepatocellular carcinoma was $0.0 \%$.

Conclusion: Caucasian patients with HBeAg-negative chronic infection and baseline HBV DNA level of $<2,000 \mathrm{IU} / \mathrm{mL}$ have an excellent long-term prognosis in the absence of immunosuppressive therapy. However, patients with baseline HBV DNA level $\geq 2,000$ $\mathrm{IU} / \mathrm{mL}$ are at risk to develop advanced liver disease. 


\section{INTRODUCTION}

Infection with hepatitis B virus (HBV) remains a global health challenge with approximately 257 million people living with chronic HBV infection, of whom 887,000 die annually from HBV-related complications such as cirrhosis and hepatocellular carcinoma (HCC). ${ }^{57}$ The natural history of chronic HBV infection can be divided in four phases, taking into account the presence of hepatitis $B$ e antigen ( $\mathrm{HBeAg}$ ), serum HBV DNA levels and serum alanine aminotransferase (ALT) values.7, 59, 65

One of these phases is the HBeAg-negative chronic infection state. ${ }^{7}$ This stage was previously called 'inactive carrier' phase, but this terminology was abandoned since previous studies indicated that some of these patients develop advanced liver disease. ${ }^{7}$

According to current management guidelines on hepatitis $B$, therapy is not indicated in patients with HBeAg-negative chronic infection but follow-up for risk of HBV reactivation, advanced liver disease and $\mathrm{HCC}$ is recommended.7, 59, 65 Most evidence on the natural history of HBeAg-negative chronic infection is based on studies in Asian patients, wherein the high sensitivity of polymerase chain reaction (PCR)-based HBV DNA assays have contributed to our understanding that even low HBV DNA levels may still be associated with the risk of liver disease progression. ${ }^{36,107,108}$ However, only a limited number of studies have assessed the risk of disease progression and its predictors in Caucasian patients. Previous European studies on the natural history of patients in the chronic infection phase were limited by the short duration of follow-up (less than 10 year follow-up), small groups of patients $(<200$ subjects), poorly defined criteria for HBeAg-negative chronic infection and the use of the low sensitivity branched HBV DNA assays for quantification. ${ }^{109-119}$

Recent sensitive PCR assays to measure HBV DNA have demonstrated that in general, patients with HBeAg-negative chronic infection have HBV DNA levels $<2,000 \mathrm{IU} / \mathrm{mL}$. However, some patients in this phase have HBV DNA levels between 2,000 and 20,000 $\mathrm{IU} / \mathrm{mL} .7,59$ The risk of liver disease progression is unclear in this subgroup of Caucasian patients with baseline HBV DNA levels $\geq 2,000 \mathrm{IU} / \mathrm{mL}$.

This is the first long-term follow-up study of more than 10 years in HBeAg-negative Caucasian patients making use of the high sensitive PCR-based assays. The main objectives were to investigate the disease outcome of those with HBV DNA levels $\geq 2,000 \mathrm{IU} / \mathrm{mL}$ and to find out whether a cut-off value of serum HBV DNA level of 2,000 IU/mL can predict those 
patients who would benefit from a strict follow-up program and those who do not require a stringent monitoring. 


\section{PATIENTS AND METHODS}

The study involved three large educational hospitals, two in Belgium and one in the Netherlands. The data were to be collected according to a protocol that followed the Strengthening the Reporting of Observational Studies in Epidemiology (STROBE) statement with clear definitions of the study population, follow-up and outcome data.

\section{STUDY POPULATION}

The study identified all consecutive chronic HBV patients of the participating centres between 1 January 1987 and 31 July 2018 who fulfilled the following inclusion criteria: (1) Caucasian race, (2) persistence of HBsAg for at least one year, (3) the presence of antibodies to $\mathrm{HBeAg}$ (anti-HBe) without HBeAg, (4) low or undetectable HBV DNA ( $<20,000 \mathrm{IU} / \mathrm{mL}$ ), (5) persistently normal ALT levels, defined as $\geq$ three ALT determinations ( $\leq 40 \mathrm{IU} / \mathrm{L}$ ) at least two months apart over a period of at least 12 months and (6) follow-up at the enrolling centre for a minimum period of 12 months. Patients previously treated with HBV antiviral agents were excluded as well as HBsAg-positive patients with prophylactic administration of antiviral therapy. Other exclusion criteria were: (1) signs of significant fibrosis (F2 based on transient elastography values $>9.0 \mathrm{kPa}$ or liver biopsy), (2) patients with hepatitis D or HIV co-infection, (3) a history of significant alcohol consumption based on a threshold of 14 units per week in men and 7 units per week in women ${ }^{8}$ and (4) evidence of coexisting liver disease (e.g. non-alcoholic steatohepatitis (NASH), autoimmune hepatitis).

\section{FolLow-UP}

The observation period was calculated from the date of presentation until death or the last visit at the outpatient clinic. At the first visit in the outpatient clinic, a complete history was taken, a physical examination was conducted, liver disease activity and severity were assessed including markers of HBV infection (e.g. HBeAg and anti-HBe, HBV DNA). ${ }^{7}$ Biochemical parameters and an abdominal ultrasound were recommended in all patients. Patients were monitored with periodical determinations of serum ALT and HBV DNA levels as well as for liver stiffness by transient elastography from 2006 onwards. Liver biopsy was not routinely advised and only performed in case of suspected advanced liver disease (based on laboratory results, abdominal ultrasound and/or transient elastography) and in the suspicion of a concomitant liver disease. ${ }^{7}$ Results from transient elastography and liver biopsies were evaluated according to the METAVIR classification. ${ }^{120}$ 


\section{DEFINITION OF CLINICAL EVENTS}

The primary outcome was the development of chronic active hepatitis (CAH), defined by increased ALT levels to more than twice the upper limit of normal (ULN) on two occasions at least two weeks apart with HBV DNA levels $\geq 2,000 \mathrm{IU} / \mathrm{mL}$ whether or not with HBeAg reversion.7, 59, 65 Increased ALT levels $>2 \times$ ULN that could not be classified as CAH were designated as non-HBV related cause. ${ }^{121}$

According to the report of the Baveno VI Consensus Workshop, advanced liver disease was suspected on transient elastography values $\geq 10 \mathrm{kPa} .{ }^{122}$ The development of cirrhosis was defined as a clinical syndrome consisting of either histological confirmation of cirrhosis or ultrasonographic findings of cirrhosis. ${ }^{115}$ Cirrhosis was further classified according to the Child-Pugh score. ${ }^{123}$ HCC diagnosis was based on non-invasive criteria (positive lesion detected by at least two different imaging techniques) or pathology. ${ }^{115}$ Additionally, this study evaluated the incidence of mortality and liver-related mortality.

\section{IMMUNOSUPPRESSIVE TREATMENT}

This study also assessed whether patients who developed a CAH were exposed to immunosuppressive or cancer chemotherapy. The immunosuppressive therapies were classified into those with low (e.g. azathioprine), moderate (cyclosporine) and high (e.g. rituximab, high-dose corticosteroids, infliximab) risk of reactivation as previously outlined by Loomba and Liang. ${ }^{124} \mathrm{CAH}$ resulting from immunosuppressive therapy was considered up to 6 months after cessation of immunosuppression, and in the case of B-cell depleting drugs (e.g. rituximab) as late as 12 months post-treatment. ${ }^{125}$

\section{LABORATORY PROCEDURES}

ALT and viral markers (HBsAg, antibodies to $\mathrm{HBsAg}$ (anti-HBs), $\mathrm{HBeAg}$, anti-HBe, hepatitis $C$ and $D$ virus antibodies, anti-HIV) were determined using conventional serological assays. Serum samples at baseline were stored at $-20^{\circ} \mathrm{C}$. Up to 2002 , serum HBV DNA levels were analysed on stored serum samples with the branched DNA signal amplification assay (Chiron Diagnostics, Emeryville, CA) lower limit of detection of $0.7 \mathrm{mEq} / \mathrm{mL}\left(7.00 \times 10^{5}\right.$ $\mathrm{IU} / \mathrm{mL}$ ). Thereafter, HBV DNA quantification was performed by ABI Prism 7900HT (Applied Biosystems, Thermo Fisher Scientific, Waltham, MA) with a detection limit of $100 \mathrm{IU} / \mathrm{mL}$ and from 2015 on by a commercial PCR assay (Abbot RealTime HBV assay, Abbott Molecular Inc, Des Plaines, IL) with a sensitivity of $10 \mathrm{IU} / \mathrm{mL}$. Serum qHBsAg was measured on the 
Elecsys HBsAg II quant (Roche Diagnostics, Penzberg, Germany) or Architect HBsAg QT (Abbott Diagnostics, IL, USA) assay.

\section{STATISTICAL ANALYSIS}

Statistical analysis was performed with the SPSS software version 25 (IBM Corp, Armonk, NY). Continuous variables are expressed as means \pm standard deviation (SD) or medians \pm interquartile range (IQR) as appropriate. For the comparison of categorical variables, either the Chi-square test or the Fisher's exact test was used. The Student's $t$ test or MannWhitney $U$ nonparametric test was used to analyse continuous variables between two independent groups. The level of statistical significance was set at $p<0.05$ in two-tailed tests.

Estimates on the rate of CAH and advanced liver disease were calculated using the KaplanMeier method, and the difference was determined using the log-rank test. Univariate analyses (log-rank tests) to identify variables associated with CAH or advanced liver disease included age at diagnosis (< 40 vs $\geq 40$ years), sex (male vs female), obesity (yes vs no), baseline ALT level (low-normal < $0.5 \times$ ULN vs high-normal $0.5-1 \times$ ULN), baseline quantitative HBsAg (qHBsAg) level $(<1,000 \mathrm{IU} / \mathrm{mL}$ vs $\geq 1,000 \mathrm{IU} / \mathrm{mL}$ ) and baseline HBV DNA level $(<2,000 \mathrm{IU} / \mathrm{mL}$ vs $\geq 2,000 \mathrm{IU} / \mathrm{mL})$.

\section{ETHICAL APPROVAL}

Following the Belgian law of the $7^{\text {th }}$ of May 2004, an approval of an ethics committee is not necessary for a retrospective non-interventional study. 


\section{RESULTS}

Out of 1,936 patients with chronic HBV infection at baseline, we identified 413 Caucasians with HBeAg-negative chronic infection according to in- and exclusion criteria of this study (Figure 1.1). The baseline characteristics of the 413 included Caucasian patients are presented in Table 1.1. The mean age at presentation was $34 \pm 13.6$ years; 210 (50.8\%) were males and $81(19.6 \%)$ had a baseline HBV DNA level $\geq 2,000 \mathrm{IU} / \mathrm{mL}$. Additional information on qHBsAg level was available in 146/413 (35.4\%) patients. In patients with detectable viremia in which genotyping could be performed: 36/61 (59.0\%) had a genotype A and 25/61 (41.0\%) a genotype D.

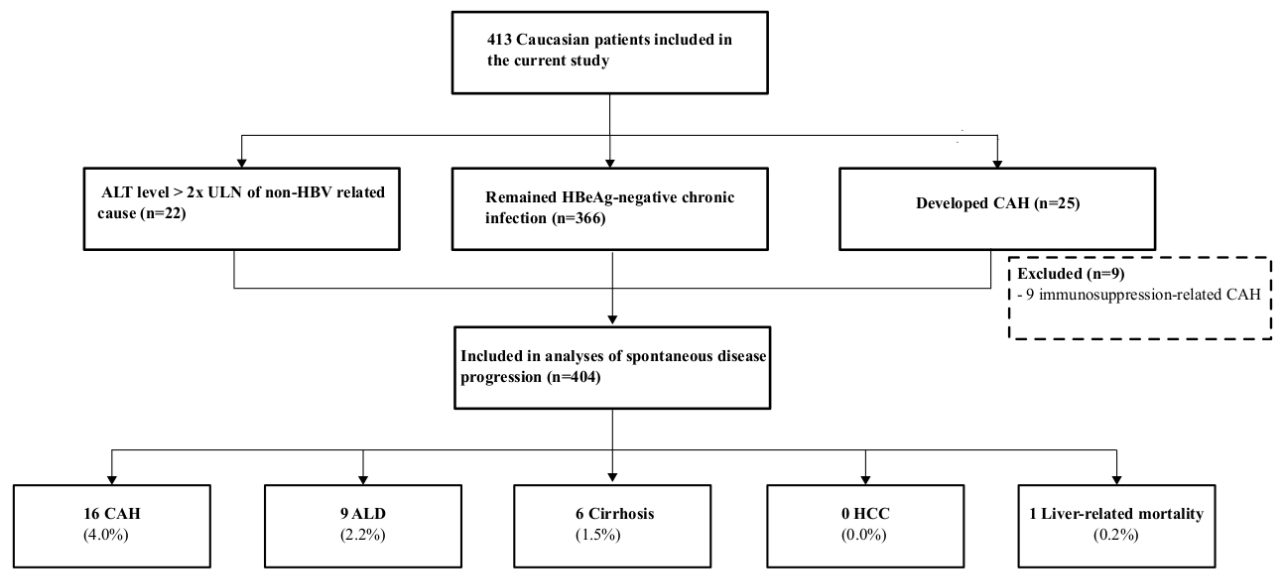

Figure 1.1: Study flowchart. Abbreviations: ALT: alanine aminotransferase; ULN: upper limit of normal; HBV: hepatitis B virus; HBeAg: hepatitis B e antigen; CAH: chronic active hepatitis; ALD: advanced liver disease; HCC: hepatocellular carcinoma. 
Table 1.1: Baseline Characteristics of 413 Caucasian patients with hepatitis $B$ e antigen negative chronic infection. A total of 366 individuals remained $\mathrm{HBeAg-negative} \mathrm{chronic} \mathrm{infection,} 25$ developed $\mathrm{CAH}$, while the remaining 22 patients had increased ALT levels $>2 \times$ ULN of non-HBV related cause

\begin{tabular}{l|c|c|c|c}
\hline Characteristics & All & $\begin{array}{c}\text { Remained } \\
\text { HBeAg-negative } \\
\text { chronic infection } \\
\mathbf{( n = 3 6 6 )}\end{array}$ & $\begin{array}{c}\text { CAH } \\
\text { Value }\end{array}$ & \\
\hline Baseline Age (years) & $34 \pm 13.6$ & $36 \pm 12.2$ & $33 \pm 14.2$ & 0.866 \\
\hline Sex, males (\%) & $210(50.8)$ & $181(49.5)$ & $15(60.0)$ & 0.308 \\
\hline Obesity ${ }^{\dagger}(\%)$ & $32(7.7)$ & $27(7.4)$ & $1(4.0)$ & 0.711 \\
\hline Baseline ALT, (IU/L) & $24 \pm 8.1$ & $23 \pm 8.4$ & $26 \pm 7.1$ & 0.214 \\
\hline $\begin{array}{l}\text { Baseline qHBsAg } \\
\text { level, (IU/mL) }\end{array}$ & $360 \pm 1,667.0$ & $362 \pm 1,613.9$ & $291 \pm 3,350.0$ & 0.617 \\
\hline $\begin{array}{l}\text { Baseline HBV DNA, } \\
\text { (log IU/mL) }{ }^{\ddagger}\end{array}$ & $2.5 \pm 3.12$ & $2.5 \pm 3.10$ & $3.3 \pm 1.38$ & 0.004 \\
\hline $\begin{array}{l}\text { HBV DNA } \geq 2,000 \\
\text { IU/mL, (\%) }\end{array}$ & $81(19.6)$ & $64(17.5)$ & $13(52.0)$ & $<0.001$ \\
\hline
\end{tabular}

Values shown as mean + standard deviation or as $\mathrm{n}(\%)$. Abbreviations: HBeAg: hepatitis B e antigen; CAH: chronic active hepatitis B; ALT: alanine aminotransferase; ULN: upper limit of normal; qHBsAg: quantification of hepatitis B surface antigen; HBV: hepatitis B virus. +Obesity was defined as BMI > 30 $\mathrm{kg} / \mathrm{m} 2$. $¥$ Mann-Whitney $\mathrm{U}$ nonparametric test was used instead and medians + interquartile range (IQR) were shown as appropriate. §Information on qHBsAg was available in 151/413 (36.6\%), 130/366 (35.5\%) and $11 / 25(44.0 \%)$ among all study patients, patients who remained HBeAg-negative chronic infection and those with CAH development, respectively.

\section{Chronic active hepatitis}

During a mean follow-up of $12 \pm 8.3$ years, $366(88.6 \%)$ of the 413 patients maintained HBeAg-negative chronic infection, whereas 25 (6.1\%) developed CAH. The remaining 22 (5.3\%) individuals had ALT level $>2 \times$ ULN of non-HBV related cause (e.g. nonalcoholic fatty liver disease (NAFLD), medication use, malignant infiltration). Out of the 25 patients with CAH, 9 were considered to be the result from immunosuppressive therapy or cancer chemotherapy. Five patients received immunosuppressive therapy with a moderate risk of hepatitis $B$ reactivation, i.e. two patients were the result from post-kidney transplant immunosuppression and three were in the setting of cancer treatment. In addition, three patients with lymphoma received rituximab containing regimens and one subject was treated with high-dose ( $>20 \mathrm{mg}$ orally daily) corticosteroids for rheumatic disease. Thus, the prevalence of spontaneous development to CAH in the study population was 16/404 
(4.0\%) (Figure 1.1). The cumulative probabilities of CAH development were $1 / 283(0.4 \%)$, $7 / 196(3.6 \%)$ and $8 / 131(6.1 \%)$ at 5,10 , and 15 years follow-up, respectively.

In univariate analyses (log-rank tests) among the 404 Caucasian patients, baseline HBV DNA level $\geq 2,000 \mathrm{IU} / \mathrm{mL}(11.7 \%$ vs $1.2 \%, p<0.001)$ and qHBsAg level $\geq 1,000 \mathrm{IU} / \mathrm{mL}$ $(7.1 \%$ vs $1.0 \%, p=0.015)$ were the only factors significantly associated with the occurrence of $\mathrm{CAH}$. Figure 1.2 shows the cumulative probabilities of spontaneous $\mathrm{CAH}$ development in two groups, i.e. baseline HBV DNA levels $<2,000 \mathrm{IU} / \mathrm{mL}$ and those with baseline HBV DNA levels $\geq 2,000 \mathrm{IU} / \mathrm{mL}$. Among patients with baseline HBV DNA level $\geq$ $2,000 \mathrm{IU} / \mathrm{mL}(\mathrm{n}=77), \mathrm{qHBsAg}$ level $\geq 1,000 \mathrm{IU} / \mathrm{mL}$ identified patients with a higher risk to develop CAH ( $p=0.002$ ): it was $28.6 \%$ for patients with a qHBsAg level $\geq 1000 \mathrm{IU} / \mathrm{mL}$ and $0.0 \%$ if qHBsAg level $<1,000 \mathrm{IU} / \mathrm{mL}$. 


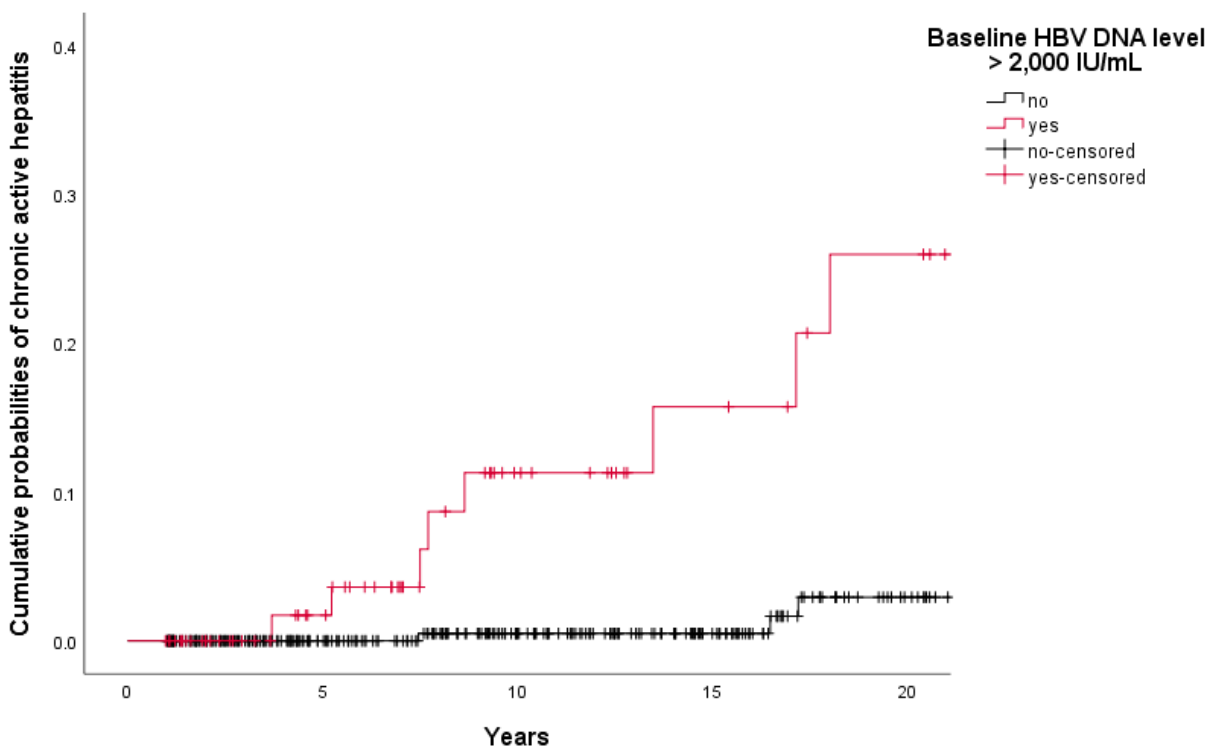

$\begin{array}{lllllllll}\text { Time (years) } & 0 & 1 & 2 & 3 & 5 & 10 & 15 & 20 \\ \text { Baseline HBV DNA level } & 77 & 75 & 65 & 59 & 52 & 27 & 18 & 13\end{array}$

2,000 IU/mL

$\begin{array}{lllllllll}\text { CAH development } & - & 0 & 0 & 0 & 1 & 4 & 1 & 2\end{array}$

$\begin{array}{lllllllll}\text { Censored } & - & 2 & 10 & 6 & 6 & 21 & 8 & 3\end{array}$

$\begin{array}{lllllllll}\text { Time (years) } & 0 & 1 & 2 & 3 & 5 & 10 & 15 & 20\end{array}$

$\begin{array}{lllllllll}\text { Baseline HBV DNA level } & 327 & 326 & 294 & 272 & 229 & 161 & 104 & 57\end{array}$

$<2,000 \mathrm{IU} / \mathrm{mL}$

$\begin{array}{lllllllll}\text { CAH development } & - & 0 & 0 & 0 & 0 & 1 & 0 & 2 \\ \text { Censored } & - & 1 & 32 & 22 & 43 & 67 & 57 & 45\end{array}$

Figure 1.2: Cumulative probabilities of spontaneous chronic active hepatitis development by baseline hepatitis B virus DNA level $(\mathbf{n}=\mathbf{4 0 4})$. A total of 404 Caucasian patients with $\mathrm{HBeAg}$ negative chronic infection were analysed after excluding 9 individuals with immunosuppression-related CAH occurrence. Among this group, progression to CAH was higher in patients with baseline HBV DNA level $\geq 2,000 \mathrm{IU} / \mathrm{mL}$ than in patients with baseline HBV DNA level $<2,000 \mathrm{IU} / \mathrm{mL}(\mathrm{p}<.001$, log-rank test). Cumulative probabilities of CAH were $1 / 53(1.9 \%)$ vs $0 / 229(0.0 \%), 5 / 32(15.6 \%)$ vs $1 / 162$ $(0.6 \%), 6 / 24(25.0 \%)$ vs $1 / 105(1.0 \%)$ at 5,10 , and 15 years follow-up, respectively. Abbreviations: HBV: hepatitis B virus; CAH: chronic active hepatitis; HBeAg: hepatitis B e antigen. +Patients were censored on the date of last outpatient clinic visit. 


\section{FOLLOW-UP OF SERUM HBV DNA LEVELS AND HBSAg}

Longitudinal follow-up of serum HBV DNA levels revealed that HBV DNA levels exceeded $2,000 \mathrm{IU} / \mathrm{mL}$ in $151 / 404$ (37.4\%) Caucasian patients during follow-up versus $77 / 404$ $(19.1 \%)$ at baseline and that 35/404 (8.7\%) patients developed a HBV DNA level $\geq 20,000$ $\mathrm{IU} / \mathrm{ml}$. Spontaneous HBsAg loss occurred in 0.94 per 100 persons-years. The cumulative incidences of HBsAg loss were 9/291 (3.1\%), 19/206 (9.2\%) and 32/145 (22.1\%) at 5, 10, and 15 years follow-up, respectively. HBsAg loss was $11.5 \%$ in the group with HBV DNA level $<2,000 \mathrm{IU} / \mathrm{mL}$ and $4.9 \%$ in those with HBV DNA $\geq 2,000 \mathrm{IU} / \mathrm{mL}, p=0.080$. In the group of patients with HBsAg loss $(n=42)$, anti-HBs appeared in $29(69.0 \%)$ patients. The cumulative appearances of anti-HBs for $1,2,5$ and 10 years were $5.1 \%(2 / 39), 13.2 \%$ (5/38), 40.0\% (14/35) and 59.4\% (19/32).

\section{Clinical outcome}

A total of $73(18.1 \%)$ out of the 404 Caucasian patients underwent percutaneous liver biopsy during follow-up on suspicion of progressive liver disease. Histologically proven advanced liver disease was present in 5/73 (6.8\%) patients. Overall, the cumulative probabilities of advanced liver disease were 0/285 (0.0\%), 2/195 (1.0\%) and 4/127 (3.1\%) at 5, 10 and 15 years of follow-up, respectively.

Risk predictors for advanced liver disease in the univariate analyses (log-rank tests) among the 404 patients were male sex ( $3.9 \%$ vs $0.5 \%, p=0.029)$ and baseline HBV DNA level $\geq$ $2,000 \mathrm{IU} / \mathrm{mL}$ ( $5.2 \%$ vs $1.5 \%, p=0.018)$. Among patients with baseline HBV DNA level $\geq$ $2,000 \mathrm{IU} / \mathrm{mL}(\mathrm{n}=77)$, obesity was associated with a higher risk of advanced liver disease $(16.7 \%$ vs $4.2 \% p=0.049$ ). In the group of patients with baseline HBV DNA level $<2,000$ $\mathrm{IU} / \mathrm{mL}(\mathrm{n}=327)$, none of the variables were significantly associated with a lower risk of progression to advanced liver disease. Figure 1.3 illustrates the progression to advanced liver disease in patients with baseline HBV DNA level $<2,000 \mathrm{IU} / \mathrm{mL}$ against those with baseline HBV DNA levels $\geq 2,000 \mathrm{IU} / \mathrm{mL}$. 


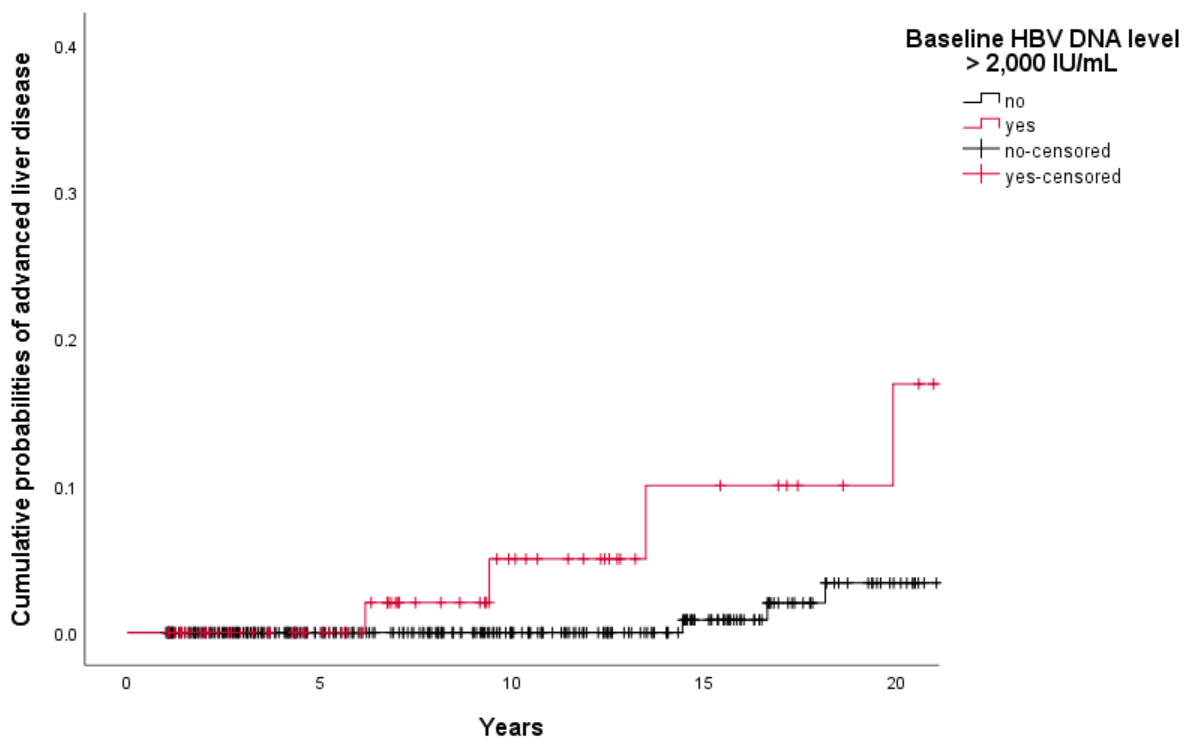

$\begin{array}{lllllllll}\text { Time (years) } & 0 & 1 & 2 & 3 & 5 & 10 & 15 & 20 \\ \text { Baseline HBV DNA level } & 77 & 76 & 66 & 60 & 53 & 29 & 17 & 11\end{array}$

$\geq 2,000 \mathrm{IU} / \mathrm{mL}$

\begin{tabular}{|c|c|c|c|c|c|c|c|}
\hline Advanced liver disease & - & 0 & 0 & 0 & 0 & 2 & 1 \\
\hline Censored & - & 1 & 10 & 6 & 7 & 22 & 11 \\
\hline Time (years) & 0 & 1 & 2 & 3 & 5 & 10 & 15 \\
\hline Baseline HBV DNA level & 327 & 326 & 296 & 274 & 231 & 163 & 105 \\
\hline \multicolumn{8}{|l|}{$<2,000 \mathrm{IU} / \mathrm{mL}$} \\
\hline Advanced liver disease & - & 0 & 0 & 0 & 0 & 0 & 1 \\
\hline Censored & - & 1 & 30 & 22 & 42 & 68 & 57 \\
\hline
\end{tabular}

Figure 1.3: Cumulative probabilities of progression to advanced liver disease by baseline hepatitis B virus DNA level $(\mathbf{n = 4 0 4 )}$. After excluding 9 individuals with HBV reactivation due to immunosuppressive therapy, progression to advanced liver disease was higher in patients with baseline HBV DNA level $>2,000 \mathrm{IU} / \mathrm{mL}$ than in patients with baseline HBV DNA level $<2,000 \mathrm{IU} / \mathrm{mL}(\mathrm{p}=.018$, log-rank test). Cumulative probabilities of advanced liver disease were $0 / 53(0.0 \%)$ vs $0 / 231(0.0 \%)$, $2 / 31(6.5 \%)$ vs $0 / 163(0.0 \%), 3 / 20(15.0 \%)$ vs $1 / 106(0.9 \%)$ at 5,10 and 15 years follow-up, respectively. Abbreviations: HBV: hepatitis $B$ virus; $\mathrm{HBeAg:} \mathrm{hepatitis} B$ e antigen. +Patients were censored on the date of last outpatient clinic visit. 
Six out of 404 patients (1.5\%) developed cirrhosis. Five had Child-Pugh score A and one died due to acute-on-chronic liver failure. There were no reports of HCC. The mean age of the patients with cirrhosis was $39 \pm 10.3$ years. The mean time to cirrhosis development was $17 \pm 4.5$ years.

A total of 381/404 (94.3\%) were alive at the end of follow-up. Death occurred in $23(5.7 \%)$ patients and among four of them reason of death was unknown. In the remaining 19 patients, there was one liver-related mortality reported. Malignant neoplasms were the leading cause of death, accounting for nine cases of death. Chronic obstructive pulmonary disease, myocardial infarction, pneumonia, end-stage renal disease and enteric fever explained the remaining ten deaths. 


\section{DISCUSSION}

The term 'inactive carrier' for patients with HBeAg-negative chronic infection was abandoned as Asian studies demonstrated that even low HBV DNA levels may still be associated with the risk of liver disease progression. ${ }^{36,107,108}$ The introduction of sensitive PCR-based HBV DNA assays over the last decade have demonstrated that most patients with HBeAgnegative chronic infection have HBV DNA levels $<2,000 \mathrm{IU} / \mathrm{mL}$. However, some patients in this phase might have HBV DNA levels between 2,000 and 20,000 IU/mL. 7, 59 Considering the fact that sensitive PCR to measure HBV DNA levels only became available the last decade, this is the first study to assess the 10 years or more disease outcome of Caucasian patients in Western Europe with HBeAg-negative chronic infection based on stringent criteria and the use of sensitive PCR-based HBV DNA assays.

Only few other studies in the past have addressed the follow-up of HBeAg-negative Caucasian patients with persistently normal ALT levels and HBV DNA levels $<20,000 \mathrm{IU} / \mathrm{mL}$ based on sensitive PCR assay. ${ }^{109}, 111,112,117,118$ Limited by a short follow-up time varying from 1 to 5 years, none had developed cirrhosis and no HCC or liver-related mortality was reported in these studies. These studies were also hampered by the small number of study participants $(n=35-195)$.

In studies with a longer follow-up, the prevalence of cirrhosis varied widely from 0.4$17.5 \% .{ }^{113-116}$ Correlation between baseline HBV DNA level and worse prognosis was not evaluated in these studies. ${ }^{113-116}$ Moreover, in the prior studies patients' serum HBV DNA level was quantified by an insensitive hybridization method. Hence, some patients may have been misclassified as HBeAg-negative chronic infection without use of PCR-based assays.

That the level of viremia can be important has been illustrated in the REVEAL study in Asian patients. There was an increased risk of cirrhosis, $\mathrm{HCC}$ and liver-related mortality in HBeAgnegative patients with baseline normal ALT level and HBV DNA level $\geq 2,000 \mathrm{IU} / \mathrm{mL} .{ }^{36}$

There are only a few studies that have addressed the issue of CAH development in Caucasian HBeAg-negative patients with persistently normal ALT values and HBV DNA

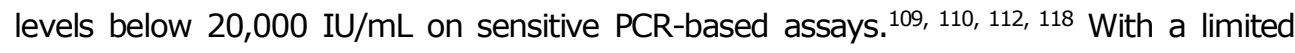
follow-up between $1-5$ years, the overall prevalence of progression to $\mathrm{CAH}$ in these studies was $0.0 \%$ in patients with $\mathrm{HBV}$ DNA level $<2,000 \mathrm{IU} / \mathrm{mL}$ and varied widely from $0.0 \%$ to $50.0 \%$ in those with HBV DNA level $\geq 2,000 \mathrm{IU} / \mathrm{mL}$. Our finding of spontaneous progression to CAH over 10 years was $1.2 \%$ and $11.7 \%$ in those patients with baseline HBV DNA level 
$<2,000 \mathrm{IU} / \mathrm{mL}$ and HBV DNA level $\geq 2,000 \mathrm{IU} / \mathrm{mL}$, respectively. This is lower than previously reported and could be ascribed to differences in study population, follow-up duration and the use of different criteria for CAH. ${ }^{109}, 110,112,118$ Moreover, the number of patients with baseline HBV DNA level $\geq 2,000 \mathrm{IU} / \mathrm{mL}$ in the previous studies was small ( $\mathrm{n}$ $=4-46) .109,110,112,118$ In the current cohort, 81 patients had a baseline HBV DNA level $\geq$ $2,000 \mathrm{IU} / \mathrm{mL}$. In line with our findings, Papatheodoridis et al ${ }^{110}$ confirmed the relation between baseline HBV DNA level $\geq 2,000 \mathrm{IU} / \mathrm{mL}$ and the risk of HBV reactivation in patients in Greece.

Recent data have shown that hepatitis B surface antigen quantification might be helpful in the decision on the frequency of follow-up in such patients.7, 59, 65, 126 However, this test is not routinely available in daily practice. In line with prior studies, our patients - in which we could do this test - had a median qHBsAg level $<1,000 \mathrm{IU} / \mathrm{mL}$ and qHBsAg level could identify patients at higher risk of progression in the subgroup with baseline HBV DNA level $\geq 2,000 \mathrm{IU} / \mathrm{mL}^{112,126}$

As a consequence of the growing obesity epidemic, more and more chronic HBV patients with co-existing NASH are expected. ${ }^{127} \mathrm{NASH}$ is an independent risk factor for cirrhosis and $\mathrm{HCC}$, and in our study obesity was also a risk factor for advanced liver disease among those patients with baseline HBV DNA level $\geq 2,000 \mathrm{IU} / \mathrm{mL}^{127}$

We could also confirm that CAH was triggered by immunosuppressive therapy or cancer chemotherapy. In that respect, we found that immunosuppression was associated with the development of CAH in more than one third of the patients, underlying the importance of screening for hepatitis B prior to starting immunosuppressive therapies. ${ }^{7,59,65}$

\section{CONCLUSION}

In conclusion, Caucasian patients from Western Europe with HBeAg-negative chronic infection and baseline HBV DNA levels $<2,000 \mathrm{IU} / \mathrm{mL}$ have a favourable condition without any risk of $\mathrm{HCC}$ and with a cumulative incidence of HBsAg loss of approximately $10 \%$ they can be considered as inactive carriers. This in contrast to patients with baseline HBV DNA levels $\geq 2,000 \mathrm{IU} / \mathrm{mL}$ who are, especially in the presence of obesity, at risk for advanced liver disease. 




\title{
CHAPTER 2
}

\section{Acute hepatitis B notification rates in Flanders, 2009 to 2017}

\author{
Koc Ö, Van Damme P, Busschots D, Bielen R, Forier A, Nevens F, \\ Robaeys G
}

Euro Surveill. July 2019, 24(30). 


\section{ABSTRACT}

Background: Belgium is a low-endemic country for hepatitis B. Universal hepatitis B vaccination in infants with catch-up in the age cohort of 10-13 year-olds began in 1999. Our objective was to evaluate the effect of prevention and control strategies on acute hepatitis B notification rates in Flanders (Belgium) from 2009 to 2017.

Methods: This observational study collected demographic data and risk factors for acute hepatitis B from mandatory notifications to the Agency for Care and Health.

Results: In Flanders, acute hepatitis B notification rates per 100,000 population decreased from 1.6 in 2009 to 0.7 in 2017. These rates declined in all age groups: 0-4-year-olds: 0.6 to 0.0, 5-14-year-olds: 0.2 to 0.0, 15-24-year-olds: 0.8 to $0.7,25$-34-year-olds: 3.4 to 1.1 and $\geq 35$-year-olds: 1.59 to 0.7 . There was also a downward trend in acute hepatitis $B$ notification rates in native Belgians and first-generation migrants. Among 15-24-year-olds and 25-34-year-olds, a possible reversal of the decreasing trend was observed in 2016 and 2015, respectively. Among 548 acute hepatitis B cases, the main route of transmission was sexual activity (30.7\%), and the pattern of transmission routes over time showed an increasing proportion of sexual transmission in men who have sex with men (MSM) after 2014. During the period from 2009 to 2017, five mother-to-child transmissions were reported.

Conclusion: Prevention and control strategies were effective in reducing the acute hepatitis $B$ notification rate. However, stronger prevention and control measures are needed in adult risk groups, particularly MSM. 


\section{INTRODUCTION}

Hepatitis B is caused by the hepatitis B virus (HBV), a member of the Hepadnaviridae family that infects liver cells, potentially causing liver cirrhosis and hepatocellular carcinoma. ${ }^{128}$ Although most acute HBV infections are self-limiting, ca $0.1-0.5 \%$ of patients will develop fulminant hepatitis. Only $7-17 \%$ of $0-4$-year-olds develop clinically apparent hepatitis after acute infection with HBV, compared with $29-35 \%$ for adults 30 years or older. ${ }^{30,129}$ In addition to the relation between age and clinical hepatitis, there is a relation between age at infection and the likelihood of subsequently becoming a chronic hepatitis B patient. The risk of developing chronic HBV infection is estimated at $80-90 \%$ among infants infected perinatally if the mother is positive for hepatitis $B$ e antigen, and this risk decreases with increasing age at infection. ${ }^{30,129}$

$\mathrm{HBV}$ is widely prevalent and it is estimated that ca 2,000 million people have been exposed to the virus, with 257 million people living with chronic HBV infection worldwide. ${ }^{128}$ In 2015, up to 887,000 deaths resulted from complications of hepatitis $B$, making it together with hepatitis $C$ virus infection the 7th leading cause of mortality globally. ${ }^{13,}{ }^{128}$ In Europe, the burden of hepatitis B differs by geographical region. Countries in eastern and southern Europe have a higher prevalence of chronic HBV infection than countries in the northern and western parts. ${ }^{53}$ Belgium is classified as a country of low HBV endemicity, with ca $0.7 \%$ of the population positive for hepatitis B surface antigen (HBsAg). ${ }^{130-132}$

In Belgium, hepatitis B vaccine has been on the market since the 1982, yet universal freeof-charge vaccination only began in September 1999. Initially, infants received three consecutive doses from age 3 months, whereas adolescents received catch-up vaccination for the age cohort with the age range of 10-13 years. Since 2004, infants have been vaccinated with a hexavalent vaccine against diphtheria, tetanus, pertussis, hepatitis $B$, poliomyelitis and Haemophilus influenza type $B$ at the ages of 8,12 and 16 weeks and 15 months. ${ }^{133,} 134$ The catch-up vaccination in adolescents was concluded in 2012, as infants vaccinated in 1999 reached target age for adolescent vaccination in 2011 and 2012.

Reimbursement for hepatitis B vaccination in other birth cohorts is foreseen for certain patient groups (e.g. patients with haemophilia, pre-dialysis and dialysis patients, individuals with mental disabilities and first-degree relatives of a chronic hepatitis B patient), healthcare workers and employees who have an occupational risk for HBV infection. Hepatitis B vaccination is recommended but not reimbursed for the following groups: travellers to 
countries with intermediate or high HBV endemicity and specific HBV risk groups (e.g. men who have sex with men (MSM), sex workers, illicit drug users, patients with sexually transmitted infections (STI), individuals with multiple sex partners and patients with chronic liver disease).

In Belgium, there is endorsement for harm reduction programmes including peer support, opioid substitution therapy to reduce the frequency of injecting drugs and needle and syringe exchange programmes offering sterile injecting material for people who inject drugs. ${ }^{135}$ Both healthcare workers and patients are encouraged to adhere to universal preventive methods and standard precautions to avoid exposure with HBV. There is also general advice to avoid unsafe sexual contacts through the use of condoms.

Strategies for screening have also been adopted. In Belgium, voluntary blood donors have been screened for HBV since 1972. Belgium has also had an antenatal HBV screening strategy since 2004 which is recommended during the first trimester of the pregnancy. ${ }^{136}$ Children of $\mathrm{HBsAg}$-positive mothers should receive the first hepatitis $\mathrm{B}$ vaccine together with a dose of 300 international units (IU) of hepatitis B immunoglobulins at birth. ${ }^{137}$

The aim of the current study was to assess the impact of the above prevention and control strategies on acute hepatitis B notification rates in Flanders, Belgium. As the Belgian registration of hepatitis $B$ did not make a distinction between acute or chronic hepatitis $B$ until 2009, the main goal was to assess the trend in acute hepatitis B notifications from 2009 to 2017. 


\section{Methods}

\section{STUDY DESIGN}

This observational study collected information on acute cases of viral hepatitis $B$ in the period from 2009 to 2017 from the mandatory notifications to the Agency for Care and Health (Flanders). In Flanders, hepatitis B has been notifiable since 1971, and information collected by the Agency for Care and Health includes diagnosis, basic demographic data (e.g. age, sex and country of birth), clinical features, serological test results and risk factors for infection on the date of diagnosis. Before 2009, a differentiation between acute or chronic hepatitis B was not possible. Since then, only acute hepatitis B has been reported by mandatory notifications from both laboratories and physicians to the Agency for Care and Health (Flanders).

\section{OUTCOME MEASURES}

The primary study endpoint was the assessment of the overall trend in acute hepatitis B notification rates in Flanders from 2009 to 2017. Secondary and exploratory endpoints were the acute HBV notification rates by age, sex and country of birth. We also assessed the main routes of transmission among our study population of acute hepatitis B cases.

\section{CASE DEFINITION}

In our criteria for differentiating acute and chronic hepatitis $B$, patients with the appropriate symptoms and signs (e.g. jaundice, elevated serum aminotransferase levels, abdominal pain, loss of appetite, nausea, vomiting, fatigue or fever) and laboratory confirmation were identified as definite acute hepatitis B cases. ${ }^{138}$ Laboratory confirmation included (i) a positive test for HBsAg and anti-HBc IgM, (ii) detection of HBsAg and negative HBsAg in the 6 months before presentation which are routinely reported if available or (iii) detection of HBV DNA and negative for HBV DNA in the 6 months before presentation which are routinely reported if available. ${ }^{138}$ In line with the European Union case definitions, unknown cases were identified as newly diagnosed HBsAg-positive individuals with the appropriate symptoms and signs but without IgM determination or previous markers for HBV infection. ${ }^{138}$

\section{NOTIFICATION RATES AND VACCINATION COVERAGE}

According to the population data from Statistics Belgium (StatBel), the total population in Flanders increased from 6,208,877 in 2009 to 6,516,011 in 2017. ${ }^{139}$ Acute hepatitis B notification rates from 2009 to 2017 were calculated per 100,000 population and were 
based primarily on the total number of acute hepatitis $B$ notifications, i.e. the sum of definite and unknown acute HBV cases. Age groups were categorised as 0-4, 5-14, 15-24, 25-34 and $\geq 35$ years on mid-decade to mid-decade. The $\geq 35$-year-olds were individuals not covered by the universal hepatitis $B$ vaccination with catch-up in children aged 10-13 year in Flanders. Based on the country of birth, infected persons were identified as Belgian or as first-generation migrants (FGM), i.e. born outside Belgium. FGM were grouped according to the six World Health Organization (WHO) regions: Africa, the Americas, the Eastern Mediterranean, Europe, South East Asia and the Western Pacific. 55

In this study, vaccination coverage data for infants and adolescents in Flanders were obtained from an extended programme of immunisation-based surveys. ${ }^{140-144}$ For calculating the influence of prevention and control strategies on the age distribution of acute hepatitis B patients over time, we stratified notification rates into two time periods, 200912 and 2013-17. The cut-off was chosen to balance the time covered, and 2012 was the end of the catch-up period for adolescents.

\section{STATISTICAL ANALYSIS}

Binary data were analysed using chi-squared test or Fisher's exact test. Comparison of two continuous variables was done with the independent t-test or Mann-Whitney U-test, depending on the presence of normality and homogeneity. Results are presented either as frequencies (\%) or as means (standard error of mean (SEM)). The level of statistical significance was set at $\mathrm{p}<0.05$.

\section{ETHICAL STATEMENT}

Following Belgian regulation, ethical approval was waived because of the non-interventional character of our study. 


\section{RESULTS}

\section{OVERALL TREND}

Acute hepatitis B notification rates decreased by 2017 to $42 \%, 40 \%$ and $55 \%$ of the 2009 rate for, respectively, the total number of cases, definite cases and unknown cases (Figure 2.1). The hepatitis $B$ incidence for the total number of cases in Flanders declined from 1.56 per 100,000 population in 2009 to 0.77 per 100,000 population in 2013 and 0.66 per 100,000 population in 2017 . For definite and unknown cases, the respective incidences were 0.85 and 0.71 per 100,000 population in $2009,0.58$ and 0.19 per 100,000 population in 2013, and, 0.34 and 0.32 per 100,000 population in 2017. Reported hepatitis B vaccination coverage among infants between 1999 and 2017 is also presented in Figure 2.1. In infants, coverage with three doses of hepatitis B vaccine exceeded $90 \%$ from the 2005 survey onwards in Flanders. In adolescents, the HBV vaccination coverage was below $90 \%$ up to 2017 (Figure 2.1).

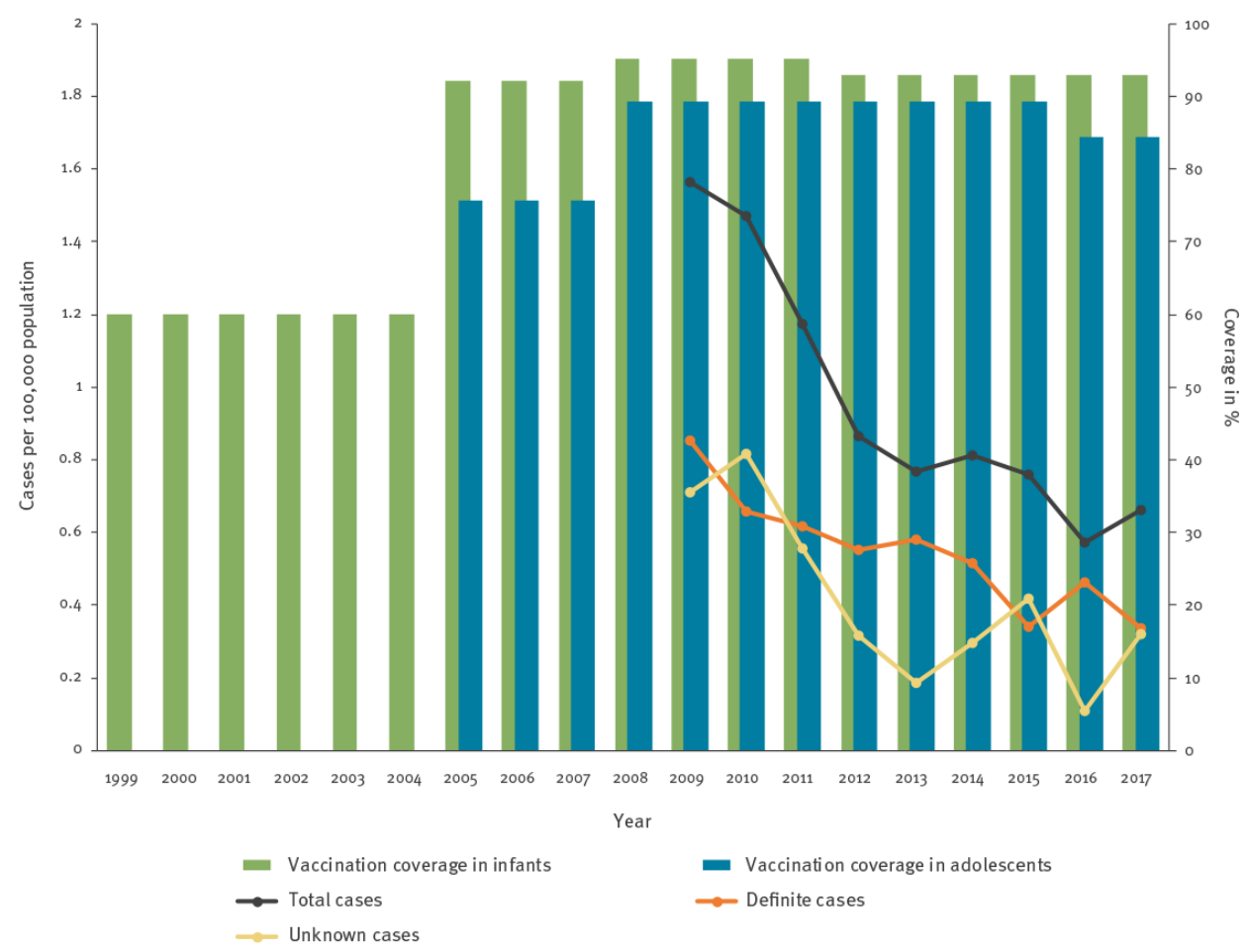

Figure 2.1: Acute hepatitis B notification rates, 2009-2017 $(n=548)$ and coverage with a complete hepatitis B vaccine schedule, 1999-2017, Flanders. Definite cases were defined as patients with the appropriate symptoms/signs and laboratory confirmation, i.e. a positive test for $\mathrm{HBsAg}$ and anti-HBc IgM, detection of HBsAg and negative markers in the 6 months before presentation or 
detection of HBV DNA and negative HBV markers in the 6 months before presentation. Unknown cases were defined as HBsAg-positive patients with the appropriate symptoms/signs without IgM determination or previous markers for HBV infection. Total cases are the sum of definite cases and unknown cases. Estimates on vaccination coverage in infants for the period 2000-2004 were based on survey results from 1999. Survey results from 2005, 2008, 2012 and 2016 were used to determine vaccination coverage in infants and adolescents for the periods 2006-07, 2009-11, 2013-15 and 2017.

\section{AGE AND SEX}

Notification rates by age groups from 2009 to 2017 are presented in Figure 2.2. The rates in 2009 for age groups 0-4, 5-14, 15-24, 25-34 and $\geq 35$ years were 0.59, 0.15, 0.82, 3.35 and 1.59 per 100,000 , respectively. In the period 2009 to 2017 , the data clearly show that the trend in hepatitis $B$ notification rates was decreasing for all age groups. The notification rates in 2017 for the 0-4, 5-14, 15-24, 25-34 and $\geq 35$ year-olds were 0.00 , $0.00,0.68,1.12$ and 0.74 per 100,000, respectively. There was an increase in incidence among those aged 15-24 years and 25-34 years in 2016 and 2015, respectively.

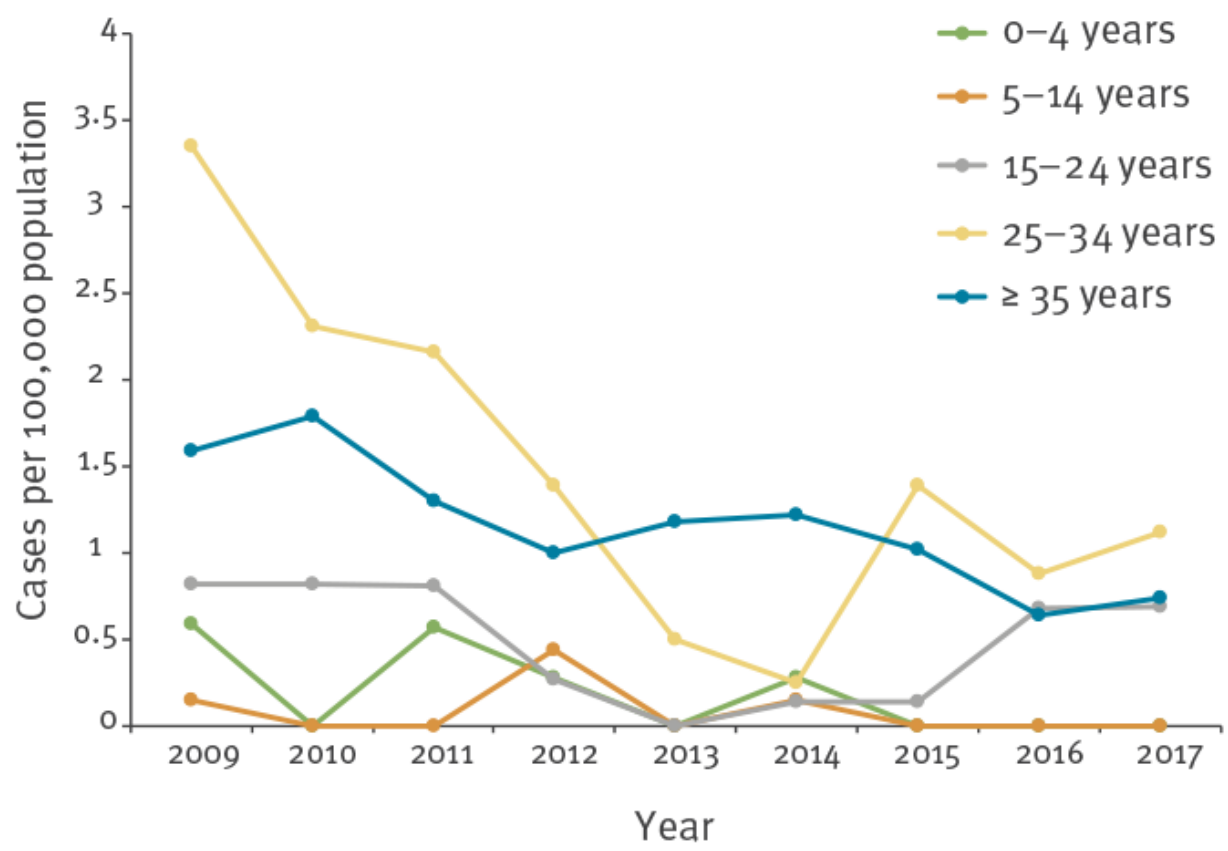

Figure 2.2: Acute hepatitis B notification rate per 100,000 population by age group, Flanders, 2009-2017 ( $n=548)$ 
Figure 2.3 shows the age distribution of acute hepatitis B notifications in the periods 2009 to 2012 and 2013 to 2017 . There was a decrease in the proportion of $15-24$ year-olds from 6.4\% between 2009 and 2012 to $5.2 \%$ between 2013 and 2017 ( $p=0.597)$. For the 2534 year-olds, this was $22.9 \%$ and $14.3 \%$, respectively $(p=0.015)$. Moreover, the mean age of the acute hepatitis $B$ cases in the period 2009 to 2012 was significantly lower than in the period 2013 to 2017 ( $43.0 \pm 0.99$ years vs $46.6 \pm 0.96$ years; $p=0.013)$.

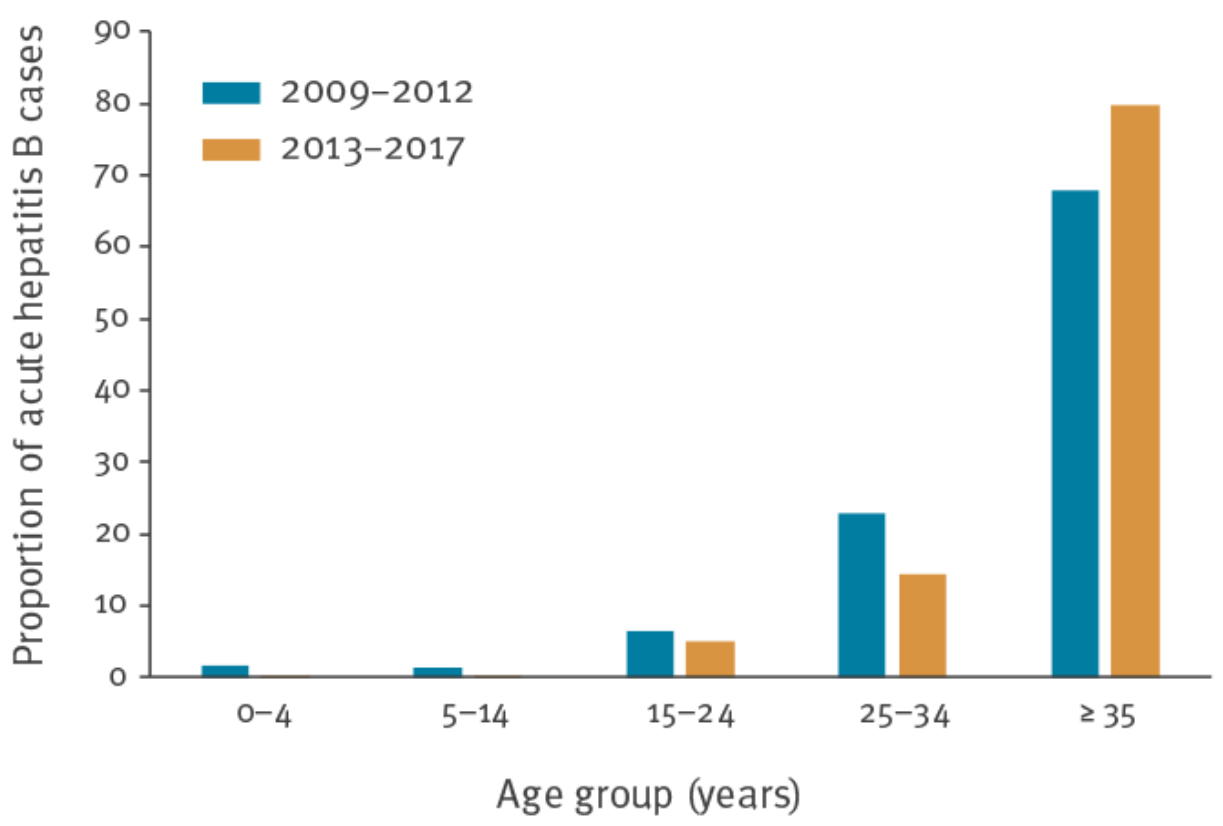

Figure 2.3: Proportion of acute hepatitis B cases by age group in 2009-2012 and 2013-2017, Flanders $(\mathbf{n}=\mathbf{5 4 8})$

Notification rates for male and female cases in 2017 were 0.99 and 0.33 per 100,000, respectively. The rates in adolescents and young adults were slightly higher among women, whereas men had higher rates than women in the age groups 25 years and older. Acute hepatitis B notification rates in 2017 were highest among 25-34-year-old men (Figure 2.4). This age group had the highest rate difference between male and female cases ( 1.73 and 0.50 per 100,000 in 2017 , respectively). 


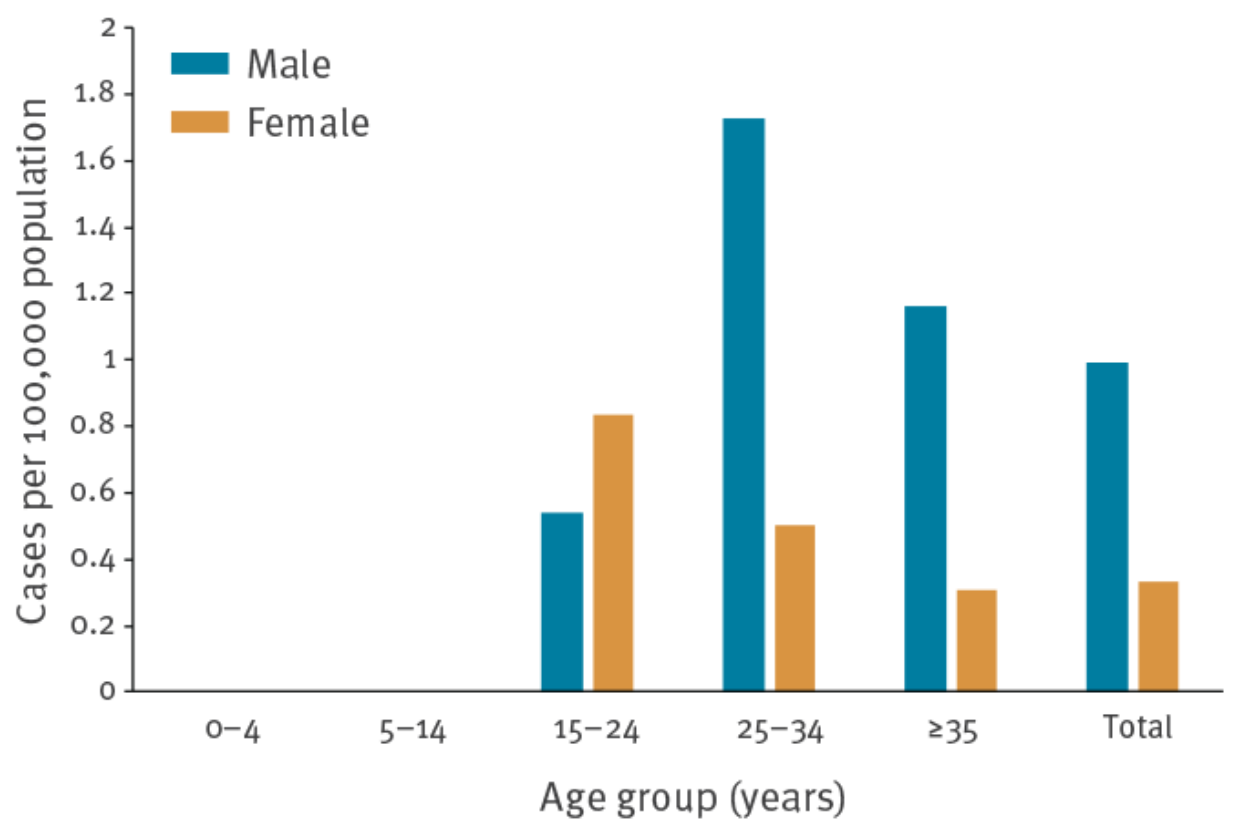

Figure 2.4: Acute hepatitis B notification rate per 100,000 population by age group and sex, Flanders, $2017(n=43)$

The notification rates for male and female cases were, respectively, 2.14 and 0.86 per 100,000 in 2009 and 1.05 and 0.50 per 100,000 in 2013. In the age group 25 years and older, the notification rates in men remained higher than in women throughout the study period (data not shown).

\section{COUNTRY OF BIRTH}

Country of birth data were available for 455 of 548 (83.0\%) acute hepatitis B cases. Among those 455 individuals, 360 (79.1\%) were born in Belgium. Among FGM, 51 (53.7\%) originated from the WHO European Region (13 from Turkey, eight from Romania and 30 from 16 other countries), 17 (17.9\%) from the WHO African Region (three from Ghana and 14 from 10 other countries), 15 (15.8\%) from the WHO Eastern Mediterranean Region (five from Morocco, four from Afghanistan and six from six other countries), six (6.3\%) from the WHO South East Asian Region (three from Indonesia and three from two other countries) and six (6.3\%) from the WHO Western Pacific Region (three from China and three from two other countries). 
The age structure between native Belgians and FGM was different, namely 16 (4.4\%) vs 16 (16.8\%) 0-24-year-olds ( $p<0.001), 61$ (16.9\%) vs 31 (32.6\%) 25-34-year-olds $(p<0.001)$ and $283(78.6 \%)$ vs $48(50.5 \%) \geq 35$-year-olds $(p<0.001)$. Figure 2.5 illustrates a downward trend over time in acute hepatitis $B$ notification rates in native Belgians as well as in FGM. The incidence of acute hepatitis B was higher among FGM and the gap between the two groups increased after 2013 .

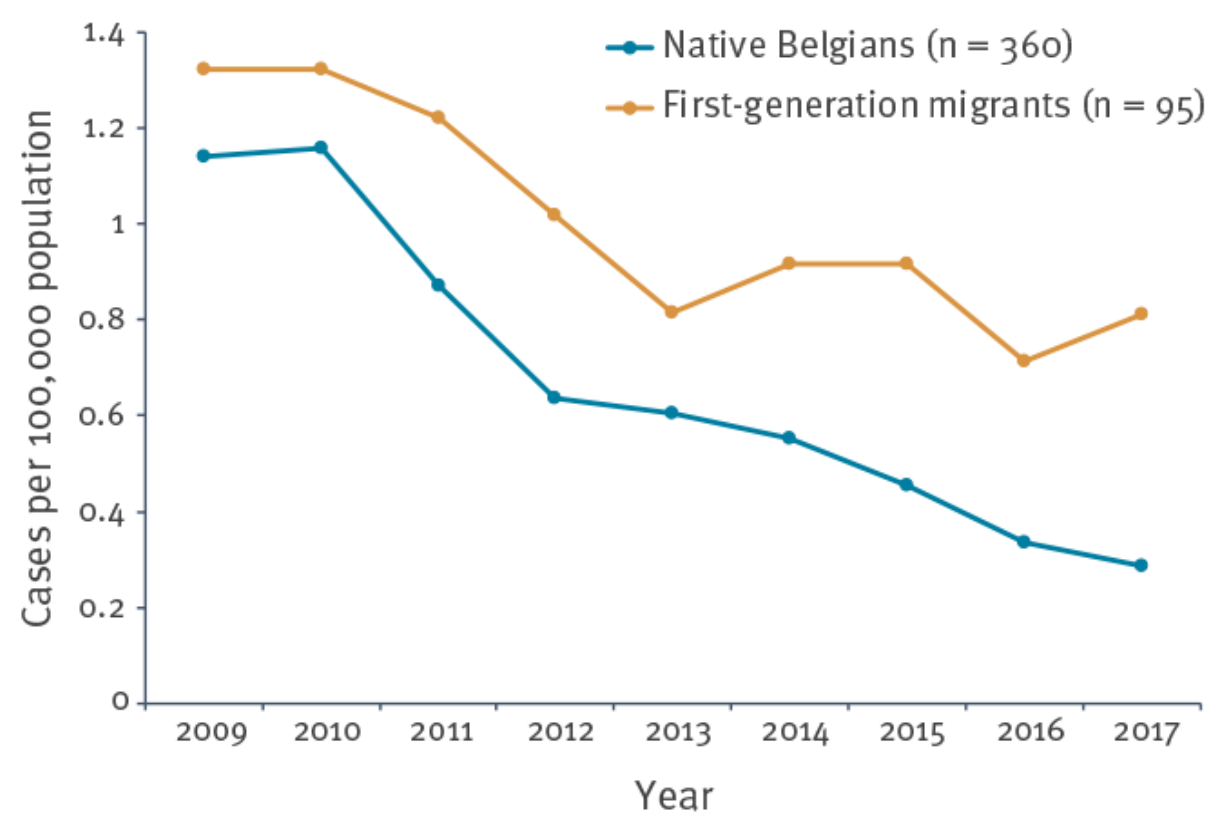

Figure 2.5: Acute hepatitis B notification rate per 100,000 population by country of birth, Flanders, 2009-2017 $(n=455)$

\section{ROUTES OF TRANSMISSION}

Information on routes of transmission was available in 213 (38.9\%) of the 548 acute hepatitis B notifications. Over the time period from 2009 to 2017, the main route of transmission for acute hepatitis B was sexual activity in 168 cases (78.9\%), of whom the majority did not specify sexual interest (78/168, 46.4\%). Forty-nine (29.2\%) of 168 individuals reported heterosexual activity and 41 (24.4\%) reported male homosexual activity. Intravenous drug use accounted for eight (3.8) of the 213 cases (Table 2.1). Table 2.1 also illustrates the routes of transmission by country of birth. All five $(2.3 \%)$ reported mother-to-child transmissions occurred in Belgium. Transmission through sexual activity was more common in men than in women $(131 / 162(80.9 \%)$ vs $37 / 51(72.5 \%)$, 
$p=0.300)$, and $41(25.3 \%)$ were MSM. The routes of transmission for acute hepatitis B cases over time are illustrated in Figure 2.6. In particular, an increasing trend of male homosexual transmission was apparent from 2014 onwards.

Table 2.1: Routes of transmission for acute hepatitis B cases, Flanders, 2009-2017 $(n=213)$

\begin{tabular}{|c|c|c|c|c|c|c|c|}
\hline \multirow[t]{2}{*}{ Routes of transmission } & \multicolumn{2}{|c|}{$\begin{array}{c}\text { Total } \\
(n=213)\end{array}$} & \multicolumn{2}{|c|}{$\begin{array}{l}\text { Native Belgian } \\
(\mathrm{n}=170)\end{array}$} & \multicolumn{2}{|c|}{$\begin{array}{c}\text { FGM } \\
(n=24)\end{array}$} & \multirow[t]{2}{*}{$P$ Value } \\
\hline & n & $\%$ & $\mathbf{n}$ & $\%$ & n & $\%$ & \\
\hline Intravenous drug use & 8 & 3.8 & 5 & 2.9 & 3 & 12.5 & 0.067 \\
\hline Sexual & 16 & 78.9 & 13 & 79.4 & 16 & 66.7 & 0.097 \\
\hline Heterosexual & 49 & 23.0 & 42 & 24.7 & 5 & 20.8 & 0.618 \\
\hline Male homosexual & 41 & 19.2 & 35 & 20.6 & 2 & 8.3 & 0.176 \\
\hline Sexual, unspecified & 78 & 36.6 & 58 & 34.1 & 9 & 37.5 & 0.838 \\
\hline Mother-to-child & 5 & 2.3 & 3 & 1.8 & 0 & 0.0 & 1.000 \\
\hline $\begin{array}{l}\text { Invasive healthcare } \\
\text { procedure/dental }\end{array}$ & 7 & 3.2 & 5 & 2.9 & 2 & 8.3 & 0.220 \\
\hline $\begin{array}{l}\text { Blood } \\
\text { transfusion/transplantation }\end{array}$ & 3 & 1.4 & 3 & 1.8 & 0 & 0.0 & 1.000 \\
\hline $\begin{array}{l}\text { Needle injury or other } \\
\text { occupational exposure }\end{array}$ & 3 & 1.4 & 3 & 1.8 & 0 & 0.0 & 1.000 \\
\hline Tattooing/body piercing & 3 & 1.4 & 2 & 1.2 & 1 & 4.2 & 0.337 \\
\hline Other & 16 & 7.5 & 14 & 8.2 & 2 & 8.3 & 1.000 \\
\hline
\end{tabular}

FGM: first-generation migrants. Information on routes of transmission was not available in 335 of 548 (61.1\%) overall, in 190 of 360 (52.8\%) native Belgians and 71 of 95 (74.7\%) FGM. 


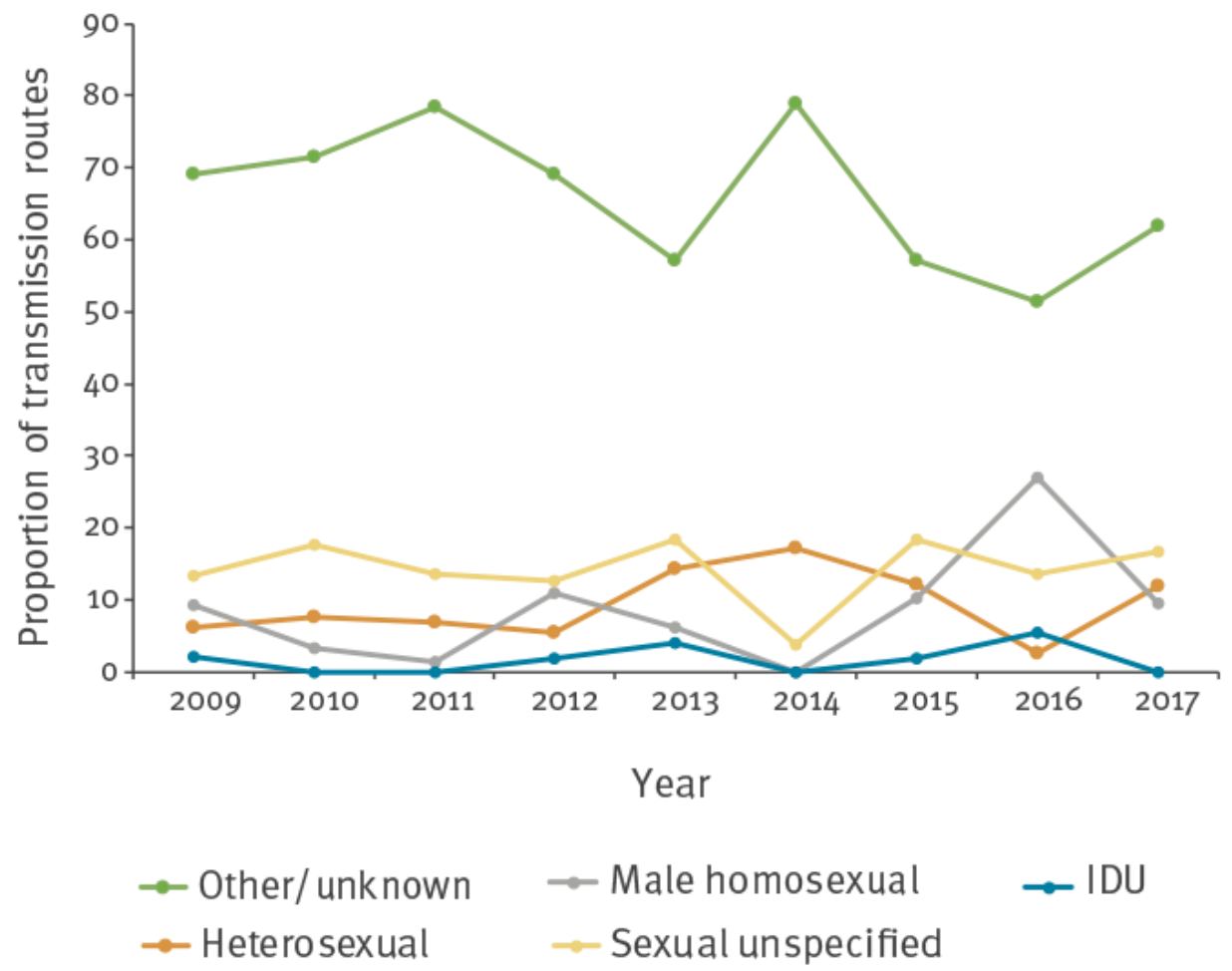

Figure 2.6: Pattern of transmission routes for acute hepatitis B notifications, Flanders, 2009$2017(n=548)$

Compared with native Belgians, FGM were more frequently infected abroad (21/285 with known information on place of transmission and country of birth (7.4\%) vs 20/61 (32.8\%); $\mathrm{p}<0.001$ ). Among the $20 \mathrm{FGM}$ infected abroad, 16 were infected while travelling in their country of birth. Among the individuals who acquired acute HBV infection abroad (44/398 with known information on place of transmission; 11.1\%), 36 acquired it in an intermediate or high HBV-endemic country: 15 in the WHO European Region, 11 in the WHO South East Asian Region, four in the WHO African Region, three in the WHO Western Pacific Region, two in the WHO Eastern Mediterranean Region and one in the WHO Region of the Americas. It was reported that 40 individuals acquired HBV infection by heterosexual transmission in Belgium and six abroad. For male homosexual and unspecified sexual transmission, the numbers were 32 vs four and 59 vs six, respectively. 


\section{DISCUSSION}

The acute hepatitis B notification rates in Flanders Belgium decreased from 2009 to 2017 in all age groups ( $0-4$ years, $5-14$ years, $15-24$ years, $25-34$ years and $\geq 35$ years). Since universal infant vaccination started in 1999, notification rates for 5-14-year-olds from 2013 onwards represent age groups that received universal infant vaccination, which may explain the decline in acute hepatitis B notification rates after 2013 in this age group. Moreover, the downward trend in 15-24- and 25-34-year-olds indicates the birth cohorts 1987 to 1998 who were covered by universal catch-up vaccination in this low-prevalence country where sexual activity is recognised as the most important exposure for HBV infection. ${ }^{145}$

The effects of a universal HBV vaccination programme in infants with catch-up in adolescents were also evaluated on serum samples collected in 2006 and 2007 from children aged 1-19 years by Theeten et al. ${ }^{134}$ They demonstrated that the prevalence of HBV infection remained low in Belgium and that overall high levels of vaccine-induced immunity were achieved in infants as well as in adolescents.

Although the infant hepatitis $B$ vaccination coverage for the three doses increased above $90 \%$ after 2004 , the continuing downward trend in acute hepatitis B notification rates in $\geq 35$-year-olds from 2009 to 2017 cannot be explained by universal infant and toddler vaccination with catch-up in adolescents. For this, an explanation should be explored in the vaccination and health behaviour of certain patient groups (e.g. dialysis patients), healthcare workers, those with occupational risk of HBV infection, travellers to intermediate or high HBV-endemic countries, patients with STI and sex workers in Belgium. However, there is no information on the uptake of vaccination in adults aside from Belgian studies in sex workers, healthcare workers, travellers to intermediate or high HBV-endemic countries and pregnant women. ${ }^{146-151}$ In order to eliminate hepatitis $B$ as a public health threat by 2030 as recommended by WHO, recent studies are warranted to evaluate hepatitis B prevention and control measures, particularly in adult risk groups such as MSM and patients with STI. ${ }^{152}$

Moreover, relatively higher notification rates of acute hepatitis B were observed in adults than in children, emphasising the importance of raising the awareness of healthcare workers, policymakers and the general public about stronger prevention and control measures targeting the adult group. These numbers could be ascribed to (i) vaccination uptake and/or (ii) sexual transmission being the most important infection route for hepatitis $B$ in a low-prevalence country and/or (iii) the relation between age and clinical hepatitis. ${ }^{129,}$ 134,145 
By 2018, 191 of 194 (98\%) WHO member states had introduced universal infant or childhood hepatitis B vaccination. This is a substantial increase compared with the year 2000 where only $129(66 \%)$ countries had included hepatitis B vaccination in their national universal immunisation system. ${ }^{153}$ In this context, we found that acute hepatitis B notification rates declined also in FGM, not only in native Belgians. However, the reduction in acute hepatitis B cases among FGM was smaller than among native Belgians; therefore, the number of FGM with acute hepatitis B could have limited the overall decreasing trend of acute hepatitis B cases found in the current study. Our findings are in line with a previous study indicating that the estimated number of vaccinated people is lower for FGM than for native Belgians. ${ }^{130}$ In view of the increase in hepatitis B incidence among FGM in 2017, it should be noted that this trend could possibly continue after 2017. There is currently no screening programme targeting this group, although vaccination is recommended but not reimbursed for immigrants travelling back to their endemic country of birth. New infections among adult FGM and their relatives could be prevented.

After 2013, the decline in hepatitis B incidence was less pronounced. This could possibly be related to the bimodal pattern of immunisation coverage with the highest proportion of vaccinated individuals in the birth cohorts targeted by the vaccination programme (19992002 and 1987-1989) with a clear dip in between. ${ }^{134}$ Moreover, there was a possible reversal of the decreasing trend for 15-24-year-olds and 25-34-year-olds in 2016 and 2015, respectively. This could in part be ascribed to a rise in the number of cases among MSM. Notification rates by sex indicated that rates were higher in men with the highest rate difference in 25-34-year-olds, i.e. 1.23 per 100,000 population. Higher rates of HBsAg positivity among men have been described in several European countries. ${ }^{154-156}$ Sex differences could be attributed to higher risk behaviour among men, particularly MSM. In the current study, male homosexual activity was reported as route of transmission in $25 \%$ of men.

Sexual activity as the most important exposure and source of transmission is well recognised in other low-prevalence countries. ${ }^{145}$ The observed low proportion of people who inject drugs (PWID) among the cases might be a result of decrease in heroin users in the country, needle and syringe exchange programmes or vaccination of PWID and their close contacts. Unfortunately, these data are not available in Belgium. During study follow-up, five mother-to-child infections were reported despite the recommendation of antenatal HBV screening in pregnant women, highlighting the need to strengthen their registration for HBV infection. A study conducted in Antwerp, Belgium indicated that HBsAg screening results were available at the moment of delivery for only $28 \%$ of the women who gave birth in 
$2010 .{ }^{146}$ It is crucial to be aware of the hepatitis B status of the mother as the child, in case of HBsAg positivity of the mother, will very likely be infected perinatally and with high risk of developing chronic hepatitis. ${ }^{137,157}$ In line with the WHO recommendation, hepatitis B vaccination and immunoglobulins should be provided to the newborn within 24 hours if antenatal screening detects HBV infection, which in $94 \%$ is effective in preventing motherto-child transmission. ${ }^{137,158}$

Limitations of our study are intrinsic to the surveillance system in Flanders, i.e. the number of actual acute hepatitis $B$ rates could be underestimated because of under-reporting and underdiagnosis. However, the acute hepatitis B notification rates from 2009 to 2017 in Flanders showed a downward trend. In the European Union, the average annual acute hepatitis B notification rate between 2006 and 2014 was 1.0 per 100,000 population. ${ }^{44}$ The surveillance data for acute hepatitis B notification rates in Flanders were therefore comparable with other European countries, although direct comparison between countries is not possible considering the heterogeneity in acute hepatitis B case definitions and reporting systems. It should also be noted that the available surveillance data do not permit comparison of hepatitis $B$ incidence before and after the introduction of universal hepatitis $B$ vaccination. It is indeed not possible to distinguish the specific impact of hepatitis $B$ vaccination from that of other prevention and control measures. Data on transmission routes were missing in $61 \%$ and in $17 \%$, country of birth was unknown. The absence of these data could reduce statistical power and as missing data are random, we could consider randomness as not producing bias.

\section{CONCLUSION}

Acute hepatitis B notification rates decreased in all age groups and declined from 1.56 per 100,000 population in 2009 to 0.66 in 2017. This may in part be explained by the universal vaccination in infants with catch-up in 10-13-year-olds, which can have a positive impact among adolescents and adults. The possible reversal of the decreasing trend for 15-24- and 25-34-year-olds in 2016 and 2015, respectively, could largely be explained by an increase in cases in MSM, demanding stronger prevention and control measures in adult risk-group. 




\section{CHAPTER 3}

\section{Prevalence and risk factors of hepatitis $B$ virus infection in Middle-Limburg Belgium, year 2017: importance of migration}

Koc ÖM, Kremer C, Bielen R, Busschots D, Hens N, Nevens F, Robaeys G

J Med Virol. August 2019, 91(8):1479-88. 


\section{ABSTRACT}

Background: The hepatitis B virus (HBV) prevalence study performed in 2003 in Belgium is believed to be underestimating HBV prevalence due to underrepresentation of the nonBelgian population. Therefore, we assessed the prevalence and risk factors of HBV infection in a multi-ethnic region situated in Middle-Limburg Belgium, in 2017.

Methods: Between May and November 2017, blood samples and questionnaires were taken from patients who presented at the emergency department of a large educational hospital. Blood samples were tested for hepatitis B surface antigen (HBsAg) and hepatitis B core antibodies (anti-HBc). A sample size of 1,000 persons was required to obtain a representative sample of the general Middle-Limburg population.

Results: Of the 1,131 patients screened, the overall HBsAg prevalence was $0.97 \%$ with differences between Belgians (0.67\%) and first-generation-migrants $(2.55 \%),(p=.015)$. Five $(45.5 \%)$ out of $11 \mathrm{HBsAg}$ positive individuals were not aware of their HBV status. All five $(100 \%)$ newly diagnosed HBsAg positive patients had further clinical evaluation and all had a normal level of alanine-aminotransferase. The prevalence of anti-HBc was $8.4 \%$, and was significantly associated with age-gender-ethnicity interaction, presence of $\mathrm{HBV}$ infected household member, hepatitis $C$ virus infection, men who have sex with men, and haemodialysis.

Conclusions: In this area with large immigrant populations, we found a higher prevalence of HBV infection compared to the nationwide study of 2003. National HBV screening for first-generation migrants is needed as this high-risk group will go unnoticed due to the possible incorrect interpretation of normal alanine-aminotransferase values. 


\section{INTRODUCTION}

Hepatitis B virus (HBV) remains a global health problem given that an estimated two billion people have been exposed to this virus and 257 million people live with chronic HBV infection worldwide in the year 2017. ${ }^{41}$ Since the onset of HBV infection is generally asymptomatic, many of the HBV infected patients may not be aware of their infection status, thereby increasing the likelihood of infecting others. ${ }^{159}$ Chronic HBV infection was also responsible for up to 887,000 deaths in 2015 , making it together with hepatitis $\mathrm{C}$ virus (HCV) infection the 7 th leading cause of mortality worldwide. ${ }^{13,41}$

The prevalence of chronic HBV varies upon the geographic distribution, from highprevalence areas ( $>8 \%$ hepatitis B surface antigen (HBsAg) positive), to intermediateprevalence areas (2-7\% HBsAg positive) and low-prevalence areas ( $<2 \% \mathrm{HBsAg}$ positive). ${ }^{160}$ Western Europe is among the low-prevalence areas, but subgroups of higher HBV prevalence may exist in regions with large immigrant populations. Even though migrants comprise only one in 20 European citizens, they account for one in four of all chronic HBV infections. In Belgium, $52 \%$ of chronic HBV cases are estimated to be among migrants from intermediate- and high-prevalence areas. This number is even $>70 \%$ in countries such as Austria, Ireland, the Netherlands and United Kingdom. ${ }^{79}$

Both prevalence studies in Flanders (Belgium), one in 1993-1994 and one in 2003, showed that $0.7 \%$ of the population was HBsAg positive. ${ }^{130,131}$ However, the prevalence of chronic HBV infection in the population-based study in 2003 is believed to be an underestimation due to underrepresentation of the non-Belgian population. Moreover, there are no data regarding the predominant risk factors for $\mathrm{HBV}$ infection in the Belgian general population. The recognized risk factors of HBV infection include having an HBSAg positive mother, HBsAg positive close family member, HBsAg positive sex partner, multiple (unsafe) heterosexual contacts, men who have sex with men (MSM), intravenous drug use (IDU), blood or blood-product transfusion, haemodialysis, invasive healthcare procedure or dental treatment and tattooing or body piercing. ${ }^{161}$

Even in low-prevalence areas such as Belgium, HBV prevention and control is a public health priority, particularly since safe and effective vaccines are available. In addition to primary prevention, recent advancements in the treatment of chronic HBV infection now allow secondary prevention. ${ }^{162,163}$

Since chronic HBV infections are often asymptomatic, sero-epidemiological studies are needed (1) to understand the extent and importance of this public health problem, (2) to identify population subgroups with an increased prevalence of infection and (3) to foresee 
its future impact on the health system and ensure an adequate allocation of financial resources.

The aim of the present study was to evaluate the current prevalence and risk factors of HBV infection in a multi-ethnic region situated in Middle-Limburg Belgium. 


\section{METHODS}

\section{STUDY POPULATION AND SAMPLE DESIGN}

This epidemiological study was conducted in a multi-ethnic region of about 240,803 inhabitants in the region of Middle-Limburg between May and November 2017. All patients between the age of 18 and 70 who presented at the emergency department of a large educational hospital were eligible for this study. Upon written informed consent, a blood sample was taken and a face-to-face questionnaire, assessing demographics (age, gender, country of birth, mother's country of birth), known viral hepatitis status (HBV positive, HCV positive, HIV positive), and risk factors was performed. These risk factors included having an HBsAg positive close family member, multiple (unsafe) sexual contacts, MSM, IDU, blood or blood-product transfusion, haemodialysis, invasive healthcare procedure or dental treatment (i.e. surgery), healthcare worker, cultural or ritual intervention, and tattooing or body piercing. Immigrants who were not bom in Belgium were considered first-generation migrants (FGMs).

Trained personnel collected a blood sample for serological testing for each patient. The Ziekenhuis Oost-Limburg laboratories tested all blood samples for HBsAg and hepatitis B core antibodies (anti-HBc) using an electrochemiluminescence assay (Cobas 8000 e602, Roche, Germany). The interpretation of positive and negative results was carried out as recommended by the test producer.

The culturally targeted, multilingual (Dutch-, English- and Turkish-speaking) first author attempted to contact persons with HBsAg positive results via telephone one week after their screening. At least six attempts at three different times of the day were made. Persons not reached within six months were considered lost to follow-up. The first author encouraged and invited all newly diagnosed HBsAg positive patients to enter an Outpatient Hepatology Department. A clinical work-up and treatment program was proposed for newly diagnosed patients based on European Association for the Study of the Liver (EASL) guidelines. ${ }^{7}$

\section{ETHICAL APPROVAL AND TRIAL REGISTRATION}

The study was approved by the local Medical Ethical Committees (16/072U), and was conducted in accordance with the provisions of the Declaration of Helsinki and its amendments. Good clinical practice guidelines were followed throughout the study. The study is registered at clinicaltrials.gov (NCT03425513). 


\section{STATISTICAL ANALYSES}

Sample size calculation was performed with the aid of Epi Info (Version 7.2.1.0, Atlanta, $\mathrm{GA})$. The number of patients needed per ethnicity was calculated so that the results of the sample group agreed with those of the Middle-Limburg population with a confidence interval of $95 \%$. The expected frequency for FGMs was $21 \%$ (Limburg in cijfers, personal communication). The sample size calculation suggested a total of 1,000 tested persons would need to be included.

Survey data were entered bed-side into a secure electronic database Castor EDC (Castor Electronic Data Capture, Ciwit Bv, Amsterdam, the Netherlands). Analysis of variance (ANOVA) was used to test for differences in mean age and prevalence between different ethnic groups.

For calculating the effect of universal HBV vaccination in Belgium, we stratified $\mathrm{HBsAg}$ and/or anti-HBc prevalence into two birth cohorts (borm before 1987 and born after 1987). The cutoff was chosen as the vaccination program since September 1999 with catch-up vaccination for one age cohort with the age range of 10-13 years covered children bom after $1987 . .^{133}$

In order to correct for differences between the sample and the Middle-Limburg population, weighted tests were conducted. Weighting was done based on the combination of age and ethnicity (Belgian vs. non-Belgian (i.e. FGM)). ${ }^{164}$ Weighted chi squared tests were used to assess significant associations between the evaluated risk factors and HBsAg or anti-HBC prevalence. Risk factors that were shown to be significantly associated $(p<.10)$ to $\mathrm{HBsAg}$ or anti-HBC in these univariate analyses were included in a weighted multiple logistic regression model. In these models, Firth's bias adjustment was used to account for data sparseness. ${ }^{165}$ Model reduction was done in a backward stepwise manner based on the .05 significance level. 
Several classification methods were also applied to the data on anti-HBc positivity for prediction purposes. First, a simple classification tree was constructed based on an almost completely balanced training dataset (i.e. $40 \%$ of the subjects were anti-HBc positive) to identify characteristics that explain the outcome in the best way. Bagging and random forests were then used in an attempt to improve the error rate of this classification tree. Since the predictions based on (almost) balanced data overestimated the true proportion of anti-HBC positives, a correction was made. ${ }^{166}$ The classification models were then compared to the weighted logistic regression model in terms of prediction accuracy. Data analyses were performed using RStudio (Version 1.0.136, Boston, MA). 


\section{RESULTS}

\section{CHARACTERISTICS OF THE STUDY POPULATION}

Of the 1,537 individuals invited, 1,131 (73.6\%) completed the questionnaire and donated blood. The study included 605 men (53.5\%) and 526 women (46.5\%), with a mean age of 46 years ( $95 \%$ CI $45.2-46.9$ years). FGMs comprised $20.8 \%$ of the study population. FGMs were mainly bom in the Netherlands (32.8\%), Turkey (18.7\%), and Italy (12.3\%). Gender distribution was similar in both ethnic groups (Belgian and FGM, $p=.629$ ). When compared to the Belgian patients (mean age of 46 years, 95\% CI 45.0-46.9 years), FGMs (mean age of 47 years, $95 \%$ CI $44.8-48.3$ years) were not significantly older $(p=.536)$.

Patients who refused participation had a mean age of 48 years (95\% CI $43.3-46.3$ years) and $52.1 \%$ were male. This did not significantly differ from patients willing to participate ( $p$ $=.135$ and $p=.699$ for age and gender, respectively). Reasons for not participating were: fear of needles $(14.5 \%)$, too sick $(26.9 \%)$, other worries than testing $(27.3 \%)$, does not want to know viral hepatitis status $(8.1 \%)$, already participating in a lot of studies $(0.3 \%)$, and other (22.9\%).

\section{PREVALENCE OF ANTI-HBC ANTIBODIES}

In two patients, blood sample volumes were insufficient for testing and in 22 patients, no anti-HBc blood sample was taken. Anti-HBc positivity was $8.4 \%$ among the remaining 1,107 participants. Anti-HBC prevalence in Belgian individuals born after 1987 was $1.6 \%$. This number was higher for those born before $1987(7.0 \%, p=.001)$. Current or past HBV infection in FGMs was apparent in 49/231 (21.2\%) with differences in those born in the Netherlands $(5 / 75,6.7 \%)$, Turkey $(16 / 44,36.4 \%)$, Italy $(8 / 28,28.6 \%)$, other low endemic countries $(2 / 30,6.7 \%)$ and other intermediate or high endemic countries $(18 / 54,33.3 \%)$, $p<.001$. In the weighted chi squared tests, age-gender-ethnicity interaction $(p<.001)$, not shown in table), living with an HBV infected person ( $p<.001)$, HCV infection $(p=.004)$, MSM $(p=.001)$, blood transfusion before $1972(p=.026)$, haemodialysis $(p<.001)$, cultural or ritual intervention $(p=.015)$ and having a tattoo or body piercing $(p=.041)$ were significantly associated with current or past HBV infection, i.e. anti-HBc positivity (Table 3.1). 
Table 3.1: Prevalence of anti-HBc by different risk factors (weighted chi squared test)

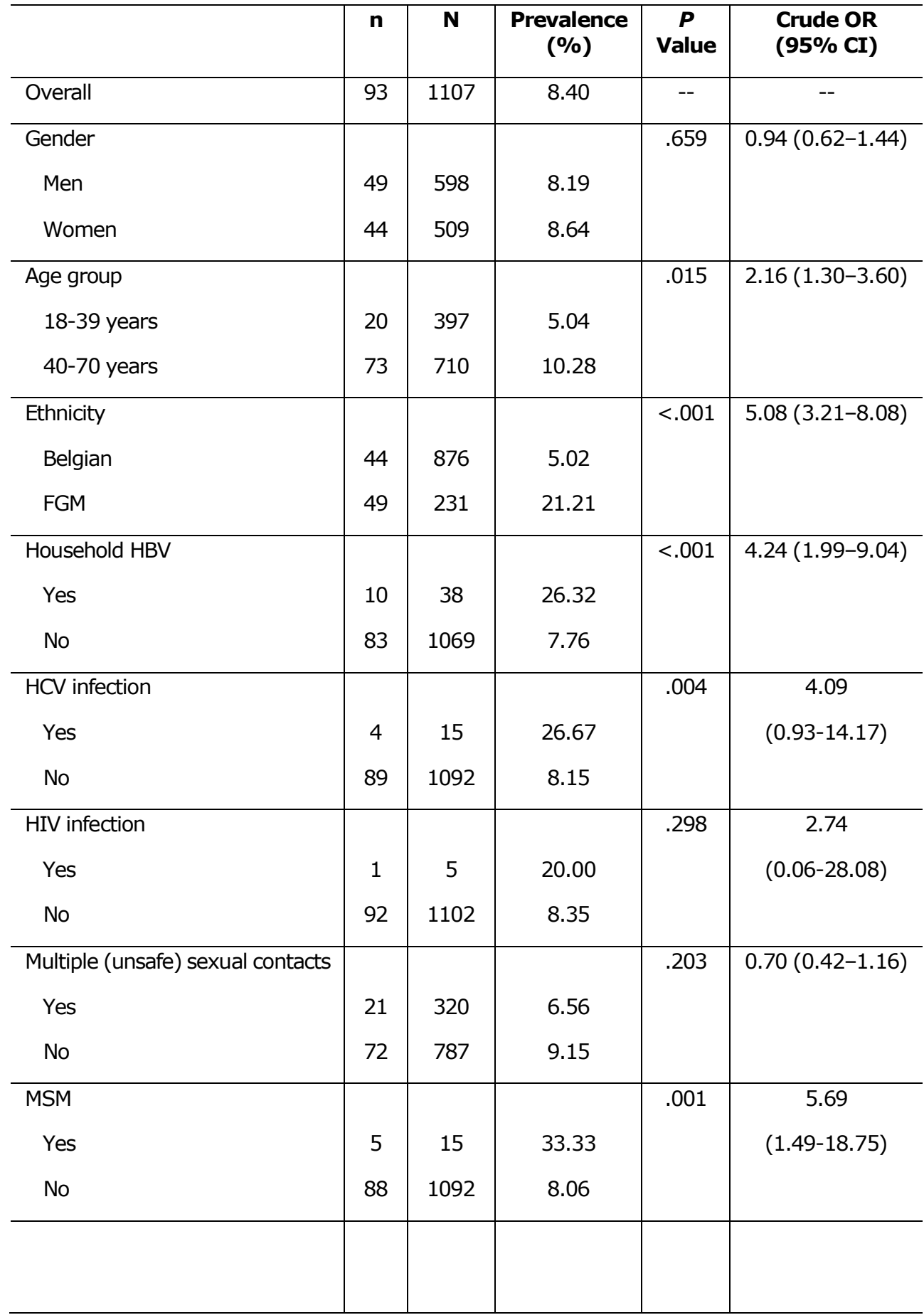




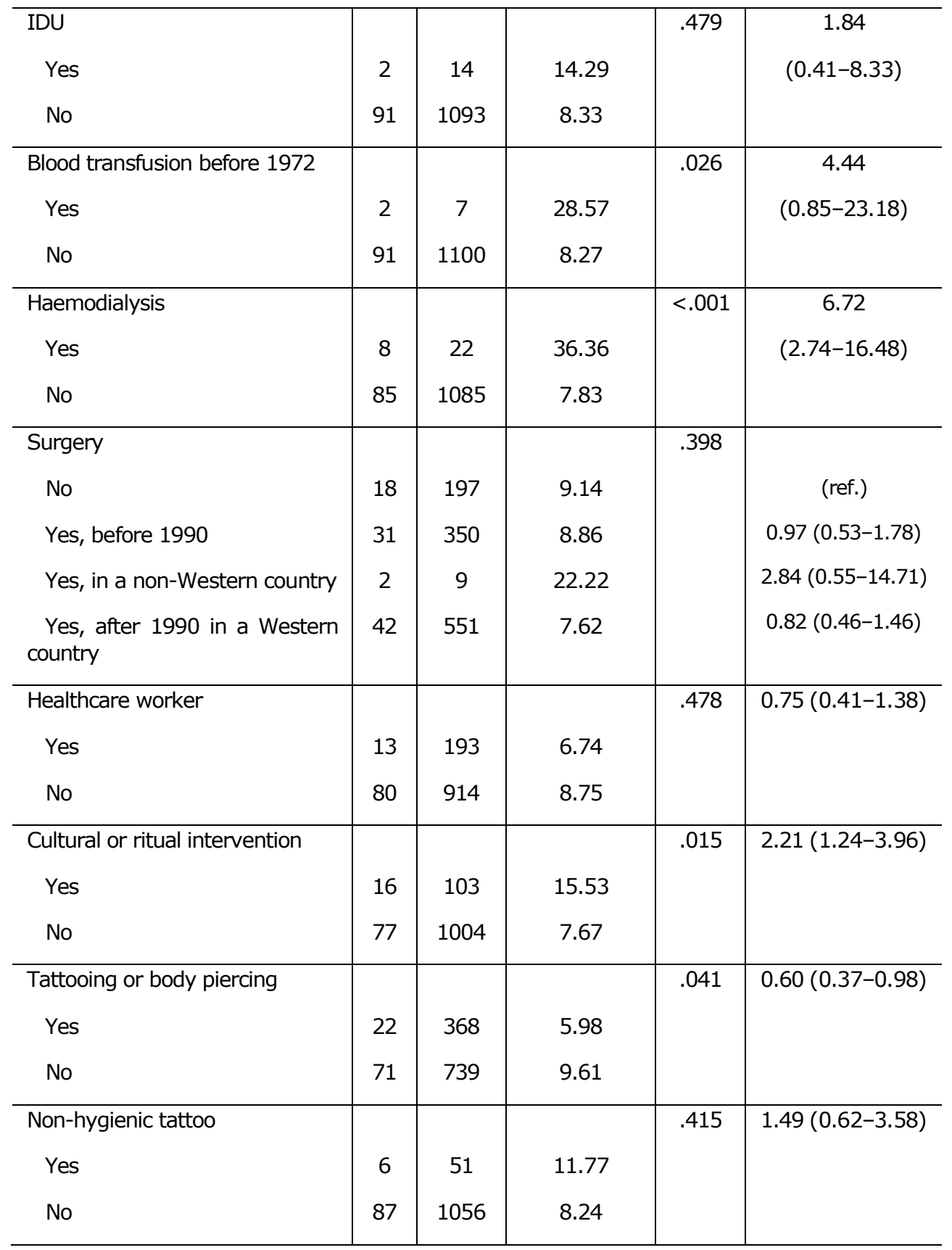

Abbreviations: anti-HBc: hepatitis B core antibodies; OR: odds ratio; CI: confidence interval; FGM: firstgeneration migrants, i.e. foreign-born persons;; HBV: hepatitis B virus; HCV: hepatitis C virus; MSM: men who have sex with men; IDU: intravenous drug use. 
Since only 2 out of 7 patients that have had a blood transfusion before 1972 were anti-HBc positive, this risk factor was not included in any further analyses. Parameter estimates of the weighted multiple logistic regression model are shown in Table 3.2. It can be seen that, compared to 18-39 years old Belgian females, there was a significantly increased risk of anti-HBc positivity in all FGMs, as well as in 40-70 years old Belgian females ( $p=.039$ ). Young Belgian males had a lower risk of anti-HBc positivity, although not statistically significant. Furthermore, living with an HBV infected person $(p<.001)$, reporting HCV infection $(p=.005)$, being on haemodialysis treatment $(p<.001)$, and being MSM $(p=$ .002 ) appeared to be associated with a higher risk of anti-HBc positivity.

Table 3.2: Parameter estimates for the final weighted model for anti-HBc

\begin{tabular}{|c|c|c|c|c|c|}
\hline Parameter & $\begin{array}{c}\mathbf{n}^{\circ} \\
\text { patients } \\
(+)\end{array}$ & Estimate & S.E. & $\begin{array}{c}P \\
\text { Value }\end{array}$ & $\begin{array}{c}\text { Adjusted OR } \\
\text { (95\% CI) }\end{array}$ \\
\hline (intercept) & & -3.98 & 0.51 & $<.001$ & -- \\
\hline Female, 18-39yrs, FGM & $44(10)$ & 2.60 & 0.71 & $<.001$ & $13.41(3.41-68.37)$ \\
\hline Male, 18-39yrs, Belgian & $160(2)$ & -0.71 & 0.81 & .380 & $0.49(0.07-2.47)$ \\
\hline Male, 18-39yrs, FGM & $34(5)$ & 1.91 & 0.84 & .023 & $6.75(1.06-38.55)$ \\
\hline Female, 40-70yrs, Belgian & $245(17)$ & 1.15 & 0.56 & .039 & $3.16(1.17-13.36)$ \\
\hline Female, 40-70yrs, FGM & $61(14)$ & 2.67 & 0.72 & $<.001$ & $14.47(3.64-74.29)$ \\
\hline Male, 40-70yrs, Belgian & $312(22)$ & 1.08 & 0.55 & .051 & $2.94(1.10-12.33)$ \\
\hline Male, 40-70yrs, FGM & $92(20)$ & 2.51 & 0.67 & $<.001$ & $12.26(3.45-59.72)$ \\
\hline Household HBV & $38(10)$ & 1.84 & 0.46 & $<.001$ & $6.30(2.44-15.38)$ \\
\hline HCV infection & $15(4)$ & 1.79 & 0.63 & .005 & $5.96(1.49-19.16)$ \\
\hline MSM & $15(5)$ & 2.16 & 0.69 & .002 & $8.69(2.02-34.52)$ \\
\hline Haemodialysis & $22(8)$ & 1.88 & 0.52 & $<.001$ & $6.58(2.15-17.60)$ \\
\hline
\end{tabular}

Abbreviations: anti-HBc: hepatitis B core antibodies; S.E.: standard error around the coefficient for the constant; OR: odds ratio; $\mathrm{CI}$ : confidence interval; yrs: years; FGM: first-generation migrants, i.e. foreignborn persons; HBV: hepatitis B virus; HCV: hepatitis C virus; MSM: men who have sex with men. 


\section{ANTI-HBC CLASSIFICATION MODELS}

In growing the classification tree, only the risk factors that were shown to be significantly associated $(p<.10)$ to anti-HBc prevalence (in the weighted chi squared tests) were used as input (except for having received a blood transfusion before 1972, for the same reason mentioned above). The obtained classification tree is shown in Figure 3.1. The predictive accuracy of this tree was $73.0 \%$ based on the ROC curve (see solid line in Figure 3.2), with a sensitivity of $57.1 \%$ and specificity of $80.1 \%$. The predictive accuracy was also calculated for the weighted logistic regression model, giving a predictive accuracy of $77.5 \%$ with a sensitivity and specificity of $68.8 \%$ and $77.8 \%$, respectively. From Figure 4.2 it can be concluded that the weighted logistic regression model using Firth's bias adjustment performed best in predicting anti-HBc prevalence in this study.

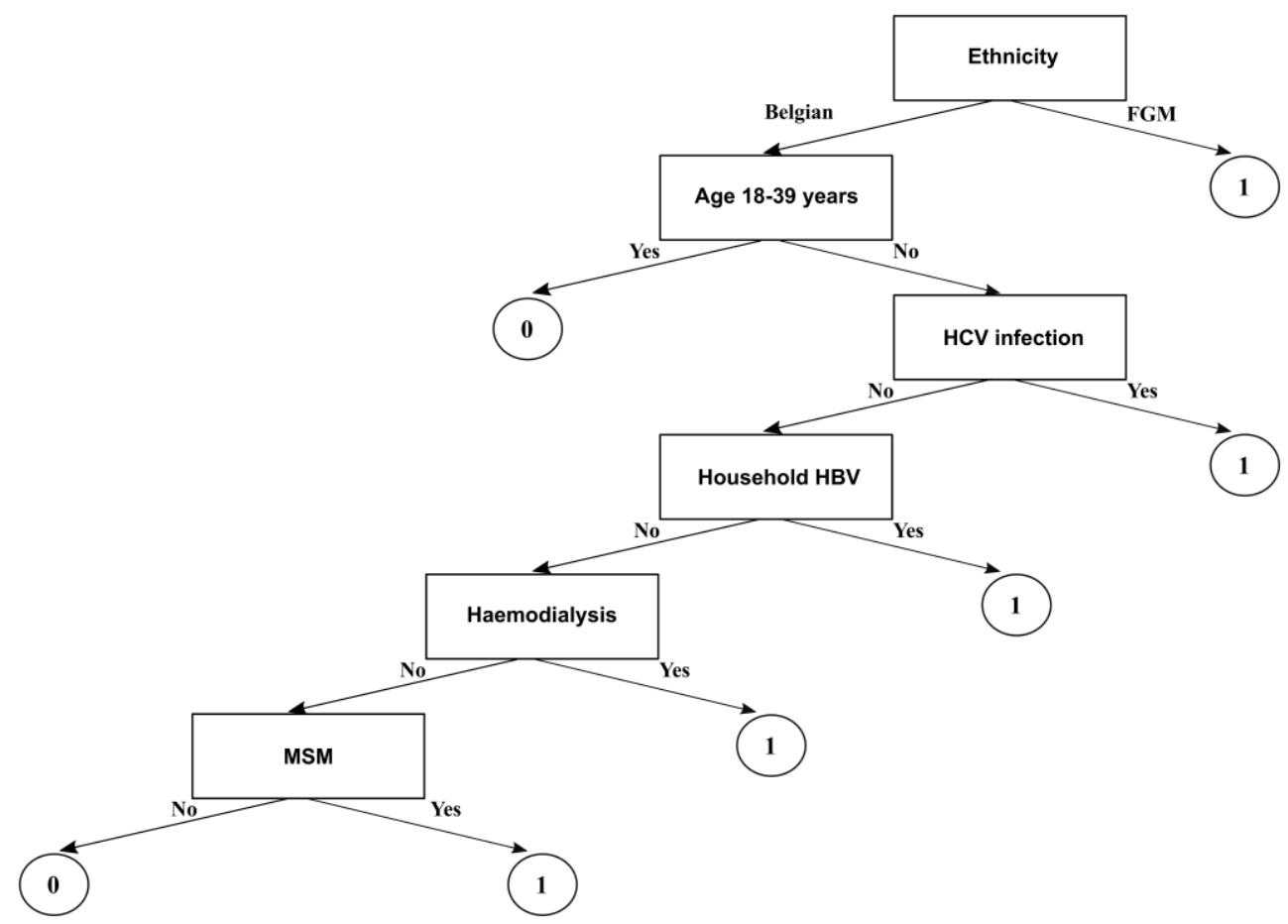

Figure 3.1: Classification tree based on (almost) balanced training sample for anti-HBc. A ' $O$ ' indicates anti-HBc negative, while a ' 1 ' indicates anti-HBc positive. Abbreviation: anti-HBc: hepatitis B core antibodies; FGM: first-generation migrants, i.e. foreign-born persons; HCV: hepatitis $C$ virus; HBV: hepatitis B virus; MSM: men who have sex with men. 


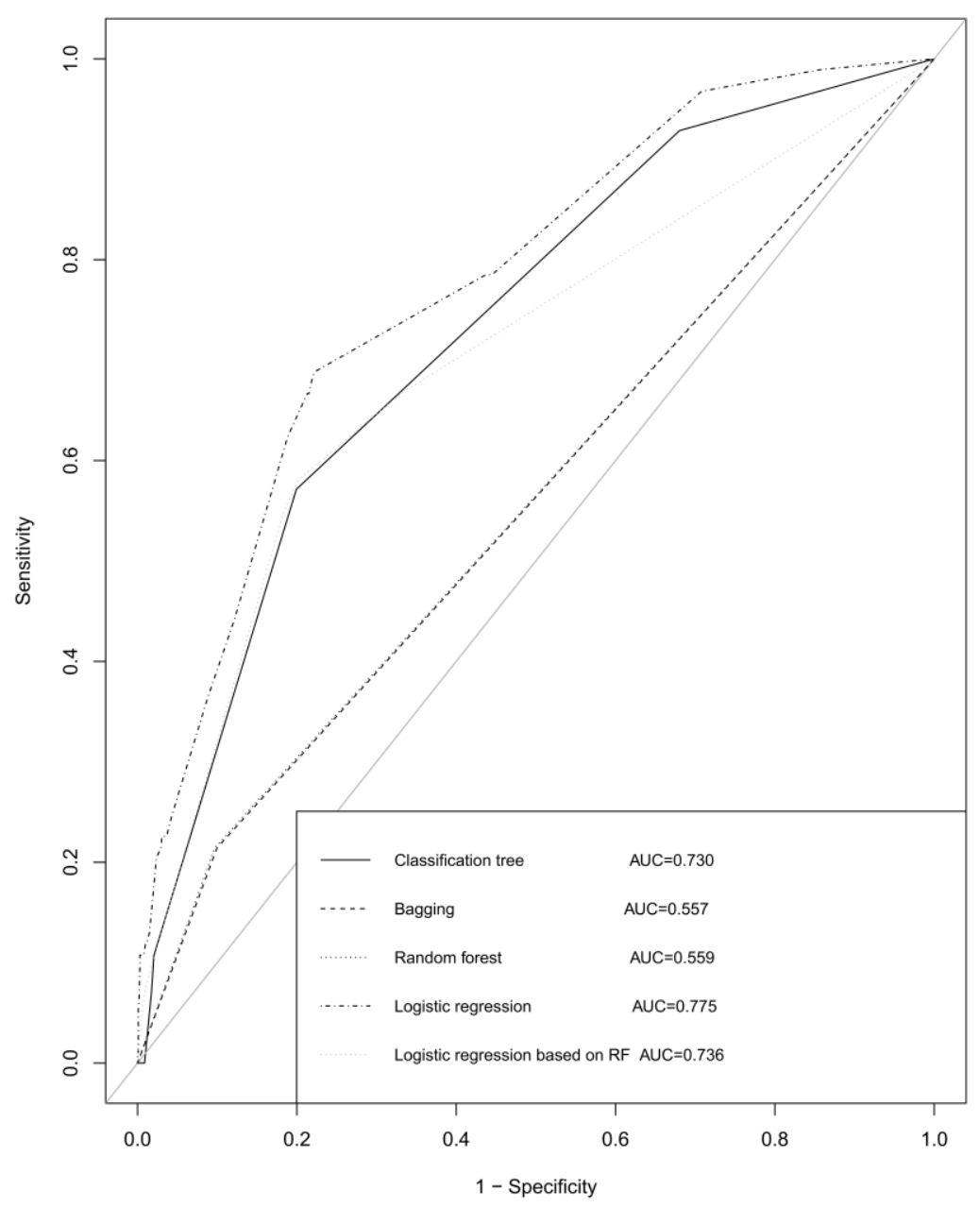

Figure 3.2: Comparison of different classification models for anti-HBC using ROC curves for which the AUC is used to quantify the predictive accuracy. In an attempt to reduce the tree misclassification error, bagging was applied. All risk factors were included and $B=400$ trees were grown. Class weights were used to correct for the (almost) balanced training sample. The predictive accuracy of this model however was only $55.7 \%$ (see dashed line). For the random forest model, at each iteration 12 randomly sampled risk factors were included and $B=5000$ trees were grown. Class weights were again used. The predictive accuracy of this model was slightly higher than for bagging, i.e. $55.9 \%$ (see dotted line). The six most important variables from the random forest (RF) analysis were included in a logistic regression model (see grey dotted line), which had a predictive accuracy of $73.6 \%$, still lower than for the abovementioned weighted logistic regression model ( $77.5 \%$, see dot-dashed line). Abbreviation: anti-HBc: hepatitis B core antibodies; ROC: receiver operating characteristic; AUC: area under the ROC curve; RF: random forest. 


\section{PREVALENCE OF HBSAG}

Of the 1,131 patients tested, 11 (1.0\%) were HBsAg positive. Five (45.5\%) HBsAg positive patients were born in Belgium, two (18.2\%) in Italy, one (9.1\%) in Turkey and three $(27.2 \%)$ in other intermediate or high endemic countries (one in Saudi Arabia, Iran, and Kenya), $\mathrm{p}=.136$. None of the HBsAg positive patients were younger than 30 years of age (born after 1987) compared to $11 \mathrm{HBsAg}$ positive patients born before $1987, \mathrm{p}=.282$. The HBsAg prevalence in FGMs was 2.55\% (6/235), with differences in those born in the Netherlands $(0 / 77,0.0 \%)$, Turkey $(1 / 44,2.27 \%)$, Italy $(2 / 29,6.9 \%)$, other low endemic countries $(0 / 30,0.0 \%)$ and other intermediate or high endemic countries $(3 / 55,5.5 \%), p$ $=.285$.

Table 3.3 shows the prevalence of HBsAg by different risk factors. In the weighted chi squared tests, HBsAg positivity was significantly associated with ethnicity $(p=.015)$, having an HBV infected household member $(p=.036)$, MSM $(p=.016)$, and tattooing or body piercing ( $p=.077$ ). Logistic regression was not conducted for HBsAg due to the low number of chronically infected patients. 
Table 3.3: Prevalence of HBsAg by different risk factors (weighted chi squared test)

\begin{tabular}{|c|c|c|c|c|c|}
\hline & $\mathbf{n}$ & $\mathbf{N}$ & $\begin{array}{c}\text { Prevalence } \\
(\%)\end{array}$ & $\begin{array}{c}P \\
\text { Value }\end{array}$ & $\begin{array}{l}\text { Crude OR } \\
(95 \% \text { CI) }\end{array}$ \\
\hline Overall & 11 & 1131 & 0.97 & -- & -- \\
\hline Gender & & & & .744 & $1.38(0.42-4.56)$ \\
\hline Men & 5 & 605 & 0.83 & & \\
\hline Women & 6 & 526 & 1.14 & & \\
\hline Age group & & & & .581 & $1.53(0.41-5.81)$ \\
\hline $18-39$ years & 3 & 412 & 0.73 & & \\
\hline $40-70$ years & 8 & 719 & 1.11 & & \\
\hline Ethnicity & & & & .015 & 4.66 \\
\hline Belgian & 5 & 896 & 0.67 & & (1.17-19.48) \\
\hline FGM & 6 & 235 & 2.55 & & \\
\hline Household HBV & & & & .036 & 6.51 \\
\hline Yes & 2 & 39 & 5.13 & & $(1.36-31.17)$ \\
\hline No & 9 & 1092 & 0.82 & & \\
\hline $\mathrm{HCV}$ infection & & & & .701 & 0.00 \\
\hline Yes & 0 & 16 & 0.00 & & $(0.00-30.20)$ \\
\hline No & 11 & 1115 & 0.99 & & \\
\hline HIV infection & & & & .818 & 0.00 \\
\hline Yes & 0 & 5 & 0.00 & & $(0.00-122.30)$ \\
\hline No & 11 & 1126 & 0.98 & & \\
\hline Multiple (unsafe) sexual contacts & & & & .498 & $1.39(0.40-4.77)$ \\
\hline Yes & 4 & 331 & 1.21 & & \\
\hline No & 7 & 800 & 0.88 & & \\
\hline MSM & & & & .016 & 7.86 \\
\hline Yes & 1 & 15 & 6.67 & & $(0.17-62.50)$ \\
\hline No & 10 & 1116 & 0.90 & & \\
\hline & & & & & \\
\hline & & & & & \\
\hline
\end{tabular}




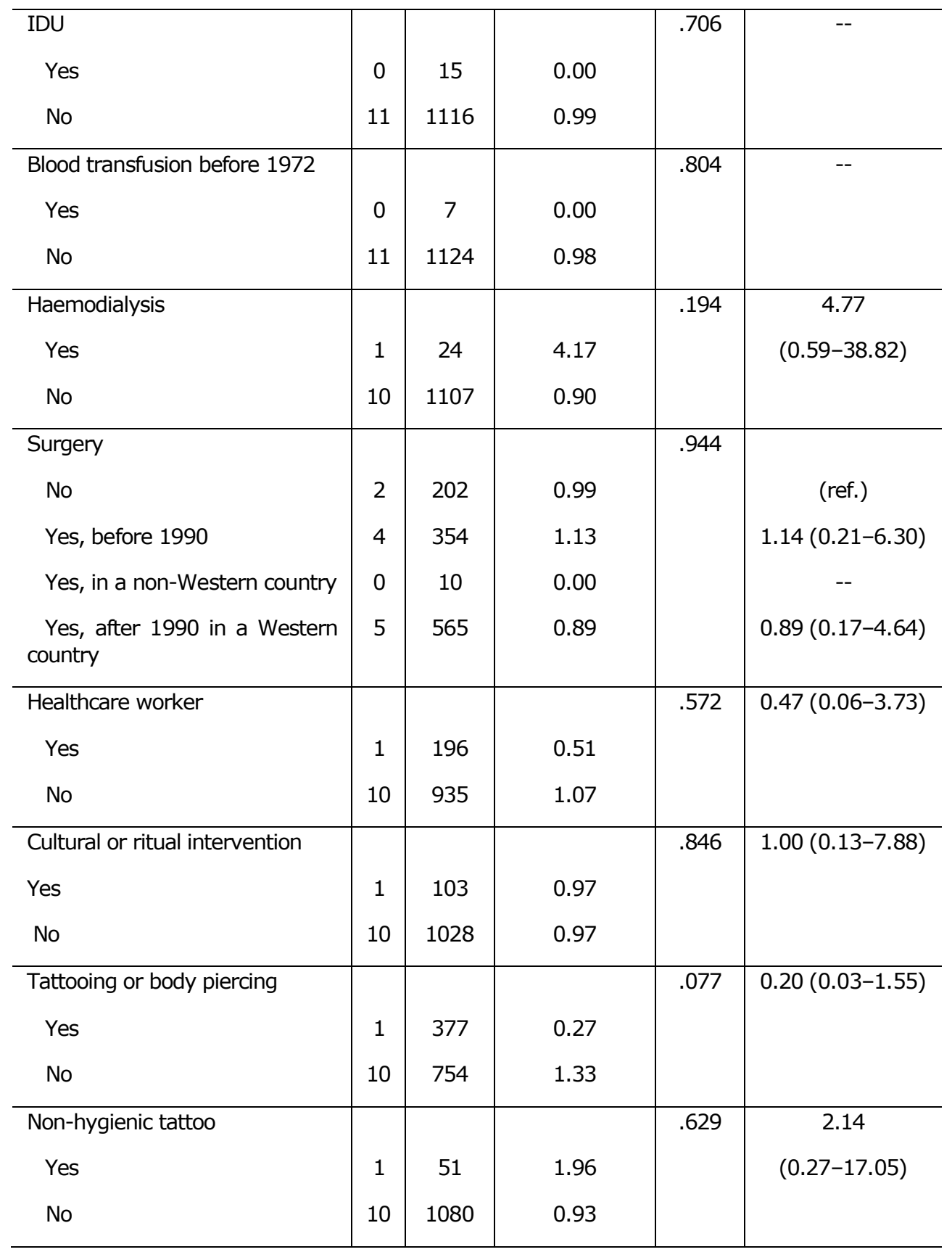

Abbreviations: HBsAg: hepatitis B surface antigen; OR: odds ratio; CI: confidence interval; FGM: firstgeneration migrants, i.e. foreign-born persons; HBV: hepatitis B virus; HCV: hepatitis C virus; MSM: men who have sex with men; IDU: intravenous drug use. 


\section{LINKAGE TO CARE}

Of the $11 \mathrm{HBsAg}$ positive individuals, five (45.5\%) were not aware of their HBV status and the other six $(54.5 \%)$ were already linked to care. Thus, the percentage of newly diagnosed HBsAg positive patients was $0.44 \%$ (5/1131). All five (100\%) patients had further clinical evaluation which revealed that all had a normal level of alanine aminotransferase (ALT $<40$ $\mathrm{U} / \mathrm{L}$ ), all were hepatitis $\mathrm{B}$ e antigen (HBeAg) negative, all had HBV DNA levels below 2,000 $\mathrm{IU} / \mathrm{mL}$, all had fibrosis score F0- 1 according to Metavir score, and none had evidence of liver cirrhosis on ultrasound. One of the five patients is currently being treated prophylactically in the Outpatient Hepatology Department before and during the administration of chemotherapy according to the EASL guidelines. 


\section{DISCUSSION}

This is the first study to assess the seroprevalence of HBV infection in a multi-ethnic Belgian region including a considerably large proportion of foreign-born individuals. Besides estimating the seroprevalence in a multi-ethnic region, risk factors associated to HBV infection were evaluated, which may assist physicians, public health practitioners and policymakers in eliminating hepatitis $B$ as a public health threat by $2030 .{ }^{14}$

The principal findings of the present study can be summarized as follows. First, there was an overall HBsAg seroprevalence of $1.0 \%$, with higher prevalence in FGMs $(2.55 \%)$ compared to Belgians (0.7\%). Second, none of the HBsAg positive patients were born after 1987. Third, an anti-HBc prevalence of $8.4 \%$ was found in the multi-ethnic region situated in Middle-Limburg with age-gender-ethnicity interaction, having an HBV infected household member, reporting HCV infection, being MSM, and ever having been on haemodialysis treatment being significantly associated with past or current $\mathrm{HBV}$ infection. Fourth, this study demonstrated an excellent linkage to care with five out of 11 (45.5\%) HBsAg positive individuals not being aware of their HBV status and further clinical evaluation showing normal levels of alanine-aminotransferase in all five patients.

In this study, about $1.0 \%$ of all patients appeared to be HBsAg positive and $8.4 \%$ showed evidence of HBV exposure. Until now, the overall prevalence in Belgium was estimated to be lower, i.e. $0.7 \%$ positive for $\mathrm{HBsAg}$ and $6.4 \%$ positive for anti-HBc. ${ }^{130,131}$ This discrepancy can be explained by the fact that both of these previous epidemiological studies also included individuals aged 0-17 years. Moreover, selection bias can explain a possible underestimation in 2003 as the recruiting of participants in the general population by mail probably missed people from certain risk groups (e.g. migrants). In the present study, we included patients aged 18-70 years who presented at the emergency department of a large educational hospital in a multi-ethnic region situated in Middle-Limburg. Furthermore, the region of Middle-Limburg has a large immigrant population, with $20.8 \%$ of the study population being FGMs, in contrast to $8.0 \%$ in Flanders, Belgium. In this respect, we found a higher HBsAg prevalence in FGMs and especially in those born in intermediate or high endemic countries, highlighting the fact that migrants are an important risk group for chronic HBV infection. 167,168

The HBsAg prevalence in the general population of the neighbouring countries ranges from $0.1 \%$ in Ireland to $0.8 \%$ in Spain..$^{53}$ In line with our findings, a higher HBV prevalence was 
found in FGMs born in intermediate- or high-prevalence areas in comparison to the native population of countries such as France, Germany, the Netherlands and Spain. $76,77,154,155$

The impact of implementation of a universal free-of-charge hepatitis B vaccination in Belgium was also apparent from the results of the current study. None of the HBsAg positive patients were born after year 1987. Anti-HBc prevalence was also lower in Belgian individuals born after 1987, when compared to those born before 1987. After all, universal infant hepatitis B vaccination with catch-up in adolescents aged 10-13 years began in September 1999 in Belgium. ${ }^{133}$ Consequently, the vaccination program covered children born after 1987. To evaluate the effects of a universal HBV vaccination program in $<20$ year-olds, prevalence of seroprotection and HBV infection were assessed by Theeten et al. ${ }^{134}$ They demonstrated that the prevalence of $\mathrm{HBV}$ infection remained low in Belgium and that overall high levels of 'vaccinated' serostatus were achieved in infants as well as in adolescents.

We also analysed the risk factors associated to anti-HBc positivity. The most prominent risk factors were being FGM and age between 40 and 70 years (except for Belgian males), having an HBV infected household member, reporting HCV infection, being MSM, and ever having received haemodialysis, with $22.22 \%, 26.32 \%, 26.67 \%, 33.33 \%$ and $36.36 \%$ testing positive for anti-HBc, respectively. A comparison of different classification methods revealed that the weighted logistic regression model performed best in classifying patients as either anti-HBC positive or negative, although the identified risk factors in this model were the same as those found in a classification tree analysis.

The implementation of a culturally and linguistically appropriate health care provider in the present study could explain the high linkage to care of newly diagnosed HBsAg positive patients. ${ }^{169}$ Moreover, all newly diagnosed HBsAg positive patients underwent ALT determination and normal ALT levels were found in all of them. The Belgian nationwide epidemiological data support the findings of our study and emphasized that $80 \%$ of the newly diagnosed chronic HBV patients had normal ALT levels at diagnosis. ${ }^{170} \mathrm{~A}$ major limitation of ALT as a biochemical marker of liver disease is that its levels often fluctuate over time during the variable course of chronic HBV infection and may fail to identify patients with necro-inflammatory activity or fibrosis. ${ }^{171}$

There are some limitations to the present study. First, by screening at the emergency department, a bias towards subjects in certain risk groups may occur. However, these risk 
groups might have been underrepresented in the previous population-based study in Belgium. ${ }^{131}$ Inclusion of certain risk groups in our study also allowed us to determine the most prominent risk factors for HBV prevalence in Belgium for the first time. Second, due to logistical factors (e.g. limited daily enrolment time, limited study research team) not every eligible participant could be informed about the study. Third, a concern is that, even though the patients' demographics, known viral hepatitis status and risk factors were recorded, certain risk behaviours could have been underreported as the questionnaire was performed using a face-to-face interview. Inferences from this study should also be drawn with caution since it is difficult to establish causal pathways from cross-sectional studies as our present study. Thus, we have attempted only to identify risk factors associated with HBV infection using odds ratios. This study could also be underpowered to find significant associations between certain risk factors and $\mathrm{HBsAg}$ or anti-HBc, as the study was powered in such a way that the distribution per ethnicity was similar to that of the Middle-Limburg population, and not to specific risk factors. However, good predictive accuracy was shown for the weighted multiple logistic regression model, providing evidence for the significant impact of abovementioned risk factors for anti-HBc.

\section{CONCLUSION}

In conclusion, this study shows that the HBsAg and anti-HBc seroprevalences in a multiethnic region in Middle-Limburg are higher than those previously found nationwide, probably because high-risk groups such as FGMs are more present. Since all newly diagnosed HBsAg positive patients had normal levels of ALT, national HBV screening for individuals born in intermediate or high endemic countries is needed as this high-risk group will go unnoticed due to the possible incorrect interpretation of normal ALT values. In order to adapt or to adopt screening practices and preventive measures, sero-epidemiological studies should not only be done nationwide, but also locally in multi-ethnic regions. 




\section{CHAPTER 4}

Hepatitis B virus prevalence and risk factors in hard-to-reach Turkish population living in Belgium: a protocol for screening

Koc ÖM, Hens N, Bielen R, Van Damme P, Robaeys G Medicine. May 2019, 98(18):e15412. 


\section{ABSTRACT}

Background: Hepatitis B virus (HBV) infection is an important public health problem in the Turkish population, ie one of the largest migrant populations in Europe. With the introduction of cost-effective antiviral treatments in the past decade, there is a need to identify HBV infected patients who may benefit from treatment. This paper describes the design of a study to assess the HBV prevalence in the Turkish population living in Belgium. Additionally, we will determine the risk factors of HBV infection and the uptake of screening, vaccination and antiviral treatment in this hard-to-reach Turkish population.

Methods: A longitudinal, epidemiological study will be conducted in the region Middle Limburg Belgium, where the Turkish adult population, 18 years of age and older, will be screened for hepatitis B surface antigen (HBsAg), antibodies against HBsAg (anti-HBs) and antibodies against hepatitis $\mathrm{B}$ core antigen (anti-HBc). Educational meetings concerning viral hepatitis B will be organized and there will be three ways to be screened for HBV: (1) immediately after the educational meetings, (2) at the Outpatient Hepatology Department of Ziekenhuis Oost-Limburg (ZOL) and (3) at home visits. Subsequently, participants will be asked to fill in a questionnaire regarding sociodemographic factors, migration history, risk factors for HBV infection (eg sharing toothbrushes, HBV infected family member) and HBV vaccination status. Six months after screening, HBsAg positive patients will be assessed whether they are under follow-up at the general practitioner or hepatologist. We will also gather information regarding the uptake of vaccination in non-immunized subjects.

Discussion: This study will provide information about the HBV prevalence and distribution of the stages of liver disease in the Turkish population in Belgium. By determining the risk factors for HBV infection, subgroups with an increased prevalence of HBV infection can be identified. 


\section{INTRODUCTION}

Hepatitis B virus (HBV) infection is an important public health problem. In the year 2017, approximately 257 million people are chronically infected worldwide and at risk of developing serious sequelae, such as cirrhosis and hepatocellular carcinoma. ${ }^{41,172}$

According to the World Health Organization, Turkey is one of the countries with intermediate endemicity for hepatitis B. The hepatitis B surface antigen (HBsAg) prevalence thereby changes from $2-3 \%$ in the Western part of the country to $7-8 \%$ in Eastern part. ${ }^{80}$ In intermediate endemic countries, such as Turkey, horizontal HBV transmission by non-sexual close contact besides perinatal, sexual and parenteral transmission is the main route of infection. ${ }^{173-176}$ Risk factors associated with horizontal transmission in childhood are poor socioeconomic conditions, the presence of a HBsAg-positive family member and the habit of sharing various personal and household articles within the home (eg contaminated toothbrush, contaminated towels). ${ }^{173,177,178}$

In contrast, the HBsAg prevalence is low $(<1 \%)$ in the general population of Belgium and many other Western European countries. ${ }^{55,131}$ Sexual transmission of HBV in persons with high-risk sexual behaviour (eg men who sex with men, heterosexual persons with multiple sex partners) remains a common source of HBV transmission in these low endemic countries. ${ }^{41}$

Starting in 1961, political, economic and social developments led Turkish people to migrate to Europe, Australia, Arab countries and former Soviet Union countries. ${ }^{179}$ According to Turkish govemment statistics, 5.5 million Turkish citizens live abroad, of whom around 4.6 million live in Western European countries. ${ }^{180}$ Turkish citizens are therefore one of the largest migrant groups in Europe. Moreover, a recent study by Ahmad et al79 indicated that the Turkish population was ranked third as migrant group with the highest absolute number of chronic HBV cases in Europe. However, their estimates of HBsAg prevalence were based on prevalence studies conducted in Turkey. Another study conducted by a Dutch group showed that the Turkish population in the Netherlands had a low level of awareness and knowledge regarding HBV infection which could subsequently impinge the attitude towards HBV screening. ${ }^{181}$ 
Nonetheless, little is known about the true prevalence and risk factors of HBV infection among the Turkish population living in Western European countries. Considering the fact that (1) infection with HBV in children most often result in chronic infection ${ }^{137}$ and (2) universal HBV vaccination in Belgium and Turkey only started after, respectively, $1999^{134}$ and $1998^{80}$, an appreciable number of the Turkish population in Belgium may be infected with HBV. Many of the HBV infected Turkish patients may also remain undiagnosed, since the onset of HBV and progression to cirrhosis and hepatocellular carcinoma are generally asymptomatic and occur many years after exposure. ${ }^{47}$ As HBV treatment options have greatly improved over the past decades and have proven to be cost-effective, there is a need to identify chronic carriers who may benefit from treatment.7,59,65 Therefore, this study aims to assess the prevalence and risk factors of HBV infection in hard-to-reach Turkish population living in Belgium. The identification and early antiviral treatment of HBV infection in the Turkish population could prevent the development of end-stage liver disease and further spread, while the associated health cost burden in this group at risk can be reduced. 


\section{METHODS}

\section{STUDY DESIGN}

The current study is a longitudinal, epidemiological study.

\section{STUDY POPULATION}

The study population consists of Turkish individuals, living in the region Middle Limburg in Belgium.

Inclusion criteria:

- 18 years and older of age

- $\quad$ Turkish individuals (defined as persons who are born in Turkey or persons of whom one of the parents is born in Turkey)

- $\quad$ All participants irrespective of being aware of having been tested and knowing their HBV status

- $\quad$ All participants irrespective of being aware of having been fully vaccinated

- $\quad$ Signed informed consent form

Minors, incapacitated subjects and non-Turkish individuals were to be excluded from the study.

\section{PRE-SCREENING PHASE}

In the pre-screening phase, we developed a brochure, flyer, poster and video focusing on HBV infection (Supplementary file S4.1 and S4.2). The patient information and consent form, questionnaire, brochure, flyer, poster and video were translated in the Turkish language by a certified translator. The final information in Dutch and Turkish language were then thoroughly checked by delegates of Turkish associations and the questionnaire was pilot tested by ten persons of Turkish origin, first- and second-generation migrants, males and females, from different age categories (age group 18-39 years, 40-59, 60-79 and 80+).

During the study, participants will be able to contact the first author by phone or e-mail for Turkish/Dutch information and questions. This study will be communicated to the association of general practitioners (GPS) in Genk, a city in the region Middle Limburg, who will be kept well informed throughout the study. 


\section{RECRUITMENT}

An estimated 17,510 Turkish persons live in the region Middle Limburg, of whom approximately 11,540 are 18 years of age and older (Limburg in cijfers, personal communication). Before the start of the screening phase, focus group discussions were held with delegates of four mosques in Middle Limburg (Waterschei, Winterslag, Kolderbos and Sledderlo) and two Turkish responsibles of the Genk city council. Group discussions included general information on hepatitis B (eg hepatitis B occurs more often in Turkey compared to Belgium, routes of transmission, asymptomatic nature of disease, disease outcome), prevention (eg screening, vaccination), design of this study, recruitment and conduct of the study. Being familiar with the stigma regarding hepatitis in the Turkish community, several motivating factors and barriers to go for HBV screening were identified during the group discussions. Table 4.1 and 4.2 illustrate the motivating factors and barriers by social-cultural, religious and other factors as well as the appropriate actions in the current screening study. 
Table 4.1: Motivating factors for hepatitis B virus screening identified during focus group discussions and actions taken in current study

\begin{tabular}{|c|c|}
\hline Motivating factors for HBV screening & Actions taken in current study \\
\hline $\begin{array}{l}\text { Social-cultural factors } \\
\text { 1. Stimulation by family members, } \\
\text { friends and delegates of the Turkish } \\
\text { community to opt for HBV screening. }\end{array}$ & 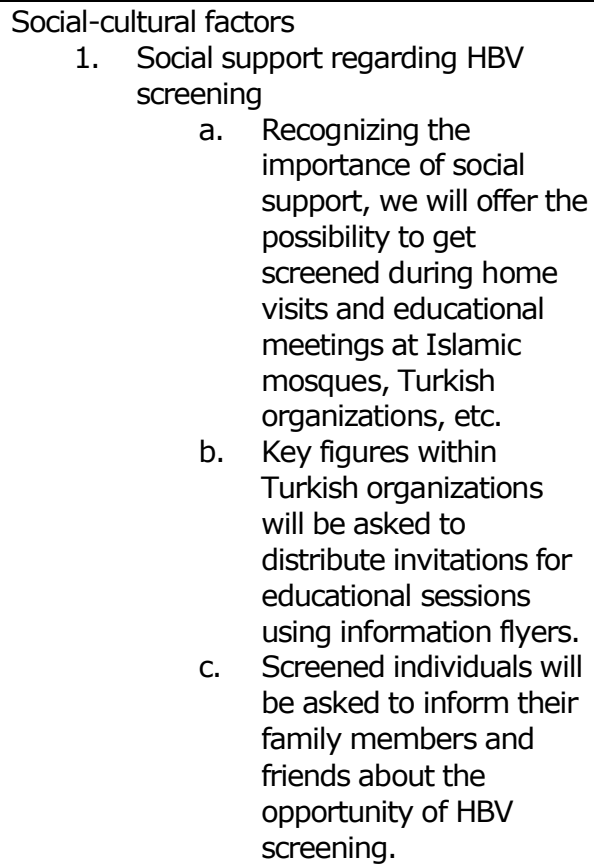 \\
\hline
\end{tabular}

2. Engagement of Turkish study personnel

2. We will involve Turkish medical doctors, nurses and volunteers for HBV screening and questionnaire.

Religious factors

1. Islamic belief towards doing your best to stay healthy.

Religious factors

1. In Islamic mosques, the imams (ie the person who leads prayers in a mosque) will be asked to invite his cemaat (ie community) for educational HBV meetings.

Other

1. Low barrier for HBV screening.

2. Availability of information in Turkish and Dutch language.
Other

1. In addition to the possibility to get screened at the Outpatient Hepatology Department of the hospital, we will implement home visits and screenings immediately after educational meetings in Turkish organizations.

2. All information materials will be available in Turkish and Dutch language. Educational meetings will be principally done in Turkish.

Abbreviations: HBV: hepatitis B virus 
Table 4.2: Barriers for hepatitis B virus screening identified during focus group discussions and actions taken in current study

\begin{tabular}{|c|c|}
\hline Barriers for HBV screening & Actions taken in current study \\
\hline $\begin{array}{l}\text { Social-cultural factors } \\
\text { 1. Association of HBV infection with } \\
\text { intravenous drug use and high-risk } \\
\text { sexual behavior. }\end{array}$ & $\begin{array}{l}\text { Social-cultural factors } \\
\text { 1. In the questionnaire, we did not } \\
\text { ask for intravenous drug use or } \\
\text { sexual behavior. However, it was } \\
\text { decided that the Turkish } \\
\text { community should have } \\
\text { knowledge about all the } \\
\text { transmission routes of HBV } \\
\text { infection but sexual behavior will } \\
\text { be addressed in a subtle way by } \\
\text { addressing the main route of } \\
\text { transmission, ie transmission } \\
\text { from mother to child. }\end{array}$ \\
\hline $\begin{array}{l}\text { 2. Confrontation with a male physician } \\
\text { for some women. }\end{array}$ & $\begin{array}{l}\text { 2. There will always be the } \\
\text { opportunity of a female Turkish } \\
\text { physician. }\end{array}$ \\
\hline $\begin{array}{l}\text { 3. Some women and men might have a } \\
\text { concern regarding joint educational } \\
\text { meetings. }\end{array}$ & $\begin{array}{l}\text { 3. We will organize educational } \\
\text { meetings for (1) men only, (2) } \\
\text { women only and ( } 3 \text { ) joint } \\
\text { educational meetings for men and } \\
\text { women. Before setting up } \\
\text { educational meetings the type of } \\
\text { audience will always be discussed } \\
\text { with key figures within the } \\
\text { organization. }\end{array}$ \\
\hline
\end{tabular}

Other factors

1. Suspicion that blood samples will be stored and analyzed for other things than mentioned.
Other factors

1. Blood sample storage and analysis

a. It was decided not to store blood samples for future studies.

b. We will involve delegates of the Turkish community during recruitment.

c. During educational HBV screening meetings we will implicitly mention that blood samples will be analyzed for HBV in the hospital and will be destroyed afterwards.

d. We will engage Turkish medical doctors and nurses. 
2. Fear of adverse consequences after HBV screening.

3. Little/no knowledge about hepatitis B.
2. Emphasis will be set on the importance of secondary prevention in HBV infection. "We do not want to make you sick, we just want you to know that effective treatment is available to prevent liver cancer."

3. Flyers, posters and video on HBV infection will be available in Turkish and Dutch language. The flyers, posters and name cards with link to the video will be disseminated among the Turkish community. Moreover, educational meetings will be planned before the actual HBV screening.

Abbreviations: HBV: hepatitis B virus.

As the Islamic mosques mainly consist of male members/visitors, we will also search for female Turkish organizations in the Middle Limburg area. From September 2017 until August 2019, with the support of key figures within these organizations, we will organize educational meetings with the possibility for immediate HBV screening afterwards. The educational and screening sessions will be scheduled after the regular meetings of each organization.

The key figures within these organizations will distribute invitations for the sessions using information flyers, posters and name cards with a link to the hepatitis B video. The flyers, posters and video contain information about risk factors for horizontal transmission (sharing personal and household articles, such as toothbrushes) and vertical transmission in addition to general information such as HBV vaccination, consequences of unrecognized HBV and the possibility of antiviral treatment. Turkish persons who are unable to attend a session will be invited to visit additional educational meetings and screening sessions in Ziekenhuis Oost-Limburg (ZOL) or can make an appointment with Ö.M.K at the Hepatology Outpatient Department (OPD) of ZOL. In addition to the above mentioned methods, Turkish people can also contact the first author for home visits with the possibility to sign an informed consent and be screened for HBV. Figure 4.1 shows the flow chart of the study design. 


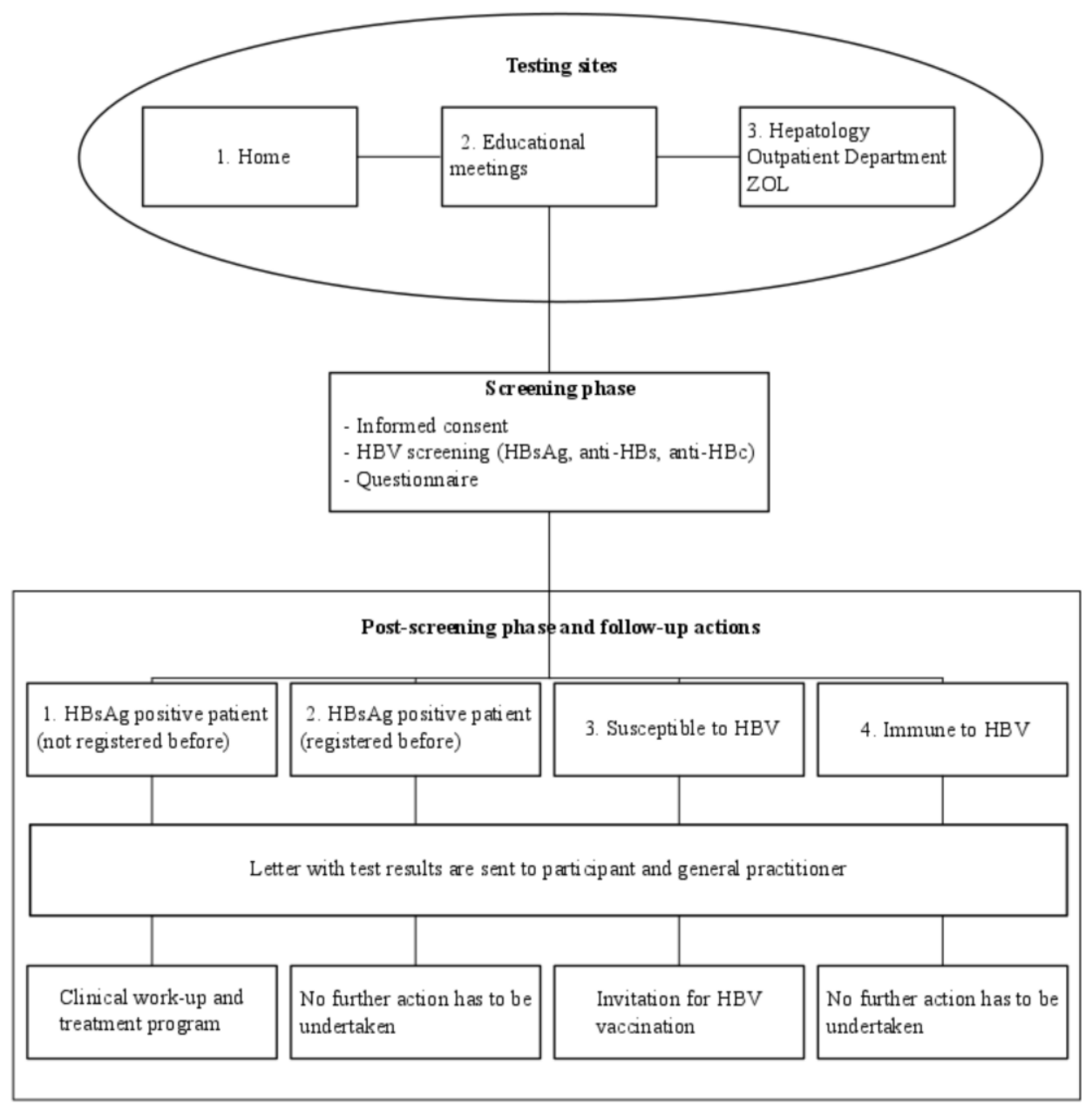

Figure 4.1: Flow chart of the study design. Abbreviations: HBV: hepatitis B virus; HBsAg: hepatitis B surface antigen; anti-HBs: antibodies against hepatitis B surface antigen; anti-HBc: antibodies against hepatitis $B$ core antigen 


\section{SCREENING PHASE}

The educational sessions will be held in Turkish by the first author who will address the risk factors, routes of transmission, the fact that screening is free of charge, consequences, prevention and HBV treatment. After the educational meetings, there will be the possibility to be screened for HBV. Those who opt for screening, will be given an informed consent form and a questionnaire, available in Dutch and Turkish. HBV screening will also be possible at home visits and at the OPD of ZOL. Blood specimens will be transported to and processed in the laboratory of ZOL.

\section{LABORATORY TESTING}

All blood samples will be tested for HBsAg, antibodies against HBsAg (anti-HBs) and antibodies against hepatitis B core antigen (anti-HBc) using an electrochemiluminescence assay (Cobas 8000 e602, Roche, Germany). The interpretation of positive and negative results will be carried out as recommended by the test producer.

\section{POST-SCREENING PHASE AND FOLLOW-UP ACTIONS}

Patients who test positive for HBsAg will have the opportunity to enter an OPD. HBV screening results will be sent by letter to the patients and to their GP. A clinical work-up and treatment program in the OPD will be proposed for newly diagnosed patients. No further action will be undertaken in previously registered HBsAg positive patients.

Non-immunized subjects and their GP will be informed about the test results by a letter. Non-immunized subjects will additionally be asked to consult their GP for HBV vaccination. In case of immunization against HBV infection, only a letter regarding the HBV screening results will be sent to the participant as well as to the GP.

\section{SAMPLE SIZE}

Sample size calculation was performed with the aid of Epi Info $®$ (version 7.2). Considering the lack of data on the number of first- and second-generation Turkish migrants living in Middle Limburg, the number of samples per age was calculated instead so that the results of the sample group agree with that of the Turkish population in Middle Limburg with a confidence interval of $95 \%$ and $3 \%$ as an acceptable margin of error. The expected frequencies for the different age categories 18-39, 40-59, 60-79 and 80+ are 54\%, 35\%, $9 \%$ and $1 \%$, respectively (Limburg in cijfers, personal communication). Our analysis would lead to a total of 1,000 tested persons. 


\section{MEASURES}

Questionnaire: we searched PubMed to identify articles on risk factors for HBV infection in the Turkish community using the following terms and keywords alone and/or in appropriate combinations: hepatitis B, Turkey, Turkish, Turks, risk factor. No publication date or language restrictions were set. In addition, reference lists of all identified articles were checked to identify additional material, including (grey) literature. The final questionnaire includes the following risk factors: blood transfusion (no, yes before 1974 in Turkey, yes before 1974 in Belgium, other), dental treatment (yes in Turkey, other), (if female) gynaecological examination (no, yes in Turkey, yes in Belgium, other), (if male) circumcision (no/yes), (if male) circumcision carried out by a doctor (no, yes, unknown), (if male) way of circumcision (alone, collective, unknown), surgery (no, yes in Turkey, yes in Belgium, other), treatment with needles (no, yes in Turkey, yes in Belgium, other), HBV infected mother (no/yes), HBV infected father (no/yes), HBV infected brother (no/yes), HBV infected sister (no/yes), HBV infected partner (no/yes), other infected family member (no/yes), sharing toothbrushes with other household members (no, yes once, yes on regular basis), sharing nail clippers with other household members (no/yes), sharing razors with other household members (no/yes), sharing used towels with other household members (no/yes), eating from the same plate as other household members (no/yes), tattoo/piercing/earlobe perforation (no, yes in Turkey, yes in Belgium, other), treatment with Fish spa (no, yes in Turkey, yes in another country than Turkey). Furthermore, the questionnaire will collect data on HBV vaccination (vaccinated no/yes/unknown, (if yes) number of vaccinations, (if no) reasons of not being vaccinated) and previous HBV test results. Data regarding sociodemographics (age, gender, educational status of mother, educational status of father), first language (Dutch/Turkish), migration history (country of birth, (if born in Turkey) year of migration to Belgium, mother's country of birth, father's country of birth, (if mother bom in Turkey) region of birth from mother, (if father born in Turkey) region of birth from father) will be collected to characterize the study population. Regarding region of birth, Turkey will be divided in the seven geographical regions: (1) Marmara, (2) Aegean, (3) Mediterranean, (4) Central Anatolia, (5) Black Sea, (6) Eastern Anatolia and (7) Southeastern Anatolia (Figure 4.2). ${ }^{80}$ The questionnaire will not cover questions regarding intravenous drug use or sexual behaviour as (1) these questions could lead to a significant lower participation rate and (2) the answers to these questions are not reliable in this Turkish population with a majority being Muslim. 


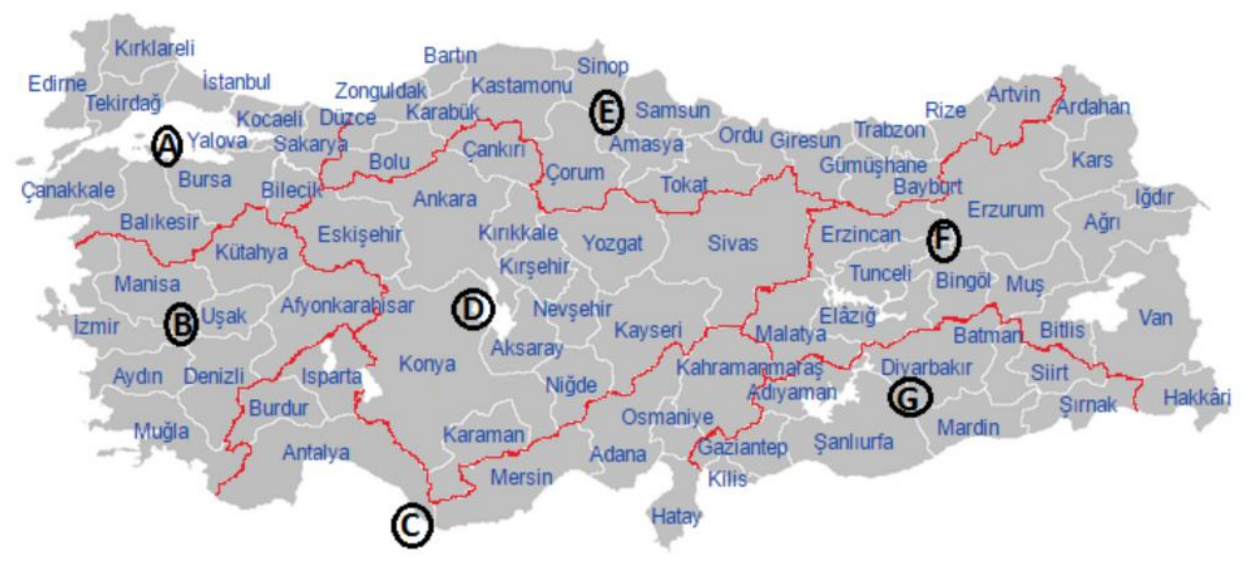

Figure 4.2: Map of Turkey according to the geographical regions. Map of Turkey according to regions: A: Marmara, B: Aegean, C: Mediterranean, D: Central Anatolia, E: Black Sea, F: Eastern Anatolian and G: Southeastern Anatolia.

Clinical outcomes: within six months of a HBsAg positive test result, we will assess whether or not HBsAg positive patients are under follow-up at the GP or hepatologist. Clinical follow-up data will be collected: co-infection (hepatitis C virus, hepatitis delta virus, HIV); determination of liver disease stage (via fibroscan, ultrasonography abdomen, Magnetic Resonance Imaging of the liver, duodenoscopy, and, if necessary, liver biopsy); and treatment eligibility, initiation and outcomes. Outcomes of Fibroscan and/or liver biopsy will be scored according to the METAVIR classification system for fibrosis (F0: no fibrosis, F1: portal fibrosis without septa, F2: few septa, F3: numerous septa without cirrhosis, F4: cirrhosis). ${ }^{182}$ Within six months after HBV screening, we will also gather data regarding nonimmunized subjects, namely if they initiated HBV vaccination by the GP.

\section{Primary outcome measure}

The primary outcome variable is the prevalence of current infection with HBV in the Turkish population living in Middle Limburg. For this reason, one Li-heparin tube collection and subsequent $\mathrm{HBsAg}$ analysis will be performed from each participant. 


\section{Secondary/Exploratory outcome measures}

The questionnaire will provide information on secondary outcomes by assessing the risk factors for recent or past HBV infection (anti-HBc positivity). We will also determine the willingness for HBV assessment in the Turkish population in Middle Limburg. This will be assessed by the number of persons who did go for HBV testing divided by the total population who attended one of the educational meetings, the OPD of ZOL or home visit. Other secondary outcome measures are (1) percentage of new HBsAg positive patients that are under follow-up at the GP or a hepatologist, (2) factors associated with HBsAg positive persons to be under follow-up at the GP/hepatologist six months after HBV screening test result, (3) distribution of stages of liver disease in HBsAg positive patients, (4) treatment eligibility, initiation and outcomes in HBsAg positive patients, (5) the percentage of Turkish population who are immune against HBV infection based on anti-HBs status and (6) percentage of Turkish population who are susceptible for HBV infection and (7) uptake of HBV vaccination in non-immunized Turkish subjects.

\section{STATISTICAL ANALYSES}

Survey data will be entered bed-side into a secure electronic database Castor EDC (Castor Electronic Data Capture, Ciwit Bv, Amsterdam, the Netherlands). Coded data analyses will be performed using SPSS (Release 25, Armonk, NY). Categorical data will be analysed with the Chi squared test or Fisher's exact test. Differences in two and several continuous variables will be assessed by the independent t-test and one way-ANOVA test, respectively. The normality and homogeneity of variances will be verified, respectively, by Shapiro-Wilk and Levene values $>0.05$. In case the assumptions for parametric tests are violated, the equivalent Mann-Whitney test and Kruskal-Wallis test will be applied for comparing two and several continuous variables, respectively. A multivariate logistic regression model will be used to identify risk factors associated with anti-HBc total positivity. Risk factors that are found to be significantly associated $(\mathrm{p}<0.05)$ with anti-HBc total positivity in univariate analysis will be included as covariates in the logistic regression model. Since all included samples will be linked to questionnaires, corrections for over- or undersampling of certain groups will be performed. In order to do this poststratification, weights for age and gender will be created. This will be done for the two variables separately, and for their interaction. Chi-squared tests will then be performed again, this time including the poststratification weights. The same will be done for logistic regression. The level of statistical significance is set at $\mathrm{p}<0.05$. 


\section{ETHICAL APPROVAL AND INFORMED CONSENT}

The Ethical Committee of ZOL Genk and Hasselt University approved this study with protocol version 1.0 dated 13 July 2017 (B371201732623) and written informed consent will be obtained from all study participants.

\section{AVAILABILITY OF DATA AND MATERIALS}

The datasets used during the current study will be available from the corresponding author on reasonable request. 


\section{DISCUSSION}

Immigration to Western Europe has a long history, but increased at an unprecedented rate over the past decades. During this time period, the incidence and mortality of hepatocellular carcinoma increased in Western Europe, likely in part due to the increased migration from countries with intermediate (HBsAg prevalence $2-7 \%$ ) or high (>8\%) HBV prevalence. ${ }^{79}$, 183

Moreover, screening in migrants from countries with an intermediate HBV endemicity, such as the Turkish population in the Netherlands and Germany, has shown a 15-25 times higher HBsAg prevalence of 3-5\% in comparison to the general population. ${ }^{184,185}$ However, data on the real HBV prevalence in the Turkish population residing in Belgium and data on the risk factors and distribution of stages of liver disease in this Turkish population are not available. Nonetheless, knowledge on the HBV prevalence, risk factors and clinical evolution in Western Europe is necessary.

\section{Strengths and limitations}

This study will determine the prevalence and risk factors of HBV infection in a large panel of first- and second-generation Turkish migrants living in Middle Limburg, Belgium. It will show whether the HBV prevalence obtained from this Turkish population study is higher than the HBV prevalence found in previous studies conducted in the general population living in Belgium. The inclusion of a large number second-generation migrants will also provide information whether second-generation Turkish migrants are at risk for HBV infection in addition to first-generation migrants. In the Netherlands, a study on 103 second-generation Turkish migrants could not find a difference in $\mathrm{HBSAg}$ and anti-HBc seroprevalence from the native population. ${ }^{185}$ Considering the small sample size of the Dutch study, but also in view of variations in HBV prevention and control strategies between European countries, it is important to assess the issue of $\mathrm{HBV}$ infection in the second-generation migrants living in Belgium together with first-generation migrants. ${ }^{186}$

In contrast to cross-sectional studies, this longitudinal follow-up study will be able to differentiate between acute/chronic HBV cases and false-positive HBsAg test results. It will also provide information on linkage to care and stages of liver disease which may assist physicians, public health practitioners and policymakers in eliminating hepatitis $\mathrm{B}$. The assessment of anti-HBs in addition to HBsAg and anti-HBc will give us insight in the proportion of individuals susceptible to HBV infection. Furthermore, this study will gather 
information on risk factors for HBV infection, sociodemographics, migration history and clinical data (eg HBsAg positivity). Combined, this information could help identify how HBV infection in this Turkish population is spreading so that further spread can be stopped. This study will also provide information on the feasibility and acceptability of HBV screening in hard-to-reach migrant groups.

There are some limitations to the present study. First, this study could be underpowered to find significant associations between certain risk factors and $\mathrm{HBSAg}$ or anti-HBc, as sample size calculation was performed on distribution of age categories and not on expected $\mathrm{HBSAg}$ or anti-HBc prevalence. Second, a concem is that, even though risk factors for HBV infection were recorded, certain risk behaviours could have been underreported due to social desirability bias. Third, it is unknown whether observations from Turkish population in Middle Limburg could be used as an estimate for Europe. However, collection of demographic factors allows subanalyses. Fourth, the questionnaire will not cover points regarding intravenous drug use or high-risk sexual behaviour as these questions could lead to a significant lower or biased participation rate and the answers to these questions are ought to be unreliable in this Turkish population in which the majority of people identify with Islam. 
Supplementary file S 4.1: Informative flyer on hepatitis B screening project in the Turkish migrant population (available in Dutch and Turkish language)

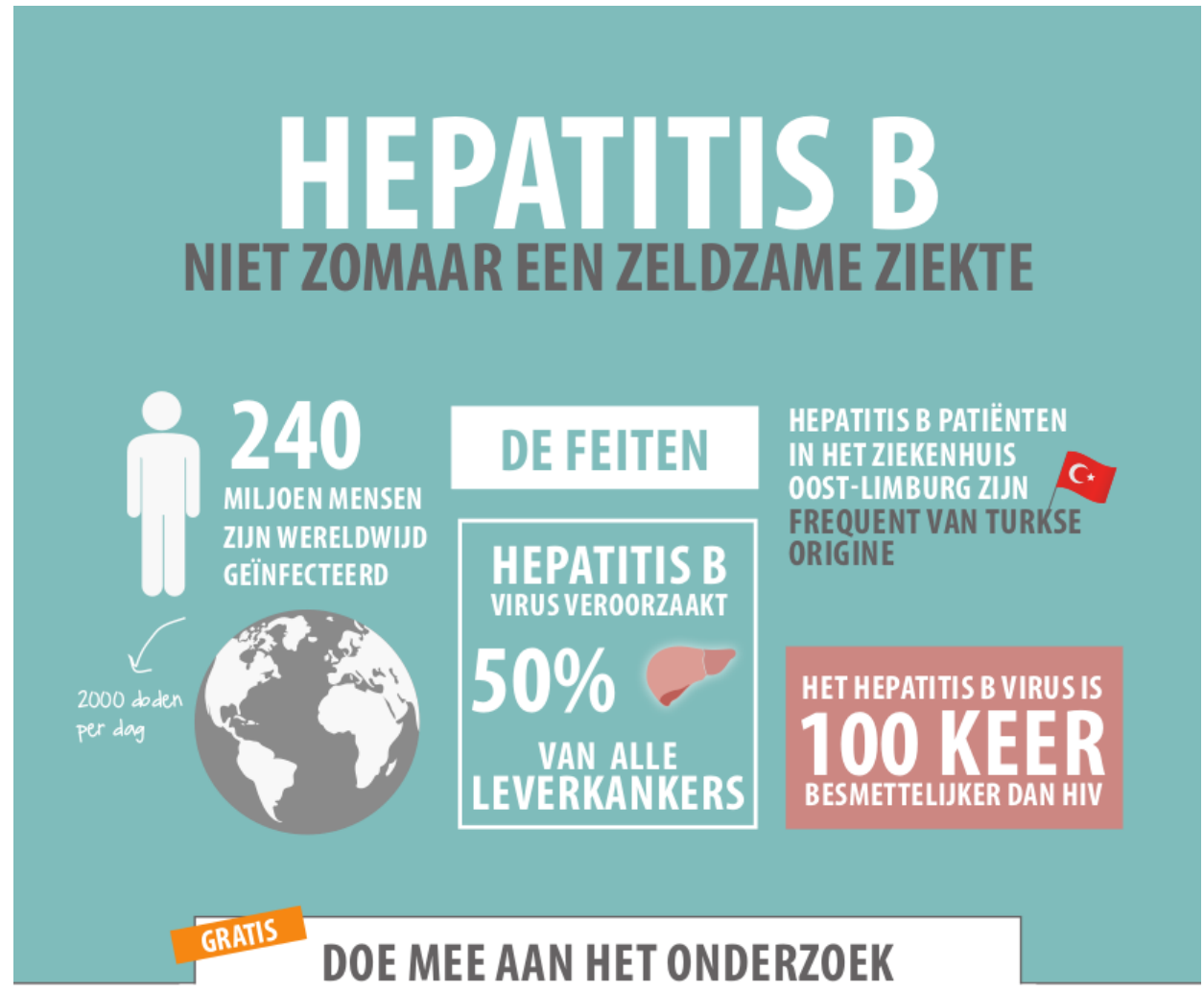

naar hepatitis B virus infectie bij de Turkse bevolking

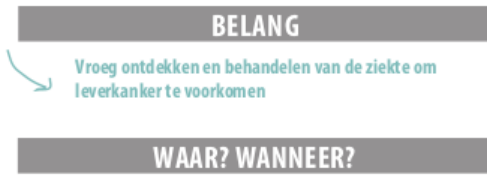

Maak een afspraak via het nummer 089/321519 of via dr. Ozgür Koc ozgur.koc@zol.be

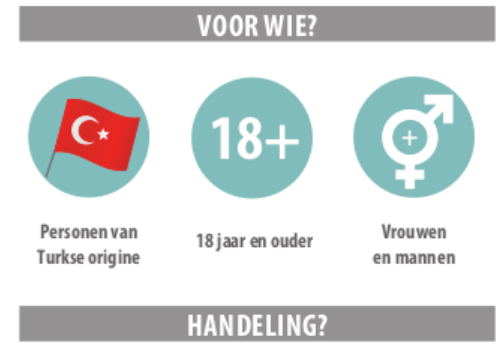

Éénmalige bloedafname en een korte vragenlijst. Men hoeft niet nuchter te zijn vo or bloedafname.

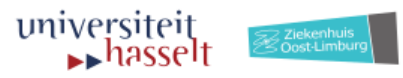




\section{Hepatit B hastalığını önle}
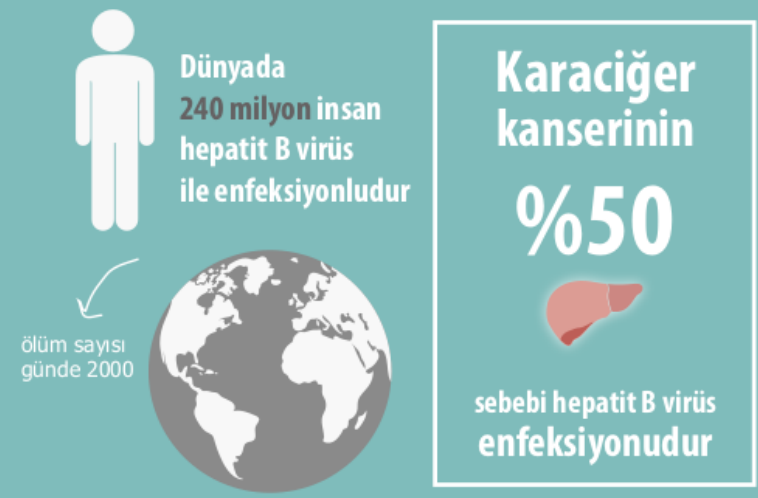

ZOL Genk hastanesindeki hepatit B hastaları çoğunlukla Türk C. kökenlidir

Hepatit B virüsü HiV den $100 X$ daha bulaşıcıdır

\section{Limburgteki Türk nüfusunda yapılan Hepatitit B projeye}

\section{katılmak için davet ediliyorsunuz}

\section{Önem ve faydalar? \\ Hepatit B virüsü enfeksiyonuna maruz kalmıș kișilerde erken teșhis konulabilmesi ve zamanında ted avi müdahalesi ile karaciōer kanserini engellemek. \\ Ne zaman ve nerede?}
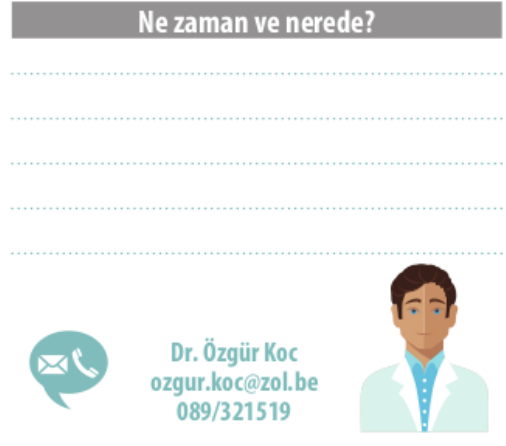

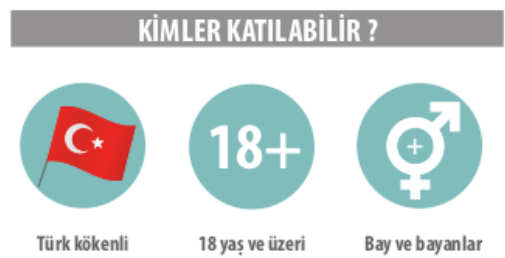

\section{ișlem?}

Bir defaya mahsus kan alınacaktır ve sizden soru listesini doldurmanı istenilecekt ir

- Kan tahlili için aç kalmaya gerek yok

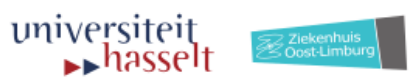




\section{HEPATITIS B NIET ZOMAAR EEN ZELDZAME ZIEKTE}
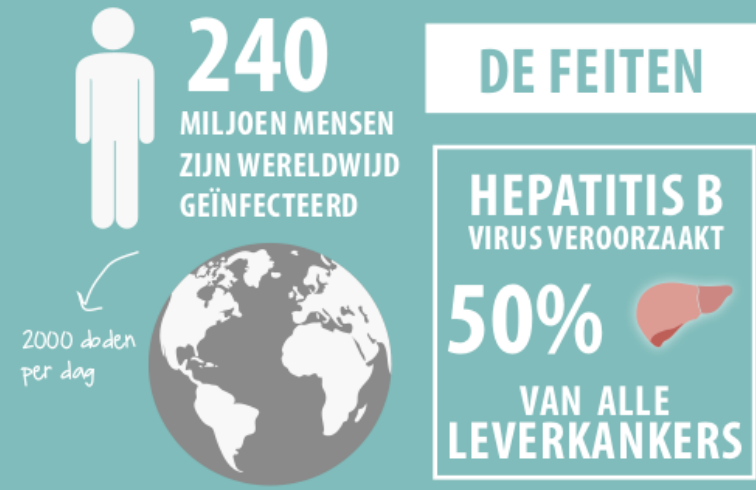

HEPATITIS B PATIËNTEN IN HET ZIEKENHUIS OOST-LIMBURG ZIJN C* FREQUENT VAN TURKSE ORIGINE

HET HEPATITIS B VIRUS IS $400 \begin{aligned} & 17 \\ & \text { a }\end{aligned}$ BESMETTELIJKER DAN HIV

\section{HEPATITIS B BESMETTINGSRISICO'S}

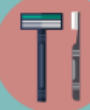

Het delen van scheer mes en tandenborstel

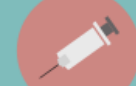

Onveilige injecties

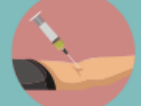

Intraveneus

drugsgebruik

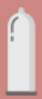

Onbescherms selsueel contact

dragente B virus (overdracht tijdens geboorte)

universiteit $\rightarrow$ hasselt

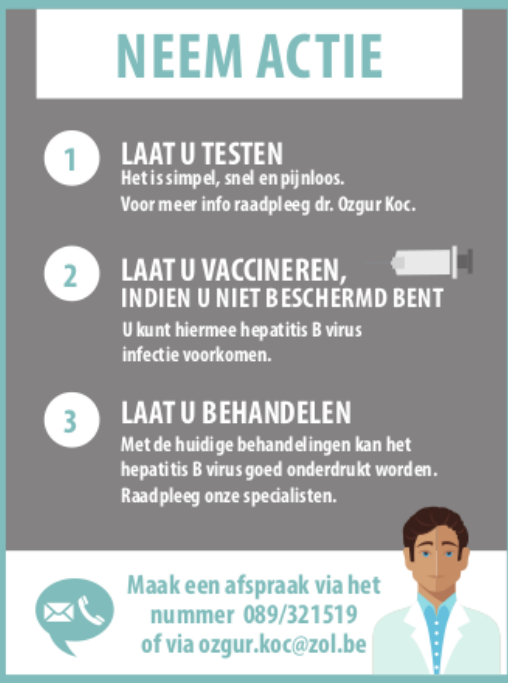

Ziekenhuis 


\section{Hepatit B hastalığını önle}
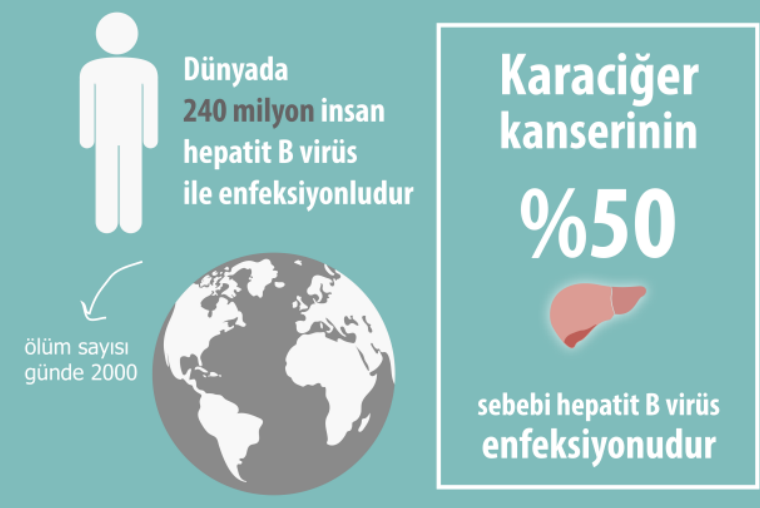

ZOL Genk hastanesindeki hepatit B hastaları çoğunlukla Türk $\odot$ kökenlidir

Hepatit B virüsü HiV den $100 X$ daha bulaşıcıdır

\section{Hepatit B bulaşma riziko faktörleri}

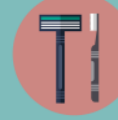

Ortak dis firça ve tra: bıçak kullanımı

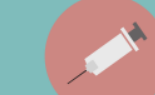

Onaylanmamıs ortamlarda yaptırlan iğneler

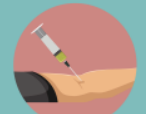

Damarici esrar kullanımı

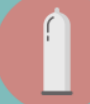

Korunmasız cinsel iliski

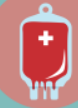

Tarama yapilmamıs kan nakli

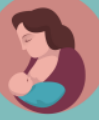

Hepatit B viruis olan annenin doğum esnasında çocuğa geçirmesi

\section{HAREKETE GEC}

(1) Test yaptır Cok basit, hızlı ve ağrısız. Daha fazla bilgi için doktor Özgür Koc'a başvurabilirsiniz

(2) Aşı ol

Eğer test sonucuna göre bağışıklığınız yoksa aşı olun. Bu şekilde hepatit B virüs enfeksiyonu önleyebilirsiniz. Ev doktorunuza başvurabilirsiniz.

(3) Tedavi ol

Günümüzdeki tedavi yöntemleri ile hepatit B virüsü başarılı bir şekilde bastırılabiliniyor. Uzman doktoruna başvurabilirsiniz.

$$
1 \div
$$

Özgür Koc ozgur.koc@zol.be 089/321519

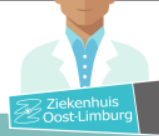





\title{
CHAPTER 5
}

\section{Early detection of chronic hepatitis B and risk factor assessment in Turkish migrants, Middle Limburg, Belgium}

\author{
Koc ÖM, Kremer C, Hens N, Bielen R, Busschots D, Van Damme P, \\ Robaeys G
}

Submitted 


\section{ABSTRACT}

Background: Turkey is an intermediate hepatitis B virus (HBV) endemic country. However, prevalence among Turkish migrants in Belgium is unknown, especially in those born in Belgium with a foreign-born parent, i.e. second-generation migrants (SGM).

Aims To evaluate the prevalence of HBV infection and associated risk factors in Turkish first-generation migrants (FGM), i.e. foreign-bom, and SGM.

Methods: Between September 2017 and May 2019, free outreach testing for hepatitis B surface antigen ( $\mathrm{HBsAg}$ ), hepatitis B core antibodies (anti-HBc), and antibodies against HBsAg was offered to Turkish migrants in Middle-Limburg, Belgium. Face-to-face questionnaire assessed HBV risk factors. HBsAg positive patients were referred and followed up. Turkish SGM were stratified into birth cohort born before and after 1987, since those born after 1987 should be covered by the universal infant vaccination program.

Results: A total of 1,081/1,113 (97.1\%) Turkish did go for HBV testing. Twenty-six (2.4\%) were HBsAg positive; $11 / 26$ were unaware of their status and 10/11 were successfully referred. HBsAg prevalence was 3.0\% in FGM and $1.5 \%$ in SGM, $\mathrm{p}=.070$. These numbers were $32.8 \%$ and $5.7 \%$ for anti-HBc, respectively, $\mathrm{p}<.001$. Only one out of seven HBsAg positive SGM was born after 1987. Anti-HBc positivity in Turkish SGM born after 1987 was $1.1 \%$, this was $9.1 \%$ for those bom before $1987, \mathrm{p}<.001$.

Conclusion: Outreach testing was well-accepted and referral to specialist care was generally successful. National HBV screening should be implemented in the Turkish FGM population and might be considered in SGM not covered by primary prevention strategies. 


\section{INTRODUCTION}

Hepatitis B virus (HBV) infection is one of the most common infectious diseases worldwide. Approximately one third of the world population has been exposed to the virus and an estimated 257 million people are chronically infected. ${ }^{57}$ Regardless of the asymptomatic nature of chronic HBV infection, patients remain infectious to others and are at risk of death from cirrhosis and hepatocellular carcinoma. ${ }^{57}$ In 2015, HBV-related complications accounted for 887,000 deaths globally. ${ }^{57}$

The possibilities for antiviral treatment of chronic HBV infection have greatly improved over the past decades, and cost-effective drug therapies are now available. ${ }^{137,187}$ However, due to the asymptomatic course, most patients are unaware of their HBV infection and do not benefit from treatment. Screening for hepatitis $B$, aimed at early detection of chronic HBV infection with follow-up and antiviral treatment of eligible patients, is needed to reduce the economic burden of HBV-related complications and health-related suffering in Europe. ${ }^{48,49}$ In addition, screening could identify persons who are susceptible to infection and would benefit from vaccination. ${ }^{48}$

In low endemic countries ( $<2 \%$ hepatitis B surface antigen (HBsAg) positive), migrants born in intermediate ( $2-7.99 \%$ HBsAg positive) or high endemic ( $\geq 8 \% \mathrm{HBsAg}$ positive) regions are an important risk group for chronic $\mathrm{HBV}$ infection. ${ }^{132}$ In Belgium, the prevalence of chronic HBV infection is estimated to be $0.67 \%$ in the general population and $4.69 \%$ in first-generation migrants (FGM) born in intermediate or high endemic countries. ${ }^{130-132}$ Migrants from intermediate or high endemic countries account for more than half of the patients with chronic HBV infection in Belgium. ${ }^{79}$ Turkish individuals form the second largest FGM population in Europe and with a HBsAg prevalence in Turkey ranging from $2-3 \%$ in the Western part up to $7-8 \%$ in Eastem part, a substantial proportion of the Turkish migrant population may be infected with HBV. ${ }^{79,} 80$

Most studies conceming hepatitis B testing in FGM involved southeast Asians in the USA, Canada and Australia. ${ }^{81}$ A cross-sectional study in Turkish FGM in Germany showed a prevalence of $5 \%$ for chronic HBV infection, and this was $3 \%$ in a study conducted in the Netherlands. ${ }^{184,} 185$ However, HBV risk factors and follow-up in Turkish FGM are mostly unclear. Furthermore, much less is known about infection prevalence, risk factors and follow-up in second-generation migrants (SGM), i.e. born in Belgium with a foreign-born parent. This is all the more important as the descendants of the FGM population grow. 
Regarding acute hepatitis B notification rates, a Dutch study showed a higher rate of $3.7 / 100,000$ in SGM compared with $1.6 / 100,000$ in native Dutch/Westem persons. ${ }^{188}$

We organized a hepatitis B testing and risk factor assessment campaign for the Turkish population in Middle Limburg, Belgium, a region with a relatively large Turkish population. ${ }^{189}$ Here we report the prevalence of $\mathrm{HBV}$ infection in individuals with a Turkish background (FGM and SGM), the results of a questionnaire on risk factors, and the follow-up of patients referred to care. 


\section{PATIENTS AND METHODS}

From 1 September 2017 until 2 May 2019, we recruited $\geq 18$ year-old Turkish migrants living in the region Middle Limburg. Follow-up was concluded on 2 November 2019, 6 months after the last inclusion. The study methods have been published previously. ${ }^{190}$ In brief, the free outreach hepatitis $B$ testing campaign was combined with risk factor assessment by a face-to-face questionnaire. Blood samples were tested for HBsAg, antibodies against HBsAg (anti-HBs) and hepatitis B core antibodies (anti-HBc) with an electrochemiluminescence assay (Cobas 8000 e602, Roche, Germany). Both participants and their general practitioner received the test result by letter and, supplementary to this, the general practitioners were advised to contact the HBsAg positive participants by phone. All patients who tested positive for HBsAg were referred to a hepatologist for a clinical workup and treatment program according to the European clinical practice guidelines. ${ }^{7} \mathrm{HBsAg}$ positive patients were divided in four phases, taking into account the presence of hepatitis B e antigen ( $\mathrm{HBeAg}$ ), serum HBV DNA levels and serum alanine aminotransferase (ALT) values. ${ }^{7}$ Persons susceptible to $\mathrm{HBV}$ infection were asked to consult their general practitioner for HBV vaccination.

\section{QUESTIONNAIRE}

Before hepatitis B testing, HBV risk factors were assessed through a face-to-face questionnaire (see Table 5.2). The questionnaire was available in the Dutch or Turkish language, and covered a total of 23 and 21 questions for males and females, respectively. The questionnaire did not cover information on intravenous drug use or sexual behaviour as these questions are sensitive and therefore socially censured; pressure to conform to societal norms could cause self-reports to be fraught with bias.

\section{STATISTICAL ANALYSIS}

The sample size calculation was performed with the aid of Epi Info ${ }^{\circledR}$ (version 7.2). Since data on country of birth in Middle Limburg are unavailable and data on nationality do not represent country of birth, the number of study participants per age group was calculated so that the results of the study group agree with that of the Turkish population living in Middle Limburg with a significance level of $5 \%$. This is important for the extrapolation of the study results to the general Turkish population (Table 5.1). 
Table 5.1: Composition of the study group compared with the composition of the Turkish population living in Middle Limburg regarding age and gender

\begin{tabular}{l|c|c|c|c|c|c}
\hline Age (years) & Total & $\mathbf{1 8 - 3 9}$ & $\mathbf{4 0 - 5 9}$ & $\mathbf{2 6 0}$ & Male & Female \\
\hline Study group (N) & 1,081 & 433 & 511 & 137 & 468 & 613 \\
\hline Study group (\%) & 100 & 40.1 & 47.3 & 12.6 & 43.3 & 56.7 \\
\hline $\begin{array}{l}\text { Turkish Middle Limburg population } \\
(\%)\end{array}$ & 100 & 53.9 & 35.4 & 10.7 & 50.5 & 49.5 \\
\hline
\end{tabular}

To assess the impact of universal HBV vaccination in Belgium among Turkish SGM, we stratified HBsAg, anti-HBc and/or anti-HBs prevalence into two birth cohorts (1930 - 1986 and 1987 - 2001). This cutoff was chosen as the free-of-charge HBV vaccination program in infants since September 1999 with catch-up vaccination for 10 - 13 year-olds covered children bom after 1987 in Belgium. ${ }^{191}$

Since participants could be part of the same household, resulting in violation of the assumption of independent observations for classical tests such as logistic regression, univariate generalized estimating equations (GEE) were used to investigate the influence of the different variables on the presence of past or current HBV infection (anti-HBc positive), chronic HBV infection (HBsAg positive) and vaccination status (solely anti-HBs positive). The correlation structure in these GEE is assumed to be of the 'compound symmetry' type, specifying that all observations within the same cluster are equally correlated. Although this might not be the correct assumption, GEE has been shown to be robust to misspecification of the working correlation structure. ${ }^{192}$

Variables showing significant association $(p<.20)$ in the univariate analyses were subsequently included in a multiple GEE model. As origin and educational level of mother and father were highly correlated, only maternal factors were included in the models. Backward selection was used to obtain a final model. In order to correct for differences between the sample and the Middle-Limburg population, weights were included in all GEE models. Weighting was done based on the combination of age and gender.

\section{ETHICAL APPROVAL}

The study was undertaken in accordance with Good Clinical Practice guidelines and the Declaration of Helsinki. The protocol was approved by the medical ethics committees of Hasselt University and Hospital East-Limburg (17-039U). 


\section{RESULTS}

In total 1,081 Turkish migrants were tested for HBV infection; 1,047 of the 1,079 (97.0\%) persons present at the educational meetings in a Turkish organization and all $34(100.0 \%)$ participants present at home visits did go for testing. Less than half of the study participants were male (43.3\%), and the mean age was $44 \pm 13.7$ years. The majority of the participants were born in Turkey (58.1\%), $41.9 \%$ were born in Belgium.

Blood samples were insufficient for anti-HBs testing in four participants. In $21.5 \%$ $(232 / 1,081$ ) there was evidence of a past or recent HBV infection (anti-HBc positive), $2.4 \%$ $(26 / 1,081)$ had a chronic HBV infection (HBsAg positive), $22.9 \%(247 / 1,077)$ of the samples were solely anti-HBs positive ('vaccinated' serostatus) and 55.5\% $(598 / 1,077)$ appeared to be susceptible for HBV infection (negative HBV markers).

\section{PAST OR RECENT HBV INFECTION}

Past or recent HBV infection in FGM was apparent in 206/628 (32.8\%) with differences between males and females, i.e. $40.4 \%$ (110/272) vs $27.0 \%$ (96/356), respectively, $p=$ .001 . Among FGM, anti-HBc prevalence in $18-39$ year-olds, $40-59$ year-olds and $>60$ yearolds was $13.2 \%(14 / 106), 31.9 \%$ (123/385) and 50.4\% (69/137), respectively, $p<.001$.

Gender difference regarding anti-HBc prevalence was not seen in Turkish SGM, i.e. 5.6\% $(11 / 196)$ in males vs $5.8 \%(15 / 257)$ in females, $p=1.000$. Anti-HBc prevalence in Turkish SGM born after 1987 was $1.1 \%$ (2/190), and was higher for those SGM bom before 1987, i.e. $9.1 \%(24 / 263), p<.001$. Older age was associated with past or recent HBV infection in SGM, i.e. $4.0 \%(13 / 327)$ in 18 -39 year-olds vs $10.3 \%(13 / 126)$ in $40-59$ year-olds, $p=$ .018. There were no SGM 60 years or older.

Factors associated with past or recent HBV infection in the weighted univariate GEE are shown in Table 5.2. From the weighted multiple GEE analyses as shown in Table 5.3, it can be seen that male gender $(p=.021)$, older age $(p<.001)$, FGM $(p<.001)$, lower (i.e. none or primary) educational level of the mother $(p=.003)$, HBV infected mother $(p=$ $.008)$, HBV infected siblings $(p=.002)$, HBV infected other family member $(p=.004)$, gynaecological examination in Turkey or unsafe male circumcision $(p=.032)$, dental treatment in Turkey $(p=.049)$, and treatment with needles in Turkey $(p=.012)$ significantly increased the odds of anti-HBc positivity. 
Table 5.2: Prevalence of past or recent hepatitis B virus infection by different risk factors among the total study population $(n=1,081)$ (weighted univariate GEE)

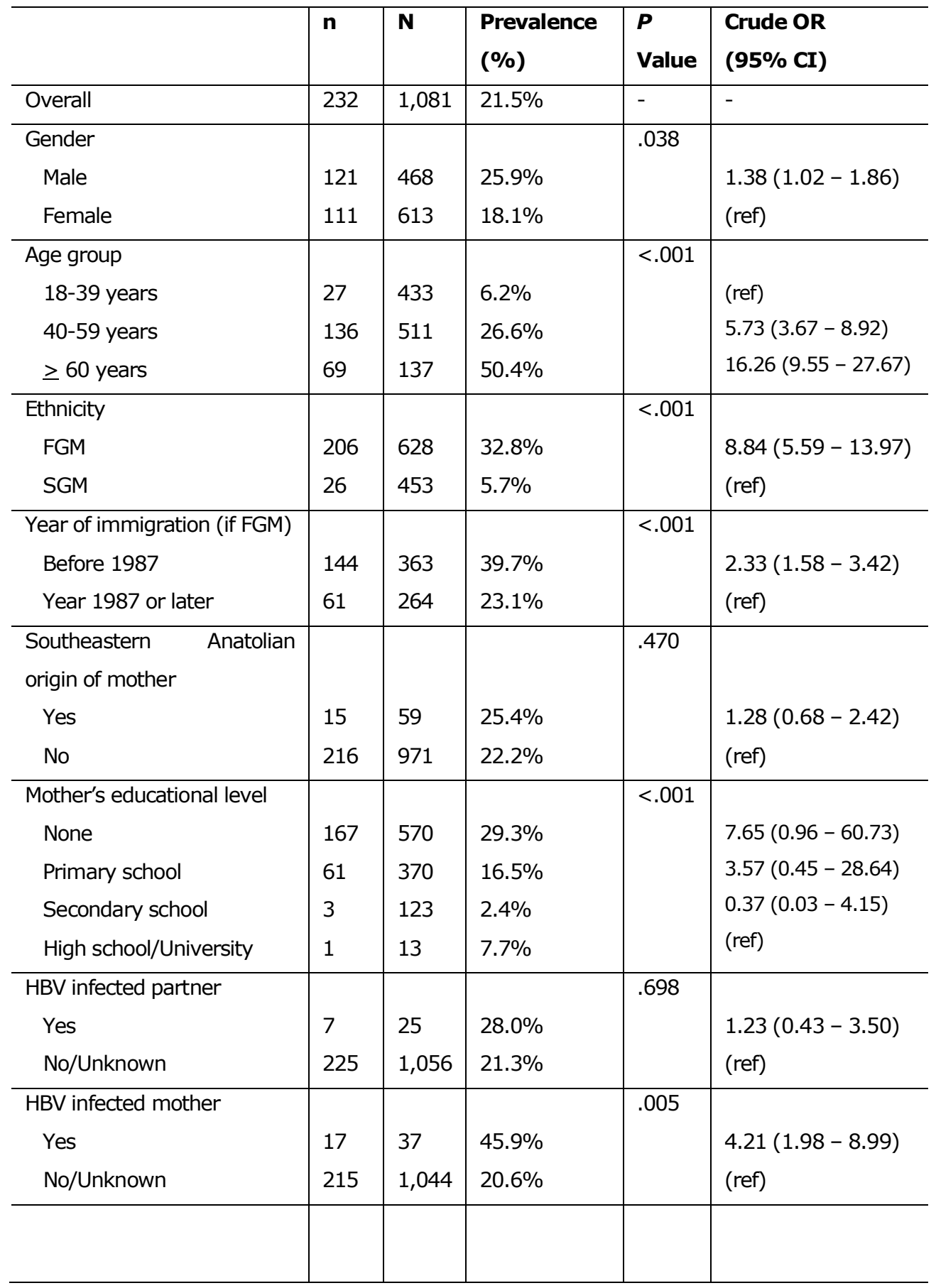




\begin{tabular}{|c|c|c|c|c|c|}
\hline $\begin{array}{l}\text { HBV infected father } \\
\text { Yes } \\
\text { No/Unknown }\end{array}$ & $\begin{array}{l}2 \\
230\end{array}$ & $\begin{array}{l}24 \\
1,057\end{array}$ & $\begin{array}{l}8.3 \% \\
21.8 \%\end{array}$ & .016 & $\begin{array}{l}0.24(0.05-1.17) \\
\text { (ref) }\end{array}$ \\
\hline $\begin{array}{l}\text { HBV infected siblings } \\
\text { Yes } \\
\text { No/Unknown }\end{array}$ & $\begin{array}{l}21 \\
211\end{array}$ & $\begin{array}{l}45 \\
1,036\end{array}$ & $\begin{array}{l}46.7 \% \\
20.4 \%\end{array}$ & .003 & $\begin{array}{l}3.77(1.81-7.87) \\
\text { (ref) }\end{array}$ \\
\hline $\begin{array}{l}\text { HBV infected other family } \\
\text { member } \\
\text { Yes } \\
\text { No/Unknown }\end{array}$ & $\begin{array}{l}26 \\
206\end{array}$ & $\begin{array}{l}70 \\
1,011\end{array}$ & $\begin{array}{l}37.1 \% \\
20.4 \%\end{array}$ & .008 & $\begin{array}{l}2.65(1.47-4.80) \\
\text { (ref) }\end{array}$ \\
\hline $\begin{array}{l}\text { Sharing toothbrushes } \\
\text { regularly } \\
\text { Yes } \\
\text { No }\end{array}$ & $\begin{array}{l}62 \\
170\end{array}$ & $\begin{array}{l}188 \\
892\end{array}$ & $\begin{array}{l}33.0 \% \\
19.1 \%\end{array}$ & $<.001$ & $\begin{array}{l}2.35(1.59-3.47) \\
\text { (ref) }\end{array}$ \\
\hline $\begin{array}{l}\text { Sharing nail clippers } \\
\text { Yes } \\
\text { No }\end{array}$ & $\begin{array}{l}208 \\
24\end{array}$ & $\begin{array}{l}991 \\
89\end{array}$ & $\begin{array}{l}21.0 \% \\
27.0 \%\end{array}$ & .296 & $\begin{array}{l}0.74(0.43-1.25) \\
\text { (ref) }\end{array}$ \\
\hline $\begin{array}{l}\text { Sharing razors } \\
\text { Yes } \\
\text { No }\end{array}$ & $\begin{array}{l}36 \\
196\end{array}$ & $\begin{array}{l}170 \\
910\end{array}$ & $\begin{array}{l}21.2 \% \\
21.5 \%\end{array}$ & .609 & $\begin{array}{l}1.13(0.73-1.75) \\
\text { (ref) }\end{array}$ \\
\hline $\begin{array}{l}\text { Sharing used towels } \\
\text { Yes } \\
\text { No }\end{array}$ & $\begin{array}{l}206 \\
26\end{array}$ & $\begin{array}{l}945 \\
135\end{array}$ & $\begin{array}{l}21.8 \% \\
19.3 \%\end{array}$ & .164 & $\begin{array}{l}1.38(0.85-2.24) \\
\text { (ref) }\end{array}$ \\
\hline $\begin{array}{l}\text { Eating from the same plate } \\
\text { Yes } \\
\text { No }\end{array}$ & $\begin{array}{l}201 \\
31\end{array}$ & $\begin{array}{l}927 \\
153\end{array}$ & $\begin{array}{l}21.7 \% \\
20.3 \%\end{array}$ & .423 & $\begin{array}{l}1.19(0.77-1.84) \\
\text { (ref) }\end{array}$ \\
\hline $\begin{array}{l}\text { Gynaecological examination } \\
\text { in Turkey (if female) } \\
\text { Yes } \\
\text { No }\end{array}$ & $\begin{array}{l}30 \\
81\end{array}$ & $\begin{array}{l}99 \\
514\end{array}$ & $\begin{array}{l}30.3 \% \\
15.8 \%\end{array}$ & .003 & $\begin{array}{l}2.73(1.60-4.67) \\
\text { (ref) }\end{array}$ \\
\hline $\begin{array}{l}\text { Circumcision (if male) } \\
\text { Collective } \\
\text { Alone }\end{array}$ & $\begin{array}{l}44 \\
66\end{array}$ & $\begin{array}{l}118 \\
305\end{array}$ & $\begin{array}{l}37.3 \% \\
21.6 \%\end{array}$ & .004 & $\begin{array}{l}2.18(1.34-3.56) \\
\text { (ref) }\end{array}$ \\
\hline
\end{tabular}




\begin{tabular}{|c|c|c|c|c|c|}
\hline $\begin{array}{l}\text { Circumcision not carried out } \\
\text { by medical doctor (if male) } \\
\text { Yes } \\
\text { No }\end{array}$ & $\begin{array}{l}84 \\
14\end{array}$ & $\begin{array}{l}228 \\
153\end{array}$ & $\begin{array}{l}36.8 \% \\
9.2 \%\end{array}$ & $<.001$ & $\begin{array}{l}5.24(2.76-9.94) \\
\text { (ref) }\end{array}$ \\
\hline $\begin{array}{l}\text { Gynaecological examination } \\
\text { in Turkey or unsafe male } \\
\text { circumcision } \\
\text { Yes } \\
\text { No }\end{array}$ & $\begin{array}{l}115 \\
117\end{array}$ & $\begin{array}{l}330 \\
751\end{array}$ & $\begin{array}{l}34.9 \% \\
15.6 \%\end{array}$ & $<.001$ & $\begin{array}{c}2.92(2.12-4.02) \\
\text { (ref) }\end{array}$ \\
\hline $\begin{array}{l}\text { Blood transfusion } \\
\text { Yes } \\
\text { No }\end{array}$ & $\begin{array}{c}44 \\
188\end{array}$ & $\begin{array}{l}167 \\
914\end{array}$ & $\begin{array}{l}26.3 \% \\
20.6 \%\end{array}$ & .062 & $\begin{array}{c}1.52(1.01-2.27) \\
(\text { ref })\end{array}$ \\
\hline $\begin{array}{l}\text { Dental treatment in Turkey } \\
\text { Yes } \\
\text { No }\end{array}$ & $\begin{array}{l}147 \\
85\end{array}$ & $\begin{array}{l}430 \\
651\end{array}$ & $\begin{array}{l}34.2 \% \\
13.1 \%\end{array}$ & $<.001$ & $\begin{array}{c}4.36(3.17-5.98) \\
\text { (ref) }\end{array}$ \\
\hline $\begin{array}{l}\text { Surgery in Turkey } \\
\text { Yes } \\
\text { No }\end{array}$ & $\begin{array}{c}50 \\
182\end{array}$ & $\begin{array}{l}133 \\
948\end{array}$ & $\begin{array}{l}37.6 \% \\
19.2 \%\end{array}$ & $<.001$ & $\begin{array}{c}3.12(2.05-4.76) \\
\text { (ref) }\end{array}$ \\
\hline $\begin{array}{l}\text { Treatment with needles in } \\
\text { Turkey } \\
\text { Yes } \\
\text { No }\end{array}$ & $\begin{array}{l}107 \\
125\end{array}$ & $\begin{array}{l}322 \\
759\end{array}$ & $\begin{array}{l}33.2 \% \\
16.5 \%\end{array}$ & $<.001$ & $\begin{array}{c}2.82(2.04-3.91) \\
(\text { ref })\end{array}$ \\
\hline $\begin{array}{l}\text { Body } \\
\text { piercing/tattooing/earlobe } \\
\text { perforation in Turkey } \\
\text { Yes } \\
\text { No }\end{array}$ & $\begin{array}{c}84 \\
148\end{array}$ & $\begin{array}{l}327 \\
754\end{array}$ & $\begin{array}{l}25.7 \% \\
19.6 \%\end{array}$ & .009 & $\begin{array}{c}1.58(1.14-2.20) \\
(\text { ref })\end{array}$ \\
\hline $\begin{array}{l}\text { Fish spa treatment } \\
\text { Yes in Turkey } \\
\text { No/Other }\end{array}$ & $\begin{array}{c}9 \\
223\end{array}$ & $\begin{array}{c}64 \\
1,017\end{array}$ & $\begin{array}{l}14.1 \% \\
21.9 \%\end{array}$ & .058 & $\begin{array}{c}0.54(0.25-1.14) \\
(\text { ref })\end{array}$ \\
\hline
\end{tabular}

Abbreviation: GEE: generalized estimating equations; OR: odds ratio; CI: confidence interval; HBV: hepatitis B virus; FGM: first-generation migrants; SGM: second-generation migrants. First-generation migrants: foreign-born individuals; second-generation migrants: individuals born in Belgium with foreignborn parents; unsafe male circumcision: collective circumcision and/or circumcision not carried out by medical doctor. 
Table 5.3: Association of past or recent hepatitis $B$ virus infection to different risk factors among the total study population $(n=1,081)$ (weighted GEE model)

\begin{tabular}{|c|c|c|c|c|}
\hline Parameter & & $\begin{array}{c}\text { Estimate } \\
\text { (SE) }\end{array}$ & P Value & aOR (95\% CI) \\
\hline (intercept) & & $-4.39(0.79)$ & & \\
\hline Gender & Male (vs Female) & $0.46(0.19)$ & .021 & $\begin{array}{c}1.58 \\
(1.08-2.31)\end{array}$ \\
\hline Age group & $\begin{array}{l}40-59 \text { years (vs } 18- \\
39 \text { years) } \\
\geq 60 \text { years (vs } 18-39 \\
\text { years) }\end{array}$ & $\begin{array}{l}0.80(0.25) \\
1.50(0.32)\end{array}$ & $<.001$ & $\begin{array}{c}2.21 \\
(1.36-3.62) \\
4.50 \\
(2.39-8.47)\end{array}$ \\
\hline Ethnicity & FGM (vs SGM) & $1.22(0.26)$ & $<.001$ & $\begin{array}{c}3.40 \\
(2.03-5.69)\end{array}$ \\
\hline $\begin{array}{l}\text { Mother's } \\
\text { educational level }\end{array}$ & $\begin{array}{l}\text { None (vs High } \\
\text { school/University) } \\
\text { Primary (vs High } \\
\text { school/University) } \\
\text { Secondary (vs High } \\
\text { school/University) }\end{array}$ & $\begin{array}{l}0.61(0.80) \\
0.53(0.80) \\
-1.18(1.05)\end{array}$ & .003 & $\begin{array}{c}1.84 \\
(0.38-8.88) \\
1.70 \\
(0.35-8.20) \\
0.31 \\
(0.04-2.41)\end{array}$ \\
\hline $\begin{array}{l}\text { HBV infected } \\
\text { mother }\end{array}$ & Yes (vs No/Unknown) & $1.51(0.45)$ & .008 & $\begin{array}{c}4.52 \\
(1.89-10.84)\end{array}$ \\
\hline $\begin{array}{l}\text { HBV infected } \\
\text { siblings }\end{array}$ & Yes (vs No/Unknown) & $1.53(0.40)$ & .002 & $\begin{array}{c}4.61 \\
(2.13-10.01)\end{array}$ \\
\hline $\begin{array}{l}\text { HBV infected } \\
\text { other family } \\
\text { member }\end{array}$ & Yes (vs No/Unknown) & $1.35(0.39)$ & .004 & $3.86(1.80-8.30)$ \\
\hline $\begin{array}{l}\text { Gynaecological } \\
\text { examination in } \\
\text { Turkey or unsafe }\end{array}$ & Yes (vs No) & $0.41(0.19)$ & .032 & $1.51(1.04-2.21)$ \\
\hline
\end{tabular}




\begin{tabular}{l|l|l|l|l}
\hline $\begin{array}{l}\text { male } \\
\text { circumcision }\end{array}$ & & & \\
\hline $\begin{array}{l}\text { Dental treatment } \\
\text { in Turkey }\end{array}$ & Yes (vs No) & $0.40(0.20)$ & .049 & $1.50(1.01-2.21)$ \\
\hline $\begin{array}{l}\text { Treatment with } \\
\text { needles in Turkey }\end{array}$ & Yes (vs No) & $0.49(0.19)$ & .012 & $1.63(1.13-2.36)$ \\
\hline
\end{tabular}

Abbreviations: GEE: generalized estimating equations; SE: standard error; aOR: adjusted odds ratio; CI: confidence interval; HBV: hepatitis B virus; FGM: first-generation migrants; SGM: second-generation migrants. First-generation migrants: foreign-born individuals; second-generation migrants: individuals born in Belgium with foreign-born parents; unsafe male circumcision: collective circumcision and/or circumcision not carried out by medical doctor.

Multiple GEE analyses were also conducted for males and females separately as well as for FGM and SGM (Supplementary file S5.1 - 5.4). The final model for males and females included age $(p=.006$ and $p<.001)$, FGM $(p<.001$ and $p<.001)$ and treatment with needles in Turkey $(p=.030$ and $p=.003)$. In males, HBV infected siblings $(p=.022)$ and circumcision not conducted by a medical doctor were additional independent risk factors.

Independent risk factors for recent or past HBV infection among FGM included age ( $p<$ $.001)$, HBV infected mother $(p=.042)$, HBV infected siblings $(p=.024)$, gynaecological examination in Turkey or unsafe male circumcision $(p<.001)$, and treatment with needles in Turkey $(p=.003)$. Among SGM, risk factors included HBV infected other family member $(p=.010)$ and treatment with needles in Turkey $(p=.030)$.

Sixty-five patients with past or recent HBV infection had a family member with HBV infection: among seven (10.8\%) patients only the partner was infected, 14 (21.5\%) with HBV infected mother only, one (1.5\%) with HBV infected father only, 16 (24.6\%) with HBV infected siblings only, 19 (29.2\%) had another family member with HBV infection, three (4.6\%) with HBV infection among mother and siblings, one (1.5\%) with HBV infected father and siblings, and four (6.2\%) with HBV infected siblings and other family member. Therefore HBV infected mother could potentially explain 17/65 (26.2\%) anti-HBc positive cases with a positive family history of HBV infection. 


\section{Chronic HBV infection}

Of the $26 \mathrm{HBsAg}$ positive individuals, 19 were FGM, leading to a HBsAg prevalence of $3.0 \%$ $(19 / 628)$ in FGM. Compared to females, male FGM had a higher prevalence of chronic HBV infection $(5.5 \%(15 / 272)$ in males vs $1.1 \%(4 / 356)$ in females, $p=.002)$.

Gender difference regarding chronic HBV infection was not seen in Turkish SGM, i.e. 1.5\% $(3 / 196)$ in males vs $1.6 \%(4 / 257)$ in females, $p=1.000$. Overall, $1.5 \%(7 / 453)$ SGM were HBsAg positive; only one out of seven HBsAg positive SGM was born after 1987 . This corresponds to a HBsAg positivity of $0.5 \%(1 / 190)$ and $2.3 \%(6 / 263)$ in those born after and before 1987, respectively, $p=.135$. All but one had HBV infection in the family: one with HBV infection in mother only, two with HBV infection in siblings only, one with HBV infection in another family member only and two with HBV infection in siblings and another family member.

Supplementary file S5. 5 shows factors associated with chronic HBV infection in the weighted univariate GEE. From the weighted multiple GEE analyses as shown in Table 5.4, it can be seen that older age $(p=.022)$ and gynaecological examination in Turkey or unsafe male circumcision ( $p=.004)$ significantly increased the odds, while body piercing/tattooing/earlobe perforation in Turkey resulted in a lower odds of chronic HBV infection $(p=.009)$. 
Table 5.4: Association of chronic HBV infection to different risk factors among the total study population ( $n=1,081)$ (weighted multiple GEE)

\begin{tabular}{|c|c|c|c|c|}
\hline Parameter & & $\begin{array}{c}\text { Estimate } \\
\text { (SE) }\end{array}$ & $\begin{array}{c}P \\
\text { Value }\end{array}$ & $\begin{array}{c}\text { aOR } \\
(95 \% \mathrm{CI})\end{array}$ \\
\hline (intercept) & & $-5.28(0.65)$ & & \\
\hline Age group & $\begin{array}{l}40-59 \text { years (vs } 18-39 \\
\text { years) } \\
\geq 60 \text { years (vs } 18-39 \\
\text { years) }\end{array}$ & $\begin{array}{l}1.28(0.64) \\
1.49(0.81)\end{array}$ & .022 & $\begin{array}{c}3.59 \\
(1.03-12.48) \\
4.45 \\
(0.90-21.92)\end{array}$ \\
\hline $\begin{array}{l}\text { Gynaecological } \\
\text { examination in } \\
\text { Turkey or unsafe } \\
\text { male circumcision }\end{array}$ & Yes (vs No) & $1.48(0.46)$ & .004 & $\begin{array}{c}4.37 \\
(1.78-10.71)\end{array}$ \\
\hline $\begin{array}{l}\text { Body } \\
\text { piercing/tattooing/ } \\
\text { earlobe perforation } \\
\text { in Turkey }\end{array}$ & Yes (vs No) & $-1.13(0.57)$ & .009 & $\begin{array}{c}0.32 \\
(0.11-0.99)\end{array}$ \\
\hline
\end{tabular}

Abbreviations: GEE: generalized estimating equations; SE: standard error; aOR: adjusted odds ratio; CI: confidence interval. Unsafe male circumcision: collective circumcision and/or circumcision not carried out by medical doctor.

\section{FOLLOW-UP IN PATIENTS WITH CHRONIC HBV INFECTION}

Eleven of 26 chronically infected patients were unaware of their HBV status and the other 15 were already linked to care (Figure 5.1). Thus, the percentage of newly diagnosed HBsAg positive patients was $1.02 \%(11 / 1,081)$. Two patients were referred to another hospital, one could not be linked to care due to incorrect contact details and the remaining eight patients were seen at the Department of Gastroenterology and Hepatology of Hospital EastLimburg.

Out of the 15 patients that were already linked to care, 11 were classified as HBeAg-negative chronic infection, three as HBeAg-negative chronic hepatitis and one with HBeAg-positive chronic hepatitis. Both patients referred to another hospital and the eight patients evaluated in our hospital were categorized into two groups according to the HBV DNA ( $\geq 2,000 \mathrm{IU} / \mathrm{mL}$ vs $<2,000 \mathrm{IU} / \mathrm{mL}$ ) and ALT level (> $40 \mathrm{IU} / \mathrm{L}$ vs $\leq 40 \mathrm{IU} / \mathrm{L}$ ) at the first visit (Figure 5.1). There was no evidence of cirrhosis or HCC on abdominal ultrasound. Advanced liver disease was suspected in one patient based on transient elastography value $\geq 10 \mathrm{kPa}$. However, 
liver biopsy revealed F1 (portal fibrosis without septa) and the presence of nonalcoholic steatohepatitis (NASH). Within one year follow-up, none of the ten newly HBsAg positive patients had an indication for antiviral treatment. Two patients were lost to follow-up after the first visit for reasons unknown.

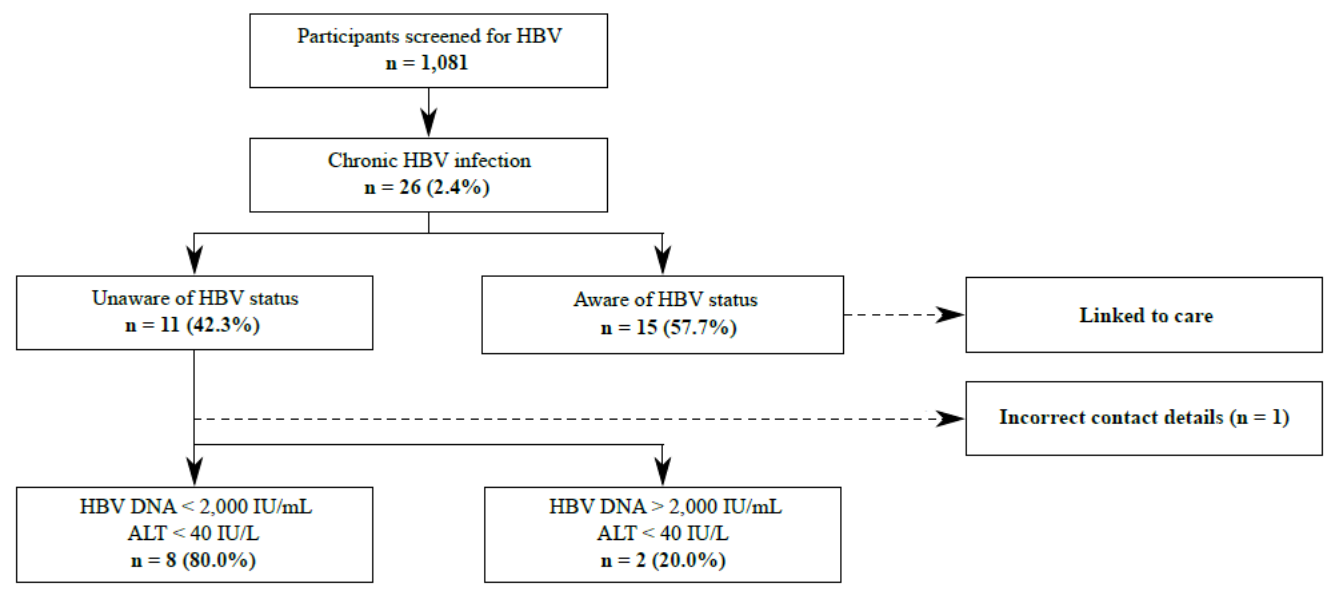

Figure 5.1: Follow-up results in patients with chronic HBV infection. Abbreviations: HBV: hepatitis B virus; ALT: alanine aminotransferase.

\section{SOLELY ANTI-HBS POSITIVE}

Regarding our question on HBV vaccination, a total of $22.2 \%(239 / 1,076)$ indicated to be vaccinated, $26.9 \%(289 / 1,076)$ were not vaccinated and history of HBV vaccination was unknown in the remaining 50.9\% $(548 / 1,076)$ participants. Among those with a history of vaccination ( $n=239), 29(12.1 \%)$ and 1 (0.4\%) were anti-HBc positive and HBsAg positive, respectively.

Solely anti-HBs positivity in Turkish SGM born after 1987 was 72.1\% (137/190), and was lower for those SGM born before 1987 (21.5\%, 56/261), $p<.001$. Supplementary file S5.6 shows factors associated with vaccination status in the weighted univariate GEE. For solely anti-HBs positivity (i.e. vaccination status), the final model included gender $(p=.008)$, age group $(p<.001)$, ethnicity $(p<.001)$, mother's educational level $(p=.007)$ and vaccination history $(p<.001)$ (Table 5.5). 
Table 5.5: Association of vaccination status (solely anti-HBs positive) to different risk factors among the total study population with information on anti-HBs $(n=1,077)$ (weighted multiple GEE)

\begin{tabular}{|c|c|c|c|c|}
\hline Parameter & & $\begin{array}{l}\text { Estimate } \\
\text { (SE) }\end{array}$ & $\begin{array}{c}P \\
\text { Value }\end{array}$ & $\begin{array}{c}\text { aOR (95\% } \\
\text { CI) }\end{array}$ \\
\hline (intercept) & & $1.50(0.69)$ & & \\
\hline Gender & Male (vs Female) & $-0.54(0.20)$ & .008 & $\begin{array}{c}0.58 \\
(0.39-0.86)\end{array}$ \\
\hline Age group & $\begin{array}{l}40-59 \text { years (vs } 18-39 \\
\text { years) } \\
\geq 60 \text { years (vs } 18-39 \\
\text { years) }\end{array}$ & $\begin{array}{l}-1.30(0.23) \\
-1.74(0.54)\end{array}$ & $<.001$ & $\begin{array}{c}0.27 \\
(0.18-0.43) \\
0.18 \\
(0.06-0.51)\end{array}$ \\
\hline Ethnicity & FGM (vs SGM) & $-1.18(0.22)$ & $<.001$ & $\begin{array}{c}0.31 \\
(0.20-0.47)\end{array}$ \\
\hline $\begin{array}{l}\text { Mother's } \\
\text { educational level }\end{array}$ & $\begin{array}{l}\text { None (vs High } \\
\text { school/University) } \\
\text { Primary (vs High } \\
\text { school/University) } \\
\text { Secondary (vs High } \\
\text { school/University) }\end{array}$ & $\begin{array}{l}-1.51(0.68) \\
-1.23(0.68) \\
-0.61(0.69)\end{array}$ & .007 & $\begin{array}{c}0.22 \\
(0.06-0.83) \\
0.29 \\
(0.08-1.11) \\
0.54 \\
(0.14-2.11)\end{array}$ \\
\hline Vaccination history & $\begin{array}{l}\text { Not vaccinated/Unknown } \\
\text { (vs Vaccinated) }\end{array}$ & $-1.90(0.21)$ & $<.001$ & $\begin{array}{c}0.15 \\
(0.10-0.22)\end{array}$ \\
\hline
\end{tabular}

Abbreviations: GEE: generalized estimating equations; SE: standard error; aOR: adjusted odds ratio; CI: confidence interval; FGM: first-generation migrants; SGM: second-generation migrants. Firstgeneration migrants: foreign-born individuals; second-generation migrants: individuals born in Belgium with foreign-born parents; unsafe male circumcision: collective circumcision and/or circumcision not carried out by medical doctor. 


\section{SUSCEPTIBLE FOR HBV INFECTION}

Six months after the last inclusion, 19.1\% (44/230 susceptible individuals with follow-up information on vaccination) of the participants susceptible for HBV infection initiated vaccination. 


\section{DISCUSSION}

In addition to the screening of FGM, i.e. those bom in Turkey, our study is one of the first hepatitis B screening projects in Europe targeting a substantial proportion of SGM, i.e. those born in Belgium with a foreign-born parent. First, we show that outreach testing was wellaccepted in Turkish migrants. Although Turkish migrants could opt for screening during home visits or at the hepatology outpatient clinic, the majority (97\%) were tested immediately after educational sessions in Islamic mosques and Turkish organizations.

Our finding of 3\% HBsAg positivity in Turkish FGM is in line with previous findings reported in the Netherlands and Germany (HBsAg prevalence varying from $3-5 \%$ ), and reflects the high prevalence in the country of origin. ${ }^{80}, 184,185,193$ However, the $1.5 \%$ prevalence of chronic HBV infection in Turkish SGM is higher than the reported $0.7 \% \mathrm{HBsAg}$ prevalence in native Belgians. ${ }^{130-132}$ This finding is novel and might in part be explained by the interaction of high prevalence in the country of origin and suboptimal coverage by primary prevention strategies in the country of birth. None of the seven cases of SGM with chronic HBV infection in our study were born after 1999, which is the year universal HBV vaccination in infants was implemented in Belgium. However, although six HBsAg positive SGM were born before 1987, one was born between 1987 and 1999, a birth cohort that should have been covered by the catch-up vaccination in 10 - 13 year-olds since 1999. In this matter, lowest immunization coverage rates in Belgium were found in those born between 1990 and 1998. ${ }^{134}$ Moreover, prior studies indicated that non-European origin and low educational level of the mother were associated with a decreased odds of vaccination coverage in children. ${ }^{144,194}$ In our study, mother's educational level was associated with vaccination coverage.

In our Turkish migrant study population, HBV infection in the mother could potentially explain less than one third of the patients with past or recent HBV infection. HBV infection in siblings possibly accounted for another major part of past or recent HBV infection in our study. In Turkey, perinatal transmission of HBV infection is uncommon as HBeAg positivity in pregnant chronic HBV patients is very low. ${ }^{174}$ The infection is mostly acquired in childhood through horizontal transmission, i.e. that occurring through non-sexual and non-parenteral contact beyond six months of age, in childhood and pre-adolescent period. ${ }^{174,}{ }^{189}$ In the Turkish families, most of the mothers are housewives and mostly stay at home as caretakers for the children. Although the mother is important for horizontal HBV transmission through non-sexual close contact, sibling-to-sibling horizontal transmission 
might also be an important route of HBV infection. ${ }^{195-197}$ Siblings share the same environment, experience the same cultural and family traditions, which may be associated with increased risks of transmission.

Physicians from countries with a selective vaccination program targeting groups at risk of HBV infection only, instead of adding a universal vaccination program, should be aware of horizontal transmission through non-sexual close contact. ${ }^{45}$ Children are more likely to have contact with each other's body fluid and are therefore at risk of horizontal transmission through non-sexual close contact. Skin lesions or sharing contaminated material such as towels, toothbrushes or razor blades has been shown to play a role in horizontal transmission through non-sexual close contact. ${ }^{174}$ In this matter, sharing toothbrushes regularly was univariately associated with past or recent HBV infection in our study population. However, this association diminished when accounting for other risk factors. The most important independent risk factors for past or recent HBV infection found in our study were male gender, older age, being a FGM, low educational level of the mother, a family history of HBV infection, gynaecological examination in Turkey or unsafe male circumcision, dental treatment in Turkey and treatment with needles in Turkey. These findings are in line with previous studies conducted in Turkish migrants living in Europe and studies conducted in Turkey. ${ }^{174,184,185,193,195}$

For a screening program aimed at secondary prevention of HBV infection, access to care is inevitable to reduce the economic burden of HBV-related complications. In Greece, it is estimated that less than half of the patients diagnosed with HBV were referred and received the appropriate care. ${ }^{198}$ This number was between $40 \%$ and $66 \%$ in the USA. ${ }^{199}$ Most screening projects provide data on the HBsAg prevalence but do not assess referral, disease stage and initiation of antiviral therapy. We showed a successful referral of more than $90 \%$ newly diagnosed patients with chronic HBV infection. The implementation of a pre-screening phase with awareness activities among general practitioners and delegates of Turkish organizations as well as the impact of educational meetings on the Turkish migrant population to make an informed decision to participate in screening, might explain the good compliance to referral. ${ }^{81}$ Within one year of follow-up, all newly diagnosed patients had HBeAg-negative chronic infection based on normal ALT levels, low HBV DNA levels, HBeAg negative status and no significant fibrosis. ${ }^{7}$ During follow-up, none had an indication for antiviral therapy, but continued monitoring was still recommended for risk of HBV 
reactivation, advanced liver disease and $\mathrm{HCC}$, especially those with HBV DNA levels $>2,000$ $\mathrm{IU} / \mathrm{mL} .{ }^{7,59,171}$

Less than one in five susceptible individuals initiated hepatitis B vaccination. This is lower than the reported $52-89 \%$ among migrant populations in the USA and might be explained by 1 ) dissimilar populations, 2 ) free of charge vaccination or vaccination at a reduced price and 3) the use of a combination of letters, phone calls, e-mail and in-person appointments to contact susceptible individuals for vaccination in these studies. ${ }^{81,83,200-203}$ This is in contrast to our study, in which susceptible individuals were invited by a letter to consult their general practitioner for hepatitis B vaccination in accordance with standard practices in Belgium. The uptake of vaccination was also low (22\%) in an outreach screening project among Chinese migrants in the Netherlands. ${ }^{204}$

\section{CONCLUSION}

In conclusion, we found that outreach testing and referral to specialist care was clinically effective in the Turkish migrant population. We confirmed that HBV prevalence among Turkish FGM reflects the high prevalence in the country of origin. An important finding was the relatively high infection prevalence in Turkish SGM compared with prevalence estimates for the general population in Belgium and other European countries. Given WHO's ambitious goal to eliminate viral hepatitis by 2030, national HBV screening for Turkish FGM should be implemented and might be considered in SGM not covered by primary prevention strategies, taking into account the asymptomatic nature of disease and misleading normal levels of ALT. Screening projects aimed at SGM are needed to further inform future screening policies for this population. 
SUPPLEMENTARY FILES

Table S 5.1: Association of past or recent hepatitis B virus infection to different risk factors among the male study population $(n=468)$ (weighted GEE model)

\begin{tabular}{|c|c|c|c|c|}
\hline Parameter & & Estimate (SE) & $\begin{array}{c}P \\
\text { Value }\end{array}$ & aOR (95\% CI) \\
\hline (intercept) & & $-2.38(0.51)$ & & \\
\hline Age group & $\begin{array}{l}40-59 \text { years (vs } 18- \\
39 \text { years) } \\
\geq 60 \text { years (vs } 18-39 \\
\text { years) }\end{array}$ & $\begin{array}{l}0.93(0.40) \\
1.64(0.49)\end{array}$ & .006 & $\begin{array}{c}2.53(1.15-5.56) \\
5.15(1.96-13.58)\end{array}$ \\
\hline Ethnicity & FGM (vs SGM) & $1.62(0.37)$ & $<.001$ & $5.05(2.43-10.49)$ \\
\hline $\begin{array}{l}\text { HBV infected } \\
\text { siblings }\end{array}$ & Yes (vs No/Unknown) & $2.35(0.97)$ & .022 & $10.43(1.55-70.24)$ \\
\hline $\begin{array}{l}\text { Circumcision } \\
\text { not carried } \\
\text { out by } \\
\text { medical } \\
\text { doctor }\end{array}$ & Yes (vs No) & $0.98(0.35)$ & .004 & $2.67(1.34-5.35)$ \\
\hline $\begin{array}{l}\text { Treatment } \\
\text { with needles } \\
\text { in Turkey }\end{array}$ & Yes (vs No) & $0.63(0.28)$ & .030 & $1.88(1.08-3.28)$ \\
\hline
\end{tabular}

Abbreviation: GEE: generalized estimating equations; SE: standard error; aOR: adjusted odds ratio; CI: confidence interval; HBV: hepatitis B virus FGM: first-generation migrants; SGM: second-generation migrants. First-generation migrants: foreign-born individuals; second-generation migrants: individuals born in Belgium with foreign-born parents. 
Table S 5.2: Association of past or recent hepatitis B virus infection to different risk factors among the female study population $(n=623)$ (weighted GEE model)

\begin{tabular}{l|l|c|c|c}
\hline Parameter & Estimate (SE) & $\begin{array}{c}\boldsymbol{P} \\
\text { Value }\end{array}$ & aOR (95\% CI) \\
\hline (intercept) & & $-3.45(0.33)$ & & \\
\hline Age group & $\begin{array}{l}40-59 \text { years (vs 18 - } \\
39 \text { years) } \\
\geq 60 \text { years (vs 18 - 39 } \\
\text { years) }\end{array}$ & $1.04(0.33)$ & $2.83(1.48-5.41)$ \\
\hline Ethnicity & FGM (vs SGM) & $1.15(0.34)$ & $5.71(2.58-12.65)$ \\
\hline $\begin{array}{l}\text { Treatment } \\
\text { with needles } \\
\text { in Turkey }\end{array}$ & Yes (vs No) & $0.75(0.24)$ & .003 & $2.16(1.63-6.11)$ \\
\hline Abbrevation: GEE: & & & \\
\hline
\end{tabular}

Abbreviation: GEE: generalized estimating equations; SE: standard error; aOR: adjusted odds ratio; CI: confidence interval; FGM: first-generation migrants; SGM: second-generation migrants. First-generation migrants: foreign-born individuals; second-generation migrants: individuals born in Belgium with foreignborn parents. 
Table S 5.3: Association of past or recent hepatitis B virus infection to different risk factors among first-generation migrants $(n=628)$ (weighted GEE model)

\begin{tabular}{|c|c|c|c|c|}
\hline Parameter & & Estimate (SE) & $\begin{array}{c}P \\
\text { Value }\end{array}$ & aOR (95\% CI) \\
\hline (intercept) & & $-2.42(0.32)$ & & \\
\hline Age group & $\begin{array}{l}40-59 \text { years (vs } 18 \\
-39 \text { years) } \\
60+\text { years (vs } 18-39 \\
\text { years) }\end{array}$ & $\begin{array}{l}1.09(0.31) \\
1.77(0.34)\end{array}$ & $<.001$ & $\begin{array}{l}2.99(1.62-5.50) \\
5.84(3.01-11.34)\end{array}$ \\
\hline $\begin{array}{l}\text { HBV infected } \\
\text { mother }\end{array}$ & Yes (vs No/Unknown) & $0.92(0.42)$ & .042 & $2.51(1.10-5.70)$ \\
\hline $\begin{array}{l}\text { HBV infected } \\
\text { siblings }\end{array}$ & Yes (vs No/Unknown) & $1.05(0.42)$ & .024 & $2.86(1.26-6.49)$ \\
\hline $\begin{array}{l}\text { Gynaecological } \\
\text { examination in } \\
\text { Turkey or } \\
\text { unsafe } \\
\text { circumcision }\end{array}$ & Yes (vs No/Unknown) & $0.64(0.18)$ & $<.001$ & $1.90(1.34-2.70)$ \\
\hline $\begin{array}{l}\text { Treatment with } \\
\text { needles in } \\
\text { Turkey }\end{array}$ & Yes (vs No/Unknown) & $0.57(0.19)$ & .003 & $1.77(1.23-2.54)$ \\
\hline
\end{tabular}

Abbreviation: GEE: generalized estimating equations; SE: standard error; aOR: adjusted odds ratio; CI: confidence interval; HBV: hepatitis B virus. First-generation migrants: foreign-born individuals; unsafe circumcision: collective circumcision and/or circumcision not carried out by medical doctor. 
Table S 5.4: Association of past or recent hepatitis B virus infection to different risk factors among second-generation migrants $(n=453)$ (weighted GEE model)

\begin{tabular}{l|l|c|c|c}
\hline Parameter & $\begin{array}{c}\text { Estimate } \\
\text { (SE) }\end{array}$ & $\begin{array}{c}\boldsymbol{P} \\
\text { Value }\end{array}$ & aOR (95\% CI) \\
\hline (intercept) & $-3.75(0.34)$ & & \\
\hline $\begin{array}{l}\text { HBV infected } \\
\text { other family } \\
\text { member }\end{array}$ & Yes (vs No/Unknown) & $1.94(0.54)$ & .010 & $6.93(2.42-19.84)$ \\
\hline $\begin{array}{l}\text { Treatment } \\
\text { with needles } \\
\text { in Turkey }\end{array}$ & Yes (vs No/Unknown) & $1.22(0.44)$ & .030 & $3.38(1.43-7.97)$ \\
\hline
\end{tabular}

Abbreviation: GEE: generalized estimating equations; SE: standard error; aOR: adjusted odds ratio; CI: confidence interval; HBV: hepatitis B virus. Second-generation migrants: individuals born in Belgium with foreign-born parents. 
Table S 5.5: Prevalence of chronic hepatitis $B$ virus infection by different risk factors among the total population $(n=1,081)$ (weighted univariate GEE)

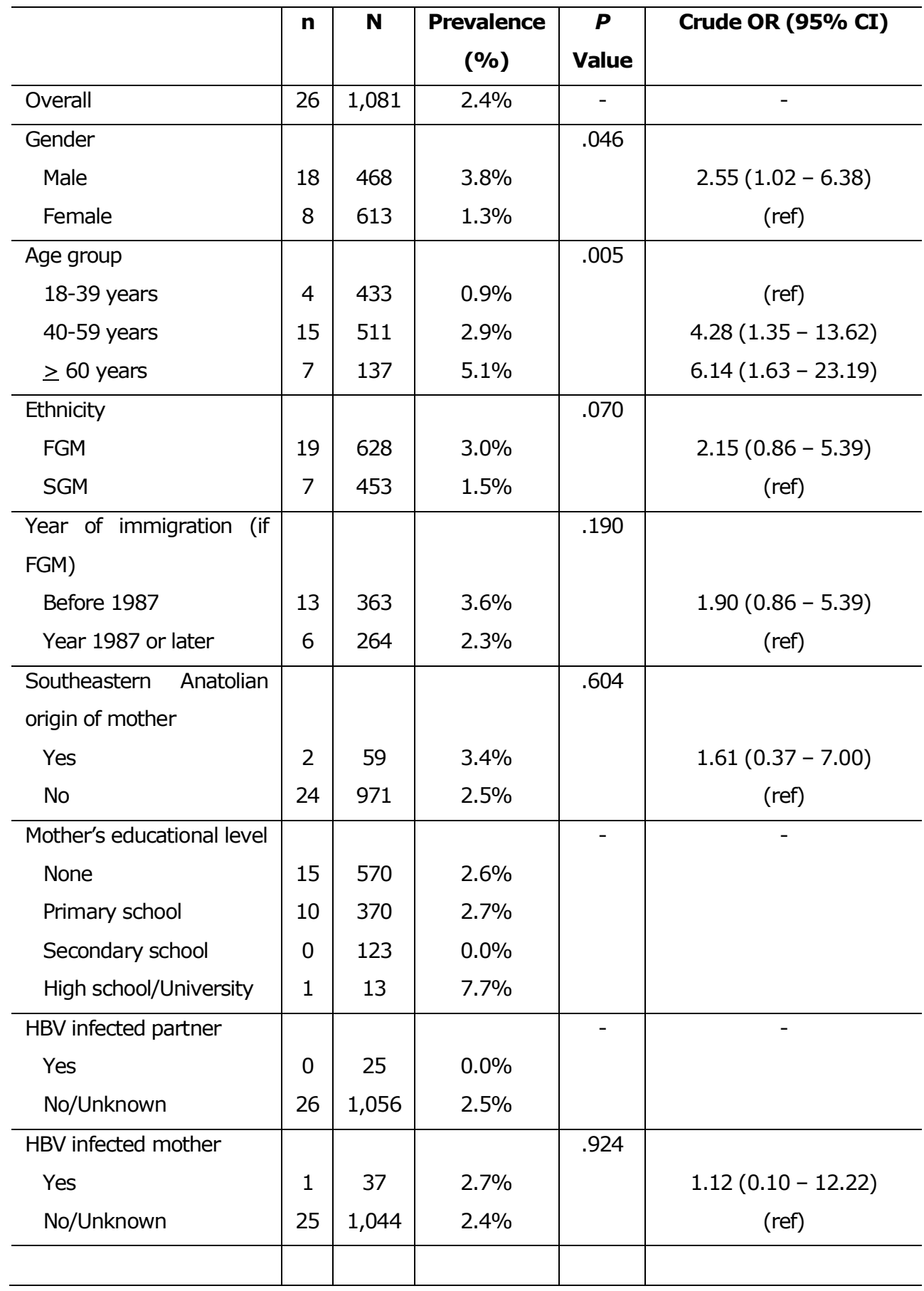




\begin{tabular}{|c|c|c|c|c|c|}
\hline $\begin{array}{l}\text { HBV infected father } \\
\text { Yes } \\
\text { No/Unknown }\end{array}$ & $\begin{array}{c}0 \\
26\end{array}$ & $\begin{array}{c}24 \\
1,057\end{array}$ & $\begin{array}{l}0.0 \% \\
2.5 \%\end{array}$ & - & - \\
\hline $\begin{array}{l}\text { HBV infected siblings } \\
\text { Yes } \\
\text { No/Unknown }\end{array}$ & $\begin{array}{c}7 \\
19\end{array}$ & $\begin{array}{c}45 \\
1,036\end{array}$ & $\begin{array}{c}15.6 \% \\
1.8 \%\end{array}$ & .025 & $\begin{array}{c}10.57(2.88-38.82) \\
(\text { ref })\end{array}$ \\
\hline $\begin{array}{l}\text { HBV infected other family } \\
\text { member } \\
\text { Yes } \\
\text { No/Unknown }\end{array}$ & $\begin{array}{c}5 \\
21\end{array}$ & $\begin{array}{c}70 \\
1,011\end{array}$ & $\begin{array}{l}7.1 \% \\
2.1 \%\end{array}$ & .111 & $\begin{array}{c}4.23(1.49-12.03) \\
(\text { ref })\end{array}$ \\
\hline $\begin{array}{l}\text { Sharing toothbrushes } \\
\text { regularly } \\
\text { Yes } \\
\text { No }\end{array}$ & $\begin{array}{c}9 \\
17\end{array}$ & $\begin{array}{l}188 \\
892\end{array}$ & $\begin{array}{l}4.8 \% \\
1.9 \%\end{array}$ & .090 & $\begin{array}{c}2.52(1.06-5.99) \\
(\text { ref })\end{array}$ \\
\hline $\begin{array}{l}\text { Sharing nail clippers } \\
\text { Yes } \\
\text { No }\end{array}$ & $\begin{array}{c}24 \\
2\end{array}$ & $\begin{array}{c}991 \\
89\end{array}$ & $\begin{array}{l}2.4 \% \\
2.2 \%\end{array}$ & .961 & $\begin{array}{c}1.04(0.24-4.49) \\
(\text { ref })\end{array}$ \\
\hline $\begin{array}{l}\text { Sharing razors } \\
\text { Yes } \\
\text { No }\end{array}$ & $\begin{array}{c}5 \\
21\end{array}$ & $\begin{array}{l}170 \\
910\end{array}$ & $\begin{array}{l}2.9 \% \\
2.3 \%\end{array}$ & .602 & $\begin{array}{c}1.37(0.46-4.06) \\
(\text { ref })\end{array}$ \\
\hline $\begin{array}{l}\text { Sharing used towels } \\
\text { Yes } \\
\text { No }\end{array}$ & $\begin{array}{c}22 \\
4\end{array}$ & $\begin{array}{l}945 \\
135\end{array}$ & $\begin{array}{l}2.3 \% \\
3.0 \%\end{array}$ & .804 & $\begin{array}{c}0.86(0.28-2.69) \\
(\text { ref })\end{array}$ \\
\hline $\begin{array}{l}\text { Eating from the same } \\
\text { plate at least once } \\
\text { Yes } \\
\text { No }\end{array}$ & $\begin{array}{c}23 \\
3\end{array}$ & $\begin{array}{l}927 \\
153\end{array}$ & $\begin{array}{l}2.5 \% \\
2.0 \%\end{array}$ & .708 & $\begin{array}{c}1.25(0.36-4.34) \\
(\text { ref })\end{array}$ \\
\hline $\begin{array}{l}\text { Gynaecological } \\
\text { examination in Turkey (if } \\
\text { female) } \\
\text { Yes } \\
\text { No }\end{array}$ & 7 & $\begin{array}{c}99 \\
514\end{array}$ & $\begin{array}{l}1.0 \% \\
1.4 \%\end{array}$ & .896 & $\begin{array}{c}1.10(0.26-4.67) \\
(\text { ref })\end{array}$ \\
\hline $\begin{array}{l}\text { Circumcision (if male) } \\
\text { Collective } \\
\text { Alone }\end{array}$ & 8 & $\begin{array}{l}118 \\
305\end{array}$ & $\begin{array}{l}6.8 \% \\
3.0 \%\end{array}$ & .105 & $\begin{array}{c}2.62(0.97-7.12) \\
(\text { ref })\end{array}$ \\
\hline
\end{tabular}




\begin{tabular}{|c|c|c|c|c|c|}
\hline $\begin{array}{l}\text { Circumcision not carried } \\
\text { out by medical doctor (if } \\
\text { male) } \\
\text { Yes } \\
\text { No }\end{array}$ & $\begin{array}{c}17 \\
0\end{array}$ & $\begin{array}{l}228 \\
153\end{array}$ & $\begin{array}{l}7.5 \% \\
0.0 \%\end{array}$ & - & - \\
\hline $\begin{array}{l}\text { Gynaecological } \\
\text { examination in Turkey or } \\
\text { unsafe circumcision } \\
\text { Yes } \\
\text { No }\end{array}$ & $\begin{array}{c}18 \\
8\end{array}$ & $\begin{array}{l}330 \\
751\end{array}$ & $\begin{array}{l}5.5 \% \\
1.1 \%\end{array}$ & .001 & $\begin{array}{c}6.93(2.71-17.75) \\
(\text { ref })\end{array}$ \\
\hline $\begin{array}{l}\text { Blood transfusion } \\
\text { Yes } \\
\text { No }\end{array}$ & $\begin{array}{c}4 \\
22\end{array}$ & $\begin{array}{l}167 \\
914\end{array}$ & $\begin{array}{l}2.4 \% \\
2.4 \%\end{array}$ & .845 & $\begin{array}{c}1.12(0.35-3.58) \\
\text { (ref) }\end{array}$ \\
\hline $\begin{array}{l}\text { Dental treatment in } \\
\text { Turkey } \\
\text { Yes } \\
\text { No }\end{array}$ & $\begin{array}{c}17 \\
9\end{array}$ & $\begin{array}{l}430 \\
651\end{array}$ & $\begin{array}{l}4.0 \% \\
1.4 \%\end{array}$ & .017 & $\begin{array}{c}2.84(1.23-6.60) \\
(\text { ref })\end{array}$ \\
\hline $\begin{array}{l}\text { Surgery in Turkey } \\
\text { Yes } \\
\text { No }\end{array}$ & $\begin{array}{c}6 \\
20\end{array}$ & $\begin{array}{l}133 \\
948\end{array}$ & $\begin{array}{l}4.5 \% \\
2.1 \%\end{array}$ & .183 & $\begin{array}{c}2.30(0.91-5.81) \\
(\text { ref })\end{array}$ \\
\hline $\begin{array}{l}\text { Treatment with needles in } \\
\text { Turkey } \\
\text { Yes } \\
\text { No }\end{array}$ & $\begin{array}{l}11 \\
15\end{array}$ & $\begin{array}{l}322 \\
759\end{array}$ & $\begin{array}{l}3.4 \% \\
2.0 \%\end{array}$ & .141 & $\begin{array}{c}2.06(0.89-4.80) \\
(\text { ref })\end{array}$ \\
\hline $\begin{array}{l}\text { Body } \\
\text { piercing/tattooing/earlobe } \\
\text { perforation in Turkey } \\
\text { Yes } \\
\text { No }\end{array}$ & $\begin{array}{c}4 \\
22\end{array}$ & $\begin{array}{l}327 \\
754\end{array}$ & $\begin{array}{l}1.2 \% \\
2.9 \%\end{array}$ & .038 & $\begin{array}{c}0.38(0.12-1.18) \\
(\text { ref })\end{array}$ \\
\hline $\begin{array}{l}\text { Fish spa treatment in } \\
\text { Turkey } \\
\text { Yes } \\
\text { No }\end{array}$ & 26 & $\begin{array}{c}64 \\
1,017\end{array}$ & $\begin{array}{l}0.0 \% \\
2.6 \%\end{array}$ & - & - \\
\hline
\end{tabular}

Abbreviation: OR: odds ratio; CI: confidence interval; FGM: first-generation migrants; SGM: secondgeneration migrants. First-generation migrants: foreign-born individuals; second-generation migrants: individuals born in Belgium with foreign-born parents; unsafe circumcision: collective circumcision and/or circumcision not carried out by medical doctor. 
Table S 5.6: Vaccination status (solely anti-HBs positive) by different risk factors among the total population with information on anti-HBs $(n=1,077)$ (weighted univariate GEE)

\begin{tabular}{|c|c|c|c|c|c|}
\hline & $\mathbf{n}$ & $\mathbf{N}$ & $\begin{array}{c}\text { Prevalence } \\
(\%)\end{array}$ & $\begin{array}{c}P \\
\text { Value }\end{array}$ & $\begin{array}{c}\text { Crude OR (95\% } \\
\text { CI) }\end{array}$ \\
\hline Overall & 247 & 1,077 & $22.9 \%$ & - & - \\
\hline Gender & & & & .006 & \\
\hline Male & 84 & 466 & $18.0 \%$ & & $0.67(0.50-0.89)$ \\
\hline Female & 163 & 611 & $26.7 \%$ & & (ref) \\
\hline Age group & & & & $<.001$ & \\
\hline $18-39$ years & 195 & 432 & $45.1 \%$ & & (ref) \\
\hline 40-59 years & 47 & 509 & $9.2 \%$ & & $0.12(0.08-0.17)$ \\
\hline$\geq 60$ years & 5 & 136 & $3.7 \%$ & & $0.04(0.02-0.11)$ \\
\hline Ethnicity & & & & $<.001$ & \\
\hline FGM & 54 & 626 & $8.6 \%$ & & $0.13(0.09-0.18)$ \\
\hline SGM & 193 & 451 & $42.8 \%$ & & (ref) \\
\hline $\begin{array}{l}\text { Year of immigration (if } \\
\text { FGM) }\end{array}$ & & & & .005 & \\
\hline Before 1987 & 22 & 361 & $6.1 \%$ & & $0.38(0.21-0.70)$ \\
\hline Year 1987 or later & 32 & 264 & $12.1 \%$ & & (ref) \\
\hline Mother's educational level & & & & $<.001$ & \\
\hline None & 67 & 567 & $11.8 \%$ & & $0.05(0.02-0.18)$ \\
\hline Primary school & 102 & 369 & $27.6 \%$ & & $0.13(0.04-0.46)$ \\
\hline Secondary school & 68 & 123 & $55.3 \%$ & & $0.40(0.11-1.43)$ \\
\hline High school/University & 9 & 13 & $69.2 \%$ & & (ref) \\
\hline Vaccination history & & & & $<.001$ & \\
\hline Not vaccinated/Unknown & 108 & 837 & $12.9 \%$ & & $0.11(0.08-0.15)$ \\
\hline Vaccinated & 139 & 239 & $58.2 \%$ & & (ref) \\
\hline
\end{tabular}

Abbreviation: OR: odds ratio; CI: confidence interval; FGM: first-generation migrants; SGM: secondgeneration migrants. First-generation migrants: foreign-born individuals; second-generation migrants: individuals born in Belgium with foreign-born parents; unsafe circumcision: collective circumcision and/or circumcision not carried out by medical doctor. 




\section{CHAPTER 6}

\section{Safety and immunogenicity of HBAI20 vaccine in healthy naïve and nonresponding adults}

Koc ÖM, Savelkoul PHM, van Loo IHM, Peeters A, Oude Lashof AML

J Viral Hepat, September 2018, 25(9):1048-56. 


\section{ABSTRACT}

Background: Approximately $5 \%$ of the healthy adult population respond inadequately to the commercial recombinant hepatitis B vaccines. As the recombinant vaccines all have an aluminium-based adjuvant, we tried to enhance the immune response by adding a cytokine-based adjuvant. This new adjuvant AI20, containing $20 \mu \mathrm{g}$ recombinant human $\mathrm{IL}-2$ attached to $20 \mu \mathrm{g}$ aluminium hydroxide, was added to HBVaxPro@- $-10 \mu \mathrm{g}$ (HBAI20).

Methods: In a double-blind randomized controlled trial (RCT), 24 naïve subjects were randomized to receive either HBAI20 or commercial HBVaxPro@- $10 \mu \mathrm{g}$ vaccine. In an openlabel study, 10 nonresponders received HBAI20 vaccine. All participants received 3 vaccinations (0, 1 and 6 months).

Results: In the RCT, the occurrence of any adverse events or severe events was similar between the trial arms. At month 7, all naïve participants were seroprotected; moreover, $92 \%$ in the HBAI20 group had protective antibodies 10 days after the second vaccination vs $58 \%$ in the HBVaxPro@ $-10 \mu$ group, $\mathrm{P}=.16$. In the open-label study, no serious adverse events were noted. The HBAI20 vaccine was able to elicit protective anti-HBs titres in $90 \%$ of nonresponders, 1 month after the third vaccination.

Conclusions: According to these results, the new HBAI20 vaccine seems safe, welltolerated and may promote more rapid protection against hepatitis B infection. 


\section{INTRODUCTION}

Hepatitis B virus (HBV) infection is still a constant and serious threat to world health. According to the World Health Organization (WHO), one third of the world's population has been infected with HBV, and more than 240 million suffer from chronic hepatitis B infection. ${ }^{57}$ It is estimated that $15-40 \%$ of patients with hepatitis B will develop cirrhosis, liver failure or hepatocellular carcinoma, thus creating a significant burden to healthcare systems due to high morbidity, mortality and costs of treatment. ${ }^{172,205}$

Hepatitis $B$ vaccination remains the best tool to prevent $\mathrm{HBV}$ infection and its complications. During the past two decades, universal implementation of HBV vaccine programs led to a dramatic decrease in the incidence of HBV infection and a subsequent decrease in hepatocellular carcinoma. ${ }^{206,} 207$ Currently available HBV vaccines in Europe and North America are formulated with recombinant hepatitis B surface antigen adsorbed to aluminum hydroxide or aluminum phosphate adjuvant. However, after a standard three-dose vaccination regimen, approximately $5 \%$ of vaccinated healthy adults have an inadequate antibody response (anti-HBs titre $<10 \mathrm{mIU} / \mathrm{mL}$ ). ${ }^{208-212}$ In the Netherlands, the vaccination schedule is stopped after a total of six hepatitis B vaccinations when development of protective antibodies is lacking. The persons with this deficient antibody response are so called true non-responders. Risk factors for non-response include age $>40$, smoking, obesity, male sex, and immunodeficiency. ${ }^{213,214}$ In addition, genetic factors are most likely involved. ${ }^{102}$ Thus, there appears to be a medical need for a more immunogenic hepatitis $B$ vaccine to develop an adequate antibody response.

One way to improve the immunogenicity to the current HBV vaccines is to enhance the adjuvant. Adjuvants are thought to improve immune response by (1) causing depot formation at the injection site; (2) increasing interaction between immunogen and antigen presenting cell and (3) improving antigen presentation to T-cells, overall producing a more targeted immune response. ${ }^{215}$

As the recombinant HBV vaccines all have an aluminum-based adjuvant, we tried to enhance the immune response by adding a cytokine-based adjuvant. This new adjuvant AI20, containing $20 \mu \mathrm{g}$ recombinant human IL-2 attached to $20 \mu \mathrm{g}$ aluminum hydroxide

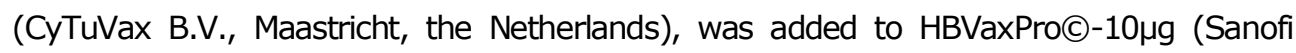
Pasteur MSD, Haarlem, the Netherlands). This combined vaccine is called HBAI20. 
In this study, we assessed the safety and immunogenicity of the HBAI20 vaccine in a randomized controlled trial (RCT) in naïve participants and in an open-label study in true non-responders. 


\section{MethODS}

\section{PARTICIPANTS}

This phase I study involved two trials: a double-blinded RCT in naïve participants and an open-label study in a cohort of true non-responders. At the first visit, a physical examination was performed and blood and urine sampling were taken, and informed written consent was required to participate in the study. For the RCT, a total of 27 participants were screened and three naïve participants were excluded for the following reasons: one with liver function test abnormalities, one with anti-HBs titre $>10 \mathrm{mIU} / \mathrm{mL}$ and one had a suspicion of Cushing's syndrome. As such, we included 24 healthy HBV vaccine naïve volunteers in the RCT. In the open-label study we screened and included 10 true non-responders. True nonresponders had to have received at least six HBV vaccinations with a documented non response (anti-HBs $<10 \mathrm{mIU} / \mathrm{mL}$ ) within six to eight weeks after the last vaccination. All participants were between 18 and 59 years of age.

The study was approved by the local ethics committee and was conducted in accordance with the provisions of the Declaration of Helsinki and its amendments. Good clinical practice guidelines were followed throughout the study. The study is registered at clinicaltrials.gov (NCT02540538).

Exclusion criteria for participation in both the RCT and open-label study were: seropositivity for HBV, hepatitis C virus and/or HIV infection, a known or suspected immune deficiency, known or suspected disease that influences the immune system (e.g. cancer, transplantation recipients), known or suspected allergy to any of the vaccine components, haemodialysis, peritoneal dialysis, a history of unusual or severe reactions to any previous vaccination, a history of any neurologic disorder (e.g. epilepsy, autism), use of systemic medication that influences the immune system (e.g. immune suppressive treatment), any vaccination within three months before screening, blood donation within one month before screening, administration of plasma (including immunoglobulins) or blood products within 12 months before screening, participation in another clinical trial within three months before screening, abnormal pre-treatment laboratory parameters which are clinically relevant according to the investigator, bleeding disorders or use of medication for bleeding disorders, use of anti-coagulants, female subjects planning to become pregnant or breastfeeding babies before the last study visit, females with positive urine pregnancy test at screening date, excessive alcohol or controlled drug use. Additional exclusion criterion for participants in the RCT was a previous hepatitis B vaccination. 


\section{VACCINES}

The experimental vaccine consisted of AI20, containing 20 $\mathrm{\mu g}$ recombinant human IL-2

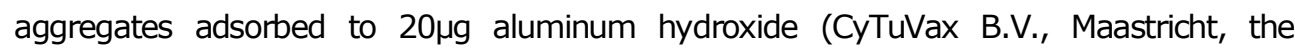

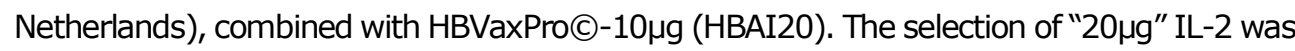
based on anti-HBs response study in BALB/C and SJL strain mice, determination of the optimal dose in Lewis rats and a toxicology study in New Zealand White rabbits. ${ }^{216}$ The control vaccine was the standard HBVaxPro@-10 $\mu$ g vaccine (Sanofi Pasteur MSD, Haarlem, the Netherlands). HBAI20 was prepared by an unblinded nurse immediately before administration. HBVaxPro@- $10 \mu$ g was added to the AI20 adjuvant, gently mixed by inversion and aspired with a needle in one syringe $(1.3 \mathrm{ml})$. The label on all vaccines conceals the volume difference between the two study vaccines. Both the HBAI20 vaccine and the HBVaxPro@-10 $\mathrm{gg}$ vaccine were injected into the deltoid muscle of the nondominant arm by a blinded nurse.

\section{STUDY DESIGN}

In the RCT, 24 healthy HBV vaccine naïve subjects were randomized in a 1:1 ratio into Group $1(n=12)$ and Group $2(n=12)$. Subjects in Group 1 received the HBAI20 vaccine at 0 and one month. The third vaccination, six months after the initial vaccination, consisted of the HBVaxProC-10 $\mu \mathrm{g}$ since data concerning shelf life of AI20 adjuvant after three months were not yet present at the time of the study. Subjects in Group 2 received the standard HBVaxPro@- $10 \mu \mathrm{g}$ vaccine at 0 , one and six months. Randomisation was performed by the ALEA screening and Enrolment Application Software of Formvision BV (Abcoude, the Netherlands). Minimisation of stratification factors age and gender were performed.

In the open-label study, $10 \mathrm{HBV}$ vaccine true non-responders received the HBAI20 vaccine at 0 and one month and the HBVaxPro@-10 $\mathrm{\mu g}$ vaccine six months after the initial vaccination.

All vaccines were given as intramuscular injections into the deltoid muscle of the nondominant arm. Vaccination response (anti-HBs titre) was evaluated 10 and 30 days after the first vaccination, 10 and 30 days after the second vaccination, on the day of third vaccination and 30 days after the third vaccination. Next to this, at each visit after the first vaccination, haematological and biochemical parameters were evaluated for safety reasons. Figure 6.1 illustrates the flowchart of the study. 


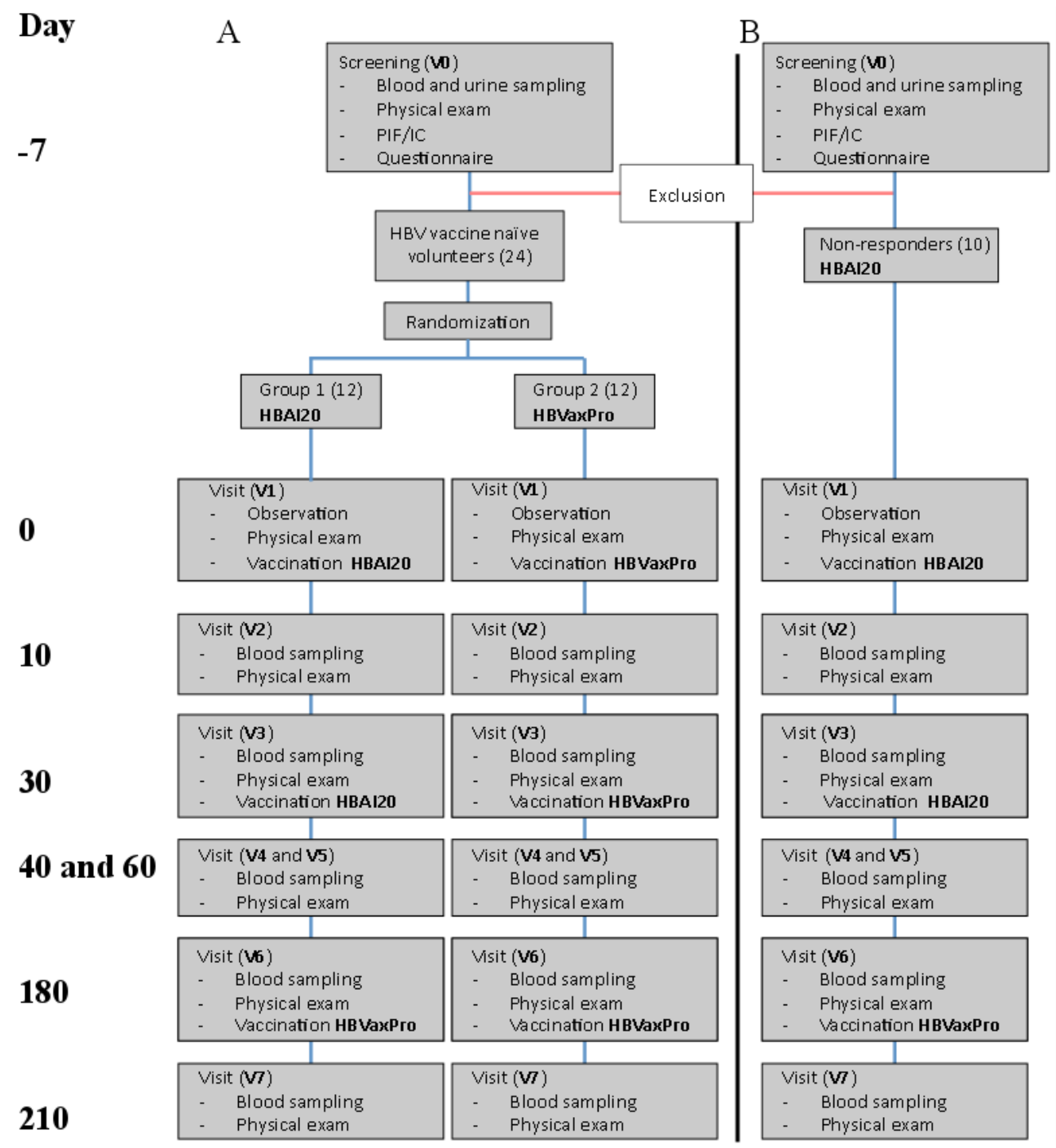

Figure 6.1.: Flowchart of the study. The phase I study involved two trials: A) a RCT in naïve participants and B) an open-label study in true non-responders. In both the RCT and open-label study, there were eight visits (V0-V7) with three vaccinations at day 0 (V1), 30 (V3) and 180 (V6). Abbreviations: PIF/IC: patient information file/informed consent; HBV: hepatitis B virus; V: visit; RCT: randomized controlled trial. 
Participants were closely observed for 30 minutes after the immunization for any immediate adverse events. In addition, the subjects were asked to measure their temperature and to fill in a symptom diary on the day of first and second vaccination and the subsequent four days. They were asked to record any local (pain, impaired movement of injected arm, redness, swelling and induration) and general reactions (fever, headache, fatigue, myalgia, vomiting and diarrhoea). Pain at the injection site was scored as none, mild (painful to touch), moderate (painful when limb is moved) or severe (spontaneously painful). Impaired movement of injected arm was scored as none, mild (bit less than normal), moderate (much less than normal) or severe (hardly, or not at all). The size of redness, swelling and induration was obtained by measuring their largest diameter and was scored as none, mild (>5- $25 \mathrm{~mm})$, moderate $(>25-50 \mathrm{~mm}$ ) or severe (>50 mm). General reactions were scored as none, mild (easily tolerated), moderate (interfered with daily activities) and severe (prevented normal daily activities). Fever was defined as oral body temperature above $37.5^{\circ} \mathrm{C}$ and was scored as none, mild $\left(37.6-37.9^{\circ} \mathrm{C}\right)$, moderate $\left(38.0-38.9^{\circ} \mathrm{C}\right)$ or severe $\left(>39.0^{\circ} \mathrm{C}\right)$. Diarrhoea was scored as none, mild (1-3 more watery stools compared to baseline), moderate (4-5 more watery stools compared to baseline) and severe ( $>5$ watery stools compared to baseline). Vomiting was scored as none, mild (once in 24 hours), moderate (twice in 24 hours) and severe ( $>3$ times in 24 hours). Unsolicited symptoms and serious adverse events were recorded throughout the whole study period. All solicited local symptoms were considered as related to vaccination.

\section{LABORATORY ASSAYS}

Haematological parameters, biochemical parameters including thyroid function and urinalysis were determined using commercially available laboratory methods (Supplementary files, Table S6.1). Further measurements of anti-HBs antibodies assayed using routine chemiluminescence assay (Anti-HBs, Cobas 8000, Roche, Germany). Titres $>10 \mathrm{mIU} / \mathrm{mL}$ were considered to be seroprotective. 


\section{RESULTS}

\section{DEMOGRAPHICS}

The demographics of the participants in the RCT and open-label study are listed in Table 6.1. The healthy HBV vaccine naïve volunteers in the RCT were comparable for mean age and mean body mass index (BMI) in both trial arms. In the open-label study, the anti-HBs titre in eight out of 10 true non-responders was $<2 \mathrm{mIU} / \mathrm{mL}$, two persons had a non protective anti-HBs titre of 4 and $5 \mathrm{mIU} / \mathrm{mL}$.

Table 6.1: Demographic characteristics in the RCT and open-label study

\begin{tabular}{|c|c|c|c|}
\hline & \multicolumn{2}{|r|}{ RCT } & Open-label \\
\hline Characteristic & $\begin{array}{l}\text { HBAI20 } \\
\text { NaÏve }\end{array}$ & 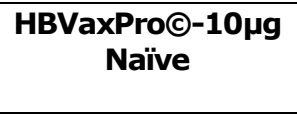 & $\begin{array}{l}\text { HBAI20 } \\
\text { Non- } \\
\text { responder }\end{array}$ \\
\hline Number of subjects & 12 & 12 & 10 \\
\hline Gender, male (\%) & $3(25 \%)$ & $4(33 \%)$ & $5(50 \%)$ \\
\hline Mean age, years (IQR) & 29 (22 to 32$)$ & $29(22$ to 35$)$ & $48(42$ to 58$)$ \\
\hline Mean BMI, $\mathrm{kg} / \mathrm{m}^{2}(\mathrm{IQR})$ & $23(22$ to 27$)$ & 25 (20 to 25$)$ & $29(24$ to 31$)$ \\
\hline Anti-HBs titre $<2 \mathrm{IU} / \mathrm{mL}(\%)$ & $12(100 \%)$ & $12(100 \%)$ & $8(80 \%)$ \\
\hline
\end{tabular}

Values shown as mean (IQR) or as $\mathrm{n}(\%)$. Abbreviations: RCT: randomized controlled trial; BMI: body mass index; IQR: interquartile range.

\section{SAFETY AND TOLERABILITY OF THE VACCINE}

After HBAI20 administration there were no laboratory abnormalities that would indicate renal, hepatic, thyroid, muscular or bone marrow dysfunctions or detectable inflammatory processes potentially attributable to the vaccine.

In the RCT, there was no significant difference between the HBAI20 group and HBVaxProC$10 \mu \mathrm{g}$ group in any adverse events $(21.7 \%$ vs $21.3 \%, \mathrm{p}=0.91)$, mild events ( $18.3 \%$ vs $19.2 \%, p=0.82)$, moderate events $(2.5 \%$ vs $1.3 \%, p=0.31)$ or severe events $(0.8 \%$ vs $0.8 \%, p=1.00$ ) during each of the four consecutive days after the first and second vaccination (Figure 6.2). 


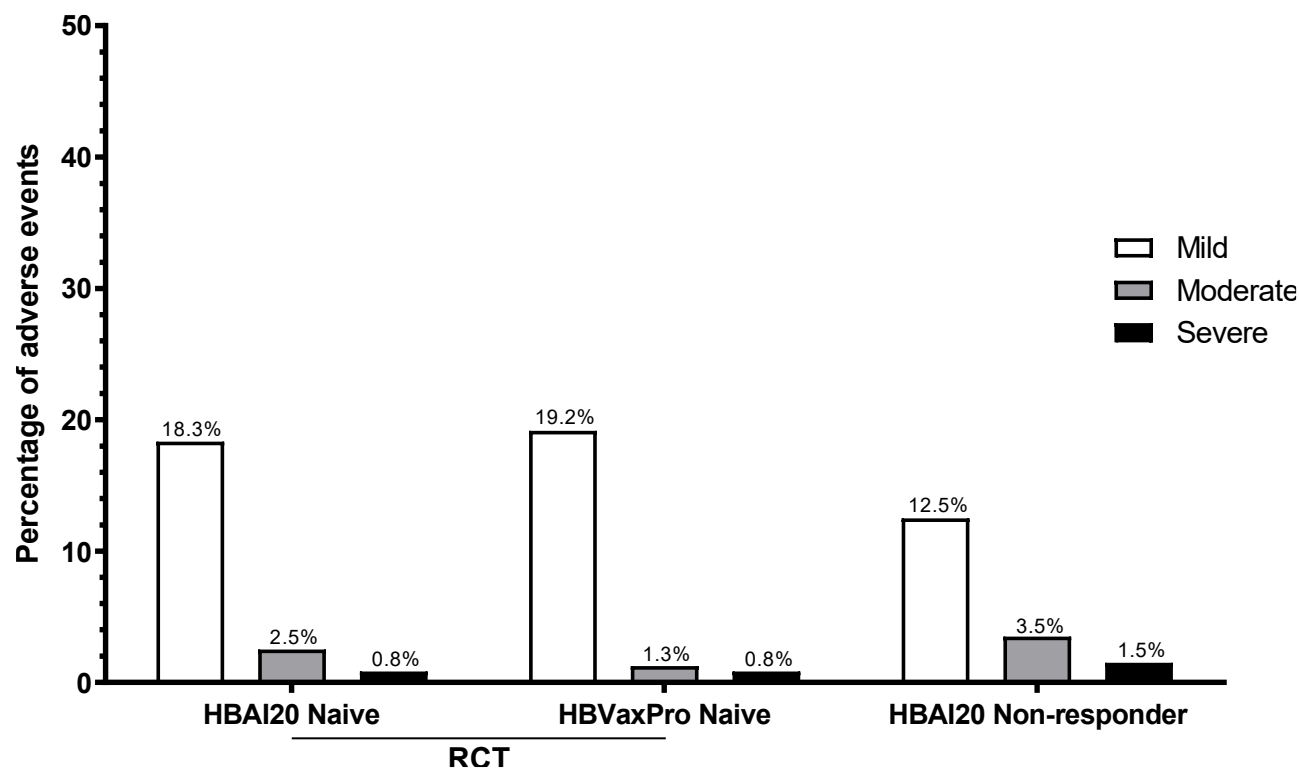

Figure 6.2.: Percentage of any adverse events and intensity of adverse events during each of the four consecutive days after the first and second vaccination in the RCT and in the openlabel study. In the RCT, naïve volunteers were randomized to receive the HBAI20 vaccine or the HBVaxPro@- $10 \mu \mathrm{g}$ vaccine. In the open-label study, all true non-responders received the HBAI20 vaccine. Abbreviation: RCT: randomized controlled trial. 
Table 6.2 lists the overall incidence of solicited local symptoms in the RCT and in the openlabel study. The most frequently reported local symptom in both the RCT and open-label study was pain at the injection site. In the RCT, there was no statistically significant difference between the HBAI20 group (75.0\%) and the HBVaxProC)-10 $\mathrm{gg}(66.7 \%)$ regarding pain at the injection site, $p=1.00$. There were no severe local symptoms in the HBAI20 group, and in the HBVaxPro@-10 $\mu$ g group the incidence of these was low: severe redness was reported in only one subject. In the open-label study there was one subject with severe redness and severe induration. All local reactions in both the RCT and openlabel study resolved within four days after vaccination for $98.5 \%$ of subjects.

Table 6.2: Incidence of solicited local symptoms in the RCT and open-label study

\begin{tabular}{|c|c|c|c|c|c|}
\hline & & \multicolumn{2}{|c|}{ RCT } & \multirow[b]{2}{*}{$\begin{array}{c}P \\
\text { Value }\end{array}$} & \multirow{2}{*}{$\begin{array}{c}\begin{array}{c}\text { Open- } \\
\text { label }\end{array} \\
\text { HBAI20 } \\
\text { Non- } \\
\text { responder } \\
(\mathrm{n}=10)\end{array}$} \\
\hline \multicolumn{2}{|l|}{ Local symptoms } & $\begin{array}{l}\text { HBAI20 } \\
\text { Naïve } \\
(n=12)\end{array}$ & 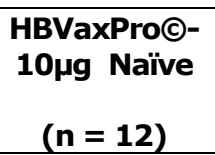 & & \\
\hline \multirow{2}{*}{$\begin{array}{l}\text { Pain at the injection } \\
\text { site }\end{array}$} & Any & $9(75 \%)$ & $8(67 \%)$ & 1.00 & $7(70 \%)$ \\
\hline & Severe & $0(0 \%)$ & $0(0 \%)$ & 1.00 & $0(0 \%)$ \\
\hline \multirow{2}{*}{$\begin{array}{l}\text { Impaired movement } \\
\text { of injected arm }\end{array}$} & Any & $8(67 \%)$ & $7(58 \%)$ & 1.00 & $4(40 \%)$ \\
\hline & Severe & $0(0 \%)$ & $0(0 \%)$ & 1.00 & $0(0 \%)$ \\
\hline \multirow[t]{2}{*}{ Redness } & Any & $4(33 \%)$ & $5(42 \%)$ & 1.00 & $3(30 \%)$ \\
\hline & Severe & $0(0 \%)$ & $1(8 \%)$ & 1.00 & $1(10 \%)$ \\
\hline \multirow[t]{2}{*}{ Swelling } & Any & $2(17 \%)$ & $3(25 \%)$ & 1.00 & $0(0 \%)$ \\
\hline & Severe & $0(0 \%)$ & $0(0 \%)$ & 1.00 & $0(0 \%)$ \\
\hline \multirow[t]{2}{*}{ Induration } & Any & $1(8 \%)$ & $1(8 \%)$ & 1.00 & $3(30 \%)$ \\
\hline & Severe & $0(0 \%)$ & $0(0 \%)$ & 1.00 & $1(10 \%)$ \\
\hline
\end{tabular}

Values shown as n (\%). Abbreviations: RCT: randomized controlled trial. 
The frequencies of any and severe solicited general symptoms are shown in Table 6.3. Myalgia was the most frequently reported general symptom in both studies ( $75 \%$ in each trial arm in the RCT and 70\% in the open label study). In the RCT, the incidence of severe events was low and only reported in the HBAI20 group. One naïve participant on HBAI20 vaccine, with known episodes of migraine, experienced severe headache from day five till day 10 after second vaccination. Another participant complained of severe diarrhoea for only one day (day three after the first vaccination). The underlying cause of the headache was most probably migraine, the cause of diarrhoea was unknown. No treatment was initiated concerning the severe headache while the participant with severe diarrhoea started antidota on his own initiative. Both occasions were possibly related to the HBAI20 vaccine, there was no requirement of hospitalization or referral to a specialist.

There were no severe general symptoms in the open-label study. In $97.1 \%$ of the subjects in both the RCT and the open-label study, the solicited general symptoms resolved within four days after vaccination.

Table 6.3: Incidence of solicited general symptoms in the RCT and open-label study

\begin{tabular}{|c|c|c|c|c|c|}
\hline \multirow{2}{*}{\multicolumn{2}{|c|}{ General symptoms }} & \multicolumn{2}{|c|}{ RCT } & \multirow[b]{2}{*}{$\begin{array}{c}P \\
\text { Value }\end{array}$} & \multirow{2}{*}{$\begin{array}{c}\text { Open-label } \\
\text { HBAI20 } \\
\text { Non- } \\
\text { responder } \\
(\mathbf{n}=\mathbf{1 0})\end{array}$} \\
\hline & & \multirow{2}{*}{$\begin{array}{c}\text { HBAI20 } \\
\text { Naïve } \\
(\mathbf{n}=\mathbf{1 2}) \\
0(0 \%)\end{array}$} & \multirow[t]{2}{*}{$\begin{array}{l}\text { HBVaxPro@- } \\
\text { 10ug Naïve } \\
\text { (n= 12) } \\
0(0 \%)\end{array}$} & & \\
\hline \multirow[t]{2}{*}{ Fever } & Any & & & 1.00 & $1(10 \%)$ \\
\hline & Severe & $0(0 \%)$ & $0(0 \%)$ & 1.00 & $0(0 \%)$ \\
\hline \multirow[t]{2}{*}{ Headache } & Any & $2(17 \%)$ & $4(33 \%)$ & 0.64 & $1(10 \%)$ \\
\hline & Severe & $1(8 \%)$ & $0(0 \%)$ & 1.00 & $0(0 \%)$ \\
\hline \multirow[t]{2}{*}{ Fatigue } & Any & $3(25 \%)$ & $5(42 \%)$ & 0.67 & $3(30 \%)$ \\
\hline & Severe & $0(0 \%)$ & $0(0 \%)$ & 1.00 & $0(0 \%)$ \\
\hline \multirow[t]{2}{*}{ Myalgia } & Any & $9(75 \%)$ & $9(75 \%)$ & 1.00 & $7(70 \%)$ \\
\hline & Severe & $0(0 \%)$ & $0(0 \%)$ & 1.00 & $0(0 \%)$ \\
\hline \multirow[t]{2}{*}{ Vomiting } & Any & $1(8 \%)$ & $0(0 \%)$ & 1.00 & $0(0 \%)$ \\
\hline & Severe & $0(0 \%)$ & $0(0 \%)$ & 1.00 & $0(0 \%)$ \\
\hline \multirow[t]{2}{*}{ Diarrhoea } & Any & $2(17 \%)$ & $2(17 \%)$ & 1.00 & $0(0 \%)$ \\
\hline & Severe & $1(8 \%)$ & $0(0 \%)$ & 1.00 & $0(0 \%)$ \\
\hline
\end{tabular}

Values shown as $\mathrm{n}(\%)$. Abbreviations: RCT: randomized controlled trial. 
Unsolicited symptoms were reported in the RCT by four subjects receiving HBAI20 and two subjects receiving $\mathrm{HBVaxProC}-10 \mu \mathrm{g}$. In the open-label study, five subjects reported unsolicited symptoms. The reported symptoms were not identical between the subject. There were no symptoms, such as migraine and bronchitis, considered to be related to the vaccine No serious adverse event was reported for any subject in the RCT or open-label study.

\section{IMMUNOGENICITY OF THE VACCINE}

In the RCT, which included naïve seronegative subjects, all patients achieved seroprotection at visit 7 , one month after the third vaccination (Figure 6.3). There was no statistically significant difference in seroprotection between the groups across the visits, $O R=0.455$, $95 \%$ CI $0.036-5.813, p=0.534$ at visit 3 (30 days after the first vaccination) and $O R=$ $0.600,95 \%$ CI $0.081-4.447, p=0.614$ at visit 5 (30 days after the second vaccination). Corrected for age and gender in logistic regression analysis of the $10 \mathrm{log}$ anti-HBs data similar results were obtained. At visit 4 (10 days after the second vaccination) 11 subjects (92\%) in the HBAI20 group versus 7 subjects (58\%) in the HBVaxPro@- $10 \mu \mathrm{g}$ had protective level of antibodies $(p=0.16)$.

In the repeated measures ANOVA analysis the general trend over the visits 2 to 7 showed a significant increase in anti-HBs titre $(p<0.001)$. Linear trend difference between treatment groups was not significant $(p=0.237)$. Age and gender showed no significant differences in the linear trend. The GMTs in the subjects receiving the HBAI20 vaccine versus HBVaxProC$10 \mu \mathrm{g}$ vaccine almost reached statistical significance 10 days after the first vaccination with 584.7 mIU/mL (95\% CI: 300.3-869.1) and 369.7 mIU/mL (95\% CI: 74.9-664.6), p = 0.05 (Figure 6.4). At visits 5 and 7 older patients had significantly more difficulty to build up immune response $(p=0.014$, resp. $p<0.001)$. Effect of gender was not significant.

In the open-label study, HBAI20 vaccine was able to elicit protective anti-HBs titres in $90 \%$ of the true non-responders at one month after the third vaccination (Figure 6.3). The GMTs of anti-HBs antibodies of the non-responders can be found in Figure 6.4. 


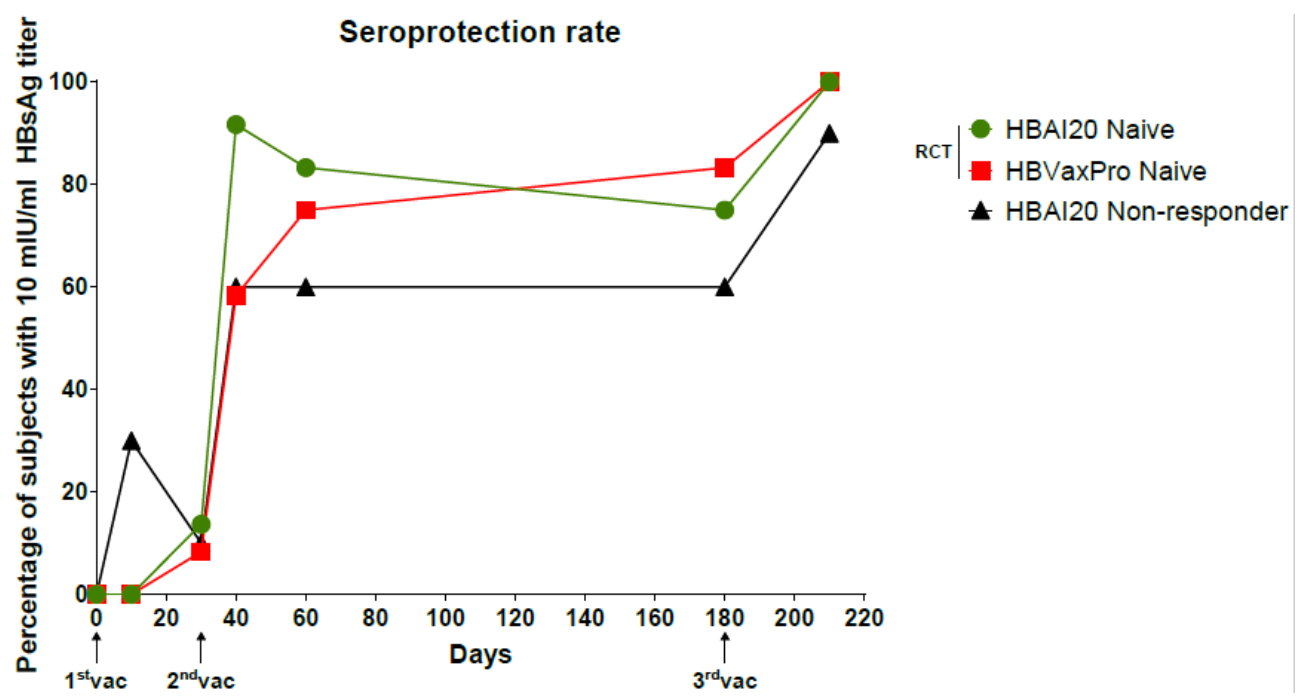

Figure 6.3.: Seroprotection rate in the RCT of healthy naïve volunteers and in the open-label study of true non-responders. In the RCT, naiive subjects received the HBAI20 vaccine (circles) or the HBVaxPro@-10 $\mathrm{\mu g}$ vaccine (squares). In the open-label study, all true non-responders received the HBAI20 vaccine (triangles). The first and second vaccination consisted of the HBAI20 vaccine or HBVaxPro@-10 $\mathrm{g}$. All participants received HBVaxPro@- $10 \mu \mathrm{g}$ as the third vaccination. Abbreviation: $\mathrm{RCT}$ : randomized controlled trial; vac: vaccination.

\section{Geometric mean titres}

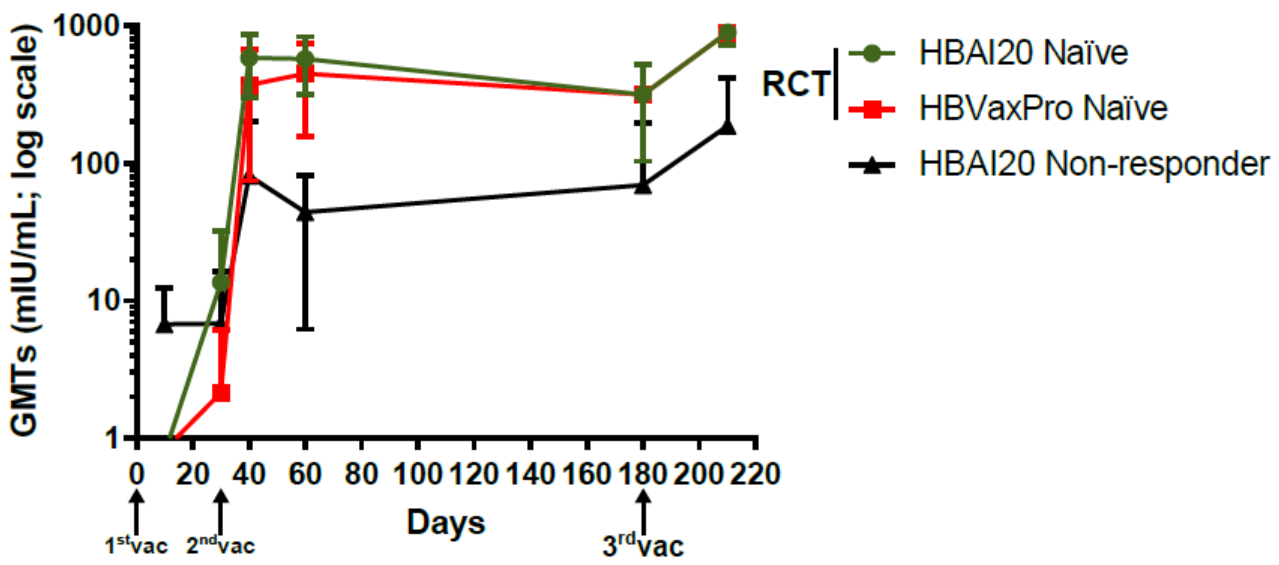

Figure 6.4.: Geometric mean titres (GMTs) of anti-HBs antibodies in the RCT of healthy naïve volunteers and in the open-label study of true non-responders. In the RCT, naive subjects received the HBAI20 vaccine (circles) or the HBVaxPro@- $10 \mu \mathrm{g}$ vaccine (squares). In the open-label study of true non-responders all received the HBAI20 vaccine (triangles). The first and second vaccination

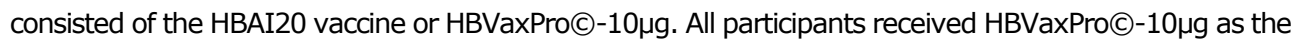
third vaccination. Abbreviation: RCT: randomized controlled trial; vac: vaccination. 


\section{DISCUSSION}

According to this phase I study, the HBAI20 vaccine seems safe, well-tolerated and may promote more rapid protection against HBV infection. In the RCT, the HBAI20 vaccine achieved seroprotection in $11(92 \%)$ of the naiive subjects 10 days after the second vaccination in comparison to 7 subjects (58\%) in the HBVaxPro@-10 $\mu$ g vaccine. Moreover, in the open-label study the HBAI20 vaccine provided protective antibodies in $90 \%$ of the true non-responders. However, one true-non responder remained seronegative at month 7. This might be due to chronic local corticosteroid use.

Severe side effects like hypotension, pulmonary edema and renal dysfunction have been associated with high-dose intravenous bolus IL-2 in metastatic renal cell cancer. ${ }^{217}$ However, the AI20 adjuvant applied intramuscularly in this trial used only $20 \mu \mathrm{g}$ of IL-2 that represents $1.8 \%$ of the recommended dose for the treatment of metastatic renal cell cancer. Moreover, $95 \%$ of the IL-2 in the adjuvant is depot bound allowing a slow release of the drug and thus effectively decreasing the local and, as a consequence, also the systemic IL-2 concentration. As the undesirable effects of IL-2 are dependent on the dose and way of administration (intravenously, subcutaneously or intramuscularly) ${ }^{218-220}$, we did not see any of the described adverse drug reactions reported for IL-2 except the common side effects seen in injection-site reactions. In clinical studies with a similar set-up, IL-2 used as adjuvant in a liposome-based influenza vaccine showed that the use of a similar dose of IL-2 $(33 \mu \mathrm{g})$ in a liposome formulation indeed resulted in a similar rate of adverse reactions compared with the current commercial influenza vaccines. ${ }^{218,221}$

The possibility of inducing specific production of antibodies against hepatitis B surface antigen (anti-HBs) with IL-2 has been studied previously in healthy HBV vaccine naïve participants ${ }^{222}$ and in HBV vaccine non-responders ${ }^{223-225}$. In a pilot study of Meuer et a ${ }^{225}$, six of only 10 non-responder patients appeared to respond to concurrent IL-2 administration and HBV revaccination. The patients had renal failure and were on long-term hemodialysis. However, these encouraging results have not been confirmed by other groups.222-224 Nonetheless, previous studies assessing IL-2 as an efficient mean of inducing HBsAg specific immune response have been hampered by the short half-life of IL-2. ${ }^{222-227}$ Our current study is the first report in humans using aggregated IL-2 molecules attached to aluminum hydroxide, facilitating the slow release of highly concentrated IL-2 nano aggregates.

Although much is known about the immunological effects of IL-2226, 228-235, the mechanism of their adjuvancy with hepatitis B vaccine has not been characterized. IL-2 exerts its effect 
by binding on the high-affinity trimeric IL-2 receptor or the low-affinity IL-2 receptor. ${ }^{236}$ The group of Velten ${ }^{237}$ and Mnasria 238 have reported that dendritic cells upregulate their expression of CD25 after antigen stimulation, and CD25 expression can serve to present IL2 in trans to antigen-specific T cells. This CD25 upregulation correlated with improved dendritic cell-mediated stimulation of allogeneic CD4 T cell proliferation. 226, 237, 238 IL-2 also promotes $\mathrm{TH} 1$ cell generation by increasing the levels of $\mathrm{IL}-12$ receptor $\beta 2$ subunit and via the induction of T-bet expression. $226,231,239$ Similarly to the generation of $\mathrm{TH} 1$ cells, $\mathrm{TH} 2$ cell differentiation appears to require stimulation by IL-2. IL-2 signals induce the upregulation of IL-4 receptor a and enhance the production of typical TH2-type cytokines, notably IL-4, IL-5 and IL-13. 226, 232, 240

\section{CONCLUSION}

The results of this phase I study support further studies with HBAI20 vaccine in healthy naïve adults and non-responders. The accelerated antibody response after two doses indicate that the HBAI20 vaccine may be useful in immunizing difficult to access populations such as injection-drug users and homeless people. Other potential uses for this novel HBAI20 vaccine with enhanced immunogenicity would be for the populations known to be non-responders such as older individuals, hemodialysis patients and other immunocompromised persons. 
SUPPLEMENTARY FILES

Table S 6.1: Laboratory parameters and normal ranges for haematology, biochemistry and urinalysis

\begin{tabular}{|c|c|}
\hline HAEMATOLOGY & Differential WBC count \\
\hline 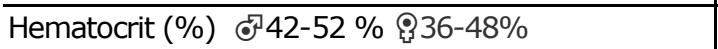 & Neutrophils (\%) $40-70 \%$ \\
\hline Hemoglobin (mmol/L) ఠ8.2-10.4 \&7.3-9.7 mmol/L & Eosinophils (\%) 0 - $10 \%$ \\
\hline RBC count $\left(10^{12} / \mathrm{L}\right)$ क्ष4.2-6.0 \&3.7-5.0 1012/L & Basophils (\%) $0-2 \%$ \\
\hline WBC count $\left(10^{9} / \mathrm{L}\right) 3.5-11.010^{9} / \mathrm{L}$ & Lymphocytes (\%) 15 - $48 \%$ \\
\hline Platelet count $\left(10^{9} / \mathrm{L}\right) 130-35010^{9} / \mathrm{L}$ & Monocytes (\%) 4 - $11 \%$ \\
\hline BIOCHEMISTRY & VIROLOGY \\
\hline Creatinine $(\mu \mathrm{mol} / \mathrm{L})$ ఠ64-104 \&50-100 $\mu \mathrm{mol} / \mathrm{L}$ & HIV-test - Negative \\
\hline Albumin (g/L) $32.0-47.0 \mathrm{~g} / \mathrm{L}$ & $\begin{array}{l}\text { HBV serology and quantitative anti-HBs } \\
\text { titre }\end{array}$ \\
\hline Alkaline phosphatase (U/L) क्ण53-128 \&42 - $98 \mathrm{U} / \mathrm{L}$ & $\mathrm{HCV}$ - Negative \\
\hline \multicolumn{2}{|l|}{ Total Bilirubin $(\mu \mathrm{mol} / \mathrm{L})<20 \mu \mathrm{mol} / \mathrm{L}$} \\
\hline ALAT $(U / L)<34 \mathrm{U} / \mathrm{L}$ & Immunogenicity of adjuvant \\
\hline ASAT (U/L) क्र<40 \&< $31 \mathrm{U} / \mathrm{L}$ & IL-2 antibody titre \\
\hline \multicolumn{2}{|l|}{ Gamma-GT $(\mathrm{U} / \mathrm{L})<38 \mathrm{U} / \mathrm{L}$} \\
\hline \multicolumn{2}{|l|}{ CRP test $(\mathrm{mg} / \mathrm{dL})<10 \mathrm{mg} / \mathrm{dL}$} \\
\hline \multicolumn{2}{|l|}{ TSH (mU/L) $0.4-4.3 \mathrm{mU} / \mathrm{L}$} \\
\hline \multicolumn{2}{|l|}{ FT4 (pmol/L) 8.0 - 18.0 pmol/L } \\
\hline URINALYSIS & $\begin{array}{l}\text { Only if urinalysis is abnormal, Urinary } \\
\text { sediment microscopically }\end{array}$ \\
\hline Leukocytes [0-15] & Leucocytes (0 - 5HPF) \\
\hline Nitrite [negative] & Erythrocytes (fresh) (0 - 3HPF) \\
\hline $\mathrm{pH} 4.5-8.0$ & Erythrocytes (dysmorphic) \\
\hline Erythrocytes [0-10] & Mucus track \\
\hline Protein (albumin) $[<0.3 \mathrm{~g} / \mathrm{L}]$ & Crystals \\
\hline$\overline{\text { Glucose [negative] }}$ & Yeast cells \\
\hline \multirow[t]{3}{*}{ Pregnancy test } & Threads of mycelium \\
\hline & Bacteria \\
\hline & Squamous cells \\
\hline
\end{tabular}

Abbreviations: RBC: red blood cell; WBC: white blood cell; HBV: hepatitis B virus; HCV: hepatitis C virus; ALAT: alanine-aminotransferase; ASAT: aspartate-aminotransferase; IL-2: interleukin-2; Gamma-GT: 
gamma-glutamyltransferase; CRP: C-reactive protein; TSH: thyroid-stimulating hormone; FT4: free thyroxine. 




\section{CHAPTER 7}

Immunogenicity and safety of HBAI20 Hepatitis

$B$ vaccine in healthy non-responders: doubleblinded, randomised, controlled phase 2 trial

Koc ÖM, De Smedt P, Kremer C, Robaeys G, Van Damme P, Hens N, Almeida JR, Falkenberg FW, Savelkoul PHM, Oude Lashof AML, and the BE RESPONDER Study Group

Submitted 


\section{ABSTRACT}

Background: Approximately $5-10 \%$ of the general population respond inadequately to licensed recombinant hepatitis $B$ vaccines. We assessed the immunogenicity and safety of a new HBAI20 vaccine.

Methods: In a double-blind, randomised, controlled phase 2 trial, 18 - 59 years old healthy non-responders were assigned (3:1 ratio) to receive either HBAI20 vaccine or HBVaxPro $(-$ $10 \mu \mathrm{g}$ in a 0,1 and 2 months schedule. The primary outcome was seroprotection (titre $>10$ $\mathrm{mIU} / \mathrm{mL}$ ) measured $1-3$ months following the third vaccination. ClinicalTrials.gov number, NCT03415672.

Findings: A total of 133 participants were randomised to receive either HBAI20 vaccine ( $\mathrm{n}$ $=101$ ) or HBVaxPro $R-10 \mu \mathrm{g}(\mathrm{n}=32$ ). In the modified intention-to-treat analysis (after excluding those according to the in- and exclusion criteria), the seroprotection rate after the

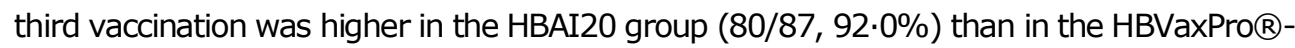
$10 \mu g$ group $(23 / 29,79.3 \%), p=0.068$. Using a generalized linear mixed model to adjust for stratification factors, a higher odds of seroprotection with HBAI20 vaccine was shown (adjusted odds ratio $=3.48, p=0.028$ ). Frequency of mild and moderate local adverse events was greater in the HBAI20 group than in the HBVaxPro $(-10 \mu \mathrm{g}$. Rates of severe local adverse events and systemic adverse events were low and similar in both groups. There were two serious adverse events, both unrelated to the intervention.

Interpretation: In this group of hepatitis B vaccine non-responders, the HBAI20 vaccine demonstrated a higher seroprotection rate and a similar safety profile compared to the licensed recombinant $\mathrm{HBVaxPro}(-10 \mu \mathrm{g}$.

Funding: CyTuVax B.V. 


\section{Research in context}

\section{Evidence before this study}

Currently, several hepatitis B vaccines are commercially available to protect people from hepatitis B virus infection. However, these vaccines do not induce protective immunity (antiHBs level $>10 \mathrm{mIU} / \mathrm{mL}$ ) in $5-10 \%$ of the healthy adult population. Persons with this inadequate immune response after a complete hepatitis B vaccination schedule are called non-responders. The standard of care for healthy non-responders consists of revaccination with commercially available hepatitis B vaccines and is associated with a seroprotection rate of $50-69 \%$ after three doses. We searched PubMed, without language restrictions, from inception until Aug 21, 2019, using the following terms: ((("Hepatitis B Vaccines"[Mesh]) OR hepatitis b vaccine)) AND ((non-responder) OR nonresponder)) AND (("Adult"[Mesh]) OR healthy adult). Among a total of 57 articles retrieved and screened, we identified one double-blind, randomised, controlled trial assessing the immunogenicity of hepatitis B vaccines in healthy non-responding adults. This study conducted in China reported a higher immunogenic response to revaccination with high antigen content $(60 \mu \mathrm{g}$ vs $10 \mu \mathrm{g}$ hepatitis B surface antigen in the commercially available hepatitis B vaccine). Further, two singleblind randomised controlled trials in healthy non-responding adults showed a higher immunogenic response with adjuvanted vaccines compared to a commercially available hepatitis $B$ vaccine. The first adjuvanted hepatitis B vaccine Fendrix $(\mathbb{B}$ is currently licensed in Europe for patients with renal dysfunction, although not indicated for the healthy nonresponder population. One should also notice that the higher seroprotection rate with Fendrix ${ }^{\circledR}$ is not only linked to the adjuvant 3-O-desacyl-4'-monophosphoryl lipid A (MPL) but also to the higher antigen content $\left(40 \mu \mathrm{g}\right.$ in Fendrix ${ }^{\circledR}$ vs $20 \mu \mathrm{g}$ in commercially available hepatitis $B$ vaccine). The second vaccine Heplisav- $B \AA$, with a phosphorothioate oligodeoxyribonucleotide adjuvant, was never licensed in Europe. 


\section{Added value of this study}

This is the first double-blind, randomised, controlled trial in healthy adult non-responders assessing the immunogenic properties of a cytokine-based adjuvant (AI20 adjuvant: $20 \mu \mathrm{g}$ recombinant human IL-2 adsorbed to $20 \mu \mathrm{g}$ aluminium hydroxide). The new vaccine is called HBAI20 and consists of the new adjuvant AI20 in combination with HBVaxPro $\AA-10 \mu g$ vaccine.

\section{Implications of all the available evidence}

In this study, we demonstrated that the new HBAI20 vaccine was $>3$ times more likely to induce seroprotection compared to the commercially available HBVaxPro $(10 \mu \mathrm{g}$ vaccine when given to healthy hepatitis B vaccine non-responders at 0,1 and 2 months schedule. Safety was comparable between both groups. These results support further studies to assess the benefits of the HBAI20 vaccine in other populations known to have a suboptimal immune response to hepatitis B vaccination, i.e. older individuals, patients with advanced liver disease, haemodialysis patients and patients with other immunodeficient conditions.

Taking into account the additional immunogenic properties of the AI20 adjuvant, it might be reasonable to consider the AI20 adjuvant for other vaccines conferring a suboptimal response, such as for influenza or tuberculosis vaccines. 


\section{INTRODUCTION}

Hepatitis B virus (HBV) infection is one of the most common and serious infectious diseases globally. It is estimated that one third of the world's population has been exposed to HBV, which has resulted in 257 million chronic HBV carriers worldwide. ${ }^{57}$ The economic burden of HBV infection is substantial because of the high morbidity and mortality associated with cirrhosis, hepatocellular carcinoma and liver failure. ${ }^{13}$

HBV is up to 100 times more infectious than HIV. ${ }^{57}$ As such, the development of a hepatitis $B$ vaccine has been a major breakthrough in the global effort to eradicate HBV infection. ${ }^{241}$ Current licensed HBV vaccines are produced in Saccharomyces cerevisiae and are composed of hepatitis B surface antigen (HBsAg) which is adsorbed to aluminium hydroxide or aluminium phosphate. ${ }^{242}$ Despite their proven immunogenicity and safety, currently available recombinant hepatitis $B$ vaccines are unable to induce an adequate immune response in $5-10 \%$ of the general adult population. ${ }^{243}$ Persons lacking this antibody immune response (anti-HBs level $<10 \mathrm{mIU} / \mathrm{mL}$ measured at 1 to 3 months after completion of the hepatitis $B$ vaccination schedule) are referred to as non-responders. ${ }^{243}$ The standard of care for non-responders consists of revaccination with currently licensed hepatitis $B$ vaccines and is associated with a seroprotection rate of $50-69 \%$ after three doses. ${ }^{93,96-99}$ Thus, there is a need for a more immunogenic vaccine in defined groups such as healthy non-responders to recombinant hepatitis $B$ vaccines.

Among healthy adult non-responders to primary hepatitis B vaccination, a previous doubleblind, randomised, controlled trial in China demonstrated seroprotection in $92.1 \%$ (394/428), 87.1\% (371/426) and 83.0\% (180/217) with hepatitis B vaccines respectively containing 60 $\mathrm{\mu g}, 30 \mu \mathrm{g}$ and $10 \mu \mathrm{g} \mathrm{HBsAg.}{ }^{104}$ Moreover, two single-blind randomised controlled trials in healthy non-responders showed a higher immunogenic response with adjuvanted vaccines, one with Fendrix $\left(R\right.$ and one with Heplisav- $B \cap .{ }^{97,} 98$ Among a total of 82 participants, the seroprotection rate was $97.5 \%$ in the group that received three doses of Fendrix $\left(\right.$ compared to $68.0 \%$ with three doses of Engerix-Bß.98 ${ }^{98}$ The observed higher seroprotection rate with Fendrix $(R$ was not only linked to the adjuvant 3-O-desacyl-4'-

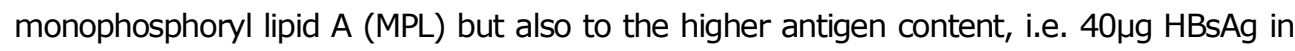
Fendrix $®$ vs $20 \mu \mathrm{g}$ in Engerix-BR. ${ }^{98}$ The study of Halperin et $\mathrm{al}^{97}$ was conducted among 35 non-responders and seroprotection was found in $88.9 \%$ and $66.7 \%$ after two doses with Heplisav- $B \AA$ and Engerix- $B \AA$, respectively. At present, Fendrix $\AA$ is only licensed for individuals with renal alteration, while Heplisav- $B \mathbb{R}$ is never licensed in Europe. 
Since the available recombinant hepatitis B vaccines all have an aluminium-based adjuvant, we report for the first time the immunogenic properties of a cytokine-based adjuvant in a well-designed double-blind, randomised controlled trial in healthy adult non-responders. In a phase 1 trial, the new AI20 adjuvanted (HBAI20) vaccine was shown to be safe, welltolerated and immunogenic in healthy naive and non-responding adults. ${ }^{244}$ The current study describes a phase 2 trial to evaluate in healthy non-responders the immunogenicity and safety of the new HBAI20 hepatitis B vaccine compared to the licensed HBVaxPro $($ $10 \mu \mathrm{g}$ vaccine. 


\section{MATERIALS AND METHODS}

\section{STUDY DESIGN}

The study was a phase 2, double-blind (participant and investigator), randomised, controlled, multicentre trial. The protocol (in accordance with the CONSORT statement which is available at thelancet.com) was approved by the local ethics committee and was conducted in accordance with the guidelines of the Declaration of Helsinki and its amendments and in accordance with good clinical practice and local laws.

\section{Participants}

The participants were hepatitis B vaccine non-responders, ranging in age from 18 to 59 years. Non-responders were defined as subjects with documented three or more hepatitis $B$ vaccinations and documentation of hepatitis B surface antibody (anti-HBs) level $<10$ $\mathrm{mIU} / \mathrm{mL}$ measured within $1-3$ months after the last vaccination. ${ }^{243}$ Non-responders were identified from Occupational Health Services located in the Netherlands and Belgium, and subsequently invited for enrolment in one of the trial sites: Maastricht UMC+ (Maastricht, the Netherlands), Antwerp University (Antwerp, Belgium) or Hospital East-Limburg (Genk, Belgium). The following exclusion criteria were used in the study: anti-HBs level >10 $\mathrm{mIU} / \mathrm{mL}$, HBsAg positivity, positive for hepatitis B core antibodies (anti-HBc), positive for HCV antibodies, positive for HIV antibodies, any infectious disease at the time of screening or enrolment, known or suspected immune deficiency, known or suspected disease that influences the immune system (e.g. cancer and transplantation recipients), known or suspected allergy to any of the vaccine components, dialysis patients, history of unusual or severe reactions to any previous vaccination, history of any neurologic disorder (e.g. epilepsy and autism), use of medication that influences the immune system (e.g. corticosteroids), hepatitis $B$ vaccination or any other vaccination within three months before screening (with the exception of influenza vaccinated individuals who were included), blood donation within one month before screening, administration of plasma or blood products within 12 months before screening, participation in another clinical trial within three months before screening, abnormal pre-treatment laboratory parameters which are clinically relevant according to the investigator, bleeding disorders, participants on coumarin anticoagulants and participants receiving two or more platelet aggregation inhibitors, female subjects planning to become pregnant or breastfeeding babies until the last study visit, females with positive urine pregnancy test at screening date, excessive alcohol or illicit drug 
use. Excessive alcohol use was defined as $>14$ units per week in males and $>7$ units per week in females. 245

\section{RANDOMISATION AND BLINDING}

Participants were randomly assigned to the HBAI20 vaccine or the HBVaxProß-10 $\mu \mathrm{g}$ vaccine at a 3:1 ratio. Randomisation was performed by the ALEA screening and Enrolment Application Software (Formvision B.V., Abcoude, the Netherlands) and with minimization of stratification factors: age (18 - 25, 26 - 35, 36 - 50 or 51 - 59 years), sex (male or female), hepatitis $B$ vaccination history (one complete cycle or more than one cycle) and trial site (Maastricht UMC+, Antwerp University or Hospital East-Limburg). Blinding of participants and investigators was achieved by a label that concealed the volume difference between the two vaccines. The colour was similar in both vaccines. All investigators and participants were kept blinded for the respective anti-HBs results after the study vaccinations.

\section{Procedures}

The investigational vaccine (HBAI20) consisted of a new adjuvant AI20, containing 20 $\mu \mathrm{g}$

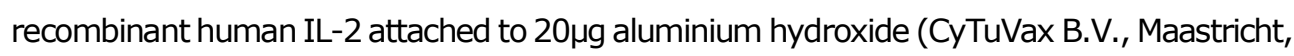
the Netherlands), in combination with $H B V a x P r o ß-10 \mu g .{ }^{244}$ The comparator vaccine was the licensed $H B V a x P r o ß-10 \mu g$ vaccine $1.0 \mathrm{~mL}$ (MSD VACCINS, Lyon, France). Within one hour before administration, the HBAI20 vaccine was prepared by an unblinded study personnel. HBVaxPro $R-10 \mu \mathrm{g}$ was added to the AI20 adjuvant, gently mixed by inversion and aspired with a needle in one syringe $(1.3 \mathrm{~mL})$. Vaccines were injected into the deltoid muscle of the non-dominant arm by an unblinded nurse following the recommended 0,1 and 2 months revaccination schedule for non-responders in the Netherlands. ${ }^{243}$ The unblinded nurse did not perform any other study tasks.

Blood samples were drawn at screening visit 0 (day -30 - 0), visit 1 (day 0), visit 2 (day 28 - 40), visit 3 (day $56-80$ ) and visit 4 (day 96 - 132). At the first visit (visit 0), study participants gave written informed consent, were checked for in- and exclusion criteria, underwent physical examination, serological screening (complete and differential blood count, renal function, liver function, thyroid function, inflammatory parameters, HIV, hepatitis $\mathrm{C}$ virus (HCV) and HBV serology) and urine sampling. Urinalysis consisted of leukocytes, nitrite, $\mathrm{pH}$, erythrocytes, protein and glucose measurement in all participants. A pregnancy test was taken from female participants. At visit 2, 3 and 4 anti-HBs antibody levels were determined, and at visit 4 additional blood samples were drawn for 
haematological and biochemical evaluation. For organizational reasons, screening visit 0 and visit 1 were combined in one out of three trial sites.

Participants were closely observed for 30 minutes after each vaccination for any immediate adverse events. On the day of vaccination and the subsequent four days, subjects were asked to record local adverse events (pain, impaired movement of injected arm, redness, swelling and induration) and systemic adverse events (fever, headache, fatigue, vomiting and diarrhoea) in individual diary cards.

\section{OUTCOMES}

The primary endpoint of this study was the immunogenicity of the HBAI20 vaccine, tested in terms of proportion with seroprotection at $1-3$ months after the third vaccination. Seroprotection rates measured at earlier time points and geometric mean concentrations (GMC) were secondary endpoints.

Local and systemic adverse events were scored as absent, mild (no interference with daily activity), moderate (some interference with daily activity), or severe (prevented normal daily activities). The size of redness, swelling and induration was scored as absent, mild (> $5-25 \mathrm{~mm}$ ), moderate (> $25-50 \mathrm{~mm}$ ), or severe (> $50 \mathrm{~mm}$ ). Fever was defined as oral body temperature above $37.5^{\circ} \mathrm{C}$ and was scored as absent, mild $\left(37.6-37.9^{\circ} \mathrm{C}\right)$, moderate $\left(38.0-38.9^{\circ} \mathrm{C}\right)$, or severe $\left(>39.0^{\circ} \mathrm{C}\right)$. Vomiting was scored as absent, mild (once in 24 hours), moderate (twice in 24 hours), or severe (three or more times in 24 hours). Diarrhoea was scored as absent, mild ( $1-3$ stools above normal), moderate ( $4-5$ stools above normal), or severe ( $>5$ stools above normal). Unsolicited symptoms and serious adverse events were recorded throughout the study period. All solicited local adverse events were considered as related to study vaccine. The investigators assessed the relationship of all other reported adverse events to vaccination.

\section{LABORATORY ASSAYS}

Haematological, biochemical, virological parameters and urinalysis were determined using commercially available laboratory methods. Serum anti-HBs antibody levels were analysed with the Cobas 8000 chemiluminescence assay (Roche, Germany). Subjects with anti-HBs antibody levels $>10 \mathrm{mIU} / \mathrm{mL}$ were considered to be seroprotected and deemed vaccine responders. ${ }^{243}$ 


\section{STATISTICAL ANALYSIS}

Sample size calculation could not directly be based on phase 1 HBAI20 study data because the study population characteristics were different with respect to hepatitis $B$ vaccination history (naive subjects vs non-responders). Our aim was to include between $132-140$ subjects in agreement with other phase 2 immunogenicity and safety studies for hepatitis B vaccines. ${ }^{97,} 98,246,247$ Sample size for this trial was based on superiority analysis. A noninferiority (NI) analysis was not initially performed. However, an NI margin is specified in case superiority cannot be shown, then a switch can be made to NI analysis. The NI margin was set to $10 \%$ in line with previous studies. ${ }^{248,249}$

All data of the outcome variable anti-HBs level were log10-transformed. To overcome problems with zero values, a value of +0.5 was added to all anti-HBs levels. Continuous variables were expressed as mean \pm standard deviation, SD. For the comparison of categorical variables, either Chi squared test or Fisher's exact test was used. Student's t test or Kruskall-Wallis test was used to compare groups in terms of continuous outcomes.

Safety analysis was performed including all participants that received at least one vaccination (Figure 7.1). The percentage of adverse events for the two vaccines was compared using a Chi squared test for the equality of proportions, or a Fisher's exact test in case of small samples. A modified intention-to-treat (mITT) approach was used for superiority analysis. In order to establish statistically significant superiority of the new vaccine, the one-sided $95 \%$ confidence interval (CI) for the odds ratio (OR) of seroprotection has to lie entirely above one.

Since there was one missing seroprotection outcome at visit 3 and 4, and two at visit 2, multiple imputation was used to impute these values. The GMC values were imputed. Multiple imputation was done using the Statistical Analysis Software (SAS Institute Inc., NC, USA) procedure PROC MI. Considering the non-monotone pattern of missingness, the fully conditional specification (FCS) regression method was used to fill in the missing values. ${ }^{250}$ Imputation was done separately for the two vaccine allocations, to avoid imposing any relationship between the outcome variables and this covariate. The data were imputed five times. For each imputed dataset, a generalized linear mixed model was used to estimate the vaccine effect at visit 4, i.e. $1-3$ months following the last vaccination. The stratification factors vaccination history, age, and sex were included as fixed effects in the model, in addition to vaccine allocation (i.e. treatment effect). Interactions between these stratification factors and vaccine allocation were also included in the model. If not significant, the 
interaction effect was removed from the model, indicating no difference between vaccine allocations within the stratification group. Trial site was included as a random effect. To assess the sensitivity of the results to the method of handling missing data, extreme case analyses were done, i.e. worst case and best case analysis. All reported p-values for vaccine allocation were based on one-sided tests.

Independent data monitoring committee Clinical Trial Center Maastricht oversaw the study. The study was registered at clinicaltrials.gov (NCT03415672).

\section{ROLE OF THE FUNDING SOURCE}

The study was partially sponsored by CyTuVax B.V., and the sponsor was involved in the study design, interpretation of the data, review and approval of the manuscript in accordance with good clinical practice. The funding source had no input in data collection and statistical analysis of the data. ÖK, CK, NH and AOL had full access to all the data in the study and the corresponding author had final responsibility for the decision to submit for publication. 


\section{RESULTS}

Participants were recruited from January 5, 2017 to September 21, 2018. The last visit occurred on January 18, 2019. Out of 1,074 persons invited, 335 HBV vaccine nonresponders replied initially for participation. A total of $41 / 335(12 \cdot 2 \%)$ individuals were deemed ineligible by the investigator and $149 / 335$ (44.5\%) subjects could not be contacted after at least two attempts. In the end, 145/335 (43.3\%) participants were screened and a total of 133 subjects were enrolled and randomly assigned to receive either HBAI20 vaccine $(n=101)$ or HBVaxPro $(-10 \mu g$ vaccine $(n=32)$ (Figure 7.1).

The baseline characteristics of the 133 included subjects are shown in Table 7.1. The HBAI20 and HBVaxPro $(-10 \mu \mathrm{gg}$ groups were balanced in terms of Body-Mass Index ( $26 \pm 4.9$ vs 26 $\pm 6.5, \mathrm{p}=0.543)$ and the number of individuals with undetectable anti-HBs levels $(<2$ $\mathrm{mIU} / \mathrm{mL})$ prior to study vaccination $(69 / 101(68 \cdot 3 \%)$ vs $27 / 32(84 \cdot 4 \%), \mathrm{p}=0 \cdot 124)$.

Table 7.1: Baseline characteristics of the subjects

\begin{tabular}{|c|c|c|}
\hline Characteristic & $\begin{array}{c}\text { HBAI20 } \\
\text { Group } \\
(\mathrm{n}=101)\end{array}$ & $\begin{array}{c}\text { HBVaxPro } ®-10 \mu g \\
\text { Group } \\
(n=32\end{array}$ \\
\hline Mean age - years & $40 \pm 14 \cdot 3$ & $40+14 \cdot 8$ \\
\hline $\begin{array}{l}\text { Sex }- \text { no. }(\%) \\
\text { Male } \\
\text { Female }\end{array}$ & $\begin{array}{l}42(41.6 \%) \\
59(58.4 \%)\end{array}$ & $\begin{array}{l}13(40.6 \%) \\
19(59.4 \%)\end{array}$ \\
\hline $\begin{array}{l}\text { Hepatitis B vaccination - no. (\%) } \\
1 \text { complete cycle } \\
\text { More than } 1 \text { cycle }\end{array}$ & $\begin{array}{l}46(45.5 \%) \\
55(54.5 \%)\end{array}$ & $\begin{array}{l}14(43.8 \%) \\
18(56 \cdot 2 \%)\end{array}$ \\
\hline
\end{tabular}


Of the 133 randomised participants, 132 received at least one dose of HBAI20 vaccine or HBVaxPro $R-10 \mu \mathrm{g}$ vaccine. There were 117 participants included in the $\mathrm{mITT}$ immunogenicity analysis; 15 subjects were excluded, mainly due to seroprotection attained prior to study vaccination (Figure 7.1). A total of 116 participants received all three doses (one drop out in the HBAI20 group due to an adverse event after one vaccination).

A total of $80(92.0 \%)$ participants in the HBAI20 group and $23(79.3 \%)$ participants in the HBVaxPro $R-10 \mu \mathrm{g}$ group achieved seroprotection, as measured at $1-3$ months after the third vaccination, $p=0.068$. At one month after the first vaccination, seroprotection rates were respectively $64.0 \%$ vs $69.0 \%(p=0.761)$ and these numbers were $82.8 \%$ vs $72.4 \%$ $(p=0.172)$ at one month after the second vaccination. One to 3 months following the last vaccination, 55 participants $(63.2 \%)$ in the HBAI20 group and $15(51.7 \%)$ in the HBVaxPro $R-10 \mu \mathrm{g}$ group had anti-HBs levels $>100 \mathrm{mIU} / \mathrm{mL}(p=0 \cdot 190)$.

The GMCs were higher in the HBAI20 group than in the HBVaxPro $®-10 \mu g$ group after vaccination with one $(21.9 \pm 15.1$ vs $17.8 \pm 10 \cdot 7, p=0.390)$, two $(72.4 \pm 12.3$ vs $41.7 \pm$ $11.5, p=0.157)$ and three study vaccines $(162 \cdot 2 \pm 7.9$ vs $64.6 \pm 10 \cdot 2, p=0.037)$. 


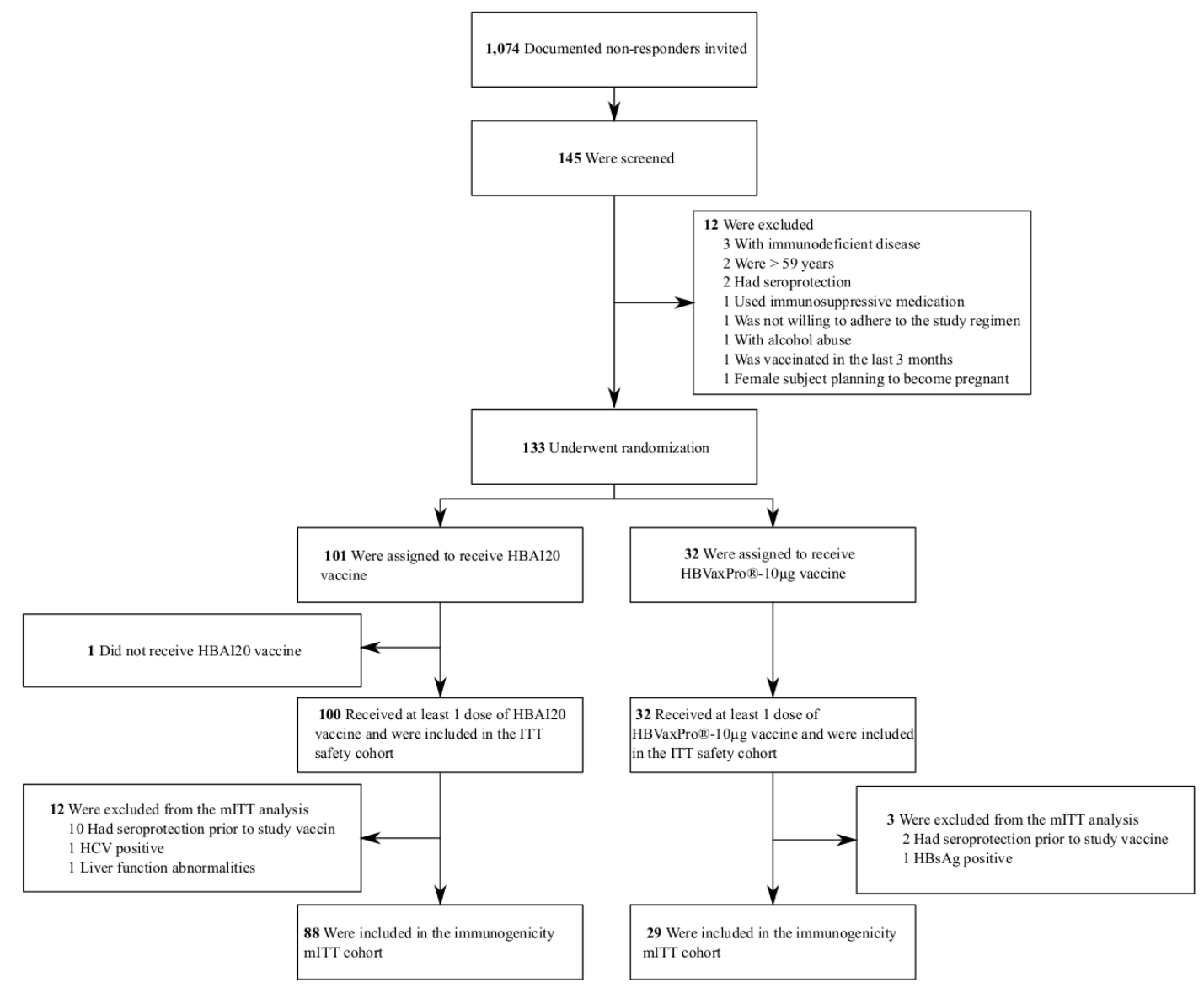

Figure 7.1: Flow chart of the study. Abbreviations: $\Pi T$ : intention-to-treat analysis; mITT: modified ITT analysis; HCV: hepatitis C virus; HBsAg: hepatitis B surface antigen.

166 | Chapter 7 
Using a generalized linear mixed model, adjusting for stratification factors, the primary endpoint was met and a higher odds of seroprotection with the HBAI20 vaccine was shown (adjusted OR $=3.48$, lower bound of $95 \% C I=1.19, p=0.028$ ) (Table 7.2). Since imputation of one missing value at visit 4, i.e. 1 - 3 months after the third vaccination, resulted in a seroprotected score, results from table 2 correspond to the best case scenario. For the worst case scenario, i.e. person with missing value did not achieve seroprotection, HBAI20 vaccine was still shown to give a higher odds of seroprotection (adjusted OR = 2.95, lower bound of $95 \% \mathrm{CI}=1.05, \mathrm{p}=0.042$ ).

Table 7.2: Results of the generalised linear mixed model. Age, sex and hepatitis B vaccination history were included as fixed effects in the model, in addition to vaccine allocation, i.e. treatment effect. Trial site was included as a random effect

\begin{tabular}{l|c|c|c}
\hline Characteristic & $\begin{array}{c}\text { Estimate } \\
\text { (SE) }\end{array}$ & OR (95\% CI) & $\boldsymbol{P}$ Value \\
\hline HBAI20 vaccine $^{\dagger}$ & $1.25(0.65)$ & $3.48(1.19-\infty)$ & 0.028 \\
\hline Age ( $\geq 40$ years) & $-0.88(0.73)$ & $0.42(0.10-1.76)$ & 0.231 \\
\hline Male sex & $-0.47(0.64)$ & $0.62(0.18-2.19)$ & 0.459 \\
\hline More than 1 hepatitis B vaccination cycle & $-1.60(0.82)$ & $0.20(0.04-1.03)$ & 0.054 \\
\hline
\end{tabular}

Abbreviations: SE: standard error; OR: odds ratio; CI: confidence interval.

Within the group of individuals who received the HBAI20 vaccine, seroprotection after three vaccinations was seen in $11(73.3 \%)$ out of 15 participants without pain at the injection site, compared to $76(96 \cdot 2 \%)$ out of 79 participants with pain at the injection site, $p=0.012$. In the HBVaxPro $(10 \mu$ g group, no association was found between pain at the injection site and seroprotection after three vaccinations (6/10 (60.0\%) without pain at the injection site vs $18 / 20(90 \cdot 0 \%)$ with pain at the injection site, $p=0 \cdot 141)$. 
There was a higher incidence of solicited local adverse events in the HBAI20 group than HBVaxPro $(10 \mu$ group $(13.7 \%$ vs $8.7 \%, p<0.001)$, while the overall incidence of systemic adverse events was similar for both vaccines $(4.0 \%$ vs $3.4 \%, p=0.198)$. The percentage of participants with mild, moderate and severe adverse events (local and systemic) in each group is illustrated in figure 7.2.

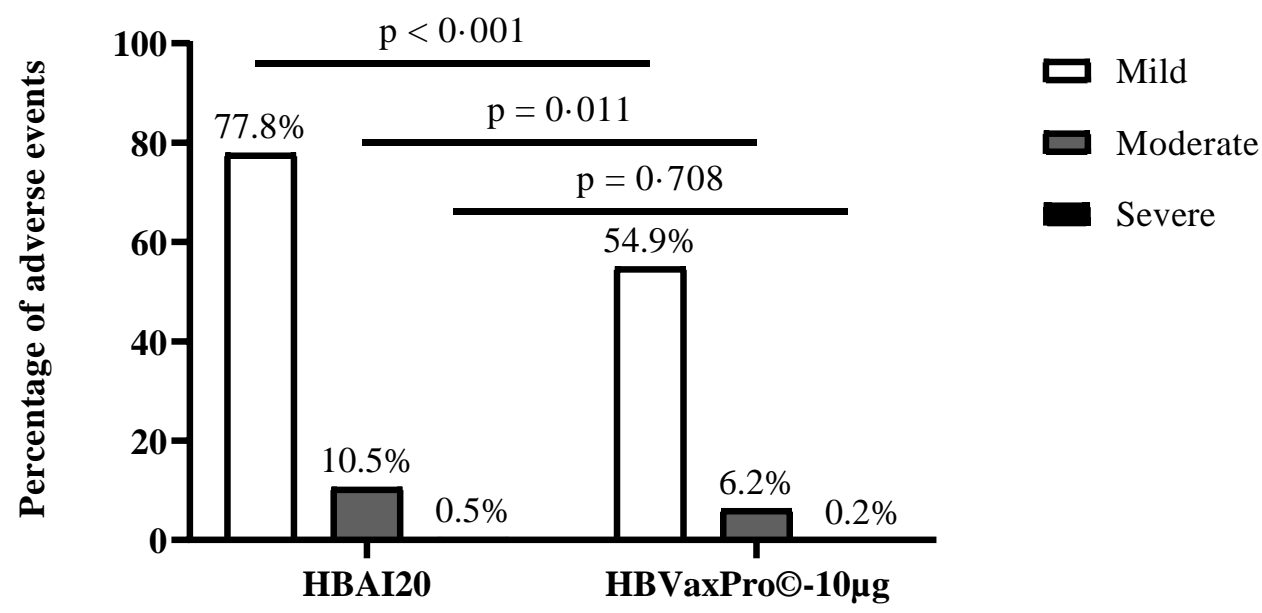

Figure 7.2: Percentage of mild, moderate and severe adverse events (local and systemic) at the day of vaccination and the four consecutive days after three vaccinations with the HBAI20 vaccine or the HBVaxPro $®-10 \mu g$ vaccine 
The most frequently reported local adverse event in both the HBAI20 group (32.7\%) and HBVaxPro $R-10 \mu g$ group (18.6\%) was pain at the injection site, $p<0.001$. Pain at the injection site resolved within four days after vaccination for $94 \%$ and $97 \%$, respectively. There were no severe local adverse events in the HBVaxPro $®-10 \mu g$ group and these were low in the HBAI20 group. None of the participants experienced severe local adverse events for longer than four days. The frequencies of any and severe local adverse events are shown in Table 7.3.

Table 7.3: Incidence of local solicited adverse events during the day of vaccination and each of the consecutive four days after the first, second and third vaccination

\begin{tabular}{|c|c|c|c|c|}
\hline Local adverse events & & $\begin{array}{c}\text { HBAI20 } \\
(n=1,345 \text { days })\end{array}$ & $\begin{array}{c}\text { HBVaxPro } \AA-10 \mu g \\
\text { (n = } 435 \text { days) }\end{array}$ & $P$ Value \\
\hline \multirow[t]{2}{*}{ Pain at the injection site } & Any & $440(32 \cdot 7 \%)$ & $81(18 \cdot 6 \%)$ & $<0.001$ \\
\hline & Severe & $0(0.0 \%)$ & $0(0.0 \%)$ &.$\cdot$ \\
\hline \multirow{2}{*}{$\begin{array}{l}\text { Impaired movement of } \\
\text { injected arm }\end{array}$} & Any & $198(14 \cdot 7 \%)$ & $43(9 \cdot 9 \%)$ & $0 \cdot 013$ \\
\hline & Severe & $0(0.0 \%)$ & $0(0.0 \%)$ & .. \\
\hline \multirow[t]{2}{*}{ Redness } & Any & $95(7.06 \%)$ & $16(3 \cdot 7 \%)$ & $0 \cdot 015$ \\
\hline & Severe & $2(0 \cdot 1 \%)$ & $0(0.0 \%)$ & $1 \cdot 000$ \\
\hline \multirow[t]{2}{*}{ Swelling } & Any & $79(5 \cdot 9 \%)$ & $25(5 \cdot 8 \%)$ & $1 \cdot 000$ \\
\hline & Severe & $1(0 \cdot 1 \%)$ & $0(0.0 \%)$ & 1.000 \\
\hline \multirow[t]{2}{*}{ Induration } & Any & $106(7.9 \%)$ & $24(5 \cdot 5 \%)$ & $0 \cdot 123$ \\
\hline & Severe & $1(0 \cdot 1 \%)$ & $0(0.0 \%)$ & 1.000 \\
\hline
\end{tabular}


The most frequently reported systemic adverse event was fatigue $(10.6 \%$ vs $9.7 \%, p=$ 0.655 ), which resolved within four days post-vaccination in $96 \%$ and $91 \%$ of the participants in the HBAI20 group and HBVaxPro $(10 \mu$ g group, respectively. The incidence of severe systemic adverse events was low and comparable in both groups. In all cases, severe systemic adverse events resolved within four days. Table 7.4 lists the overall incidence of systemic adverse events.

Table 7.4: Incidence of systemic solicited adverse events during the day of vaccination and each of the consecutive four days after the first, second and third vaccination

\begin{tabular}{|c|c|c|c|c|}
\hline $\begin{array}{c}\text { Systemic adverse } \\
\text { events }\end{array}$ & & $\begin{array}{c}\text { HBAI20 } \\
(\mathrm{n}=\mathbf{1}, \mathbf{3 4 5} \text { days })\end{array}$ & $\begin{array}{c}\text { HBVaxPro@-10 } \mu g \\
\text { (n = } 435 \text { days) }\end{array}$ & $P$ Value \\
\hline \multirow[t]{2}{*}{ Fever } & Any & $10(0 \cdot 7 \%)$ & $2(0.5 \%)$ & $0 \cdot 771$ \\
\hline & Severe & $1(0 \cdot 1 \%)$ & $1(0 \cdot 2 \%)$ & 0.985 \\
\hline \multirow[t]{2}{*}{ Headache } & Any & $89(6 \cdot 6 \%)$ & $25(5 \cdot 7 \%)$ & 0.595 \\
\hline & Severe & $0(0.0 \%)$ & $1(0 \cdot 2 \%)$ & $0 \cdot 552$ \\
\hline \multirow[t]{2}{*}{ Fatigue } & Any & $142(10 \cdot 6 \%)$ & $42(9 \cdot 7 \%)$ & $0 \cdot 655$ \\
\hline & Severe & $2(0 \cdot 1 \%)$ & $0(0.0 \%)$ & $1 \cdot 000$ \\
\hline \multirow[t]{2}{*}{ Vomiting } & Any & $1(0 \cdot 1 \%)$ & $1(0 \cdot 2 \%)$ & 0.985 \\
\hline & Severe & $0(0.0 \%)$ & $0(0.0 \%)$ &.. \\
\hline \multirow[t]{2}{*}{ Diarrhoea } & Any & $28(2 \cdot 1 \%)$ & $4(0.9 \%)$ & $0 \cdot 168$ \\
\hline & Severe & $0(0.0 \%)$ & $0(0.0 \%)$ & .. \\
\hline
\end{tabular}

Unsolicited symptoms were reported by 58 (57.4\%) subjects receiving HBAI20 vaccine and by $18(56 \cdot 3 \%)$ subjects receiving HBVaxPro $(-10 \mu g, p=0 \cdot 210$. Six (5.9\%) individuals in the HBAI20 group and four (12.5\%) individuals in the HBVaxPro $(10 \mu \mathrm{g}$ had increased alanine aminotransferase values ( $>$ ULN) after intervention, $p=0 \cdot 220$. There were 10 cases with signs of asymptomatic urinary tract infection, all in healthy non-pregnant women receiving HBAI20 vaccine; this number was zero in those receiving HBVaxPro $R-10 \mu g$ vaccine, $p=0 \cdot 250$. No medically significant abnormalities were observed in haematological, renal and thyroid parameters. Two serious adverse events were reported during the study period, one in the HBAI20 group (i.e. hernia nuclei pulposi) and one in the HBVaxProß$10 \mu \mathrm{g}$ (i.e. epileptic seizure). Both were considered to be unrelated to vaccination by the investigators. 


\section{DISCUSSION}

Hepatitis B vaccine non-responders, i.e. individuals with a deficient antibody response after three or more vaccinations, represent an unresolved problem in hepatitis $B$ vaccination. ${ }^{103}$ In order to reach hepatitis B elimination by 2030 as advocated by the World Health Organization, it is important to establish protective anti-HBs levels also in hepatitis B vaccine non-responders, who represent $5-10 \%$ of the vaccinated adult population. ${ }^{14,94,103}$

This phase 2 trial demonstrated that immunogenicity of the investigational HBAI20 vaccine was superior to that of the licensed $\mathrm{HBVaxPro}(\mathbb{B}-10 \mu \mathrm{g}$ vaccine, when given to hepatitis $B$ vaccine non-responders at 0,1- and 2-months schedule. Safety was comparable between both vaccines.

Seroprotection rates in our comparator arm HBVaxPro $(-10 \mu \mathrm{g}$ were higher compared to previous studies. ${ }^{93,96-99}$ Previous studies enrolling hepatitis $B$ vaccine non-responders have found that the first revaccination dose with a licensed hepatitis $B$ vaccine induced seroprotection in $25-58 \%$ of the individuals, with seroprotection reaching $50-69 \%$ after three revaccination doses. ${ }^{93,96-99}$ In our study, three revaccinations with HBVaxPro $(-10 \mu \mathrm{g}$ induced protective anti-HBs levels in $79 \%$ of the non-responders. These variations can be explained by the use of different licensed vaccines (e.g. Engerix- $B \circledast$, Recombivax $H B \otimes$ ) and distinct study populations with different definitions of non-responder. ${ }^{102,} 213,214$

The primary endpoint of this study was met: compared to $\mathrm{HBVaxPro}(-10 \mu \mathrm{g}$, subjects receiving HBAI20 vaccine were about 3.5 times more likely to be seroprotected around 1 3 months following the last vaccination. The observed seroprotection rates after three vacccinations with HBAI20 vaccine was $92 \%$, which is higher than expected in this population of hepatitis $B$ vaccine non-responders. Moreover, seroprotection rates after two doses of HBAI20 vaccine were comparable to those attained after three doses of the licensed HBVaxPro $(10 \mu g$ vaccine in this healthy non-responder population. It would be worth to investigate HBAI2O vaccine in HBV naive travellers to intermediate or high HBV endemic areas and those with high-risk behaviour (e.g. injecting drug users, persons with multiple sex partners, men who have sex with men, and sex workers), whether an accelerated antibody response compared to the control vaccine could be achieved. 
One should acknowledge that the difference in seroprotection between both vaccines in this study is only linked with the adjuvant AI20. ${ }^{244}$ AI20 is a cytokine-based adjuvant consisting of $20 \mu \mathrm{g}$ recombinant human IL-2 attached to $20 \mu \mathrm{g}$ aluminium hydroxide. ${ }^{216,244} \mathrm{IL}-2$ is critical in promoting generation of Thelper 1 (Th1) and Th2 cells, while IL-2 also improves dendritic cell-mediated stimulation of allogeneic CD4 T cell proliferation. $226,231,232,244,251$ Taking into account the additional immunogenic properties of the AI20 adjuvant, it might be reasonable to consider the AI20 adjuvant for other vaccines conferring a suboptimal response, such as for influenza or tuberculosis vaccines. Moreover, the use of cytokines as adjuvants can support the rational design of vaccines by targeting specific immune pathways.

Safety data from this phase 2 study indicate comparable rates of systemic solicited adverse events, unsolicited symptoms and serious adverse events, except for significantly higher rates of local adverse events within the HBAI20 group. The majority of the adverse events resolved within five days and only a few adverse events were reported as severe. The higher incidence of local adverse events could mainly be attributed to pain at the injection site which was reported by $33 \%$ in HBAI20 group and $19 \%$ in HBVaxPro $\AA-10 \mu$ g group, respectively, and was similar to those reported in previous studies with adjuvanted hepatitis

B vaccines. ${ }^{97,98}$ With respect to local adverse events, we could also show greater immunity, i.e. seroprotection, in those participants with pain at the injection site in the HBAI20 group. Further research is warranted whether the presence of pain at the injection site is associated with more attraction of innate cells to the inoculum and subsequent higher seroprotection rate.

\section{CONCLUSIONS}

In conclusion, these results are suggestive of increased immunogenicity of the HBAI20 vaccine among healthy non-responders to three or more hepatitis $B$ vaccinations, in addition to confirming that the HBAI20 vaccine could be safely administered. These results support further studies to assess the benefits of the HBAI20 vaccine in other risk groups for a suboptimal immune response, i.e. patients with advanced liver disease, haemodialysis patients, and patients with other immunodeficient conditions. 


GENERAL DISCUSSION

AND

SUMMARY 



\section{GENERAL DISCUSSION}

Europe is one of the regions committed to the global goal of eliminating viral hepatitis B as a major public health threat by 2030 , i.e. $90 \%$ reduction in annual incidence and a $65 \%$ decrease in annual viral hepatitis B-related deaths. ${ }^{14}$ With a focus on the past, the present and future directions in HBV infection and control, this thesis partakes in this path to eliminate hepatitis B in Europe.

\section{HEPATITIS B DISEASE PROGRESSION}

In chapter 1 we aspired to understand the disease progression of Caucasian patients in the HBeAg-negative chronic infection phase (previously termed 'inactive carrier') with the aim to precise the management for chronic HBV infection. In fact, much of the data upon which the management of this infection phase is based has been derived from past studies in Asia. 7, 59, 109-119 Considering the fact that sensitive PCR-based HBV DNA assays only became available the last decade, the long-term (10 years or more) disease outcome of Caucasian patients in Europe with HBeAg-negative chronic infection, particularly those with baseline HBV DNA level $>2,000 \mathrm{IU} / \mathrm{mL}$, is unclear. Our study showed that the estimated 10 -year risk of progression to chronic active hepatitis in patients with baseline HBV DNA level $\leq$ $2,000 \mathrm{IU} / \mathrm{mL}$ was significantly lower (1.2\%) than those patients with baseline HBV DNA level $>2,000 \mathrm{IU} / \mathrm{mL}$ (11.7\%). Advanced liver disease developed in $2.2 \%$ with higher probability in patients with HBV DNA level $>2,000 \mathrm{IU} / \mathrm{mL}(5.2 \%)$ in those with HBV DNA > $2,000 \mathrm{IU} / \mathrm{mL}$ vs $1.5 \%$ in those with HBV DNA $\leq 2,000 \mathrm{IU} / \mathrm{mL}$ ). In conclusion, Caucasian patients living in Europe with a HBV DNA level $\leq 2,000 \mathrm{IU} / \mathrm{mL}$ have an excellent long-term prognosis and can therefore be considered as true inactive carriers, challenging the need of a strict long-term follow-up by a hepatologist in these patients. On the other hand, patients with HBV DNA level > 2,000 IU/mL are at risk for advanced liver disease and need regular specialized follow-up. According to international practice guidelines on hepatitis $B$, this subgroup with HBV DNA levels $>2,000 \mathrm{IU} / \mathrm{mL}$ should be assessed with ALT determination every 3 months for 1 year and subsequently every 6 months in the absence of treatment indication. 7, 59, 65 Patients with HBeAg-negative chronic infection should also be monitored with periodical determinations of HBV DNA levels as well as for liver fibrosis severity by noninvasive methods. ${ }^{7,59,65}$ 


\section{HEPATITIS B EPIDEMIOLOGY}

Along with a better understanding of disease progression in patients with chronic HBV infection, progress towards hepatitis B elimination in Europe will depend on the extent to which countries are able to elucidate the true extent of the hepatitis $B$ disease burden. Accordingly, in chapter $\mathbf{2}$ we determined the present acute hepatitis B notification rates and in chapter $\mathbf{3}$ we assessed the current prevalence of chronic HBV infection in Belgium. Recent data on acute hepatitis B notification rates and prevalence of chronic HBV infection were available for the neighbouring countries (i.e. the Netherlands, France and Germany), but prior data on hepatitis B notification rates in Belgium could not distinguish between acute or chronic, and the last prevalence study in the general Belgian population dated from 2003. $44,76-78,131$

In our study on acute hepatitis B notification rates (chapter 2), we collaborated with the Agency for Care and Health, Flanders, Belgium. Before 2009, a differentiation between acute or chronic HBV infection was not possible. Accordingly, we collected information between 2009 and 2017 since from that time only acute hepatitis B was reported to the Agency for Care and Health. In line with findings in other European countries, we showed a decreasing trend of acute hepatitis B notification rates in Flanders from 1.6 per 100,000 population in 2009 to 0.7 in 2017.44 The downward trend in $5-14$ year-olds, $15-24$ year-olds and 25 - 34 year-olds in our study might be explained by the universal infant vaccination with a temporarily catch-up vaccination for the age cohort $10-13$ years, which has been implemented since 1999 in Flanders. A decrease in the acute hepatitis B notification rates for the age group $\geq 35$ years could not be explained by universal infant hepatitis $B$ vaccination but might be clarified by targeted vaccination and health attitudes of specific adult patient groups (e.g. haemophilia patients), employees who have an occupational risk for HBV infection, travellers to HBV endemic countries and certain HBV risk groups (e.g. men who have sex with men). Besides reported vaccination uptake in sex workers, health care workers, travellers to HBV endemic countries and pregnant women, there are no recent studies assessing the uptake of vaccination in other adult groups in Belgium (e.g. men who have sex with men) which is howbeit warranted to further evaluate hepatitis $B$ infection and control measures. ${ }^{146-151}$ 
Belgium has a national hepatitis C plan, but a national strategy addressing hepatitis $B$ is at present nonexistent. Neighbouring countries, i.e. the Netherlands, France and Germany, are - among others - one of the few European countries to implement a comprehensive viral hepatitis policy for prevention and control including hepatitis B. ${ }^{252-254}$

Despite the recommendation of hepatitis B screening in pregnant women in Belgium and the reported high effectiveness of hepatitis $B$ vaccination and immunoglobulins in preventing mother-to-child transmission, five mother-to-child infections were documented during study follow-up. ${ }^{137,158}$ Infants who become infected perinatally have a $80-90 \%$ likelihood of developing chronic HBV infection if the mother is positive for hepatitis B e antigen, highlighting the need to strengthen the hepatitis $B$ registration for pregnant women. ${ }^{30,129}$

As part of the European Vaccine Action Plan 2015 - 2020, the WHO European Region pledged to prioritize the control of hepatitis $B$ through vaccination. The target for hepatitis $B$ are as follows: $(1) \geq 95 \%$ coverage with the three or four doses of hepatitis $B$ vaccine within the universal infant vaccination program, (2) $\geq 90 \%$ coverage with screening in pregnant women, (3) $\geq 90 \%$ birth-dose vaccination coverage within 24 hours of birth and (4) HBsAg prevalence $\leq 0.5 \%$ among vaccinated children. ${ }^{256}$ For the first target, the coverage with four doses hepatitis B vaccine was $92.9 \%$ in 2016, Flanders, Belgium. ${ }^{142}$ The HBsAg prevalence among the vaccinated cohort in Belgium was $0.2 \%$, thereby attaining the fourth target of the European Vaccine Action Plan 2015 - 2020. ${ }^{134}$ For the second and third target, it is currently unknown how many pregnant women are actually screened for HBV infection and how many infants from infected mothers receive the timely birth dose vaccination in Belgium. A national electronic database for the recording of HBV markers in pregnant women, such as Praeventis in the Netherlands, is therefore desired in Belgium. ${ }^{257}$ Process evaluation on the data from Praeventis in the Netherlands indicated that $>99 \%$ of the pregnant women were screened for HBV infection between the year $2009-2015.258$ The implementation of an electronic registry database for pregnant women in Belgium with subsequent process evaluation could identify gaps in current HBV prevention and control.

Aside from acute hepatitis B notification rates in chapter 2, chapter $\mathbf{3}$ described the present hepatitis $B$ prevalence of chronic HBV infection in a multi-ethnic region situated in Middle-Limburg, Belgium, year 2017. In this study, we found an overall HBsAg prevalence of $1.0 \%$ in the emergency department population. Previous population-based studies in Belgium, one in 1993 - 1994 and one in 2003, indicated a lower HBsAg prevalence of $0.7 \%$ in the general population. ${ }^{130,131} \mathrm{~A}$ concern is that the emergency department population in 
our study might impose a bias towards subjects in certain risk groups. However, high risk groups for HBV infection might have been underrepresented in the previous populationbased studies. ${ }^{130,131}$ Moreover, the inclusion of specific HBV risk groups in our study allowed us to demonstrate the most important risk factors for HBV infection in Belgium for the first time: age-gender-ethnicity interaction, presence of HBV infected household member, hepatitis $C$ virus infection, men who have sex with men, and haemodialysis. Although we established the association between abovementioned characteristics and HBV infection, we could not accurately estimate the HBsAg prevalence in the different risk groups due to low numbers in each risk group. This was outside the scope of the current study. It is therefore warranted to conduct new epidemiological studies also in HBV risk groups, such as men who have sex with men and prisoners, in order to obtain complete figures for Belgium.

Discrepancy in HBsAg prevalence in our study population in relation to previous populationbased studies could also be explained by the large immigrant population in Middle-Limburg, i.e. $21.0 \%$ in contrast to $8.0 \%$ in Flanders (Limburg in cijfers, personal communication). In this respect, we found a high HBsAg prevalence (4.7\%) in first-generation migrants (FGMs) born in intermediate- or high-prevalence areas, highlighting the fact that migrants are an important group at risk for HBV infection and therefore national HBV screening in this group is warranted. ${ }^{167,} 168$ In line with our findings, compared to the native population a higher HBsAg prevalence was found in FGMs living in neighbouring countries such as the Netherlands, France and Germany. ${ }^{76,77,154}$

\section{HEPATITIS B SCREENING}

Surveillance data show that more than $50 \%$ of chronic HBV patients in Belgium were born in intermediate- or high-prevalence countries. ${ }^{79}$ In the Netherlands, Ireland, Sweden and Cyprus, migrants from intermediate or high endemic countries even contribute up to $\geq 90 \%$ of the total chronic HBV cases. ${ }^{79}$ The difference between Belgium and the Netherlands in relative contribution of foreign-born migrants to the total chronic HBV population could be explained by the higher HBsAg prevalence among native Belgians (0.4-1.2\%) compared to native Dutch $(0.1-0.2 \%)$ individuals, which subsequently might be a reflection of variations in prevention and control strategies between both countries. ${ }^{79}$ Modelling studies further established that screening migrants for HBV infection is likely to be clinically effective and cost-effective. $74,75,259,260$ However, most hepatitis B screening studies in FGMs involved southeast Asians in the USA, Canada and Australia. ${ }^{81-90}$ Less is known about Turkish migrants in Belgium, especially those born in Belgium with a foreign-born parent, i.e. 
second-generation migrants (SGMs). Henceforth, in chapter 4, we described a study protocol for an outreach hepatitis B screening program in the Turkish migrant population (FGMs and SGMs), Middle-Limburg. The results from this outreach hepatitis B testing campaign were consecutively depicted in chapter 5 .

Focus group discussions with Turkish delegates in Middle Limburg suggested several sociocultural, religious and other factors to be important for hepatitis B screening. These were among others - the belief of being responsible for one's own health, association of HBV infection with high-risk sexual behaviour and little knowledge about hepatitis B. Our findings with respect to determinants of screening are supported by other researchers in the field of cancer screening as well as hepatitis B screening. ${ }^{181,261-264}$ We therefore developed a flyer and poster to increase the awareness regarding hepatitis $B$ and to emphasize the benefits of screening in order to motivate the Turkish population to opt for HBV screening. The information was made available in the Dutch and Turkish language. Key figures of Turkish organizations were also engaged in the outreach hepatitis B testing as they were to invite the Turkish population for educational sessions using flyers and posters. Educational sessions in Turkish organizations were to be coordinated after traditional meetings and the Turkish participants would subsequently have the opportunity to be screened for HBV infection.

In our outreach hepatitis B program, increasing awareness of the Turkish migrant population might explain the high participation rate $(97 \%)$ and the high referral to the hepatologist $(90 \%)$ in case of newly diagnosed HBsAg positive patients. ${ }^{81}$ While we did not evaluate changes in knowledge, earlier studies suggest that using the target population's language and engaging community leaders - as was the case in our study - are important in improving awareness of viral hepatitis. ${ }^{81,84}$ Collaborations with general practitioners and other health care professionals are also crucial as it increases referral numbers and adherence to follow-up. ${ }^{81,265}$ In that respect, our study was communicated with the general practitioners in the pre-screening phase as well as during and after the conduct of the community-based hepatitis B testing. The study was also embedded within Limburg Clinical Research Center (LCRC) with a close collaboration between the two hospitals in Middle Limburg, i.e. Hospital East-Limburg (ZOL) and Jessa Hospital, and the University Hasselt.

With a HBsAg prevalence of 3.0\% in Turkish FGMs in our study, we confirmed previous findings of $3.0-5.0 \% \mathrm{HBsAg}$ positivity in studies conducted in the Netherlands and Germany. ${ }^{184,185}$ Although the high HBsAg prevalence in Turkish FGMs reflects the hepatitis 
B endemicity in the country of origin, our finding of $1.5 \% \mathrm{HBSAg}$ positivity in Turkish SGM is higher than that found in the native Belgian population $(0.7 \%)$ and might be explained by the combination of intermediate hepatitis B prevalence in Turkey and suboptimal primary prevention strategies in the country of birth, i.e. Belgium. ${ }^{80,130-132,193}$ First, all Turkish SGM with chronic HBV infection were borm before the recommendation of hepatitis $B$ screening in pregnant women in Belgium in $1998 .{ }^{191}$ Second, all of the seven HBsAg positive SGMs were borm before 1999, the year universal infant vaccination with catch-up of one age cohort 10 - 13 year-olds was implemented in Belgium. However, although catch-up vaccination of adolescents in Belgium should also cover birth cohorts between 1987 and 1999, one out of seven SGMs with chronic HBV infection in our study belonged to one of these birth cohorts. An explanation for this could be sought in the reported high coverage rates in the birth cohorts targeted by the Belgian vaccination program (after 1999 and 1987-1989) with a clear dip in between (1990 - 1998). ${ }^{134}$ Moreover, in birth cohorts targeted by catch-up vaccination in adolescents (1987 - 1998), prior Belgian studies indicated lower immunisation coverage rates when the mother was born outside of Western Europe. ${ }^{144,} 194$ Thus, our study adds interesting data to support national HBV screening in Turkish FGMs and emphasizes the importance of further research on HBV prevalence in SGMs not covered by primary prevention strategies.

All Turkish participants who ought to be susceptible for HBV infection were asked by letter to contact their general practitioner for initiation of hepatitis B vaccination. In our study, general practitioners were also informed of the hepatitis B screening result by letter. However, only $20 \%$ of the susceptible individuals initiated hepatitis B vaccination in our study, which is lower than the expected $52-89 \%$ among migrant populations in the USA but in line with an outreach screening project among Chinese migrants in the Netherlands reporting a vaccination uptake of $22 \% .81,83,200-204$ These differences could be attributed to different migrant populations, costs for vaccination and different contact approaches to invite for vaccination.

When assuming an HBsAg prevalence of 2.6 - 5.3\% in the Turkish FGMs, a participation rate of $30 \%$, a linkage to care of $80 \%$ and a HBeAg-negative chronic infection state in $90 \%$ of HBsAg positive patients, a community-based HBsAg testing and subsequent treatment in Turkish FGMs within a European health system would be cost-effective. ${ }^{49}$ Even in the situation of low participation rate (10\%) and low linkage to care $(60 \%)$, HBsAg screening and early antiviral treatment would still be cost-effective according to Suijkerbuijk and 
colleagues. ${ }^{49} \mathrm{HBSAg}$ screening and treatment in FGMs dominated the strategy of adding vaccination to all susceptible migrants in two studies conducted in Canada and one study from USA with the majority of migrants being Asian and African. ${ }^{266-268}$ The approach of screening all migrants for anti-HBs and vaccination was furthermore not cost-effective in the three studies. ${ }^{266-268}$ Nonetheless, when screening for HBsAg and anti-HBs was offered to close contacts of HBsAg positive patients and vaccinated if needed, it was associated with more gained quality-adjusted life years (QALY) and only a little increase in costs compared to screen and treat strategy (39,903 dollars/QALY vs 36,088 dollars/QALY). ${ }^{266}$ In the absence of cost-effectiveness studies of vaccination in migrants within the European health system, we call for a European cost-effective analysis of three strategies compared to no HBV screening in FGMs: 1) screen and treat strategy, 2) screen, treat and vaccinate close contacts if needed and 3) screen, treat and vaccinate all.

Along with our outreach hepatitis $B$ testing in the Turkish migrant population, large-scale trials in USA, Asia and Europe demonstrated the feasibility of community-based hepatitis B screening. ${ }^{83,169,185,200,202-204,269-273}$ Although testing in community setting is more resource intensive than testing in health care setting, scaling up community based interventions could screen patients who may not otherwise reach the health care system and these interventions could decrease the hepatitis B disease burden in Europe. ${ }^{274}$

\section{UNRESOLVED PROBLEM IN HEPATITIS B VACCINATION}

Since the introduction of recombinant hepatitis B vaccines in 1986, over 1,000 million doses have been given and these vaccines have been proven to be safe. However, non-response (anti-HBs titre $<10 \mathrm{mIU} / \mathrm{mL}$ ) to primary hepatitis B vaccination schedule occurs in $5-12 \%$ of the healthy people. ${ }^{93-95}$ Persons with this deficient antibody response are called nonresponders and remain an unresolved problem in hepatitis $B$ vaccination in order to reach hepatitis B elimination. As the currently recombinant hepatitis B vaccines all have an aluminium-based adjuvant, we attempted to increase the immune response by combining the current recombinant HBVaxPro@- $10 \mu \mathrm{g}$ vaccine with a new cytokine-based adjuvant AI20. The new AI20 adjuvant consists of IL-2 $(20 \mu \mathrm{g})$ adsorbed to aluminium-hydroxide $(20 \mu \mathrm{g})$. This new combined vaccine is called HBAI20 hepatitis B vaccine and seemed safe according to the phase 1 study in healthy naive adults and non-responders as described in chapter 6. Moreover, seroprotection was achieved in $90 \%$ of the healthy non-responders. The number of healthy naïve adults $(n=24)$ and healthy non-responders $(n=10)$ was small in this phase 1 study. Subsequently, in a well-designed double-blinded, randomised, 
controlled phase 2 trial in healthy non-responders $(n=133)$ we further assessed the immunogenicity and safety of the new HBAI20 hepatitis $B$ vaccine compared to the recombinant $H B V a x P r o(C)-10 \mu g$ vaccine. As shown in chapter 7 , next to confirming safety of the HBAI20 vaccine, the results of the phase 2 study demonstrated increased immunogenicity of the HBAI20 vaccine compared to the recombinant HBVaxPro@- $10 \mu \mathrm{g}$ vaccine when given at a 0,1 and 2 months schedule in healthy non-responders. These results support future studies on the immunogenicity and safety of HBAI20 vaccine in other persons who are at an increased risk of a deficient immune response to hepatitis $B$ vaccination, e.g. transplant recipients and haemodialysis patients. Moreover, our finding of comparable seroprotection rates after two doses of HBAI20 vaccine with three doses of HBVaxPro@- $-10 \mu \mathrm{g}$ vaccine highlights the need to investigate whether HBAI20 vaccines could provide an accelerated antibody response in individuals with high-risk at HBV infection, e.g. injecting drug users and men who have sex with men. Since the increased immunogenicity of HBAI20 vaccine compared to HBVaxPro(C)-10 $\mu \mathrm{g}$ vaccine is only linked to the new adjuvant AI20, it is also worth to investigate the benefits of adding this new AI20 adjuvant to other vaccines conferring a suboptimal immune response, such as for influenza or tuberculosis vaccine.

Although vaccine hesitancy, i.e. delay in acceptance or refusal of vaccination, is a global problem impairing the success of vaccination programs, vaccine hesitancy in hepatitis $B$ naïve and non-responder population was not systematically assessed in the current thesis. ${ }^{279}$ Determinants of vaccine hesitancy could be arranged in three categories according to the Strategic Advisory Group of Experts (SAGE) on immunization: contextual influences (e.g. media environment), individual and group influences (e.g. knowledge/awareness), and vaccine-specific issues (e.g. risk/benefit, costs). ${ }^{280}$ In view of risk-benefit relations, knowledge/awareness and religion/culture/gender/socio-economic factors being the three main reasons for vaccine hesitancy across the globe, we presume that vaccine hesitancy is less prevalent among our study population of healthcare workers compared to the general adult population. ${ }^{280}$ An important first step to address vaccine hesitancy is active listening and understanding the reasons why an individual is hesitant. Once there is more information available about what is motivating vaccine hesitancy, one should engage accordingly. On a community level, online platforms or the engagement of local figures were found to increase positive impressions on vaccination programs and reduce misperceptions. ${ }^{281}$ 


\section{CONCLUSION}

In this thesis, we focused on the past, present and future directions of HBV infection and control in Europe. First, we illustrated that using the cut-off HBV DNA value of $<2,000$ $\mathrm{IU} / \mathrm{mL}$ in Caucasian patients from Western Europe with HBeAg-negative chronic infection truly identified patients with a favourable long-term prognosis. Second, we determined present estimates on acute hepatitis $B$ notification rates and prevalence of chronic HBV infection in Belgium. Although recent data were available for the neighbouring countries, this information was nonexistent for Belgium. Third, focusing on the Turkish migrant population in Belgium, we provided data on the necessity of a national screening program in Europe for migrants from intermediate or high endemic countries, in addition to showing the feasibility of a community-based screening. Lastly, we demonstrated future directions for a new potent adjuvanted HBAI20 hepatitis B vaccine.

\section{FUTURE WORK}

Along with the contribution of new data on HBV infection and control in Europe, this thesis identified gaps in the systematic collection and monitoring of data related to prevention, e.g. number of pregnant women screened for HBV infection and timely birth dose vaccination in children from HBsAg positive mothers. Systematic data collection for the different steps along the cascade of care are also required at the level of the Agencies and Federal Government in Belgium. We further await the results from the recent population-based hepatitis B and C prevalence study conducted in Belgium by Sciensano. Moreover, while the number of new HBV infections have declined as a result of the implementation of a universal hepatitis B vaccination program in most European countries, large-scale interventions aimed to identify and treat those already infected (e.g. migrants from intermediate or high endemic country) are still necessary to achieve a $65 \%$ reduction in viral hepatitis B-related mortality as advocated by the WHO. 



\section{SUMMARY}

An estimated 257 million people are chronically infected with the hepatitis B virus (HBV), a disease that could manifest as none/minimal to severe inflammation of the liver. Patients with chronic HBV infection are mostly asymptomatic until severe complications develop, such as cirrhosis and hepatocellular carcinoma. Due to the asymptomatic nature of the disease, there is a considerable underdiagnosis of chronic HBV infection. This is a missed opportunity since diagnosis and subsequent early antiviral treatment could reduce the risk of cirrhosis and hepatocellular carcinoma. The numbers of hepatitis B-related deaths worldwide further show an increase from 520 thousand deaths in 1990 to 690 thousand in 2013. This number is 36 thousand for the European region. The World Health Organization, an organisation aiming at promoting public health, has called action towards the elimination of hepatitis B by 2030. The current thesis is embedded within these goals and strives towards elimination of HBV infection in Europe.

Inactive carriership, i.e. a chronic HBV infection phase with none/minimal liver inflammation, was previously defined on a maximum viral load of 20,000 units in the blood, i.e. HBV DNA $<20,000 \mathrm{IU} / \mathrm{mL}$. However, in chapter 1 we illustrated that those patients with a viral load below 2,000 IU/mL are the true inactive carriers with an excellent long-term prognosis and could be followed by the general practitioner. In contrast, patients with a viral load between 2,000 and 20,000 have a higher risk of advanced liver disease and are therefore in need of regular specialized follow-up.

Besides reviewing the natural history of chronic HBV infection, we determined the current hepatitis B burden in Belgium (chapter 2 and chapter 3). Recent data on hepatitis B were available for the neighbouring countries the Netherlands, France and Germany. In line with other European countries, a declining trend of new hepatitis B cases were found in Belgium. While hepatitis $B$ vaccination induces a decrease in the number of new cases, it has no impact on the number of individuals already infected with HBV infection. Accordingly it is of importance to diagnose and treat the undiagnosed patients with chronic HBV infection. In chapter 3, we tested the emergency department population of Ziekenhuis Oost-Limburg for HBV infection and showed that 1 out of 100 individuals was already infected with chronic HBV infection. Individuals born in countries endemic for hepatitis B (e.g. Middle-East, Africa) had a higher risk of chronic HBV infection, namely 4.5 out of 100 , compared to only 0.7 out of 100 individuals born in Belgium. 
In chapter 4 we described a protocol for hepatitis B testing in the Turkish community living in Belgium. Turkey is a country with a high prevalence for HBV infection and it is estimated that approximately 92 thousand Turkish individuals with chronic HBV infection live in Europe. The results from this study are found in chapter 5 . In conclusion, we showed that 3 out of 100 individuals born in Turkey had chronic HBV infection. This number was comparable to the country of origin, i.e. Turkey. Interestingly, we found that individuals born in Belgium with Turkish parents also had an increased risk of chronic HBV infection, namely 2 out of 100 . This could be attributed to a combination of 1 ) hepatitis B endemicity in country of origin, i.e. Turkey, and 2) inadequate prevention strategies in country of birth, i.e. Belgium.

Lastly, in chapter 6 and 7 we analysed a promising new HBAI20 hepatitis B vaccine. The new HBAI2O vaccine contributed to a higher seroprotection rate when compared to the standard hepatitis B vaccine, although safety was comparable. These studies were conducted in healthy hepatitis $B$ vaccine non-responders, i.e. individuals with inadequate immune response after primary hepatitis $B$ vaccination schedule. The future directions of the new HBAI20 hepatitis B vaccine should subsequently be assessed in other groups at risk of suboptimal immune response after hepatitis B vaccination (e.g. patients with renal insufficiency, transplant recipients). 


\section{SAMENVATTING}

Naar schatting zijn er wereldwijd 257 miljoen mensen met een chronische hepatitis B virus infectie. Deze ziekte veroorzaakt door het hepatitis B virus kan zich manifesteren als geen/minimale tot agressieve ontsteking van de lever. Een patiënt met chronische hepatitis $B$ virus infectie heeft meestal geen klachten totdat er sprake is van emstige leverbeschadiging of leverkanker. De diagnose van hepatitis B virus infectie wordt dan ook regelmatig over het hoofd gezien. Dit is echter een gemiste kans omdat vroegtijdige behandeling van hepatitis $\mathrm{B}$ het risico op ernstige leverbeschadiging en leverkanker aanzienlijk kan doen dalen. We merken dit ook aan het aantal doden door chronische hepatitis $B$ virus infectie. Cijfers wereldwijd tonen namelijk aan dat het aantal doden door chronische hepatitis B virus infectie is gestegen van 520 duizend doden in 1990 naar 690 duizend in 2013. Dit aantal is 36 duizend voor de regio Europa. De Wereldgezondheidsorganisatie, een organisatie met als doel de gezondheid van de wereldbevolking te bevorderen, heeft dan ook opgeroepen om hepatitis $B$ te elimineren in 2030. De huidige thesis ondersteunt deze doelstellingen met wetenschappelijke onderbouwing en streeft naar eliminatie van hepatitis B virus infectie in Europa.

Inactieve dragerschap (een vorm van chronische hepatitis B virus infectie met geen/minimale leverontsteking) werd vroeger gedefinieerd op basis van een maximum hoeveelheid virus in het bloed van 20,000 eenheden. In hoofdstuk 1 tonen wij echter aan dat patiënten met een hoeveelheid van $\leq 2,000$ viruseenheden in het bloed echte inactieve dragers zijn met een zeer lage kans op ernstige gevolgen door chronische hepatitis $B$ virus infectie. Deze patiënten zouden dan ook opgevolgd kunnen worden door de huisarts. Anderzijds lopen patiënten met een hoeveelheid van 2,000 - 20,000 viruseenheden in het bloed een degelijk risico op emstige beschadiging van de lever en hebben regelmatig gespecialiseerde opvolging nodig.

Naast de herbeoordeling van het natuurlijk beloop van chronische hepatitis B virus infectie, hebben we in hoofdstuk 2 en 3 de huidige situatie in België beoordeeld. Recente informatie rond hepatitis B was wel beschikbaar voor de naburige landen Nederland, Frankrijk en Duitsland. In lijn met de rest van Europa, zagen we een daling van het aantal nieuwe gevallen van hepatitis $B$ in België. Ondanks dat hepatitis $B$ vaccinatie het aantal nieuwe gevallen van hepatitis $B$ virus infectie kan doen dalen, heeft vaccinatie geen effect op het aantal personen die reeds geïnfecteerd zijn met het hepatitis B virus. Het is dan ook belangrijk om te achterhalen hoeveel mensen reeds geïnfecteerd zijn met het hepatitis $B$ 
virus, opdat vroegtijdige behandeling gestart kan worden. In de afwezigheid van recente gegevens in België, hebben we in 2017 alle patiënten in de spoedgevallen Ziekenhuis OostLimburg getest op hepatitis B (hoofdstuk 3). Hieruit bleek dat 1 op de 100 individuen geïfecteerd was met het hepatitis $B$ virus. Mensen die geboren waren in een land waar hepatitis B vaker voorkomt (vb. Midden-Oosten, Afrika) hadden een hogere risico op chronische hepatitis B virus infectie, namelijk 4.5 op de 100, in vergelijking met 0.7 op de 100 individuen geboren in België.

In hoofdstuk 4 beschreven we de opzet van een studie om de Turkse bevolking in België buiten het ziekenhuis te testen op hepatitis B virus infectie. Turkije is namelijk een land waar chronische hepatitis B virus infectie vaak voorkomt. De resultaten van deze studie hebben we vermeld onder hoofdstuk 5 . Samenvattend toonden wij aan dat 3 op de 100 individuen geboren in Turkije een chronische hepatitis B virus infectie hadden. Dit getal was vergelijkbaar met dat van de algemene bevolking in Turkije. Verrassend vonden we dat individuen geboren in België met Turkse ouders ook een verhoogd risico hadden op chronische hepatitis B virus infectie, namelijk 2 op de 100. Dit zou te wijten kunnen zijn aan de combinatie 1) verhoogd risico van hepatitis B virus infectie in Turkije en 2) inadequate preventiestrategieën in België.

Als laatste toonden wij in hoofdstuk 6 en 7 een beloftevolle nieuw HBAI20 hepatitis B vaccin. Het nieuw HBAI20 vaccin zorgde voor een grotere beschermingsgraad dan het standaard hepatitis $B$ vaccin, terwijl de veiligheid vergelijkbaar was. Dit werd aangetoond bij gezonde hepatitis $B$ vaccin non-responders. Non-responders zijn personen die geen beschermende antilichamen hebben gevormd na een primair hepatitis B vaccinatieschema. Aangezien wij enkel gekeken hebben naar de rol van het nieuw HBAI20 vaccin bij gezonde nonresponders, dient de toekomstmogelijkheden van dit nieuw vaccin ook verder bekeken te worden in andere groepen ( $v b$. patiënten met nierfunctiestoomissen, transplantatiepatiënten). 


\section{ÖZET}

Hepatit B virüs enfeksiyonu karaciğerde hepatit B virüsünden dolayı oluşan bir iltihaplanmadır. Bu hepatit B virüs enfeksiyonu dünyada olagelen ve sıkça görülen enfeksiyon hastalıkları arasında ilk başta gelen ve ölümcüldür. Dünya Sağlık Organizasyonu tahminlerine göre, dünyada aşağı yukarı 257 milyon insan uzun süreli (diğer adıyla kronik) hepatit B virüs enfeksiyonu ile yaşamaktadır. Hepatit B hastalıkların genelde hiçbir uyarı işareti ya da semptom göstermeden, siroz (karaciğerde ciddi yaralanma) ve karaciğer kanserine ilerliyebilir. Bu nedenle hepatit B virüs enfeksiyonu çoğunlukla geç teşhis edilir. Bu kaçırımış bir fırsattır çünkü hepatit B virüs enfeksiyonun başlangıç evresinde ve zamanında tedavi müdahalesi sunumuyla siroz ve karaciğer kanseri oluşması engellenebilmektedir. Bunu, kronik hepatit B virüs enfeksiyonundan kaynaklanan ölüm sayısı ile de fark ediyoruz. Dünya çapındaki rakamlar, kronik hepatit B virüs enfeksiyonundan ölümlerin sayısının 1990 'da 520.000'den 2013'te 690.000'e yükseldiğini göstermektedir. Avrupa bölgesi için bu sayı 36 bindir. Bu nedenle, Dünya Sağlık Organizasyonu 2030 yılına kadar hepatit B'nin ortadan kaldırıması çağrısında bulundu. Mevcut tez, bu hedefleri bilimsel kanıtlarla desteklemekte ve Avrupa'da hepatit B virüs enfeksiyonunu ortadan kaldırmayı amaçlamaktadır.

Kronik infeksiyon klinik seyri açısından ikiye ayrılır. Çoğu kişide virüs vücutta olmasına rağmen, çoğalma yeteneği çok sınırıdır ve karaciğer hasarı yapamayacak düzeydedir. Bu kişilerdeki durum "İnaktif Taşıyıcılık" olarak adlandıııır. Taşıyıcılık önceden virüs miktarı maksimum 20.000 ünitenin dayanarak tanımlanmıştı. Bölüm 1'de, kanda <2.000 virüs birimi olan hastaların gerçek inaktif taşıyıcılar olduğunu gösteriyoruz. Bu hastalar ev doktor tarafından izlenebilinir. Öte yandan, kanda 2.000 - 20.000 virüs ünitesi olan hastalar, karaciğerde ciddi hasar riski taşır ve düzenli olarak özel hekim tarafından takip gerektirir.

Kronik hepatit B virüs enfeksiyonunun doğal seyrini değerlendirmenin yanında, Bölüm 2 ve 3'te Belçika'daki mevcut hepatit B durumu değerlendirdik. Hepatit B ile ilgili son bilgiler Hollanda, Fransa ve Almanya komşu ülkeleri için mevcuttu. Avrupa'nın geri kalanına paralel olarak, Belçika'daki yeni hepatit B vakalarının sayısında bir azalma gördük. Hepatit B aşısı, yeni hepatit $B$ virüs enfeksiyonu vakalarının sayısını azaltabilmesine rağmen, hepatit $B$ virüs ile enfekte olan insan sayısı üzerinde aşılamanın hiçbir etkisi yoktur. Bu nedenle, kaç kişinin hepatit B virüs ile enfekte olduğunu bulmak önemlidir, böylece erken tedaviye başlanabilir. Belçika'da son verilerin yokluğunda, 2017 yılında Ziekenhuis Oost-Limburg hastanesindeki tüm acil hastaları hepatit $B$ açısından test ettik (bölüm 3). Her 100 kişiden birine hepatit $B$ 
virüsü bulaştı̆ı̆ını gösterdik. Hepatit B'nin daha yaygın olduğu bir ülkede doğan insanlar (örneğin, Orta Doğu, Afrika), Belçika'da doğan 100 kişiden 0.7'sine kıyasla, kronik hepatit B virüsü enfeksiyonu riski 100 'den 4.5 'e, daha yüksek bir riske sahipti.

4. bölümde, Türk popülasyonunu hastane dışında hepatit $B$ virüs enfeksiyonu açısından test etmek için bir çalışma tasarladık. Türkiye, kronik hepatit B virüs enfeksiyonunun sıklıkla meydana geldiği bir ülkedir. Bu çalışmanın sonuçlarını bölüm 5 'te bildirdik. Özetle, Türkiye'de doğan her 100 kişiden 3'ünde kronik hepatit B virüs enfeksiyonu olduğunu gösterdik. Bu rakam Türkiye'deki genel nüfus ile karşılaştırlabilir düzeydeydi. Şaşıtıcı olan, ikinci nesil Türklerdede kronik hepatit B virüs enfeksiyonun riski yüksek olmasıdır (100'de 2). Bunun nedeni, Belçika'daki önleme ve kontrol programı yetersiz olmasıdır.

Son olarak, 6'ıncı ve 7'ıncı bölümde yeni bir HBAI20 hepatit B aşı hakkında bilgi veriyoruz. Standart hepatit B aşısılyla karşılaştıııldığında, HBAI20 hepatit B aşısı daha yüksek bir koruma seviyesi sağladığını görüyoruz. Bu sonuç standart hepatit B aşıya yanıt vermeyenlerde görülmüstür. Yeni aşının etkisi sadece sağlıkı kişilerde araştırımışır. Böylece, gelecekte yeni aşının faydaları hasta olan kişilerdede araştııımasi önerilir (ömeğin diyaliz hastalarında, nakilli hastalarında). 




\section{IMPACT PARAGRAPH}

Europe has a considerable burden of viral hepatitis $B$ with 13.3 million people with chronic (i.e. long-term) HBV infection. ${ }^{12}$ Since HBV infection predominantly affects men and women of working age, eliminating hepatitis $B$ as a public health problem will not only benefit the individual and health system, but also the economy and business sectors. ${ }^{4}$ With a focus on the past, the present and future directions in HBV infection and control, this thesis supports the elimination of hepatitis $B$ in Europe by substantiating scientific evidence.

\section{HEPATITIS B DISEASE PROGRESSION}

Patients with chronic HBV infection can be divided in four phases based on hepatitis B viral markers in blood..$^{7,59,65}$ One of these phases is the inactive carrier phase, i.e. HBeAg-negative chronic infection phase. This phase is characterized by none/minimal liver inflammation and low viral load in the blood (i.e. < 20,000 units).

With the introduction of sensitive laboratory detection methods in the last decade, it is now possible to differentiate patients with $\mathrm{HBeAg}$-negative chronic infection into those with a viral load below 2,000 units versus those patients with a viral load between 2,000 and 20,000 units. The long-term outcome of the subgroup of patients with a viral load between 2,000 and 20,000 units $/ \mathrm{mL}$ is less clear and mainly assessed in the Asian population. ${ }^{36,39}$ Subsequently, this thesis determined the risk of advanced liver disease progression in Caucasian patients with HBeAg-negative chronic infection and a viral load below 2,000 units versus those patients with a viral load between 2,000 and 20,000 units.

In chapter 1, we illustrated that patients with a viral load below 2,000 units have an excellent long-term prognosis and accordingly they are no candidates for antiviral treatment.7, 59, 65 In contrast, patients with a viral load between 2,000 and 20,000 have a higher risk of advanced liver disease.

These results could be of particular interest for general practitioners and specialist physicians. Based on regional cooperation agreements, one could suggest the follow-up of patients with a viral load below $<2,000$ units by general practitioners while those patients with a viral load between 2,000 and 20,000 units are still in need of continued follow-up by specialist physicians. Follow-up in primary care should be conducted by a general practitioner with sufficient knowledge on hepatitis B management and close collaboration with specialist physician is invariably warranted, through the identification of their respective tasks. ${ }^{282}$ 


\section{HEPATITIS B EPIDEMIOLOGY}

Europe is one of the regions struggling to combat the viral hepatitis B pandemic, but the exact size of the problem remains unclear to adequately inform prevention strategies. Recent estimates on acute (i.e. new) and chronic (i.e. long-term) HBV infections among the general population are therefore necessary. These data were not available for Belgium, while recent information on HBV infection was available for neighbouring countries, i.e. the Netherlands, France and Germany. ${ }^{44,76-78,131}$ In chapter $\mathbf{2}$ and 3, we provided respectively the recent estimates for acute and chronic HBV infections in Belgium. In line with findings in other European countries, acute HBV infections per 100,000 population decreased from 1.6 in 2009 to 0.7 in 2017, Flanders, Belgium. ${ }^{44}$ In our study conducted in 2017, the proportion of chronic HBV infection among the general population in Middle-Limburg Belgium was low $(<2 \%)$, namely $1.0 \%$.

The decrease in acute HBV infection rates over the period 2009 to 2017 could in part be explained by the universal hepatitis $B$ vaccination in Belgium vaccinating all infants since 1999. In chapter 2, we also identified opportunities for improvement. We observed higher acute HBV infection rates among adults, there was a rise in the number of MSM over the period 2009 to 2017 and five mother-to-child infections were reported despite the recommendation of hepatitis $B$ screening in pregnant women in Belgium. ${ }^{137,} 158$

In contrast to neighbouring countries such as the Netherlands, France and Germany, to date no national hepatitis $B$ strategy has been issued in Belgium to adequately eliminate hepatitis B by 2030 as advocated by the WHO. Accordingly, we call for the organization of a national hepatitis $B$ plan in Belgium with the inclusion of action points conceming vaccination and identification of infected individuals. A national plan should be prepared conjointly by groups involved in the prevention and management of HBV infection in Belgium (e.g. Sciensano, general practitioners, gastroenterologists). An indispensable action point is the establishment of a uniform multidisciplinary registration system for HBV infection with subsequent yearly monitoring by involved parties (e.g. Sciensano, Belgian Association for the Study of the Liver (BASL), Vlaamse Vereniging voor Gastroenterologie (WGE), Société Royale Belge de Gastroentérologie (SRBGE)). The collection of data should make a difference between acute, chronic and unknown HBV status in line with the recommendations of the European Centre for Disease Prevention and Control (ECDC). ${ }^{255}$ 


\section{HEPATITIS B SCREENING}

In chapter 3, we noted a higher proportion of chronic HBV infection among FGMs compared to native Belgians. However, there is currently no national hepatitis B screening program targeted at FGMs.

Considering the silent nature of chronic HBV infection until development of serious complications, there is an important role for HBV vaccination (primary prevention) and screening with subsequent early antiviral treatment (secondary prevention). ${ }^{41} \mathrm{HBV}$ infection can cause acute and chronic hepatitis and subsequently life threatening liver complications, including cirrhosis (i.e. a late stage of liver scarring, annual risk of $1.6-9.7 \%$ ) and HCC $(0.1-0.6 \%)^{7,59,65}$ Liver transplantation is indicated in patients with cirrhosis and HCC in whom liver transplantation would extend the normal life expectancy. ${ }^{283}$ According to a European healthcare system, the annual medical management costs for compensated cirrhosis, decompensated cirrhosis, HCC and liver transplantation were estimated at $€ 2,035$, $€ 7,068, € 15,600$ and $€ 125,000$, respectively. ${ }^{75}$

To illustrate the priority, feasibility and acceptability of hepatitis B screening and vaccination in migrant populations, we conducted a screening program in the Turkish migrant population living in Middle-Limburg. The results of this campaign were depicted in chapter 5. In our study, the proportion of chronic HBV infection among first-generation Turkish migrants was $3.0 \%$, underlying the priority of screening in this population as screening for HBV is likely to be cost-effective in populations with a prevalence $\geq 2.0 \% .{ }^{49,284}$ Two studies in USA found that HBV screening might even be effective in groups with a lower prevalence, namely $\geq 0.3 \%$. ${ }^{268,284}$ Moreover, with a participation rate of $>95 \%$ and linkage to care of $>90 \%$, our community-based approach was feasible and acceptable in this migrant group. As depicted in chapter $\mathbf{4}$, the high participation rate and high linkage to care of hepatitis $B$ screening program might be explained through the preceding identification of motivating factors for hepatitis B virus screening during focus group discussions.

Within a national hepatitis B strategy, combining hepatitis B testing in primary care, hospital and community-based setting may lead to a higher coverage of HBV diagnosis as well as a higher coverage of HBV treatment. Utilization of electronic medical record reminders in primary care and health care setting may further increase HBV screening rates. ${ }^{275}$ In primary care, checking liver blood tests is another opportunity to diagnose liver problems (including HBV infection) and treat liver disease at an early stage. ${ }^{276}$ However, it was previously demonstrated that only $50 \%$ of abnormal liver blood tests were ever followed up 
in patients seen in primary care. ${ }^{11,277}$ In a study conducted in the United Kingdom, an automated system was developed that investigated abnormal liver blood tests to generate a probable diagnosis. This system was further integrated into the laboratory management system and was able to substantially increase the diagnostic yield of abnormal liver blood tests. ${ }^{276}$ Efforts are currently being made to assess the feasibility of an electronic medical record reminder and automated liver blood test system in primary care, Belgium.

Although our community-based hepatitis B screening program among the Turkish population in Middle Limburg used venipuncture for HBsAg testing, it has been shown that finger stick blood point-of-care testing could increase HBsAg testing rates. ${ }^{278}$ Finger stick blood tests should therefore be used in the community-based setting. Considering the attained experiences on regional outreach screening programs in Limburg, the next step is to set up a nationwide hepatitis B community-based screening program among migrants identifying legal and ethical challenges during development

\section{UNRESOLVED PROBLEM IN HEPATITIS B VACCINATION}

Globally, the introduction of hepatitis B vaccination has dramatically reduced the number of chronic HBV infection in children under 5 years from $4.7 \%$ in the 1990 s to $1.3 \%$ in 2015 , thereby preventing 4.5 million infections each year. ${ }^{256,285}$ The implementation of a universal infant hepatitis B immunization program in 48 of the 53 WHO European countries has contributed to this worldwide decline in HBV infections by reaching a prevalence of chronic HBV infection of $0.4 \%$ in children under 5 years, thus achieving one of the targets of the European Vaccine Action Plan 2015 - 2020. ${ }^{254}$

In spite of the abovementioned progress with hepatitis B vaccination, more is needed to eliminate hepatitis $\mathrm{B}$. Five to $12 \%$ of the general adult population do not achieve adequate immune response (anti-HBs $<10 \mathrm{mIU} / \mathrm{mL}$ ) after completion of the primary hepatitis $B$ vaccination schedule and are referred to as non-responders. ${ }^{96-100}$ Hepatitis $B$ vaccine nonresponders remain susceptible for HBV infection and its complications, and are an unresolved problem in hepatitis $B$ vaccination. ${ }^{243}$ The standard of care for non-responders consists of revaccination with currently licensed hepatitis $B$ vaccines in a $0,1,6$ months schedule or a schedule of two doses followed by another two doses after 2 months, which is associated with a seroprotection rate of approximately $50-69 \% .{ }^{96-100}$ Thus, there appears to be a need for a more immunogenic hepatitis $B$ vaccine. 
We tried to enhance the immune response to currently licensed hepatitis $B$ vaccines by adding a cytokine-based adjuvant. The new HBAI20 is a combination of the licensed HBVaXPro $(-10 \mu g$ vaccine and the AI20 adjuvant, containing $20 \mu \mathrm{g}$ recombinant human IL2 adsorbed to $20 \mu \mathrm{g}$ aluminium hydroxide. In the phase 1 study (chapter 6), the new HBAI20 vaccine seemed safe and well-tolerated among healthy naive individuals and healthy non-responders. The phase 2 trial (chapter 7) further demonstrated superior immunogenicity of the HBAI20 vaccine compared to that of the licensed HBVaxProß-10 $\mathrm{\mu g}$ vaccine in healthy non-responders, in addition to confirming that the HBAI20 vaccine could be safely administered.

The benefits of higher protection with HBAI20 vaccine among healthy non-responders as compared to the licensed $\mathrm{HBVaxPro} \cap-10 \mu \mathrm{g}$ vaccine are only linked to the AI20 adjuvant and make this an important option for HBV prevention. In the interest of licensing the AI20 adjuvant, more randomized clinical trials would be necessary to further determine the effectiveness on HBV prevention, assess adverse events and increase the evidence. Aside from the healthy non-responding population, the results from chapter 6 \& 7 support further studies to assess the benefits and harms of the HBAI20 vaccine in immunocompromised individuals, such as patients with advanced liver disease. 



\section{REFERENCES}

1. Janssen HLA, Drenth JPH, van Hoek B. Leverziekten. 1st ed. Houten: Bohn Stafleu van Loghum; c2009. $230 \mathrm{p}$.

2. Wendon J, Cordoba J, Dhawan A, Larsen FS, Manns M, Samuel D, et al. EASL Clinical Practical Guidelines on the management of acute (fulminant) liver failure. J Hepatol. 2017;66(5):1047-81.

3. WHO Regional Office for Europe. European Health Information Gateway Deaths(\#), chronic liver disease and cirrhosis. Copenhagen, Denmark: WHO Regional Office for Europe; $2019 . \quad$ Available from:

https://gateway.euro. who.int/en/indicators/hfamdb 149-deaths-chronic-liver-diseaseand-cirrhosis/visualizations/\#id=29455. Accessed 31 January 2020. .

$4 . \quad$ Pimpin L, Cortez-Pinto H, Negro F, Corbould E, Lazarus JV, Webber L, et al. Burden of liver disease in Europe: Epidemiology and analysis of risk factors to identify prevention policies. J Hepatol. 2018;69(3):718-35.

5. Asrani SK, Devarbhavi H, Eaton J, Kamath PS. Burden of liver diseases in the world. J Hepatol. 2019;70(1):151-71.

6. Peery AF, Crockett SD, Barritt AS, Dellon ES, Eluri S, Gangarosa LM, et al. Burden of Gastrointestinal, Liver, and Pancreatic Diseases in the United States. Gastroenterology. 2015;149(7):1731-41.e3.

7. European Association for the Study of the Liver. EASL 2017 Clinical Practice Guidelines on the management of hepatitis B virus infection. Journal of hepatology. 2017;67(2):370-98.

8. $\quad$ EASL Clinical Practice Guidelines: Management of alcohol-related liver disease. J Hepatol. 2018;69(1):154-81.

9. European Association for the Study of the Liver. EASL Recommendations on Treatment of Hepatitis C 2018. J Hepatol. 2018;69(2):461-511.

10. European Association for the Study of the Liver. EASL-EASD-EASO Clinical Practice Guidelines for the management of non-alcoholic fatty liver disease. J Hepatol. 2016;64(6):1388-402.

11. Newsome PN, Cramb R, Davison SM, Dillon JF, Foulerton M, Godfrey EM, et al. Guidelines on the management of abnormal liver blood tests. Gut. 2018;67(1):6-19.

12. World Health Organization. Hepatitis - Data and statistics. Geneva, Switzerland: World Health Organization; 2019. Available from: http http://www.who.int/mediacentre/factsheets/fs204/en/. Accessed 16 October 2019.

13. Stanaway JD, Flaxman AD, Naghavi M, Fitzmaurice C, Vos T, Abubakar I, et al. The global burden of viral hepatitis from 1990 to 2013: findings from the Global Burden of Disease Study 2013. Lancet. 2016;388(10049):1081-8.

14. World Health Organization. Combating hepatitis $B$ and $C$ to reach elimination by 2030. Geneva, Switzerland: World Health Organization; May 2016. Available from: https://apps.who.int/iris/bitstream/handle/10665/206453/WHO HIV 2016.04 eng.pdf.

15. Hadziyannis SJ. Milestones and perspectives in viral hepatitis B. Liver international : official journal of the International Association for the Study of the Liver. 2011;31 Suppl $1: 129-34$.

16. Blumberg BS, Alter HJ, Visnich S. A "New" Antigen in Leukemia Sera. JAMA. 1965;191:541-6.

17. Krugman S, Giles JP, Hammond J. Infectious hepatitis. Evidence for two distinctive clinical, epidemiological, and immunological types of infection. JAMA. 1967;200(5):365-73. 18. Ganem D. Assembly of hepadnaviral virions and subviral particles. Current topics in microbiology and immunology. 1991;168:61-83. 
19. Bayer ME, Blumberg BS, Wemer B. Particles associated with Australia antigen in the sera of patients with leukaemia, Down's Syndrome and hepatitis. Nature. 1968;218(5146):1057-9.

20. Dane DS, Cameron CH, Briggs M. Virus-like particles in serum of patients with Australia-antigen-associated hepatitis. Lancet. 1970;1(7649):695-8.

21. Robinson WS, Lutwick $\amalg$. The virus of hepatitis, type B (first of two parts). N Engl J Med. 1976;295(21):1168-75.

22. Ganem D, Prince AM. Hepatitis B virus infection--natural history and clinical consequences. N Engl J Med. 2004;350(11):1118-29.

23. Kramvis A. The clinical implications of hepatitis B virus genotypes and $\mathrm{HBeAg}$ in pediatrics. Reviews in medical virology. 2016;26(4):285-303.

24. Magnius LO, Espmark JA. New specificities in Australia antigen positive sera distinct from the Le Bouvier determinants. Journal of immunology (Baltimore, Md : 1950). 1972;109(5):1017-21.

25. Magnius LO. Characterization of a new antigen-antibody system associated with hepatitis B. Clinical and experimental immunology. 1975;20(2):209-16.

26. Lai M, Liaw YF. Chronic hepatitis B: past, present, and future. Clinics in liver disease. 2010;14(3):531-46.

27. Gibson UE, Heid CA, Williams PM. A novel method for real time quantitative RTPCR. Genome research. 1996;6(10):995-1001.

28. Gordillo RM, Gutierrez J, Casal M. Evaluation of the COBAS TaqMan 48 real-time PCR system for quantitation of hepatitis B virus DNA. Journal of clinical microbiology. 2005;43(7):3504-7.

29. Ranki M, Schatzl HM, Zachoval R, Uusi-Oukari M, Lehtovaara P. Quantification of hepatitis $B$ virus DNA over a wide range from serum for studying viral replicative activity in response to treatment and in recurrent infection. Hepatology. 1995;21(6):1492-9.

30. McMahon BJ, Alward WL, Hall DB, Heyward WL, Bender TR, Francis DP, et al. Acute hepatitis $B$ virus infection: relation of age to the clinical expression of disease and subsequent development of the carrier state. J Infect Dis. 1985;151(4):599-603.

31. Chu CM, Karayiannis P, Fowler MJ, Monjardino J, Liaw YF, Thomas HC. Natural history of chronic hepatitis $B$ virus infection in Taiwan: studies of hepatitis $B$ virus DNA in serum. Hepatology. 1985;5(3):431-4.

32. Hoofnagle JH, Dusheiko GM, Seeff LB, Jones EA, Waggoner JG, Bales ZB. Seroconversion from hepatitis $B$ e antigen to antibody in chronic type $B$ hepatitis. Ann Intern Med. 1981;94(6):744-8.

33. Chu CM, Liaw YF, Sheen IS, Lin DY, Huang MJ. Sex difference in chronic hepatitis $B$ virus infection: an appraisal based on the status of hepatitis $B$ e antigen and antibody. Hepatology. 1983;3(6):947-50.

34. Hadziyannis SJ, Lieberman HM, Karvountzis GG, Shafritz DA. Analysis of liver disease, nuclear HBCAg, viral replication, and hepatitis B virus DNA in liver and serum of HBeAg Vs. anti-HBe positive carriers of hepatitis B virus. Hepatology. 1983;3(5):656-62.

35. Lok AS, Heathcote EJ, Hoofnagle JH. Management of hepatitis B: 2000--summary of a workshop. Gastroenterology. 2001;120(7):1828-53.

36. Chen $\mathrm{CJ}$, Yang HI, Su J, Jen CL, You SL, Lu SN, et al. Risk of hepatocellular carcinoma across a biological gradient of serum hepatitis B virus DNA level. JAMA. 2006;295(1):65-73.

37. Chen JD, Yang HI, Iloeje UH, You SL, Lu SN, Wang LY, et al. Carriers of inactive hepatitis B virus are still at risk for hepatocellular carcinoma and liver-related death. Gastroenterology. 2010;138(5):1747-54. 
38. Gui HL, Wang $H$, Yang YH, Wu YW, Zhou HJ, Guo SM, et al. Significant histopathology in Chinese chronic hepatitis B patients with persistently high-normal alanine aminotransferase. Journal of viral hepatitis. 2010;17 Suppl 1:44-50.

39. Iloeje UH, Yang HI, Su J, Jen CL, You SL, Chen CJ, et al. Predicting cirrhosis risk based on the level of circulating hepatitis B viral load. Gastroenterology. 2006;130(3):67886.

40. Lazarus JV, Picchio C, Dillon JF, Rockstroh JK, Weis N, Buti M. Too many people with viral hepatitis are diagnosed late - with dire consequences. Nature reviews Gastroenterology \& hepatology. 2019;16(8):451-2.

41. World Health Organization. Hepatitis B. Geneva, Switzerland: World Health Organization; $2018 . \quad$ Available from: http://www.who.int/mediacentre/factsheets/fs204/en/. Accessed 21 January 2019.

42. World Health Organization. Thirteenth meeting of Global Advisory Group of EPI. Weekly Epidemiol Res 1992; 3: 9-12. .

43. Van Damme $P$, Vorsters A. Hepatitis B control in Europe by universal vaccination programmes: the situation in 2001. J Med Virol. 2002;67(3):433-9.

44. Miglietta A, Quinten C, Lopalco PL, Duffell E. Impact of hepatitis B vaccination on acute hepatitis B epidemiology in European Union/European Economic Area countries, 2006 to 2014. Euro Surveill. 2018;23(6).

45. Lernout T, Hendrickx G, Vorsters A, Mosina L, Emiroglu N, Van Damme P. A cohesive European policy for hepatitis B vaccination, are we there yet? Clinical microbiology and infection : the official publication of the European Society of Clinical Microbiology and Infectious Diseases. 2014;20 Suppl 5:19-24.

46. Mandal S. Introduction of universal infant hepatitis B immunisation in the UKpaving the way to elimination. Human vaccines \& immunotherapeutics. 2019;15(2):440-3. 47. Seto WK, Lo YR, Pawlotsky JM, Yuen MF. Chronic hepatitis B virus infection. Lancet. 2018;392(10161):2313-24.

48. Myran DT, Morton R, Biggs BA, Veldhuijzen I, Castelli F, Tran A, et al. The Effectiveness and Cost-Effectiveness of Screening for and Vaccination Against Hepatitis B Virus among Migrants in the EU/EEA: A Systematic Review. International journal of environmental research and public health. 2018;15(9).

49. Suijkerbuijk AWM, van Hoek AJ, Koopsen J, de Man RA, Mangen MJ, de Melker HE, et al. Cost-effectiveness of screening for chronic hepatitis $\mathrm{B}$ and $\mathrm{C}$ among migrant populations in a low endemic country. PLoS One. 2018;13(11):e0207037.

50. European Centre for Disease Prevention and Control. Public health guidance on HIV, hepatitis B and C testing in the EU/EEA - An integrated approach. Stockholm: ECDC; 2018.

51. Andermann A, Blancquaert I, Beauchamp S, Dery V. Revisiting Wilson and Jungner in the genomic age: a review of screening criteria over the past 40 years. Bulletin of the World Health Organization. 2008;86(4):317-9.

52. European Centre for Disease Prevention and Control. Hepatitis B and C epidemiology in selected population groups in the EU/EEA. Stockholm: ECDC; 2018.

53. European Centre for Disease Prevention and Control. Systematic review on hepatitis B and C prevalence in the EU/EEA. Stockholm: ECDC; 2016.

54. Ott J], Stevens GA, Groeger J, Wiersma ST. Global epidemiology of hepatitis B virus infection: new estimates of age-specific HBsAg seroprevalence and endemicity. Vaccine. 2012;30(12):2212-9.

55. Schweitzer A, Hom J, Mikolajczyk RT, Krause G, Ott JJ. Estimations of worldwide prevalence of chronic hepatitis $B$ virus infection: a systematic review of data published between 1965 and 2013. Lancet. 2015;386(10003):1546-55. 
56. Zhang Q, Qi W, Wang X, Zhang Y, Xu Y, Qin S, et al. Epidemiology of Hepatitis B and Hepatitis C Infections and Benefits of Programs for Hepatitis Prevention in Northeastern China: A Cross-Sectional Study. Clinical infectious diseases : an official publication of the Infectious Diseases Society of America. 2016;62(3):305-12.

57. World Health Organization. Hepatitis B. Geneva, Switzerland: World Health Organization; $2017 . \quad$ Available Available from: http://www.who.int/mediacentre/factsheets/fs204/en/. Accessed 31 January 2018.

58. MacLachlan JH, Cowie BC. Hepatitis B virus epidemiology. Cold Spring Harbor perspectives in medicine. 2015;5(5):a021410.

59. Terrault NA, Lok ASF, McMahon BJ, Chang KM, Hwang JP, Jonas MM, et al. Update on prevention, diagnosis, and treatment of chronic hepatitis B: AASLD 2018 hepatitis B guidance. Hepatology. 2018;67(4):1560-99.

60. Sundaram V, Kowdley K. Management of chronic hepatitis B infection. BMJ (Clinical research ed). 2015;351:h4263.

61. Allain JP, Opare-Sem O. Screening and diagnosis of HBV in low-income and middleincome countries. Nature reviews Gastroenterology \& hepatology. 2016;13(11):643-53.

62. Mast EE, Margolis HS, Fiore AE, Brink EW, Goldstein ST, Wang SA, et al. A comprehensive immunization strategy to eliminate transmission of hepatitis B virus infection in the United States: recommendations of the Advisory Committee on Immunization Practices (ACIP) part 1: immunization of infants, children, and adolescents. MMWR Recommendations and reports : Morbidity and mortality weekly report Recommendations and reports. 2005;54(RR-16):1-31.

63. World Health Organization. Guidelines on hepatitis B and C testing. Geneva, Switzerland: World Health Organization; February 2017. Available from: https://apps.who.int/iris/bitstream/handle/10665/254621/9789241549981eng.pdf?sequence $=1$.

64. Terrault NA, Bzowej NH, Chang KM, Hwang JP, Jonas MM, Murad MH. AASLD guidelines for treatment of chronic hepatitis B. Hepatology. 2016;63(1):261-83.

65. Sarin SK, Kumar M, Lau GK, Abbas Z, Chan HL, Chen CJ, et al. Asian-Pacific clinical practice guidelines on the management of hepatitis B: a 2015 update. Hepatol Int. 2016;10(1):1-98.

66. Wong GL, Chan HL, Mak CW, Lee SK, Ip ZM, Lam AT, et al. Entecavir treatment reduces hepatic events and deaths in chronic hepatitis $B$ patients with liver cirrhosis. Hepatology. 2013;58(5):1537-47.

67. Wu CY, Lin JT, Ho HJ, Su CW, Lee TY, Wang SY, et al. Association of nucleos(t)ide analogue therapy with reduced risk of hepatocellular carcinoma in patients with chronic hepatitis B: a nationwide cohort study. Gastroenterology. 2014;147(1):143-51.e5.

68. Marcellin P, Zoulim F, Hezode C, Causse X, Roche B, Truchi R, et al. Effectiveness and Safety of Tenofovir Disoproxil Fumarate in Chronic Hepatitis B: A 3-Year, Prospective, Real-World Study in France. Dig Dis Sci. 2016;61(10):3072-83.

69. Marcellin P, Heathcote EJ, Buti M, Gane E, de Man RA, Krastev Z, et al. Tenofovir disoproxil fumarate versus adefovir dipivoxil for chronic hepatitis B. N Engl J Med. 2008;359(23):2442-55.

70. Buti M, Tsai N, Petersen J, Flisiak R, Gurel S, Krastev Z, et al. Seven-year efficacy and safety of treatment with tenofovir disoproxil fumarate for chronic hepatitis $B$ virus infection. Dig Dis Sci. 2015;60(5):1457-64.

71. Kunkel J, Sweeney L, Falla A, Veldhuijzen I, Foster GR. Screening for viral hepatitis among migrants in the EU: What lessons can we learn from poor response to a pilot trial using GP registers? J Hepatol. 2015;62:S838.

72. Sweeney L, Owiti JA, Beharry A, Bhui K, Gomes J, Foster GR, et al. Informing the design of a national screening and treatment programme for chronic viral hepatitis in 
primary care: qualitative study of at-risk immigrant communities and healthcare professionals. BMC health services research. 2015;15:97.

73. Andersen KL, Larsen CS, Petersen MS, Leutscher PD. Need for improvements in the surveillance and management of chronic viral hepatitis in HIV patients followed in a Danish outpatient clinic. Scandinavian joumal of infectious diseases. 2014;46(8):578-84.

74. Flanagan S, Kunkel J, Appleby V, Eldridge SE, Ismail S, Moreea S, et al. Case finding and therapy for chronic viral hepatitis in primary care (HepFREE): a cluster-randomised controlled trial. The lancet Gastroenterology \& hepatology. 2019;4(1):32-44.

75. Veldhuijzen IK, Toy M, Hahne SJ, De Wit GA, Schalm SW, de Man RA, et al. Screening and early treatment of migrants for chronic hepatitis $B$ virus infection is costeffective. Gastroenterology. 2010;138(2):522-30.

76. Wolffram I, Petroff D, Bat O, Jedrysiak K, Kramer J, Tenckhoff H, et al. Prevalence of elevated ALT values, $\mathrm{HBsAg}$, and anti-HCV in the primary care setting and evaluation of guideline defined hepatitis risk scenarios. J Hepatol. 2015;62(6):1256-64.

77. Hahne SJ, De Melker HE, Kretzschmar M, Mollema L, Van Der Klis FR, Van Der Sande MA, et al. Prevalence of hepatitis B virus infection in The Netherlands in 1996 and 2007. Epidemiol Infect. 2012;140(8):1469-80.

78. Bottero J, Boyd A, Lemoine M, Carrat F, Gozlan J, Collignon A, et al. Current state of and needs for hepatitis B screening: results of a large screening study in a low-prevalent, metropolitan region. PLoS One. 2014;9(3):e92266.

79. Ahmad AA, Falla AM, Duffell E, Noori T, Bechini A, Reintjes R, et al. Estimating the scale of chronic hepatitis $B$ virus infection among migrants in EU/EEA countries. BMC infectious diseases. 2018;18(1):34.

80. Toy M, Onder FO, Wormann T, Bozdayi AM, Schalm SW, Borsboom GJ, et al. Ageand region-specific hepatitis $B$ prevalence in Turkey estimated using generalized linear mixed models: a systematic review. BMC infectious diseases. 2011;11:337.

81. Ortiz E, Scanlon B, Mullens A, Durham J. Effectiveness of Interventions for Hepatitis $B$ and C: A Systematic Review of Vaccination, Screening, Health Promotion and Linkage to Care Within Higher Income Countries. Journal of community health. 2019.

82. Chen MS, Jr., Fang DM, Stewart SL, Ly MY, Lee S, Dang JH, et al. Increasing hepatitis $B$ screening for hmong adults: results from a randomized controlled communitybased study. Cancer Epidemiol Biomarkers Prev. 2013;22(5):782-91.

83. Chang ET, Sue E, Zola J, So SK. 3 For Life: a model pilot program to prevent hepatitis B virus infection and liver cancer in Asian and Pacific Islander Americans. Am J Health Promot. 2009;23(3):176-81.

84. Chao SD, Chang ET, Le PV, Prapong W, Kiernan M, So SK. The Jade Ribbon Campaign: a model program for community outreach and education to prevent liver cancer in Asian Americans. J Immigr Minor Health. 2009;11(4):281-90.

85. Ma GX, Fang CY, Seals B, Feng Z, Tan Y, Siu P, et al. A Community-Based Randomized Trial of Hepatitis B Screening Among High-Risk Vietnamese Americans. Am J Public Health. 2017;107(3):433-40.

86. Ma GX, Gao W, Tan Y, Chae WG, Rhee J. A community-based participatory approach to a hepatitis B intervention for Korean Americans. Prog Community Health Partnersh. 2012;6(1):7-16.

87. Navarro N, Lim N, Kim J, Joo E, Che K, Runyon BA, et al. Lower than expected hepatitis $B$ virus infection prevalence among first generation Koreans in the U.S.: results of HBV screening in the Southem California Inland Empire. BMC infectious diseases. 2014;14:269.

88. Sheikh MY, Mouanoutoua M, Walvick MD, Khang L, Singh J, Stoltz S, et al. Prevalence of hepatitis B virus (HBV) infection among Hmong immigrants in the San Joaquin Valley. Joumal of community health. 2011;36(1):42-6. 
89. Vedio AB, Ellam H, Rayner F, Stone B, Kudesia G, McKendrick MW, et al. Hepatitis B: report of prevalence and access to healthcare among Chinese residents in Sheffield UK. J Infect Public Health. 2013;6(6):448-55.

90. Zibrik L, Huang A, Wong V, Novak Lauscher H, Choo Q, Yoshida EM, et al. Let's Talk About B: Barriers to Hepatitis B Screening and Vaccination Among Asian and South Asian Immigrants in British Columbia. J Racial Ethn Health Disparities. 2018;5(6):1337-45. 91. Schillie S, Murphy TV, Sawyer M, Ly K, Hughes E, Jiles R, et al. CDC guidance for evaluating health-care personnel for hepatitis $\mathrm{B}$ virus protection and for administering postexposure management. MMWR Recommendations and reports : Morbidity and mortality weekly report Recommendations and reports. 2013;62(Rr-10):1-19.

92. World Health Organization. Information sheet observed rate of vaccine reactions: hepatitis B vaccine. Geneva, Switzerland: World Health Organization; 2012. Available from: http://www.who.int/vaccine safety/initiative/tools/Hep B Vaccine rates information she et.pdf.

93. Averhoff F, Mahoney F, Coleman P, Schatz G, Hurwitz E, Margolis H. Immunogenicity of hepatitis B Vaccines. Implications for persons at occupational risk of hepatitis B virus infection. American journal of preventive medicine. 1998;15(1):1-8.

94. Chathuranga LS, Noordeen F, Abeykoon AM. Immune response to hepatitis B vaccine in a group of health care workers in Sri Lanka. International joumal of infectious diseases : IJID : official publication of the International Society for Infectious Diseases. 2013;17(11):e1078-9.

95. Cockcroft A, Soper P, Insall C, Kennard Y, Chapman S, Gooch C, et al. Antibody response after hepatitis $B$ immunisation in a group of health care workers. British journal of industrial medicine. 1990;47(3):199-202.

96. Hadler SC, Francis DP, Maynard JE, Thompson SE, Judson FN, Echenberg DF, et al. Long-term immunogenicity and efficacy of hepatitis $B$ vaccine in homosexual men. $\mathrm{N}$ Engl J Med. 1986;315(4):209-14.

97. Halperin SA, Ward BJ, Dionne M, Langley JM, McNeil SA, Smith B, et al. Immunogenicity of an investigational hepatitis $B$ vaccine (hepatitis $B$ surface antigen coadministered with an immunostimulatory phosphorothioate oligodeoxyribonucleotide) in nonresponders to licensed hepatitis B vaccine. Human vaccines \& immunotherapeutics. 2013;9(7):1438-44.

98. Jacques P, Moens G, Desombere I, Dewijngaert J, Leroux-Roels G, Wettendorff M, et al. The immunogenicity and reactogenicity profile of a candidate hepatitis $B$ vaccine in an adult vaccine non-responder population. Vaccine. 2002;20(31-32):3644-9.

99. Yen $\mathrm{YH}$, Chen $\mathrm{CH}$, Wang JH, Lee CM, Changchien CS, Lu SN. Study of hepatitis B (HB) vaccine non-responsiveness among health care workers from an endemic area (Taiwan). Liver international : official journal of the International Association for the Study of the Liver. 2005;25(6):1162-8.

100. Hoge Gezondheidsraad. Vaccinatie tegen hepatitis B. Vaccinatie van volwassenen. Herziening 2013.http://www.vaxinfopro.be/IMG/pdf/hgrvaccinatiehepatitis b 2013.pdf.

101. Wood RC, MacDonald KL, White KE, Hedberg CW, Hanson M, Osterholm MT. Risk factors for lack of detectable antibody following hepatitis $B$ vaccination of Minnesota health care workers. Jama. 1993;270(24):2935-9.

102. Hohler T, Reuss E, Evers N, Dietrich E, Rittner C, Freitag CM, et al. Differential genetic determination of immune responsiveness to hepatitis $B$ surface antigen and to hepatitis A virus: a vaccination study in twins. Lancet. 2002;360(9338):991-5.

103. Walayat S, Ahmed Z, Martin D, Puli S, Cashman M, Dhillon S. Recent advances in vaccination of non-responders to standard dose hepatitis $B$ virus vaccine. World journal of hepatology. 2015;7(24):2503-9. 
104. Pan HX, Zeng Y, Song XF, Zhang YJ, Xu K, Liang ZL, et al. Immune response to hepatitis $B$ vaccine with high antigen content in non-responders after standard primary vaccination in Chinese adults. Vaccine. 2014;32(29):3706-12.

105. European Medicines Agency. Annex I Summary of product characteristics. Amsterdam, the Netherlands: European Medicines Agency; 2009. Available from: https://www.ema.europa.eu/en/documents/product-information/fendrix-epar-productinformation en.pdf. Accessed 16 October 2019.

106. European Medicines Agency. Heplisav: withdrawal of the marketing authorisation application. Amsterdam, the Netherlands: European Medicines Agency; 2014. Available from: https://www.ema.europa.eu/en/medicines/human/withdrawn-applications/heplisav. Accessed 16 October 2019.

107. Lai M, Hyatt BJ, Nasser I, Curry M, Afdhal NH. The clinical significance of persistently normal ALT in chronic hepatitis B infection. J Hepatol. 2007;47(6):760-7.

108. Ikeda K, Arase Y, Saitoh S, Kobayashi M, Someya T, Hosaka T, et al. Long-term outcome of HBV carriers with negative HBe antigen and normal aminotransferase. Am J Med. 2006;119(11):977-85.

109. Martinot-Peignoux M, Boyer N, Colombat M, Akremi R, Pham BN, Ollivier S, et al. Serum hepatitis B virus DNA levels and liver histology in inactive HBsAg carriers. J Hepatol. 2002;36(4):543-6.

110. Papatheodoridis GV, Chrysanthos N, Hadziyannis E, Cholongitas E, Manesis EK. Longitudinal changes in serum HBV DNA levels and predictors of progression during the natural course of $\mathrm{HBeAg-negative} \mathrm{chronic} \mathrm{hepatitis} \mathrm{B} \mathrm{virus} \mathrm{infection.} \mathrm{Joumal} \mathrm{of} \mathrm{viral}$ hepatitis. 2008;15(6):434-41.

111. Papatheodoridis GV, Manesis EK, Manolakopoulos S, Elefsiniotis IS, Goulis J, Giannousis J, et al. Is there a meaningful serum hepatitis B virus DNA cutoff level for therapeutic decisions in hepatitis B e antigen-negative chronic hepatitis B virus infection? Hepatology. 2008;48(5):1451-9.

112. Oliveri F, Surace L, Cavallone D, Colombatto P, Ricco G, Salvati N, et al. Long-term outcome of inactive and active, low viraemic HBeAg-negative-hepatitis B virus infection: Benign course towards HBsAg clearance. Liver international : official journal of the International Association for the Study of the Liver. 2017;37(11):1622-31.

113. Gigi E, Lalla T, Orphanou E, Sinakos E, Vrettou E, Raptopoulou-Gigi M. Long term follow-up of a large cohort of inactive HBsAg (+)/ HBeAg (-)/ anti-HBe (+) carriers in Greece. J Gastrointestin Liver Dis. 2007;16(1):19-22.

114. Manno M, Camma C, Schepis F, Bassi F, Gelmini R, Giannini F, et al. Natural history of chronic HBV carriers in northern Italy: morbidity and mortality after 30 years. Gastroenterology. 2004;127(3):756-63.

115. Fattovich G, Olivari N, Pasino M, D'Onofrio M, Martone E, Donato F. Long-term outcome of chronic hepatitis B in Caucasian patients: mortality after 25 years. Gut. 2008;57(1):84-90.

116. de Franchis R, Meucci G, Vecchi M, Tatarella M, Colombo M, Del Ninno E, et al. The natural history of asymptomatic hepatitis B surface antigen carriers. Ann Intern Med. 1993;118(3):191-4.

117. Manesis EK, Papatheodoridis GV, Sevastianos V, Cholongitas E, Papaioannou C, Hadziyannis SJ. Significance of hepatitis B viremia levels determined by a quantitative polymerase chain reaction assay in patients with hepatitis $B$ e antigen-negative chronic hepatitis B virus infection. Am J Gastroenterol. 2003;98(10):2261-7.

118. Zacharakis G, Koskinas J, Kotsiou S, Tzara F, Vafeiadis N, Papoutselis M, et al. The role of serial measurement of serum HBV DNA levels in patients with chronic HBeAg(-) hepatitis $B$ infection: association with liver disease progression. A prospective cohort study. J Hepatol. 2008;49(6):884-91. 
119. Villeneuve JP, Desrochers M, Infante-Rivard C, Willems B, Raymond G, Bourcier M, et al. A long-term follow-up study of asymptomatic hepatitis B surface antigen-positive carriers in Montreal. Gastroenterology. 1994;106(4):1000-5.

120. Bedossa P, Poynard T. An algorithm for the grading of activity in chronic hepatitis C. The METAVIR Cooperative Study Group. Hepatology. 1996;24(2):289-93.

121. Chu CM, Hung SJ, Lin J, Tai DI, Liaw YF. Natural history of hepatitis B e antigen to antibody seroconversion in patients with normal serum aminotransferase levels. Am J Med. 2004;116(12):829-34.

122. de Franchis R. Expanding consensus in portal hypertension: Report of the Baveno VI Consensus Workshop: Stratifying risk and individualizing care for portal hypertension. J Hepatol. 2015;63(3):743-52.

123. Infante-Rivard C, Esnaola S, Villeneuve JP. Clinical and statistical validity of conventional prognostic factors in predicting short-term survival among cirrhotics. Hepatology. 1987;7(4):660-4.

124. Loomba R, Liang TJ. Hepatitis B Reactivation Associated With Immune Suppressive and Biological Modifier Therapies: Current Concepts, Management Strategies, and Future Directions. Gastroenterology. 2017;152(6):1297-309.

125. Seto WK, Chan TS, Hwang YY, Wong DK, Fung J, Liu KS, et al. Hepatitis B reactivation in patients with previous hepatitis $B$ virus exposure undergoing rituximabcontaining chemotherapy for lymphoma: a prospective study. J Clin Oncol. 2014;32(33):3736-43.

126. Comberg M, Wong VW, Locarnini S, Brunetto M, Janssen HLA, Chan HL. The role of quantitative hepatitis B surface antigen revisited. J Hepatol. 2017;66(2):398-411.

127. Verhaegh P, Bavalia R, Winkens B, Masclee A, Jonkers D, Koek G. Noninvasive Tests Do Not Accurately Differentiate Nonalcoholic Steatohepatitis From Simple Steatosis: A Systematic Review and Meta-analysis. Clinical gastroenterology and hepatology : the official clinical practice journal of the American Gastroenterological Association. 2018;16(6):837-61.

128. World Health Organization. Hepatitis B. Geneva, Switzerland: World Health Organization; 2017. Available from: http http://www.who.int/mediacentre/factsheets/fs204/en/. Accessed 6 April 2018.

129. Inoue T, Tanaka Y. Hepatitis B virus and its sexually transmitted infection - an update. Microbial cell (Graz, Austria). 2016;3(9):420-37.

130. Beutels M, Van Damme P, Aelvoet W, Desmyter J, Dondeyne F, Goilav C, et al. Prevalence of hepatitis $A, B$ and $C$ in the Flemish population. European journal of epidemiology. 1997;13(3):275-80.

131. Quoilin S, Hutse V, Vandenberghe H, Claeys F, Verhaegen E, De Cock L, et al. A population-based prevalence study of hepatitis $A, B$ and $C$ virus using oral fluid in Flanders, Belgium. European journal of epidemiology. 2007;22(3):195-202.

132. Koc OM, Kremer C, Bielen R, Buscchots D, Hens N, Nevens F, et al. Prevalence and risk factors of hepatitis $B$ virus infection in Middle-Limburg Belgium, year 2017: importance of migration. J Med Virol. 2019.

133. Van Kerschaver E. The Belgian Expanded Programme on Immunization (EPI) and hepatitis B vaccination. Southern African Joumal of Epidemiology and Infection. 2008; 23(1): 40-44.

134. Theeten $H$, Hutse V, Hoppenbrouwers $K$, Beutels P, P VAND. Universal hepatitis B vaccination in Belgium: impact on serological markers 3 and 7 years after implementation. Epidemiol Infect. 2014;142(2):251-61.

135. Larney S, Peacock A, Leung J, Colledge S, Hickman M, Vickerman P, et al. Global, regional, and country-level coverage of interventions to prevent and manage HIV and 
hepatitis $\mathrm{C}$ among people who inject drugs: a systematic review. The Lancet Global health. 2017;5(12):e1208-e20.

136. European Centre for Disease Prevention and Control. Antenatal screening for HIV, hepatitis B, syphilis and rubella susceptibility in the EU/EEA. Stockholm: ECDC; 2016.

137. Ward JW, Hinman AR. What Is Needed to Eliminate Hepatitis B Virus and Hepatitis C Virus as Global Health Threats. Gastroenterology. 2019;156(2):297-310.

138. European Centre for Disease Prevention and Control. Annual Epidemiological Report 2016 - Hepatitis B. Stockholm: ECDC; 2016. Available at: http://ecdc.europa.eu/en/healthtopics/hepatitis-b/Pages/Annual-epidemiological-report-2 016.aspx. Accessed 26 July 2018.

139. Statbel. Structuur van de bevolking. Brussels: Statbel; 2018. Available from: https://statbel.fgov.be/nl/themas/bevolking/structuur-van-de-bevolking. Accessed 26 July 2018.

140. Hoppenbrouwers K, Vandermeulen C, Roelants M, et al. Studie van de vaccinatiegraad bij jonge kinderen en adolescenten in Vlaanderen in 2008. Brussels: Vlaams Agentschap Zorg en Gezondheid; 2009 Feb. 110p.

141. Theeten $\mathrm{H}$, Roelants $\mathrm{M}$, Lernout $\mathrm{T}$, et al. Vaccinatiegraad bij jonge kinderen en adolescenten in Vlaanderen in 2012. Vlaams Infectieziektebulletin. 2013;4:6-12.

142. Vandermeulen C, Hoppenbrouwers K, Roelants $M$, et al. Studie van de vaccinatiegraad in Vlaanderen 2016. Brussels: Vlaams Agentschap Zorg en Gezondheid; 2017 Mar. 188p.

143. Theeten H, Hens N, Vandermeulen C, Depoorter AM, Roelants M, Aerts M, et al. Infant vaccination coverage in 2005 and predictive factors for complete or valid vaccination in Flanders, Belgium: an EPI-survey. Vaccine. 2007;25(26):4940-8.

144. Vandermeulen C, Roelants $M$, Theeten $H$, Depoorter AM, Van Damme $P$, Hoppenbrouwers K. Vaccination coverage in 14-year-old adolescents: documentation, timeliness, and sociodemographic determinants. Pediatrics. 2008;121(3):e428-34.

145. Trepo C, Chan HL, Lok A. Hepatitis B virus infection. Lancet. 2014;384(9959):2053-63.

146. De Vrieze J, De Paep DL, De Roeck Y, Dockx S, Van Damme P, Theeten H. Immunization policy in children born to hbsag seropositive mothers. Tijdschrift van de Belgische Kinderarts. 2014;16(3):174-7.

147. Leuridan E, Wouters K, Stalpaert M, Van Damme P. Male sex workers in Antwerp, Belgium: a descriptive study. Int J STD AIDS. 2005;16(11):744-8.

148. Mak R, Traen A, Claeyssens M, Van Renterghem L, Leroux-Roels G, Van Damme P. Hepatitis B vaccination for sex workers: do outreach programmes perform better? Sex Transm Infect. 2003;79(2):157-9.

149. Van Ardenne N, Roelofs I, Leuridan E, Wouters K, Van Damme P. Audit on offering and accepting hepatitis B vaccine by sex workers. Int J STD AIDS. 2004;15(7):493-4.

150. Vranckx R, Jacques P, De Schrijver A, Moens G. Hepatitis B vaccination coverage in Belgian health care workers. Infection. 2004;32(5):278-81.

151. Zuckerman JN, Hoet B. Hepatitis B immunisation in travellers: poor risk perception and inadequate protection. Travel Med Infect Dis. 2008;6(5):315-20.

152. World Health Organization. Global health sector strategy on viral hepatitis 20162021. Geneva: WHO. 2016. WHO/HIV/2016.06.

153. World Health Organization (WHO). Hepatitis B Birth dose (HepB-BD) vaccination strategies in the national immunization programme. In: Vaccine in national immunization programme update. [PowerPoint Presentation]. Geneva: WHO. Available from: http://www.who.int/immunization/monitoring surveillance/VaccineIntroStatus.pptx.

Accessed 27 August 2018. 
154. Meffre $C$, Le Strat $Y$, Delarocque-Astagneau E, Dubois F, Antona D, Lemasson JM, et al. Prevalence of hepatitis B and hepatitis C virus infections in France in 2004: social factors are important predictors after adjusting for known risk factors. J Med Virol. 2010;82(4):546-55.

155. Pedraza-Flechas AM, Garcia-Comas L, Ordobas-Gavin M, Sanz-Moreno JC, RamosBlazquez B, Astray-Mochales J, et al. Hepatitis B virus infection and vaccine-induced immunity in Madrid (Spain). Gaceta sanitaria. 2014;28(6):492-5.

156. Poethko-Muller C, Zimmermann R, Hamouda O, Faber M, Stark K, Ross RS, et al. [Epidemiology of hepatitis A, B, and C among adults in Germany: results of the German Health Interview and Examination Survey for Adults (DEGS1)]. Bundesgesundheitsblatt, Gesundheitsforschung, Gesundheitsschutz. 2013;56(5-6):707-15.

157. Chang MH, Chen CJ, Lai MS, Hsu HM, Wu TC, Kong MS, et al. Universal hepatitis B vaccination in Taiwan and the incidence of hepatocellular carcinoma in children. Taiwan Childhood Hepatoma Study Group. N Engl J Med. 1997;336(26):1855-9.

158. Beasley RP, Hwang LY, Lee GC, Lan CC, Roan CH, Huang FY, et al. Prevention of perinatally transmitted hepatitis $B$ virus infections with hepatitis $B$ immune globulin and hepatitis B vaccine. Lancet. 1983;2(8359):1099-102.

159. Lin SY, Chang ET, So SK. Why we should routinely screen Asian American adults for hepatitis B: a cross-sectional study of Asians in California. Hepatology. 2007;46(4):1034-40.

160. Mahoney FJ. Update on diagnosis, management, and prevention of hepatitis B virus infection. Clinical microbiology reviews. 1999;12(2):351-66.

161. Chu CJ, Keeffe EB, Han SH, Perrillo RP, Min AD, Soldevila-Pico C, et al. Hepatitis B virus genotypes in the United States: results of a nationwide study. Gastroenterology. 2003; 125(2):444-51.

162. Janssen HL, van Zonneveld M, Senturk H, Zeuzem S, Akarca US, Cakaloglu Y, et al. Pegylated interferon alfa-2b alone or in combination with lamivudine for HBeAg-positive chronic hepatitis B: a randomised trial. Lancet. 2005;365(9454):123-9.

163. Lok AS, McMahon BJ, Brown RS, Jr., Wong JB, Ahmed AT, Farah W, et al. Antiviral therapy for chronic hepatitis B viral infection in adults: A systematic review and metaanalysis. Hepatology. 2016;63(1):284-306.

164. Centraal Bureau voor de Statistiek. Bevolking; leeftijd, migratieachtergrond, geslacht en regio. Den Haag, the Netherlands: Centraal Bureau voor de Statistiek; 2018. Available from: http://statline.cbs.n//Statweb/publication/?DM=SLNL\&PA=37713\&D1=1$2,7-8 \& \mathrm{D} 2=0 \& \mathrm{D} 3=1,3-4 \& \mathrm{D} 4=16 \& \mathrm{D} 5=\mid \& \mathrm{HDR}=\mathrm{G} 4, \mathrm{~T}, \mathrm{G} 1, \mathrm{G} 2 \& \mathrm{STB}=\mathrm{G} 3 \& \mathrm{VW}=\mathrm{T}$. Accessed 22 May 2018.

165. Firth D. Bias reduction of maximum likelihood estimates. Biometrika. 1993;80(1):27-38.

166. Lemmens A, Croux C. Bagging and boosting classification trees to predict churn. Journal of Marketing Research. 2006;43(2):276-86.

167. Kowdley KV, Wang CC, Welch S, Roberts H, Brosgart CL. Prevalence of chronic hepatitis B among foreign-born persons living in the United States by country of origin. Hepatology. 2012;56(2):422-33.

168. Rossi C, Shrier I, Marshall L, Cnossen S, Schwartzman K, Klein MB, et al. Seroprevalence of chronic hepatitis B virus infection and prior immunity in immigrants and refugees: a systematic review and meta-analysis. PLoS One. 2012;7(9):e44611.

169. Perumalswami PV, Factor SH, Kapelusznik L, Friedman SL, Pan CQ, Chang C, et al. Hepatitis Outreach Network: a practical strategy for hepatitis screening with linkage to care in foreign-bom communities. J Hepatol. 2013;58(5):890-7.

170. De Vroey B, Moreno C, Laleman W, van Gossum M, Colle I, de Galocsy C, et al. Hepatitis B virus and hepatitis C virus infections in Belgium: similarities and differences in 
epidemics and initial management. European journal of gastroenterology \& hepatology. 2013;25(5):613-9.

171. Papatheodoridis GV, Manolakopoulos S, Liaw YF, Lok A. Follow-up and indications for liver biopsy in $\mathrm{HBeAg-negative} \mathrm{chronic} \mathrm{hepatitis} \mathrm{B}$ virus infection with persistently normal ALT: a systematic review. J Hepatol. 2012;57(1):196-202.

172. Lavanchy D. Hepatitis B virus epidemiology, disease burden, treatment, and current and emerging prevention and control measures. Journal of viral hepatitis. 2004;11(2):97-107.

173. Ay P, Torunoglu MA, Com S, Cipil Z, Mollahaliloglu S, Erkoc Y, et al. Trends of hepatitis B notification rates in Turkey, 1990 to 2012. Euro Surveill. 2013;18(47).

174. Degertekin H, Gunes G. Horizontal transmission of hepatitis B virus in Turkey. Public health. 2008;122(12):1315-7.

175. Degertekin H, Tuzcu A, Yalcin K. Horizontal transmission of HBV infection among students in Turkey. Public health. 2000;114(5):411-2.

176. Ergunay K, Balaban Y, Cosgun E, Alp A, Simsek H, Sener B, et al. Epidemiologic trends in HBV infections at a reference centre in Turkey: an 11-year retrospective analysis. Annals of hepatology. 2012;11(5):672-8.

177. Louise Heiberg I, Hogh B. Horizontal transmission of hepatitis B virus--why discuss when we can vaccinate? J Infect Dis. 2012;206(4):464-5.

178. Mansour-Ghanaei $F$, Joukar F, Yaseri M, Soati F, Atrkar-Roushan Z. Intrafamilial spread of hepatitis B virus in Guilan Province-North of Iran. International journal of molecular epidemiology and genetics. 2013;4(4):250-7.

179. De Bel-Air F. Migration profile: Turkey; 2016. Available from: http://cadmus.eui.eu/bitstream/handle/1814/45145/MPC PB 2016 09.pdf?sequence=1. Accessed 26 March 2019. .

180. Republic of Turkey Ministry of Foreign Affairs. Turkish citizens living abroad; 2011. Available from: http://www.mfa.gov.tr/the-expatriate-turkish-citizens.en.mfa. Accessed 26 March 2019.

181. van der Veen YJ, Voeten HA, de Zwart O, Richardus JH. Awareness, knowledge and self-reported test rates regarding Hepatitis $B$ in Turkish-Dutch: a survey. BMC public health. 2010;10:512.

182. Afdhal NH, Bacon BR, Patel K, Lawitz EJ, Gordon SC, Nelson DR, et al. Accuracy of fibroscan, compared with histology, in analysis of liver fibrosis in patients with hepatitis B or C: a United States multicenter study. Clinical gastroenterology and hepatology : the official clinical practice joumal of the American Gastroenterological Association. 2015;13(4):7729.e1-3.

183. Chu JJ, Wormann T, Popp J, Patzelt G, Akmatov MK, Kramer A, et al. Changing epidemiology of hepatitis B and migration--a comparison of six Northern and North-Western European countries. European journal of public health. 2013;23(4):642-7.

184. Burgazli KM, Mericliler M, Sen C, Tuncay M, Gokce Y, Nayir B, et al. The prevalence of hepatitis B virus (HBV) among Turkish immigrants in Germany. European review for medical and pharmacological sciences. 2014;18(6):869-74.

185. Richter C, Beest GT, Sancak I, Aydinly R, Bulbul K, Laetemia-Tomata F, et al. Hepatitis $B$ prevalence in the Turkish population of Arnhem: implications for national screening policy? Epidemiol Infect. 2012;140(4):724-30.

186. European Centre for Disease Prevention and Control. Surveillance and prevention of hepatitis B and C in Europe. Stockholm: ECDC; 2010.

187. Toy M. Cost-effectiveness of viral hepatitis B \& C treatment. Best Pract Res Clin Gastroenterol. 2013;27(6):973-85. 
188. Whelan J, Sonder G, Heuker J, van den Hoek A. Incidence of acute hepatitis B in different ethnic groups in a low-endemic country, 1992-2009: increased risk in second generation migrants. Vaccine. 2012;30(38):5651-5.

189. Koc OM, Robaeys G, Yildirim B, Posthouwer D, Hens S, Koek GH. Horizontal hepatitis $B$ virus transmission through non-sexual close contact in Turkish chronic hepatitis B patients living outside of Turkey. Acta Gastroenterol Belg. 2018;81(4):503-8.

190. Koc OM, Hens N, Bielen R, Van Damme P, Robaeys G. Hepatitis B virus prevalence and risk factors in hard-to-reach Turkish population living in Belgium: A protocol for screening. Medicine (Baltimore). 2019;98(18):e15412.

191. Koc O, Van Damme P, Busschots D, Bielen R, Forier A, Nevens F, et al. Acute hepatitis B notification rates in Flanders, Belgium, 2009 to 2017. Euro Surveill. 2019;24(30). 192. Molenberghs G, Verbeke G. Models for Discrete Longitudinal Data. 1st ed. New York: Springer; 2005. 687p.

193. Tozun N, Ozdogan O, Cakaloglu Y, Idilman R, Karasu Z, Akarca U, et al. Seroprevalence of hepatitis $B$ and $C$ virus infections and risk factors in Turkey: a fieldwork TURHEP study. Clinical microbiology and infection : the official publication of the European Society of Clinical Microbiology and Infectious Diseases. 2015;21(11):1020-6.

194. Theeten H, Vandermeulen C, Roelants M, Hoppenbrouwers K, Depoorter AM, Van Damme P. Coverage of recommended vaccines in children at 7-8 years of age in Flanders, Belgium. Acta Paediatr. 2009;98(8):1307-12.

195. Doganci T, Uysal G, Kir T, Bakirtas A, Kuyucu N, Doganci L. Horizontal transmission of hepatitis B virus in children with chronic hepatitis B. World J Gastroenterol. 2005;11(3):418-20.

196. Erol S, Ozkurt Z, Ertek M, Tasyaran MA. Intrafamilial transmission of hepatitis B virus in the eastern Anatolian region of Turkey. European journal of gastroenterology \& hepatology. 2003;15(4):345-9.

197. Ucmak H, Faruk Kokoglu O, Celik M, Ergun UG. Intra-familial spread of hepatitis B virus infection in eastern Turkey. Epidemiol Infect. 2007;135(8):1338-43.

198. Papatheodoridis G, Sypsa V, Kantzanou M, Nikolakopoulos I, Hatzakis A. Estimating the treatment cascade of chronic hepatitis B and C in Greece using a telephone survey. Journal of viral hepatitis. 2015;22(4):409-15.

199. Cohen C, Holmberg SD, McMahon BJ, Block JM, Brosgart CL, Gish RG, et al. Is chronic hepatitis $B$ being undertreated in the United States? Journal of viral hepatitis. 2011;18(6):377-83.

200. Bailey MB, Shiau R, Zola J, Fernyak SE, Fang T, So SK, et al. San Francisco hep B free: a grassroots community coalition to prevent hepatitis $B$ and liver cancer. Journal of community health. 2011;36(4):538-51.

201. Harris AM, Link-Gelles R, Kim K, Chandrasekar E, Wang S, Bannister N, et al. Community-Based Services to Improve Testing and Linkage to Care Among Non-U.S.-Born Persons with Chronic Hepatitis B Virus Infection - Three U.S. Programs, October 2014September 2017. MMWR Morb Mortal Wkly Rep. 2018;67(19):541-6.

202. Juon HS, Strong C, Oh TH, Castillo T, Tsai G, Oh LD. Public health model for prevention of liver cancer among Asian Americans. Journal of community health. 2008;33(4):199-205.

203. Pollack $\mathrm{H}$, Wang $\mathrm{S}$, Wyatt $\mathrm{L}$, Peng $\mathrm{CH}$, Wan $\mathrm{K}$, Trinh-Shevrin $\mathrm{C}$, et al. A comprehensive screening and treatment model for reducing disparities in hepatitis $\mathrm{B}$. Health Aff (Millwood). 2011;30(10):1974-83.

204. Veldhuijzen IK, Wolter R, Rijckborst V, Mostert M, Voeten HA, Cheung Y, et al. Identification and treatment of chronic hepatitis $B$ in Chinese migrants: results of a project offering on-site testing in Rotterdam, The Netherlands. J Hepatol. 2012;57(6):1171-6. 
205. Lo KJ, Tong MJ, Chien MC, Tsai YT, Liaw YF, Yang KC, et al. The natural course of hepatitis B surface antigen-positive chronic active hepatitis in Taiwan. J Infect Dis. 1982;146(2):205-10.

206. Chen HL, Chang MH, Ni YH, Hsu HY, Lee PI, Lee CY, et al. Seroepidemiology of hepatitis $B$ virus infection in children: Ten years of mass vaccination in Taiwan. JAMA. 1996;276(11):906-8.

207. McMahon BJ, Bulkow LR, Singleton RJ, Williams J, Snowball M, Homan C, et al. Elimination of hepatocellular carcinoma and acute hepatitis $B$ in children 25 years after a hepatitis B newborn and catch-up immunization program. Hepatology. 2011;54(3):801-7. 208. Francis DP, Hadler SC, Thompson SE, Maynard JE, Ostrow DG, Altman N, et al. The prevention of hepatitis $B$ with vaccine. Report of the centers for disease control multicenter efficacy trial among homosexual men. Ann Intern Med. 1982;97(3):362-6.

209. Jack AD, Hall AJ, Maine N, Mendy M, Whittle HC. What level of hepatitis B antibody is protective? J Infect Dis. 1999;179(2):489-92.

210. Szmuness W, Stevens CE, Harley EJ, Zang EA, Alter HJ, Taylor PE, et al. Hepatitis $B$ vaccine in medical staff of hemodialysis units: efficacy and subtype cross-protection. $\mathrm{N}$ Engl J Med. 1982;307(24):1481-6.

211. Szmuness W, Stevens CE, Harley EJ, Zang EA, Oleszko WR, William DC, et al. Hepatitis $B$ vaccine: demonstration of efficacy in a controlled clinical trial in a high-risk population in the United States. N Engl J Med. 1980;303(15):833-41.

212. Szmuness W, Stevens CE, Zang EA, Harley EJ, Kellner A. A controlled clinical trial of the efficacy of the hepatitis B vaccine (Heptavax B): a final report. Hepatology. 1981;1(5):377-85.

213. Heyward WL, Kyle M, Blumenau J, Davis M, Reisinger K, Kabongo ML, et al. Immunogenicity and safety of an investigational hepatitis $B$ vaccine with a Toll-like receptor 9 agonist adjuvant (HBsAg-1018) compared to a licensed hepatitis B vaccine in healthy adults 40-70 years of age. Vaccine. 2013;31(46):5300-5.

214. Hollinger FB. Factors influencing the immune response to hepatitis $B$ vaccine, booster dose guidelines, and vaccine protocol recommendations. Am J Med. 1989;87(3A):36S-40S.

215. Gupta RK, Siber GR. Adjuvants for human vaccines--current status, problems and future prospects. Vaccine. 1995;13(14):1263-76.

216. Falkenberg FW. Composition comprising cytokine macro-aggregates. World Patent. International Publication Number WO 2014/068085 A1.

217. Margolin KA, Rayner AA, Hawkins MJ, Atkins MB, Dutcher JP, Fisher RI, et al. Interleukin-2 and lymphokine-activated killer cell therapy of solid tumors: analysis of toxicity and management guidelines. J Clin Oncol. 1989;7(4):486-98.

218. Ben-Yehuda A, Joseph A, Zeira E, Even-Chen S, Louria-Hayon I, Babai I, et al. Immunogenicity and safety of a novel liposomal influenza subunit vaccine (INFLUSOMEVAC) in young adults. J Med Virol. 2003;69(4):560-7.

219. Heinzer $H$, Huland $E$, Huland $H$. Systemic chemotherapy and chemoimmunotherapy for metastatic renal cell cancer. World J Urol. 2001;19(2):111-9.

220. Yang JC, Sherry RM, Steinberg SM, Topalian SL, Schwartzentruber DJ, Hwu P, et al. Randomized study of high-dose and low-dose interleukin-2 in patients with metastatic renal cancer. J Clin Oncol. 2003;21(16):3127-32.

221. Ben-Yehuda A, Joseph A, Barenholz Y, Zeira E, Even-Chen S, Louria-Hayon I, et al. Immunogenicity and safety of a novel IL-2-supplemented liposomal influenza vaccine (INFLUSOME-VAC) in nursing-home residents. Vaccine. 2003;21(23):3169-78.

222. Rose RM, Rey-Martinez J, Croteau C, Silvestri RC, Haley K, DePamphilis J, et al. Failure of recombinant interleukin-2 to augment the primary humoral response to a recombinant hepatitis B vaccine in healthy adults. J Infect Dis. 1992;165(4):775-7. 
223. Jungers $\mathrm{P}$, Devillier $\mathrm{P}$, Salomon $\mathrm{H}$, Cerisier JE, Courouce AM. Randomised placebocontrolled trial of recombinant interleukin-2 in chronic uraemic patients who are nonresponders to hepatitis B vaccine. Lancet. 1994;344(8926):856-7.

224. Mauri JM, Valles M. Effects of recombinant interleukin-2 and revaccination for hepatitis B in previously vaccinated, non-responder, chronic uraemic patients. Collaborative Group of Girona. Nephrol Dial Transplant. 1997;12(4):729-32.

225. Meuer SC, Dumann $\mathrm{H}$, Meyer zum Buschenfelde $\mathrm{KH}$, Kohler $\mathrm{H}$. Low-dose interleukin-2 induces systemic immune responses against HBsAg in immunodeficient nonresponders to hepatitis B vaccination. Lancet. 1989;1(8628):15-8.

226. Boyman O, Sprent J. The role of interleukin-2 during homeostasis and activation of the immune system. Nat Rev Immunol. 2012;12(3):180-90.

227. Valdez H, Mitsuyasu R, Landay A, Sevin AD, Chan ES, Spritzler J, et al. Interleukin2 Increases CD4+ lymphocyte numbers but does not enhance responses to immunization: results of A5046s. J Infect Dis. 2003;187(2):320-5.

228. Boyman $\mathrm{O}, \mathrm{Cho} \mathrm{JH}$, Sprent J. The role of interleukin-2 in memory CD8 cell differentiation. Adv Exp Med Biol. 2010;684:28-41.

229. Choi YS, Kageyama R, Eto D, Escobar TC, Johnston RJ, Monticelli L, et al. ICOS receptor instructs $T$ follicular helper cell versus effector cell differentiation via induction of the transcriptional repressor Bcl6. Immunity. 2011;34(6):932-46.

230. Kalia V, Sarkar S, Subramaniam S, Haining WN, Smith KA, Ahmed R. Prolonged interleukin-2Ralpha expression on virus-specific CD8+ $T$ cells favors terminal-effector differentiation in vivo. Immunity. 2010;32(1):91-103.

231. Liao W, Lin JX, Wang L, Li P, Leonard WJ. Modulation of cytokine receptors by IL-2 broadly regulates differentiation into helper T cell lineages. Nat Immunol. 2011;12(6):5519.

232. Liao W, Schones DE, Oh J, Cui Y, Cui K, Roh TY, et al. Priming for T helper type 2 differentiation by interleukin 2-mediated induction of interleukin 4 receptor alpha-chain expression. Nat Immunol. 2008;9(11):1288-96.

233. Malek TR. The biology of interleukin-2. Annu Rev Immunol. 2008;26:453-79.

234. Pepper M, Pagan AJ, Igyarto BZ, Taylor JJ, Jenkins MK. Opposing signals from the Bcl6 transcription factor and the interleukin-2 receptor generate T helper 1 central and effector memory cells. Immunity. 2011;35(4):583-95.

235. Wuest SC, Edwan JH, Martin JF, Han S, Perry JS, Cartagena CM, et al. A role for interleukin-2 trans-presentation in dendritic cell-mediated T cell activation in humans, as revealed by daclizumab therapy. Nat Med. 2011;17(5):604-9.

236. Taniguchi T, Minami Y. The IL-2/IL-2 receptor system: a current overview. Cell. 1993; 73(1):5-8.

237. Velten FW, Rambow F, Metharom P, Goerdt S. Enhanced T-cell activation and Tcell-dependent IL-2 production by CD83+, CD25high, CD43high human monocyte-derived dendritic cells. Mol Immunol. 2007;44(7):1544-50.

238. Mnasria K, Lagaraine C, Velge-Roussel F, Oueslati R, Lebranchu Y, Baron C. AntiCD25 antibodies affect cytokine synthesis pattern of human dendritic cells and decrease their ability to prime allogeneic CD4+ T cells. J Leukoc Biol. 2008;84(2):460-7.

239. Zhu J, Yamane H, Paul WE. Differentiation of effector CD4 T cell populations (*). Annu Rev Immunol. 2010;28:445-89.

240. Cote-Sierra J, Foucras G, Guo L, Chiodetti L, Young HA, Hu-Li J, et al. Interleukin 2 plays a central role in Th2 differentiation. Proc Natl Acad Sci U S A. 2004;101(11):3880-5.

241. Whitford K, Liu B, Micallef J, Yin JK, Macartney K, Van Damme P, et al. Long-term impact of infant immunization on hepatitis B prevalence: a systematic review and metaanalysis. Bulletin of the World Health Organization. 2018;96(7):484-97. 
242. Shen Z, Rao Y, Tao S, Luo M, Ming L, Liu J, et al. Unimpaired immunogenicity of yeast-expressed hepatitis $B$ surface antigen stored at elevated temperatures. Acta Biochim Biophys Sin (Shanghai). 2016;48(12):1094-100.

243. Schillie S, Vellozzi C, Reingold A, Harris A, Haber P, Ward JW, et al. Prevention of Hepatitis B Virus Infection in the United States: Recommendations of the Advisory Committee on Immunization Practices. MMWR Recommendations and reports : Morbidity and mortality weekly report Recommendations and reports. 2018;67(1):1-31.

244. Koc OM, Savelkoul PHM, van Loo IHM, Peeters A, Oude Lashof AML. Safety and immunogenicity of HBAI20 Hepatitis B vaccine in healthy naive and nonresponding adults. Journal of viral hepatitis. 2018;25(9):1048-56.

245. EASL Clinical Practice Guidelines: Management of alcohol-related liver disease. J Hepatol. 2018;69(1):154-81.

246. Ambrosch F, Wiedermann G, Kundi M, Leroux-Roels G, Desombere I, Garcon N, et al. A hepatitis $B$ vaccine formulated with a novel adjuvant system. Vaccine. 2000;18(20):2095-101.

247. Halperin SA, Dobson S, McNeil S, Langley JM, Smith B, McCall-Sani R, et al. Comparison of the safety and immunogenicity of hepatitis B virus surface antigen coadministered with an immunostimulatory phosphorothioate oligonucleotide and a licensed hepatitis B vaccine in healthy young adults. Vaccine. 2006;24(1):20-6.

248. Janssen JM, Heyward WL, Martin JT, Janssen RS. Immunogenicity and safety of an investigational hepatitis $B$ vaccine with a Toll-like receptor 9 agonist adjuvant (HBsAg-1018) compared with a licensed hepatitis $B$ vaccine in patients with chronic kidney disease and type 2 diabetes mellitus. Vaccine. 2015;33(7):833-7.

249. Hartvickson R, Cruz M, Ervin J, Brandon D, Forleo-Neto E, Dagnew AF, et al. Noninferiority of mammalian cell-derived quadrivalent subunit influenza virus vaccines compared to trivalent subunit influenza virus vaccines in healthy children: a phase III randomized, multicenter, double-blind clinical trial. International journal of infectious diseases : IJID : official publication of the International Society for Infectious Diseases. 2015;41:65-72.

250. Morris TP, White IR, Royston P. Tuning multiple imputation by predictive mean matching and local residual draws. BMC Med Res Methodol. 2014;14:75.

251. Liao W, Lin JX, Leonard WJ. Interleukin-2 at the crossroads of effector responses, tolerance, and immunotherapy. Immunity. 2013;38(1):13-25.

252. Rijksinstituut voor Volksgezondheid en Milieu. Meer dan opsporen - Nationaal hepatitisplan: een strategie voor actie. Bilthoven: RIVM; 2016.

253. Federal Ministry for Economic Cooperation and Development. Integrated strategy for HIV, hepatitis B and C and other sexually transmitted infections. Berlin: Federal Ministry of Health; 2016.

254. Ministère des affaires sociales et de la santé. Stratégie nationale de santé sexuelle. Agenda 2017-2030. Paris: Ministère des affaires sociales et de la santé; 2017.

255. European Centre for Disease Prevention and Control. Annual Epidemiological Report 2016 - Hepatitis B. Stockholm: ECDC; 2016. Available at:

http://ecdc.europa.eu/en/healthtopics/hepatitis-b/Pages/Annual-epidemiological-report-2 016.aspx. Accessed 26 July 2018.

256. WHO Regional Office for Europe. How to present the European Vaccine Action Plan 2015-2020 (EVAP). Copenhagen, Denmark: WHO Regional Office for Europe; 2014. Available from: http://www.euro.who.int/ data/assets/pdf file/0008/276659/EVAPENG. with-front.pdf?ua=1. Accessed 4 February 2020.

257. Op de Coul EL, Hahne S, van Weert YW, Oomen P, Smit C, van der Ploeg KP, et al. Antenatal screening for HIV, hepatitis B and syphilis in the Netherlands is effective. BMC infectious diseases. 2011;11:185. 
258. Visser M, van der Ploeg CPB, Smit C, Hukkelhoven C, Abbink F, van Benthem BHB, et al. Evaluating progress towards triple elimination of mother-to-child transmission of HIV, syphilis and hepatitis B in the Netherlands. BMC public health. 2019;19(1):353.

259. Geue C, Wu O, Xin Y, Heggie R, Hutchinson S, Martin NK, et al. Cost-Effectiveness of HBV and HCV Screening Strategies--A Systematic Review of Existing Modelling Techniques. PLoS One. 2015;10(12):e0145022.

260. Hahne SJ, Veldhuijzen IK, Wiessing L, Lim TA, Salminen M, Laar M. Infection with hepatitis $B$ and $C$ virus in Europe: a systematic review of prevalence and cost-effectiveness of screening. BMC infectious diseases. 2013;13:181.

261. van der Veen YJ, de Zwart O, Voeten HA, Mackenbach JP, Richardus JH. Hepatitis B screening in the Turkish-Dutch population in Rotterdam, the Netherlands; qualitative assessment of socio-cultural determinants. BMC public health. 2009;9:328.

262. Ajzen I. The theory of planned behaviour: reactions and reflections. Psychol Health. 2011;26(9):1113-27.

263. Fishbein M. The role of theory in HIV prevention. AIDS Care. 2000;12(3):273-8.

264. Stewart SL, Rakowski W, Pasick RJ. Behavioral constructs and mammography in five ethnic groups. Health Educ Behav. 2009;36(5 Suppl):36s-54s.

265. Harris AM, Schoenbachler BT, Ramirez G, Vellozzi C, Beckett GA. Testing and Linking Foreign-Born People with Chronic Hepatitis B Virus Infection to Care at Nine U.S. Programs, 2012-2014. Public Health Rep. 2016;131 Suppl 2:20-8.

266. Hutton DW, Tan D, So SK, Brandeau ML. Cost-effectiveness of screening and vaccinating Asian and Pacific Islander adults for hepatitis B. Ann Intern Med. 2007;147(7):460-9.

267. Rossi C, Schwartman K, Oxlade O, Klein MB, Greenaway C. Hepatitis B screening and vaccination strategies for newly arrived adult Canadian immigrants and refugees: a cost-effectiveness analysis. PLoS One. 2013;8(10):e78548.

268. Wong WW, Woo G, Jenny Heathcote $E$, Krahn M. Cost effectiveness of screening immigrants for hepatitis B. Liver intemational : official journal of the International Association for the Study of the Liver. 2011;31(8):1179-90.

269. Milne A, Allwood GK, Moyes CD, Pearce NE, Lucas CR. Prevalence of hepatitis $B$ infections in a multiracial New Zealand community. N Z Med J. 1985;98(782):529-32.

270. Chen CH, Yang PM, Huang GT, Lee HS, Sung JL, Sheu JC. Estimation of seroprevalence of hepatitis $B$ virus and hepatitis $C$ virus in Taiwan from a large-scale survey of free hepatitis screening participants. J Formos Med Assoc. 2007;106(2):148-55.

271. Lee H, Hontz I, Wamer A, Park SJ. Hepatitis B infection among Asian American Pacific Islanders in the Rocky Mountain area. Appl Nurs Res. 2005;18(1):2-6.

272. Xu JJ, Tien C, Chang M, Rhee J, Tien A, Bae HS, et al. Demographic and serological characteristics of Asian Americans with hepatitis B infection diagnosed at community screenings. Journal of viral hepatitis. 2013;20(8):575-81.

273. Trinh-Shevrin C, Pollack HJ, Tsang T, Park J, Ramos MR, Islam N, et al. The Asian American hepatitis B program: building a coalition to address hepatitis B health disparities. Prog Community Health Partnersh. 2011;5(3):261-71.

274. Robotin MC, George J. Community-based hepatitis B screening: what works? Hepatol Int. 2014;8(4):478-92.

275. Pham C, Sin MK. Use of Electronic Health Records at Federally Qualified Health Centers: a Potent Tool to Increase Viral Hepatitis Screening and Address the Climbing Incidence of Liver Cancer. J Cancer Educ. 2020.

276. Dillon JF, Miller MH, Robinson EM, Hapca A, Rezaeihemami M, Weatherbum C, et al. Intelligent liver function testing (iLFT): A trial of automated diagnosis and staging of liver disease in primary care. J Hepatol. 2019;71(4):699-706. 
277. Donnan PT, McLemon D, Dillon JF, Ryder S, Roderick P, Sullivan F, et al. Development of a decision support tool for primary care management of patients with abnormal liver function tests without clinically apparent liver disease: a record-linkage population cohort study and decision analysis (ALFIE). Health Technol Assess. 2009;13(25):iii-iv, ix-xi, 1-134.

278. Ho E, Michielsen P, Van Damme P, Ieven M, Veldhuijzen I, Vanwolleghem T. Pointof-Care Tests for Hepatitis B Are Associated with A Higher Linkage to Care and Lower Cost Compared to Venepuncture Sampling During Outreach Screenings in an Asian Migrant Population. Ann Glob Health. 2020;86(1):81.

279. Lane S, MacDonald NE, Marti M, Dumolard L. Vaccine hesitancy around the globe: Analysis of three years of WHO/UNICEF Joint Reporting Form data-2015-2017. Vaccine. 2018;36(26):3861-7.

280. Marti M, de Cola M, MacDonald NE, Dumolard L, Duclos P. Assessments of global drivers of vaccine hesitancy in 2014-Looking beyond safety concerns. PLoS One. 2017;12(3):e0172310.

281. European Centre for Disease Prevention and Control. Catalogue of interventions addressing vaccine hesitancy. Stockholm: ECDC; 2017.

282. Bechini A, Levi M, Falla A, Ahmad A, Veldhuijzen I, Tiscione E, et al. The role of the general practitioner in the screening and clinical management of chronic viral hepatitis in six EU countries. J Prev Med Hyg. 2016;57(2):E51-60.

283. EASLClinical Practice Guidelines: Liver transplantation. J Hepatol. 2016;64(2):43385.

284. Hargreaves S, Seedat F, Car J, Escombe R, Hasan S, Eliahoo J, et al. Screening for latent $\mathrm{TB}, \mathrm{HIV}$, and hepatitis $\mathrm{B} / \mathrm{C}$ in new migrants in a high prevalence area of London, UK: a cross-sectional study. BMC infectious diseases. 2014;14:657.

285. World Health Organization. Global hepatitis report, 2017. Geneva, Switzerland: World Health Organization; 2017. Available from: https://apps.who.int/iris/bitstream/handle/10665/255016/9789241565455eng.pdf;jsessionid=16A3912A4DB111AC356EFEAA95E207A1? sequence $=1$. 



\section{CURRICULUM VITAE}

Özgür Muhammet Koc was born on April 30 1991 in Genk, Belgium. After graduation from Onze-Lieve-Vrouwlyceum in Genk in 2009, he started Biomedical Sciences at the Hasselt University. In 2010 he made the switch towards the Faculty of Health, Medicine and Life Sciences at the Maastricht University. During medical school, he combined his BelgianDutch-Turkish background in his scientific traineeship at the divisions of Gastroenterology and Hepatology in Ziekenhuis Oost-Limburg (ZOL, BE), Maastricht UMC+ (MUMC+, NL) and Ondokuz Mayis University Hospital (OMU, TR). After obtaining his medical degree in 2016, Özgür continued working across the borders in a joint PhD UHasselt/Maastricht UMC+ under the supervision of Dr. G. Robaeys, prof. Dr. P. Savelkoul, dr. A. Oude Lashof, Dr. G. Koek and prof. Dr. P. Vandamme. Özgür has published several peer-reviewed articles and received various awards during his $\mathrm{PhD}$, but his biggest achievement was marrying Kubra Akpinar in 2017. 



\section{Fortes soli, fortiores una}

Strong alone, stronger together

Sterk alleen, sterker samen

Na 4 jaar intensief autorijden ben ik eindelijk aangekomen bij mijn bestemming, mijn thesis. Dit schriftelijk werkstuk kon slechts tot stand komen door de steun van veel mensen. Ik wil dan ook de tijd nemen om iedereen te bedanken.

Allereerst wil ik de deelnemers bedanken zonder wiens toestemming we nooit deze resultaten hadden kunnen bereiken. Bedankt. Teşekkürler.

Ik wil graag prof. Dr. Rianne Letschert (rector van Maastricht University), prof. Dr. Annemie Schols (decaan van NUTRIM Maastricht University ten tijde van het schrijven van deze thesis), prof. Dr. Luc De Schepper (rector van Universiteit Hasselt ten tijde van het schrijven van deze thesis) en prof. Dr. Piet Stinissen (decaan van de faculteit Geneeskunde en Levenswetenschappen) bedanken voor de opportuniteit tot het gezamenlijk doctoraat tussen Maastricht University en Universiteit Hasselt.

Dank aan de leden van de beoordelingscommissie voor het lezen van dit proefschrift.

Uiteraard wil ik mijn (co-)promoters bedanken. Professor Paul Savelkoul, dank om mijn rijinstructeur te zijn. $U$ zorgde ervoor dat ik wist wanneer ik moest vertragen, gas geven of voorrang geven om mijn doctoraat tijdig tot een goed einde te brengen. Dr. Geert Robaeys, $u$ was altijd gedreven om samen met mij op reis te gaan naar verschillende steden. Anders geformuleerd u stond altijd open om interessante studieprojecten buiten het doctoraat om te starten. Uw enthousiasme heeft me aangestoken. Dr. Ger Koek, zonder u was ik mogelijk nooit gestart aan dit mooie avontuur. $U$ kocht mij een auto en introduceerde mij zo aan een PhD Viral hepatitis $B$ : the past, the present and future directions. Bedankt voor alles! Astrid, je was als een benzinestation die ervoor zorgde dat ik steeds energie had om ijverig door te werken aan mijn thesis. Onze alledaagse gesprekken zorgden voor de nodige pauze om deze 4 jaar durende autoreis te kunnen afmaken. Professor Pierre Van Damme, u bent een leidersfiguur binnen infectieziekten epidemiologie maar daarnaast ook een zeer goede 
begeleider. Bedankt voor de vele kritische en zeer nuttige commentaren op de artikels. U heeft deze reis beter gemaakt.

Dank ook aan al mijn co-auteurs op de verschillende artikels. Sommigen onder jullie ken ik ondertussen al iets beter, dus ik wil zeker ook professor Frederik Nevens, Cécile Kremer, professor Niel Hens en dr. Annemie Forier bedanken. Professor Frederik Nevens, het is mij zeer duidelijk waarom u internationaal een veelbesproken hepatoloog bent. Ik bewonder uw kritische blik op de internationale richtlijnen en heb dan ook veel geleerd van u. Cécile, sorry dat ik je zo vaak lastigviel om mij te helpen met de statistische analyses. Ik kon altijd op jou vertrouwen dat de analyses van een hoog niveau waren en dat de analyses tijdig afgerond werden. Professor Niel Hens, bedankt om mij en Cécile in deze statistische analyses te begeleiden. Hoe ingewikkeld de analyses ook waren, u probeerde mij steeds in lekentermen uitleg te geven. Ik wil u dan ook bedanken voor alle tijd die $u$ heeft genomen voor mij. Dr. Annemie Forier, dank om de data van Agentschap Zorg en Gezondheid ter beschikking te stellen.

Ik wil alle vrijwilligers bedanken voor hun hulp bij de hepatitis B studie bij de Turkse bevolking: dank aan mijn tweelingbroer Baris (arts), mijn goede vriend Ugur (arts), aangetrouwd familielid Özcan (verpleegkundige), Songül (verpleegkundige), Zeliha (verpleegkundige), Ceyda (verpleegkundige), Zeynep Akdag (verpleegkundige), mijn vrouw Kübra, mijn moeder Fatma, mijn zus Eylem, mijn goede vrienden Senol, Nazim, Koray, Muhammet, Ayber en mijn goede vriendinnen Zeynep Topçu, Sevgi en Sinem . Met sommigen van jullie heb ik zelfs tot laat in de avond (22u00) gewerkt aan dit project. Klinkt krankzinnig maar we waren een hechte en leuke groep! Natuurlijk was dit project niet mogelijk zonder de focusgroep discussies met de Turkse vertegenwoordigers van de vier moskeeën in Midden Limburg (Waterschei, Winterslag, Kolderbos en Sledderlo) en twee Turkse verantwoordelijken van het gemeentehuis. Arkan abi bedankt om de Turkse tekst in te spreken bij onze korte film rond hepatitis B. Vanuit ZOL en Universiteit Hasselt hadden we jullie nog graag willen bedanken met de beste keuken ter wereld, natuurlijk de Turkse! $\mathrm{Er}$ is wat vertraging maar als alles normaliseert, zullen we zeker samenkomen om bij te praten en te genieten van de Turkse gerechten!!!!

Ik wil ook de tijd nemen om Lisa Castelli en Jurgen Ritzen (communicatie ZOL) te bedanken voor het opstellen van de flyers, posters en korte films die onmisbaar waren bij het communiceren van dit hepatitis B project met de Turkse bevolking. Ook ZOL labo verdient waardering voor hun bereidheid om naast hun dagelijks klinisch werk duizenden bloedstalen 
te analyseren voor onderzoek. Ik verstoorde hun dagelijkse werkzaamheden namelijk niet enkel met de studie hepatitis B bij de Turkse bevolking maar ook met de projecten hepatitis B bij spoedgevallen en fase 2 HBAI20 vaccin studie.

De fase 2 HBAI20 vaccin studie was van een zeer hoge kwaliteit om de werkzaamheid en veiligheid van het nieuw HBAI20 vaccin te beoordelen. Met kwaliteit komt echter ook complexiteit. Hiervoor kon ik gelukkig rekenen op de hulp van verschillende mensen. Jorge, we were very lucky to have you as a study coordinator arranging the many documents needed to initiate, conduct and close the study. You made it seem so easy! I learned a lot from you as an investigator. Thank you so much! Mohannad, you arrived in the last year of the study and I admire your commitment to be able to practice your profession again as a medical doctor in the Netherlands after leaving Syria. Your commitment is contagious. Keep up the good work! Deze studie was niet mogelijk zonder de zorgvuldige uitvoering van het onderzoek door het personeel van Ease Travel Clinic \& Health Support (Maastricht, Nederland), de afdeling Gastroenterologie en Hepatologie (Genk, België) en het Centrum voor de Evaluatie van Vaccinaties (Antwerp, België). Ook dank aan Monique Rutten, Antoon de Schryver, Marienoelle Schmickler, Annemie Cattrysse, Vincent Moermans, Christel Schabon, Hans van der Krans, Jana Kalenda voor het uitnodigen van de hepatitis B vaccin nonresponders.

Dank aan Helene Piccard, Leen Willems, Sophie Indestege en iedereen die onderzoek binnen LCRC mogelijk maakt. Ik kon jullie altijd laagdrempelig bereiken in verband met mijn vele vragen rond contracten en joint PhD. Sorry dat ik ook steeds jullie allen in cc zette als ik niet wist naar wie ik de mail moest richten. Veronique Pousset en Len Cuppens bedankt voor de begeleiding tot aan mijn PhD verdediging.

Tevens wil ik alle MDL en Medische Microbiologie collega's van het MUMC+ bedanken bestaande uit de artsen, arts-assistenten en (arts-)onderzoekers. Bedankt voor de prettige samenwerking. Ook hartelijk dank aan de gastro-enterologen binnen ZOL Genk en aan alle collega's (doctoraatstudenten en onderzoekers) van het LCRC in de kelder van ZOL Genk. Aangezien ik afwisselend werkte in Maastricht en Genk was ik niet altijd mee met het gebeuren in de kelder en zorgde ik soms voor awkward late felicitaties.

Verder wil ik uiteraard mijn familie bedanken. Anne, sana teşekkür ediyorum çünkü "karşılıksız, koşulsuz, şartsız sevmek" nedir bana öğreten ve yaşatan sensin. Senin için bulabileceğim en iyi kelimeler, seni tüm kalbimle sevdiğim! Canım babam. Ilk öğretmenim. 
İyi bir yaşam sürmek için gereken her şeyi senden öğrendim. Her zaman orada olduğun için teşekkür ederim baba. Abla, ik ben geen slijmbal zoals Baris maar ik meende het toen ik op facebook zei dat jij de beste zus in de wereld bent. Baris, mijn eeneiige tweelingbroer. Al van in moeders buik zijn we onafscheidelijk. Nu ook in Maastricht UMC+. Ik ben enorm fier om te zeggen dat mijn tweelingbroer naast zijn opleiding tot specialist ook nog heel wat onderzoek doet. We moeten ook eens een onderzoek samen publiceren. Het wordt alleen lastig om een onderwerp te vinden dat past bij zowel Maag-Darm-Leverziekten en Orthopedie.

Zonder ontspanning ook geen inspanning, dus dan ook maar eens bedankt aan alle vrienden! Hier hoeft geen verdere uitleg bij!

Tenslotte, mijn askim, mijn Kübra the Explorer. Jij vult mij geweldig aan. Ik heb niet het geduld om een 3-weekse reis in extreme detail als jou uit te werken. Je bent een zeer goede reisplanner en reispartner. Wel voel ik me veiliger als ikzelf autorijd op drukke wegen of navigeer tijdens de 00000 zo lange wandelingen. Ik vind het ook geweldig hoe jij mij hebt kunnen transformeren in een instagram husband. Alhoewel ik in het begin van de relatie tegenstribbelde om foto's van jou te nemen tijdens onze buitenlandse avonturen, geef ik nu zelfs advies om beter te poseren. Van de vele reisbestemmingen, vind ik echter het uitzicht op jou het mooist. I love all your perfect imperfections! 